\title{
Die Bedeutung der Epiphyten im ökosystemaren Wasser- und Nährstoffumsatz verschiedener Altersstadien eines Bergregenwaldes in Costa Rica
}

\author{
Dissertation \\ zur Erlangung des Doktorgrades \\ der Mathematisch-Naturwissenschaftlichen Fakultäten \\ der Georg-August-Universität zu Göttingen
}

\author{
vorgelegt von \\ Lars Köhler \\ aus Osterode
}

Göttingen, den 16. September 2002 
D7

Referent: Prof. Dr. Ch. Leuschner

Korreferent: Prof. Dr. M. Runge

Tag der mündlichen Prüfung: 31.10.2002 


\section{Inhaltsverzeichnis}

1 Einleitung

2 Untersuchungsgebiet 3

2.1 Topographische Lage der Untersuchungsflächen 3

\begin{tabular}{ll|l}
2.2 & Böden des Untersuchungsgebietes & 5
\end{tabular}

\begin{tabular}{ll|ll}
2.3 & Klima & 6
\end{tabular}

2.3.1 Großklimatische Einheiten des Landes 6

2.3.2 Klima der montanen Eichenwaldzone der Cordillera Talamanca 9

\begin{tabular}{|l|ll}
2.4 & Vegetation & 11
\end{tabular}

2.4.1 Vegetation der montanen Eichenwälder in der Cordillera Talamanca 11

\begin{tabular}{ll|l} 
2.4.2 Sekundäre Sukzession der montanen Eichenwälder & 12
\end{tabular}

2.4.3 Vegetation der Untersuchungsflächen $\quad 14$

3 Material und Methoden 17

\begin{tabular}{ll|l}
3.1 & Mikrometeorologische Messungen & 17
\end{tabular}

3.1.1 Mikrometeorologische Messungen im Freiland 17

3.1.2 Mikrometeorologische Messungen in den Beständen 19

\begin{tabular}{|ll|l}
\hline 3.2 Wasserumsatz im Kronenraum & 21
\end{tabular}

3.2.1 Messung des Bestandesniederschlags 21

\begin{tabular}{ll|l}
3.2 .2 & Ermittlung des Stammablaufs & 21
\end{tabular}

3.2.3 Bestimmung der Interzeption und Kronenspeicherkapazität 23

\begin{tabular}{ll|l}
3.2 .4 & Messung des horizontalen Niederschlags & \\
\hline 3
\end{tabular}

3.2.5 Untersuchung der Wasserspeicherkapazität der Epiphyten $\quad 24$

3.2.6 Experimentelle Ansätze zur Wasserspeicherung und Wasserabgabe der Epiphyten im Altbestand $\quad 24$

\begin{tabular}{|ll|l}
\hline 3.3 & Blattflächenindex und Epiphytenbiomasse & 26
\end{tabular}

3.3.1 Messung des Blattflächenindex mit dem LAI 2000 26

\begin{tabular}{ll|l} 
3.3.2 Untersuchung der Streuproduktion & \\
\hline
\end{tabular}

3.3.3 Ermittlung der Blattlebensdauer von Eichenblättern 27

\begin{tabular}{ll|l} 
3.3.4 & Bestimmung der Epiphytenbiomasse & 27
\end{tabular}

\begin{tabular}{|ll|l}
\hline 3.4 Nährstoffflüsse & 29
\end{tabular}

3.4.1 Ermittlung der Nährstoffgehalte in den Niederschlägen 29

3.4.2 Bestimmung der Nährstoffgehalte von Baumblättern und Epiphyten 30 
4 Ergebnisse $\quad 32$

4.1 Bestandesstruktur und Epiphytenbiomasse 32

4.1.1 Struktur der Baumschicht der Bestände 32

4.1.2 Spezifische Blattfläche $\quad 34$

4.1.3 Streuproduktion $\quad 35$

\begin{tabular}{ll|l} 
4.1.4 Blattlebensdauer & 39
\end{tabular}

4.1.5 Blattflächenindex der Bestände 40

4.1.6 Epiphytenbiomasse der Bestände 41

4.2 Wasserumsatz und Mikroklima in den Beständen 45

4.2.1 Klimabedingungen im Untersuchungszeitraum 45

4.2.2 Temperatur und Luftfeuchte in den Beständen $\quad 48$

4.2.3 Wasserumsatz in den Beständen $\quad 59$

4.2.3.1 Bestandesniederschlag, Stammablauf und Interzeption im Jahresmittel 59

4.2.3.2 Bestandesniederschlag und Stammablauf in monatlicher Auflösung $\quad 60$

4.2.3.3 Ermittlung der Kronenspeicherkapazität $\quad 62$

4.2.3.4 Räumliche Variabilität des Bestandesniederschlags 63

4.2.3.5 Zusammenhang zwischen Bestandesstruktur und Niederschlag $\quad 64$

\begin{tabular}{|ll|l}
\hline 4.3 Wasserhaushalt der Epiphyten, Blattmasse und Eichenborke & 66
\end{tabular}

4.3.1 Potentielle Wasseraufnahme der Epiphyten im Altbestand 66

4.3.2 Aktuelle Wassergehalte der Epiphyten im Altbestand $\quad 68$

\begin{tabular}{ll|l} 
4.3.3 Wasserspeicherkapazität von Bromelien & 70
\end{tabular}

4.3.4 Auskämmen von Nebel und horizontalem Regen durch die Moosvegetation 71

\begin{tabular}{|ll|l} 
4.3.5 Wasserrückhaltevermögen der Moose, Flechten und Baumborke & 72
\end{tabular}

\begin{tabular}{|l|ll}
4.4 Ökosystemare Nährstoffflüsse & 76
\end{tabular}

4.4.1 Nährstoffgehalte im Freilandniederschlag, Bestandesniederschlag und Stammablauf

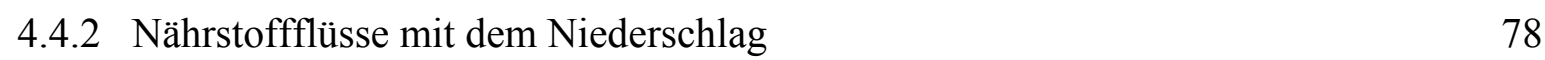

4.4.3 Nährstoffgehalte der Baumblätter und Epiphyten $\quad 80$

4.4.4 Nährstoffflüsse durch den Streufall von Blättern und Epiphyten 82

\section{Diskussion}

5.1 Unterschiedliche Epiphytenbiomassen in Bergregenwäldern und deren Ursachen 
5.2 Die Bedeutung der Epiphyten für den ökosystemaren Wasserumsatz und das Bestandesmikroklima

\begin{tabular}{ll|l} 
5.2.1 & Der Kronenwasserumsatz der drei Bestände & 91
\end{tabular}

5.2.2 Die Bedeutung der Epiphyten für den Kronenwasserumsatz 95

5.2.3 Die Beeinflussung des Bestandesmikroklimas durch die Epiphyten 99

5.3 Oberirdische Nährstoffflüsse in den Beständen und die Bedeutung der Epiphyten 101

\begin{tabular}{|ll|l} 
5.3.1 Nährstoffflüsse mit dem Niederschlag & 101
\end{tabular}

\begin{tabular}{ll|l} 
5.3.2 Nährstoffflüsse mit dem Streufall & 104
\end{tabular}

5.3.3 Die Bedeutung der Epiphyten im Nährstoffkreislauf $\quad 107$

5.4 Hydrologische Folgen der Zerstörung primärer Bergregenwälder $\quad 112$

$\begin{array}{ll}6 \text { Zusammenfassung } & 115\end{array}$

\begin{tabular}{ll|}
7 Summary & 117
\end{tabular}

8 Resumen 119

9 Literaturverzeichnis 121

\begin{tabular}{|l|} 
Verzeichnis der Tabellen und Abbildungen im Text \\
\hline
\end{tabular}

Anhang I

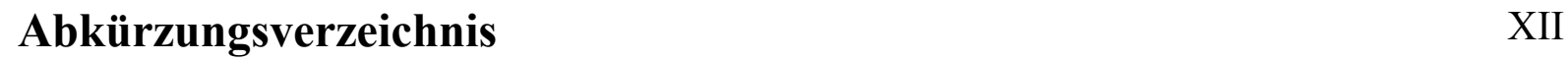




\section{Einleitung}

Tropische Bergregenwälder sind gegenüber Wäldern des Tieflandes vor allem durch eine andersartige Bestandesstruktur und Artenzusammensetzung gekennzeichnet (RICHARDS 1952, GRUBB 1977). Charakteristisch sind die klimatischen Bedingungen der Bergwaldregionen mit einem hohen Wasserangebot, häufiger Wolkenbedeckung und verhältnismäßig niedrigen Temperaturen. Die Vegetation dieser Wälder zeichnet sich besonders durch eine hohe Artenzahl und Biomasse an Epiphyten im Kronenraum aus. Es wird vermutet, daß das Wachstum dieser Organismen durch die genannten klimatischen Besonderheiten gefördert wird (RICHARDS 1984).

Den Epiphyten wird eine wichtige Rolle im ökosystemaren Wasserhaushalt tropischer Bergregenwälder zugesprochen. Besonders kryptogamische Epiphyten können große Mengen Regenwasser speichern und so den hydrologischen Kreislauf der Wälder beeinflussen (Pócs 1980, VeneKLAAS \& VAN EK 1990). Auf diese Weise scheint die Kronenspeicherkapazität von Waldbeständen in hohem Maße durch die Epiphyten beeinflußt zu werden. Bedingt durch ihre Rolle im ökosystemaren Wasserhaushalt können Epiphyten durch Nährstoffaufnahme aus dem Bestandesniederschlag sowie durch Nährstofffreisetzung durch Auswaschung (leaching) auch Einfluß auf den bestandesinternen Nährstoffkreislauf haben (COXSON 1991, CLARK et al. 1998b). Gerade für die häufig als nährstofflimitiert geltenden Bergregenwälder (TANNER et al. 1998) könnte dies von besonderer Bedeutung sein. Trotz dieser Hypothesen sind intensive Studien über die hydrologische Funktion kryptogamischer Epiphyten und deren Rolle im ökosystemaren Nährstoffkreislauf allerdings eher selten.

Bergwälder in den humiden Tropen gelten als besonders sensitiv gegenüber anthropogenen Störungen (EWEL 1980) und sind im Rückgang begriffen. Die Entwaldungsraten sind vermutlich höher als in allen anderen neotropischen Ökosystemen (LABASTILLE \& POOL 1978, Doumenge et al. 1995). Die Ursachen für ihr Verschwinden sind vielfältig, doch weltweit gesehen führt die Umwandlung in Weideland zu den größten Verlusten (HAMILTON 1995). Nach Aufgabe der landwirtschaftlichen Nutzung werden diese Flächen oftmals der sekundären Sukzession überlassen. So nimmt die Fläche der Sekundärwälder überall in den Tropen zu und umfaßte schon in den 80er Jahren etwa 31\% aller geschlossenen Waldgebiete (BROwN \& LugO 1990). Mit der Umwandlung von Primärwäldern gehen tiefgreifende Veränderungen in der Vegetationsstruktur und im ökosystemaren Wasser- und Nährstoffkreislauf einher (BRUIJNZEEL 1990). Obwohl vermutet wird, daß Bergregenwälder eine wichtige Rolle im Wasserhaushalt vieler Tropenländer spielen (ZADROGA 1981, STADTMÜLlER 1987), liegen erst wenige Daten über die Hydrologie dieser Wälder vor. Auch ist völlig ungeklärt, ob die genannten Veränderungen im Verlauf der Waldsukzession reversibel sind und wie lange es gegebenenfalls dauert, bis Sekundärwälder die ursprünglichen Ökosystemfunktionen der Primärwälder erfüllen können.

In der vorliegenden Arbeit soll eine Chronosequenz verschiedener Sukzessionsstadien eines Bergregenwaldes der oberen montanen Stufe Costa Ricas vergleichend untersucht werden. 
Diese reicht von einem 10-15jährigen über einen 40jährigen Sekundärwald bis hin zu einem Altbestand (Primärwald). Die Untersuchungen werden in der Cordillera Talamanca in Costa Rica durchgeführt, in der sich in Höhenlagen von 1800 bis 3400 m ü.M. immergrüne, von Eichenarten dominierte Bergregenwälder erstrecken. Diese Studie soll Antworten auf die Fragen geben, (a) wie sich die Struktur und die epiphytische Biomasse der Bestände im Sukzessionsverlauf verändern und (b) welche ökosystemare Bedeutung die Epiphyten für den Kronenwasserumsatz und die Nährstoffflüsse in den drei Waldstadien haben. Zur Klärung dieser Fragen soll eine bestandesstrukturelle Analyse sowie ökophysiologische Experimente mit Epiphyten beitragen. 


\section{Untersuchungsgebiet}

\subsection{Topographische Lage der Untersuchungsflächen}

Die Untersuchungen wurden in der Cordillera Talamanca im Südosten Costa Ricas durchgeführt. Dieser Gebirgszug ist Teil der zentralen Kordilleren Mittel- und Südamerikas und innerhalb Costa Ricas das größte Gebirge und das heute waldreichste Gebiet des Landes. Große Teile liegen im Biosphärenreservat La Amistad, das sich aus mehreren Schutzgebieten mit unterschiedlichem Schutzstatus zusammensetzt. Heute sind hier die letzten großen zusammenhängenden Gebiete ungestörten tropischen Bergregenwaldes in Zentralamerika zu finden.

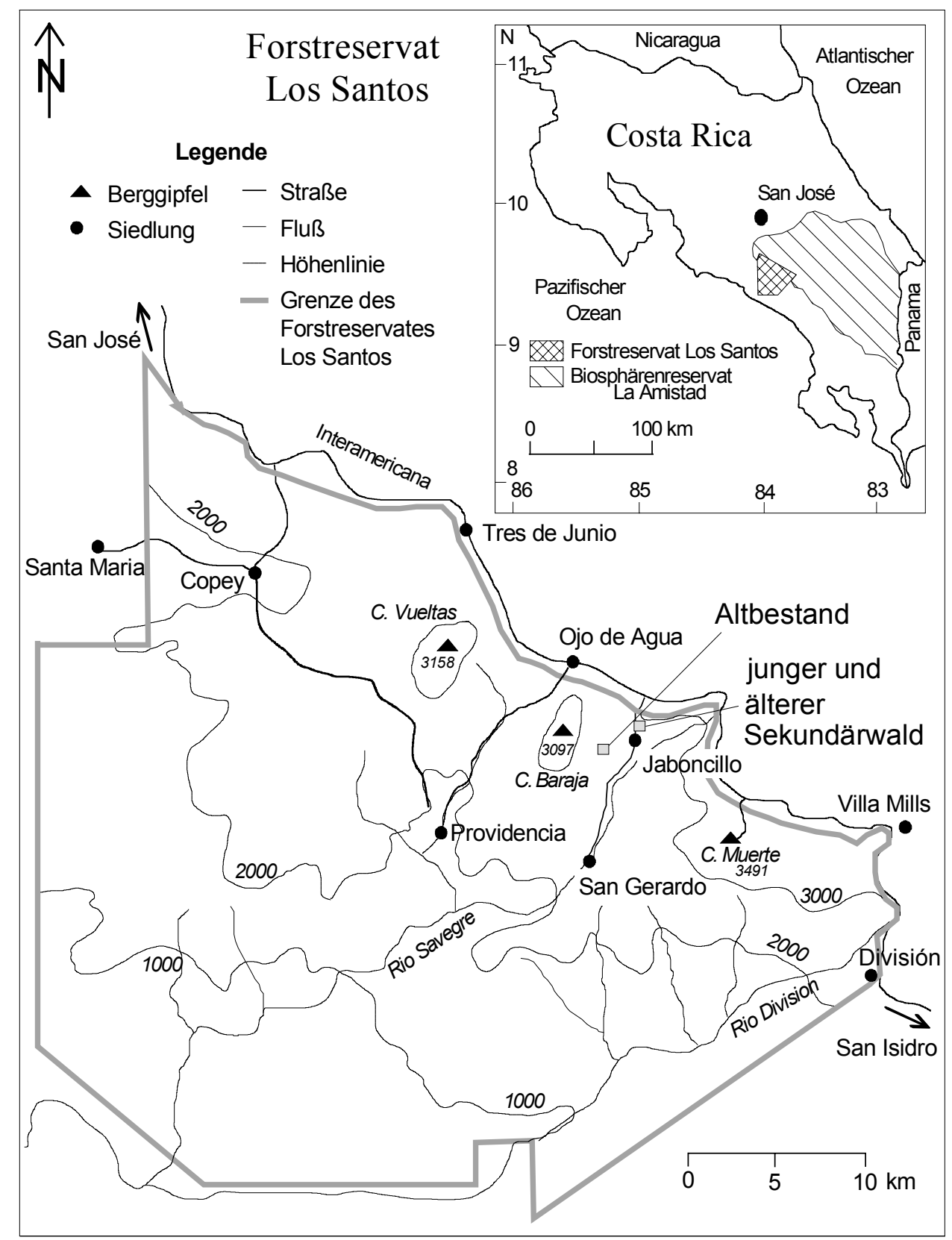

Abb. 2-1: Lage des Forstreservates Los Santos und die Lage der untersuchten Waldbestände. Karte nach KAPPELLE \& JUÁREZ (1995), verändert. 
Die untersuchten Waldbestände befinden sich im 62000 ha großen Forstreservat Los Santos, das im Nordwesten der Cordillera Talamanca eine Pufferzone zum Biosphärenreservat La Amistad bildet (Abb. 2-1).

Die Untersuchungsflächen liegen im oberen Talbereich des Rio Savegre nahe der Ortschaft

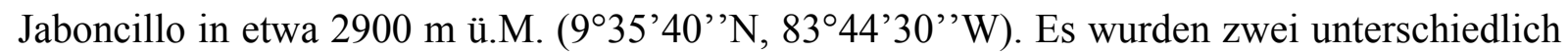
alte Sekundärwaldbestände sowie ein Altbestand ausgewählt. Sowohl der ältere Sekundärwald als auch der Altbestand wurden bereits von KAPPELLE (1995) floristisch bearbeitet, so daß die Zusammensetzung der terrestrischen Flora und die Vegetationsstruktur dieser Standorte gut bekannt ist.

Die beiden untersuchten Sekundärwälder sind durch ihre Nähe zur Interamericana und zur Verbindungsstraße nach San Gerardo de Dota leicht zugänglich, während der Altbestand nur in einem rund einstündigen Fußmarsch zu erreichen ist. Alle untersuchten Flächen haben eine Größe von etwa 50 × 20 m und weisen eine starke Hangneigung von durchschnittlich 25 bis $31^{\circ}$ auf. Die Sekundärwälder haben eine südliche Exposition, während die Untersuchungsfläche im Altbestand nach NO geneigt ist. Die Entfernung zwischen den Sekundärwäldern beträgt $200 \mathrm{~m}$, der Altbestand liegt etwa $2 \mathrm{~km}$ Luftlinie von den Sekundärwäldern entfernt.

Zusätzlich zu den Untersuchungsflächen in den Waldbeständen wurden 2 Freilandflächen für mikrometeorologische Untersuchungen eingerichtet. Eine der beiden Flächen lag zwischen den untersuchten Sekundärwaldbeständen, die zweite $100 \mathrm{~m}$ unterhalb des untersuchten Altbestandes. Zur Registrierung der Tagesniederschläge wurde eine dritte Freifläche auf halber Strecke zwischen dem Altbestand und den Sekundärwäldern auf der Finca Serrano eingerichtet.

Die Nomenklatur der Bergwälder ist sehr vielfältig, nicht eindeutig und zum Teil auch widersprüchlich (STADTMÜLLER 1987). Nach BRUIJNZEEL \& HAMILTON (2000) können die untersuchten Waldbestände in der Cordillera Talamanca als „, upper montane cloud forests“ bezeichnet werden. Nach der Definition von STADTMÜLLER (1987) und HAMILTON et al. (1995) stehen „cloud forests“ (Wolkenwälder) häufig unter dem Einfluß von Wolken oder Nebel. Da hierüber in der Cordillera Talamanca erst sehr wenig bekannt ist und die Untersuchung des Nebeleinflusses einen Teilaspekt der vorliegenden Arbeit darstellt, wird im Folgenden für die untersuchten Waldbestände der neutralere Terminus „Bergregenwald“ verwendet. 


\subsection{Böden des Untersuchungsgebietes}

Die Cordillera Talamanca wird von intrusiven, tertiären vulkanischen Gesteinen sowie marinen Sedimenten gebildet (WEYL 1980). Die Böden haben sich in erster Linie auf aus der Cordillera Central stammenden vulkanischen Aschen entwickelt. Nach VAN UfFELEN (1991) und KenNis \& De VRIES (1993) in KAPPELle (1995) werden die Böden bei Jaboncillo als Humic Andosols (FAO 1988) und als Hapludands nach dem USDA System (SoIL SURVEY STAFF 1975) klassifiziert. Meist zeigen diese Böden eine braun-gelbe Färbung und sind reich an organischer Substanz, in Altbeständen mit organischen Auflagen von mehr als $15 \mathrm{~cm}$. Die Böden sind mäßig nährstoffreich, Staunässe tritt in der Regel nicht auf.

Die Ergebnisse der von HERTEL et al. (2002) auf den drei Untersuchungsflächen durchgeführten bodenchemischen Untersuchungen zeigen eine starke Zunahme der Mächtigkeit der organischen Auflage und der Nährstoffvorräte in der Humusauflage an Calcium, Magnesium und Kalium mit steigendem Bestandesalter (Tab. 2-1). Die C/NVerhältnisse in der organischen Auflage zeigen nur geringe Unterschiede. Die Stickstoffkonzentrationen liegen im jungen Sekundärwald niedriger als in den beiden anderen Beständen, während die Phosphorgehalte nur geringe Unterschiede erkennen lassen.

Tab. 2-1: Bodenchemische Parameter der drei Untersuchungsflächen nach HERTEL et al. (2002).

\begin{tabular}{|c|c|c|c|}
\hline & $\begin{array}{c}\text { junger } \\
\text { Sekundärwald }\end{array}$ & $\begin{array}{c}\text { älterer } \\
\text { Sekundärwald }\end{array}$ & Altbestand \\
\hline \multicolumn{4}{|l|}{ Organische Auflage } \\
\hline Mächtigkeit [cm] & 3.2 & 8.6 & 17.0 \\
\hline $\mathrm{Ca}+\mathrm{Mg}+\mathrm{K}-$ Vorrat $\left[\mathrm{mmol} \mathrm{m} \mathrm{m}^{-2}\right]$ & 1464 & 1991 & 2065 \\
\hline $\mathrm{C} / \mathrm{N}-$ Verhältnis $\left[\mathrm{mol} \mathrm{mol}^{-1}\right]$ & 23.4 & 25.2 & 27.6 \\
\hline $\mathrm{N}\left[\mathrm{mol} \mathrm{m}^{-3}\right]$ & 84.4 & 101.2 & 103.2 \\
\hline $\mathrm{P}\left[\mathrm{mol} \mathrm{m}{ }^{-3}\right]$ & 2.73 & 2.71 & 2.58 \\
\hline \multicolumn{4}{|l|}{ Mineralboden $(0-10 \mathrm{~cm})$} \\
\hline $\mathrm{pH}(\mathrm{KCl})$ & 4.9 & 3.5 & 3.4 \\
\hline $\mathrm{C} / \mathrm{N}-$ Verhältnis $\left[\mathrm{mol} \mathrm{mol}^{-1}\right]$ & 16.1 & 22.1 & 25.0 \\
\hline $\mathrm{N}\left[\mathrm{mol} \mathrm{m}^{-3}\right]$ & 148.0 & 141.0 & 144.2 \\
\hline $\mathrm{P}\left[\mathrm{mol} \mathrm{m}{ }^{-3}\right]$ & 16.9 & 12.5 & 11.7 \\
\hline $\mathrm{Ak}_{\mathrm{e}}\left[\mu \mathrm{mol}_{\mathrm{c}} \mathrm{g}^{-1}\right]$ & 250.0 & 173.2 & 158.1 \\
\hline Basensättigung [\%] & 95.6 & 12.4 & 7.9 \\
\hline
\end{tabular}


Der mineralische Oberboden im älteren Sekundärwald und im Altbestand zeichnet sich durch sehr niedrige $\mathrm{pH}(\mathrm{KCl})$-Werte von 3.5 und 3.4 aus. Im jungen Sekundärwald wurde mit 4.9 ein deutlich höherer $\mathrm{pH}(\mathrm{KCl})$-Wert gemessen. In diesem Bestand zeigt sich auch eine größere Kationenaustauschkapazität $\left(\mathrm{Ak}_{\mathrm{e}}\right)$ und eine wesentlich höhere Basensättigung als in den beiden älteren Beständen. Mit zunehmendem Bestandesalter steigt das $\mathrm{C} / \mathrm{N}-$ Verhältnis im Mineralboden deutlich an, während die Stickstoffkonzentrationen nur geringe Unterschiede zwischen den Beständen erkennen lassen. Die Phosphorkonzentrationen sind im jungen Sekundärwald vergleichsweise hoch. Die bodenchemischen Unterschiede zwischen den Beständen sind vermutlich auf Kahlschlag, Brand und Holzkohlegewinnung in den heutigen Sekundärwaldflächen zurückzuführen. Insgesamt ist die Nährstoffverfügbarkeit im Mineralboden des jungen Sekundärwaldes als gut einzuschätzen. Im älteren Sekundärwald und insbesondere im Primärwald gewinnt die Humusauflage bei der Bereitstellung von Nährstoffen eine zunehmend größere Bedeutung im Vergleich zum Mineralboden.

\subsection{Klima}

\subsubsection{Großklimatische Einheiten des Landes}

Die bis zu 3800 m ü.M. aufsteigenden Kordillerenketten, die Costa Rica von Nordwesten nach Südosten durchziehen, wirken als Klimascheide und teilen das Land in zwei klimatische Hauptregionen.

Die immerfeuchte Atlantikseite unterliegt während des ganzen Jahres dem Einfluß des Nordostpassates (Abb. 2-2). Die Niederschläge sind hier in erster Linie orographischer Herkunft, wobei die Niederschlagsmaxima in Höhenlagen zwischen etwa 1400 und 2200 m ü.M. zu finden sind (HERRERA 1986). Oberhalb des Wolkengürtels, der nach ZADROGA (1981) bei etwa 2000 m ü.M. liegt, nehmen die Niederschläge aufgrund der Passatwindinversion wieder ab. Obwohl in einigen Gebieten die Monatssummen der Niederschläge zum Teil große Unterschiede aufweisen, fehlt auf der Atlantikseite eine klar erkennbare Trockenzeit.

In den Monaten Dezember bis Mai nehmen die Nordostpassate an Stärke zu und überschreiten die zentralen Gebirge, wobei sie als warme, trockene Fallwinde die Pazifikseite beeinflussen. In diesen Monaten, die in Costa Rica als „Verano“ (Sommer) bezeichnet werden, herrscht auf der wechselfeuchten Pazifikseite eine zum Teil ausgeprägte Trockenzeit, die im Nordwesten des Landes bis zu sechs Monate andauern kann. 

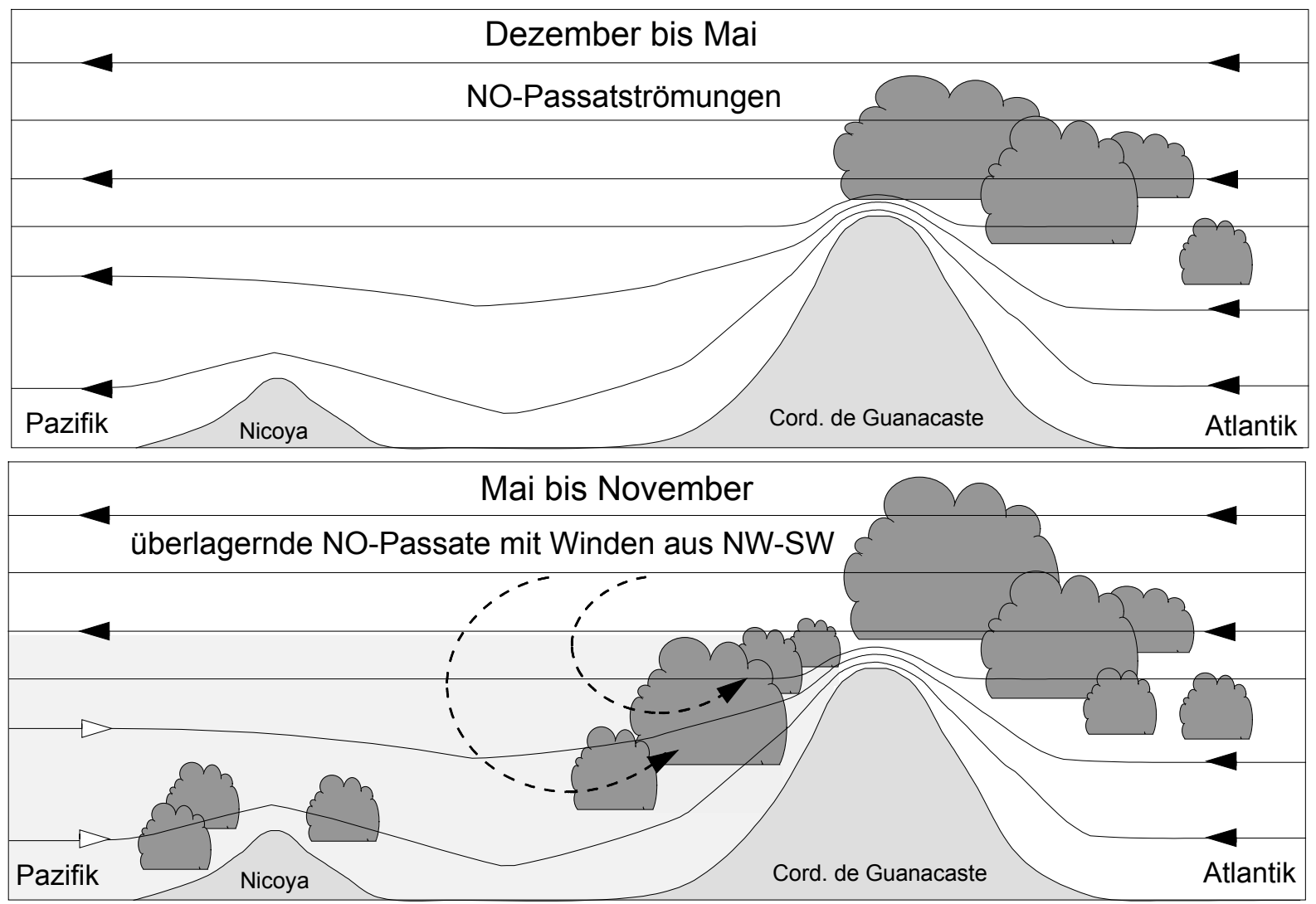

Abb. 2-2: Windströmungen der Cordillera de Guanacaste - Halbinsel Nicoya zur Verdeutlichung der in Costa Rica vorherrschenden Windsysteme. Nach THOMAS (1988), verändert.

Während der Regenzeit in den Monaten Mai bis November (in Costa Rica „Invierno“ = Winter) wird die Pazifikregion durch feuchte Winde aus nordwestlicher Richtung und durch die bei der Überschreitung des Äquators abgelenkten Südostpassate aus südwestlicher Richtung beeinflußt. Diese erreichen aber nur geringe Höhen und werden von den Nordostpassaten überlagert. An der Grenzschicht zwischen den beiden Luftströmungen kommt es zu Turbulenzen, die die regenbringenden Pazifikwinde unterstützen (THOMAS 1988). Neben dem deutlichen Jahresrhythmus der Niederschläge auf der Pazifikseite ist hier auch ein ausgeprägter Tagesgang zu beobachten. Der Regen setzt meist zwischen 13 und 17 Uhr ein, wobei es sich in erster Linie um konvektive Niederschläge handelt (BRENES \& SABORÍO 1995).

Während der Monate Juli und August kann es erneut $\mathrm{zu}$ einer Intensivierung der Nordostpassate kommen, was auf der Pazifikseite eine Abnahme der Niederschläge zur Folge hat. Diese niederschlagsärmere Zeit wird in Costa Rica als „Veranillo“ (kleiner Sommer) bezeichnet.

Nach HALL (1984) betragen die Niederschläge in einigen atlantischen Gebirgsregionen bis über $9000 \mathrm{~mm}$ pro Jahr. Aufzeichnungen des Instituto MeteorolóGiCo NACIONAL (IMN) (1988) zeigen, daß Jahressummen über $8000 \mathrm{~mm}$ jedoch nur bei wenigen Meßstationen verzeichnet wurden und auf einzelne Jahre begrenzt sind. Die niederschlagärmsten Gebiete 
befinden sich im Nordwesten des Landes und erhalten etwa $1300 \mathrm{~mm}$ im Jahresmittel, wobei eine bis zu sechs Monaten andauernde Trockenzeit auftreten kann.

Die Temperaturen liegen in der pazifischen Küstenregion im Jahresmittel bei $27.6{ }^{\circ} \mathrm{C}$ und damit um etwa $1.6{ }^{\circ} \mathrm{C}$ höher als auf der Atlantikseite (HERRERA 1986). Die kältesten Gebiete findet man im Bereich der höchsten Gebirgsregionen, die nach NiEUWOLT (1977) neben dem atlantischen und dem pazifischen Klimabereich als eigenständige klimatische Zone betrachtet werden können.

Neben dem Nordost-Passatwindsystem, das über weite Bereiche des Jahres das Wettergeschehen Costa Ricas prägt und von der Lage der innertropischen Konvergenzzone (ITC) bestimmt wird, können verschiedene andere Wetterlagen auftreten. Ein Beispiel sind die Kaltlufteinbrüche aus nördlicher Richtung, die „Nortes“ oder „Temporales del Atlantico“, die in den Wintermonaten an der Atlantikseite zu Sturmböen und Niederschlägen führen. Bei besonders heftigen „Nortes“ können die Niederschläge über die zentralen Gebirgskämme gedrückt werden, was im oberen, windabgewandten Bereich der Gebirge zu einem feinen Sprühregen und hohen Windgeschwindigkeiten führt, während in tieferen Lagen häufig ein wolkenloser Himmel zu beobachten ist. Diese Wetterlage wird als „Derrame del Caribe“ bezeichnet (BRENES \& SABORÍO 1995).

Die „Temporales del Pacifico“ sind feuchte Westwinde, die vor allem im September und Oktober auf der Pazifikseite zu starken und anhaltenden Niederschlägen führen und hier für das Niederschlagsmaximum in diesen Monaten mitverantwortlich sind (COEN 1983).

$\mathrm{Zu}$ den wichtigsten, periodisch auftretenden, nicht jahreszeitgebundenen Ereignissen, die das Klima Costa Ricas deutlich beeinflussen, zählt El Niño / Southern Oscillation (ENSO). Dabei handelt es sich um eine Erwärmung der Meeresoberfläche des Pazifiks, die im Durchschnitt alle drei bis vier Jahre auftritt und 12 bis 18 Monate andauert. Im pazifischen Raum sind dann ein Anstieg der Temperaturen und geringere Niederschlagsmengen zu beobachten, während es im atlantischen Bereich zu einer Verstärkung der Niederschläge kommt (VAHRSON 1997). Auf ein ENSO-Ereignis folgt häufig eine überdurchschnittlich starke Abkühlung der Meeresoberfläche. Dieses als La Niña bezeichnete Phänomen führt in der Regel zu gegensätzlichen klimatischen Auswirkungen wie ENSO (QUIRós 1990, HOLMGREN et al. 2001). Die in Costa Rica durchgeführten Untersuchungen fanden während eines La NiñaEreignisses geringer bis moderater Stärke statt (Instituto METEOROLÓGICO NACIONAL 2000). Niederschlagsmessungen des InSTITUTO COSTARRICENSE DE ELECTRICIDAD (2000) in Villa Mills zeigen, daß die Niederschläge im Jahr 1999, während der Durchführung der vorliegenden Arbeit, im Untersuchungsgebiet 12\% über dem mehrjährigen Mittel lagen. 


\subsubsection{Klima der montanen Eichenwaldzone der Cordillera Talamanca}

Nach der Köppen-Klimaklassifikation entspricht das Klima auf der Atlantikabdachung des Untersuchungsgebietes dem Cf-Klimabereich (feuchtgemäßigt ohne Trockenzeit) und in den Gebirgsregionen der Pazifikseite dem Cw-Klimabereich (feuchtgemäßigt mit Trockenzeit), wobei die Trockenzeit in den Monaten Dezember oder Januar beginnt und etwa bis April andauert. Die Jahresniederschläge liegen im Untersuchungsgebiet meist zwischen 2000 und $3000 \mathrm{~mm}$. So wurden bei der meteorologischen Station Tres de Junio (2669 m ü.M.) im mehrjährigen Mittel Jahresniederschläge von etwa $3000 \mathrm{~mm}$ gemessen, während am Cerro de la Muerte (3365 m ü.M.) oberhalb der Waldgrenze nur $2447 \mathrm{~mm}$ registriert wurden (Instituto Meteorológico Nacional 1988). Die meteorologischen Stationen Ojo de Agua (2960 m ü.M.) und Villa Mills (3000 m ü.M.), die sich auf vergleichbarer Meereshöhe und ebenfalls in der Nähe der Untersuchungsflächen befinden, verzeichneten im mehrjährigen Mittel einen Jahresniederschlag von 2648 bzw. 2812 mm (Abb. 2-3). Die jährliche Variabilität der Niederschläge kann jedoch beträchtlich sein. So reicht die Spanne der in Ojo de Agua gemessenen Werte von $1581 \mathrm{~mm}$ (1965) bis $4140 \mathrm{~mm} \mathrm{(1970).} \mathrm{Die}$ niederschlagsreichsten Monate sind in der Regel September und Oktober, wobei in Villa Mills die Werte im Oktober im Mittel $488 \mathrm{~mm}$ betragen. Im Durchschnitt liegen die Monatsmittel im Februar und März unter dem Ariditätsindex von De Martonne und gelten daher als aride Monate; allerdings treten diese nur mit einer Wahrscheinlichkeit um $60 \%$ auf (BLASER 1987).
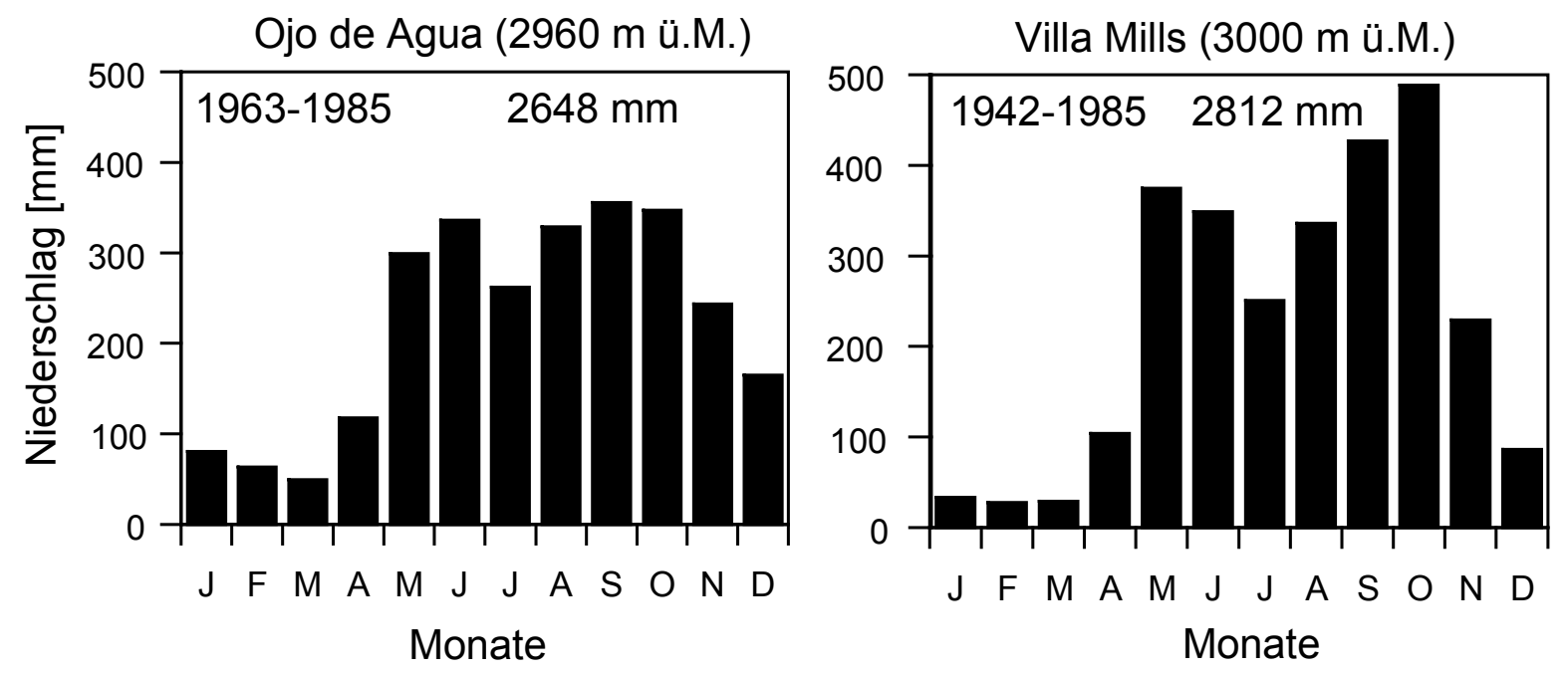

Abb. 2-3: Jahresgang der mittleren monatlichen Niederschläge der meteorologischen Meßstationen Ojo de Agua und Villa Mills (InSTITUTO MeTEOROLÓGICO NACIONAL 1988). 
Unberücksichtigt bleiben bei diesen Niederschlagsangaben jedoch die meßtechnisch nur schwer erfaßbaren Nebelniederschläge (horizontale Niederschläge, STADTMÜLLER 1987). Bekannt ist jedoch, daß ein Auskämmen des Nebels durch die Vegetation in sehr nebelreichen Gebieten (Wolkenwälder) zu einem beträchtlichen zusätzlichen Wassereintrag führen kann. Dieses ist besonders für die nebelreiche Atlantikabdachung der Gebirge zu berücksichtigen und soll auch in der vorliegenden Arbeit untersucht werden.

Die Jahresmitteltemperaturen liegen in der montanen Eichenwaldzone zwischen $6{ }^{\circ} \mathrm{C}$ in den Gipfelregionen der Gebirge in 3000-3200 m ü.M. und etwa $18{ }^{\circ} \mathrm{C}$ in windgeschützten Tälern in $2000 \mathrm{~m}$ ü.M. (HERRERA 1986). Nach BLASER (1987) wurden in der nordwestlichen Cordillera Talamanca im Jahresmittel $12.3{ }^{\circ} \mathrm{C}$ (2380 m ü.M.) und $7.3{ }^{\circ} \mathrm{C}$ (3365 m ü.M.) gemessen. Bei den Stationen Ojo de Agua und Villa Mills liegen die Jahresmitteltemperaturen bei $11.2^{\circ} \mathrm{C}$ bzw. $10.9^{\circ} \mathrm{C}$ (Instituto Meteorológico NaCiOnal 1988).

Die Schwankungen der mittleren Temperatur zwischen dem wärmsten Monat April und dem kältesten Monat Januar betragen auf 3365 m ü.M. 1.4 K (BLASER 1987). Größer ist hingegen die Amplitude der Tagestemperaturen, die sich bei Villa Mills zwischen $6{ }^{\circ} \mathrm{C}$ während der Nacht und $22{ }^{\circ} \mathrm{C}$ während des Tages bewegen. In den niederschlagsärmeren Monaten mit geringerer Bewölkung können die Temperaturen während der Nacht mit Tiefstwerten bis zu $-3{ }^{\circ} \mathrm{C}$ auch unter den Gefrierpunkt fallen (KAPPELLE 1995). Mit zunehmender Höhe nehmen die Temperaturen im Untersuchungsgebiet im Mittel um $0.55 \mathrm{~K}$ pro 100 Höhenmeter ab, was in etwa auch dem von RUDOLFF (1981) berechneten allgemeinen Wert für tropische Klimate von 0.56 K pro 100 Höhenmeter entspricht (BLASER 1987). 


\subsection{Vegetation}

\subsubsection{Vegetation der montanen Eichenwälder in der Cordillera Talamanca}

Verschiedene Autoren haben die durch klimatische Faktoren bedingte Höhenzonierung der Vegetation in der Cordillera Talamanca beschrieben (HOLDRIDGE et al. 1971, GRUBB 1974, GÓMEZ 1986, BLASER 1987, KAPPELLE 1991). Im Folgenden soll hier auf die montanen Eichenwälder eingegangen werden, die sich in der Cordillera Talamanca in Höhenlagen von 1800 bis 3400 m ü.M. erstrecken. Nach der Gliederung von KAPPELLE (1996) liegen diese im Höhenbereich der unteren und oberen montanen Stufe (Abb. 2-4).

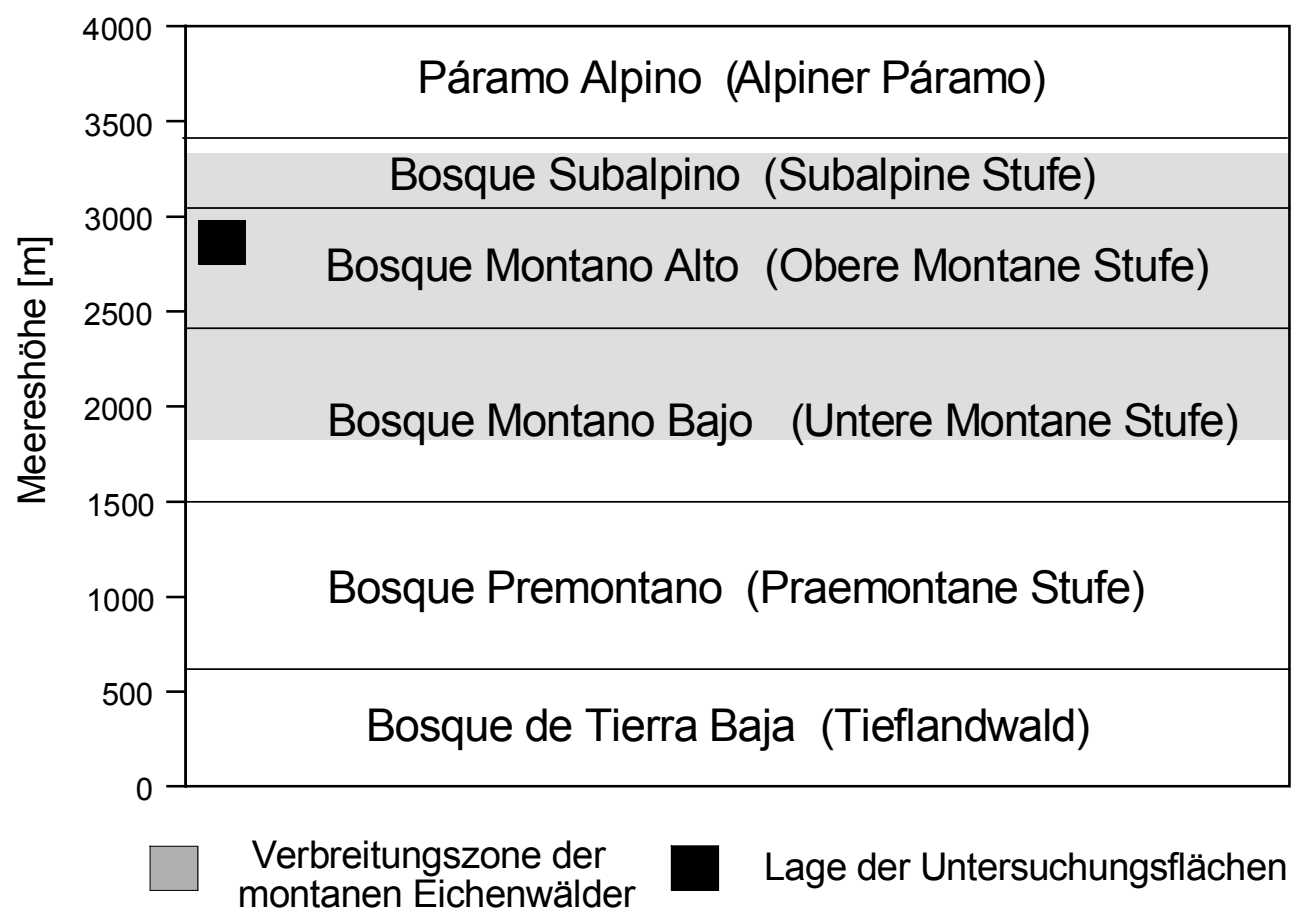

Abb. 2-4: Verbreitungszone der montanen Eichenwälder in der Cordillera Talamanca, und die Lage der eigenen Untersuchungsflächen nach KAPPELLE (1996), verändert.

An ihrer unteren Verbreitungsgrenze bei 1800 bis 2000 m ü.M. werden die Eichenwälder von einem an Lauraceen reichen Mischwald begrenzt (KAPPELLE \& ZAMORA 1995). Die Eichenwälder oberhalb dieser Höhenlage werden in der oberen Kronenschicht von Quercus copeyensis C.H.Müll., Quercus costaricensis Liebm. und in geringem Maße auch von Quercus seemannii Liebm. dominiert und können zum Teil Höhen von mehr als $50 \mathrm{~m}$ erreichen (BLASER \& CAMACHO 1991).

KAPPELLE et al. (1991) konnten in den Eichenwäldern der Cordillera Talamanca insgesamt 483 Gehölzarten unterscheiden. 30 Prozent der gefundenen Arten zählen zu den Familien der 
Rubiaceen, Melastomataceen, Lauraceen, Asteraceen und Ericaceen. Besonders reich vertreten sind die Gattungen Chusquea, Miconia, Ocotea, Palicourea und Oreopanax. Im Unterwuchs tritt Bambus der Gattung Chusquea häufig mit hohen Deckungsgraden auf. Ein auffallendes Merkmal der montanen Eichenwälder ist ihr Reichtum an Epiphyten, vor allem an Orchidaceen, Bromeliaceen, Araceen, Piperaceen sowie Farnen und Bryophyten.

Ihre obere Verbreitungsgrenze erreichen die montanen Eichenwälder in der subalpinen Stufe in 3100 bis 3400 m ü.M., die den Übergang zum Páramo bildet. Hier zeigen die Bäume häufig eine verkrüppelte Wuchsform und sind mit epiphytischen Flechten und Moosen bedeckt. Sie bleiben meist unter $12 \mathrm{~m}$ Höhe. In der Kronenschicht dominieren Ericaceen wie Comarostapylis arbutoides und Vaccinium consanguineum. Eichen (Quercus costaricensis) sind nur noch als unterständige Bäume im unteren Bereich dieses Asteraceen-Ericaceen Zwergwaldgürtels vertreten (KAPPELLE 1991). Bambusarten der Gattung Chusquea dominieren auch hier häufig im Unterwuchs.

Allgemein ist mit zunehmender Meereshöhe eine kontinuierliche Abnahme der Anzahl der Baumarten zu beobachten (KAPPELLE \& ZAMORA 1995). In den Eichenwäldern oberhalb 2000 m ü.M. konnten in der Cordillera Talamanca bisher 1095 Gefäßpflanzenarten nachgewiesen werden (KAPPELLE 1996). Diese Zahlen sind jedoch als vorläufig zu betrachten, da viele Gebiete dieser Region bisher floristisch noch kaum untersucht worden sind.

Die montanen Eichenwälder der Cordillera Talamanca zeichnen sich ferner durch eine hohe Kryptogamendiversität aus. In Höhenlagen von 2000 bis 3400 m ü.M. konnten KAPPELLE \& SiPMAN (1992) 94 verschiedene Flechtenarten unterscheiden. Holz et al. (2002) führten im Untersuchungsgebiet in Höhenlagen zwischen 2200 und $2500 \mathrm{~m}$ ü.M. eine komplette Inventarisierung der Bryophytenflora durch und fanden 206 unterschiedliche Moosarten (100 Laubmoose, 105 Lebermoose und 1 Hornmoos). Ebenfalls in der Cordillera Talamanca konnten KAPPELLE \& GÓMEZ (1992) in Höhen von 2000 bis 3300 m ü.M. 129 Farnarten nachweisen. Auch diese Ergebnisse zur Untersuchung der Kryptogamenflora in dieser Region müssen als vorläufig gelten.

\subsubsection{Sekundäre Sukzession der montanen Eichenwälder}

Ursprünglich war fast die gesamte Cordillera Talamanca von montanem Eichenwald bedeckt. Die geschichtlichen Zeugnisse lassen auf keine wesentlichen anthropogenen Einflüsse auf die Wälder des Untersuchungsgebietes bis zum Bau der panamerikanischen Straße (Interamericana) von 1942-45 schließen (BLASER 1987). Nach dem Bau dieser wichtigen Verkehrsstraße fand eine zunehmende Nutzung des Eichenholzes statt, um den Bedarf an Bauholz zu decken. Die nach dem Straßenbau bis Anfang der 70er Jahre stetig zunehmende Bevölkerung im Untersuchungsgebiet bestritt ihren Lebensunterhalt vorwiegend durch die 
Holzkohleproduktion (SchUBEL 1980 IN BLASER 1987) und auch der Bedarf an Weide- und Ackerland wuchs. Dies trifft auch für das obere Tal des Rio Savegre zu. Durch den Bau einer Verbindungsstraße von der Interamericana nach San Gerardo de Dota war zwischen 1956 und 1969 eine starke Zunahme der Rodungsaktivitäten durch Siedler zu beobachten (VAN OMME 1998). Seit 1984 wurden hier jedoch kaum noch primäre Eichenwaldgebiete abgeholzt, was unter anderem mit einem Wandel in der Landnutzung von flächenintensiver Viehweidewirtschaft zum produktiveren Obstanbau zu erklären ist (KAPPELlE \& JUÁREZ 1995). Auch die Gründung des Forstreservates Los Santos im Jahre 1975 und der zunehmende Tourismus im Gebiet haben zu einer Verminderung der Entwaldungsrate beigetragen. Diese Nutzungsgeschichte führte zu einem sehr heterogenen Muster an Vegetationstypen im oberen Tal des Rio Savegre. Die heutige Vegetationsbedeckung in diesem Gebiet ist durch einen verhältnismäßig hohen Anteil an primären Bergregenwäldern gekennzeichnet (Tab. 2-2).

Tab. 2-2: Vegetationsbedeckung des oberen Tales des Rio Savegre, Costa Rica im Jahre 1996. Nach VAN OMME (1998), verändert.

\begin{tabular}{lrlr}
\hline primärer Bergwald & $70.8 \%$ & Weideland & $3.3 \%$ \\
subalpiner Zwergwald & $7.7 \%$ & sekundäre Buschvegetation & $1.1 \%$ \\
Strauch-Páramo & $6.4 \%$ & Obstplantagen & $1.0 \%$ \\
Sekundärwald & $5.3 \%$ & unbedeckter Boden & $0.2 \%$ \\
Bambus-Páramo & $4.2 \%$ & Holzplantagen & $0.05 \%$ \\
\hline
\end{tabular}

Nach Aufgabe der Bewirtschaftung der genutzten Flächen setzt eine sekundäre Sukzession ein. KAPPELLE (1993) konnte dabei vier unterschiedliche Sukzessionsstadien unterscheiden, die von einer Pionierphase über ein junges und älteres Sekundärwaldstadium bis hin zum Altbestand reichen. Während der Sukzession war eine kontinuierliche Zunahme der Anzahl der Baumarten $\mathrm{zu}$ beobachten, wobei die höchste Artenzahl in dem älteren Sekundärwaldstadium erreicht wurde. $\mathrm{Zu}$ Beginn dominierten schnellwachsende Lichtbaumarten (häufig Asteraceen), im weiteren Sukzessionsverlauf waren schattentolerante Unterwuchsbaumarten (meist Araliaceen, Lauraceen und Myrsinaceen) verbreitet. Die Gattung Quercus war in allen untersuchten Altersstadien, mit Ausnahme der Pionierphase, die dominierende Baumgattung. Sekundärwälder in den Bergregionen Costa Ricas zeichnen sich durch eine hohe Gefäßpflanzendiversität aus, die sich mit den Tieflandregenwäldern der Neotropen vergleichen läßt (KAPPELLE et al. 1995). Es ist anzunehmen, daß nach einer Entwaldung die vollständige Wiederherstellung der floristischen Artenzusammensetzung mindestens 65 Jahre, die der ursprünglichen Waldstruktur mindestens 84 Jahre in Anspruch nimmt (KAPPELLE et al. 1995, 1996). 


\subsubsection{Vegetation der Untersuchungsflächen}

Die jüngere untersuchte Sekundärwaldfläche ist etwa 10 bis 15 Jahre alt und hat eine Bestandeshöhe von 5 bis $9 \mathrm{~m}$. Einzelne ältere Eichen sind auf der Fläche vorhanden und überragen den Bestand um einige Meter, was zu einer relativ heterogenen Struktur führt. Für diesen Bestand wurde im Rahmen der eigenen Arbeiten eine Liste der Gehölzarten erstellt und deren Deckungsgrade nach der erweiterten Skala von Braun-Blanquet geschätzt (Tab. 23). Typische Pionier- und frühsukzessionale Baumarten sind Bocconia frutescens, Abatia parviflora, Oreopanax xalapense, Cornus disciflora, Fuchsia paniculata und Monochaetum spec. Aber auch Quercus copeyensis und Quercus costaricensis erreichen hohe Deckungsgrade. Im Unterwuchs tritt Chusquea spec. mit Deckungsgraden von etwa 5 bis $10 \%$ auf. Die Krautschicht ist mit einer Deckung von 30 bis $40 \%$ nur schwach ausgebildet. Mindestens 12 verschiedene terrestrische Farnarten konnten unterschieden werden. Genauere Untersuchungen der Krautschicht wurden jedoch nicht durchgeführt. Kletterpflanzen der Gattungen Bomarea und Smilax waren des öfteren $\mathrm{zu}$ finden. Im untersuchten Bestand konnten allein auf Quercus copeyensis 92 epiphytische Moosarten nachgewiesen werden (Holz 2003). Unter den Gefäßepiphyten waren Jungpflanzen von Bromelien und einzelne kleine Orchideen sowie Farne zu finden. Vereinzelt kam auch Macleanea rupestris (Ericaceae) epiphytisch auf den untersuchten Eichen vor.

Die ältere Sekundärwaldfläche ist etwa 40 Jahre alt und hat eine Höhe von 11 bis $15 \mathrm{~m}$. Der Bestand unterscheidet sich strukturell stark vom jungen Sekundärwald, da die obere Baumschicht sehr homogen und dicht ist und fast ausschließlich von Quercus copeyensis gebildet wird. Nur Weinmannia pinnata und Quercus costaricensis können vereinzelt bis in die obere Kronenschicht durchdringen. Viele der im jungen Sekundärwald abundanten Arten wie Viburnum costaricanum, Styrax argentus, Cleyera theaeoides oder Cornus disciflora sind noch in der Strauchschicht des älteren Sekundärwaldes zu finden. Außerdem kommen mehrere Arten wie Drimys granadensis L.f., Schefflera rodriguesiana Frodin ex M.J.Cannon \& Cannon, Rhamnus oreodendron L.O.Williams und Miconia spec. neu hinzu. Dies gilt auch für Anthurium concinnatum Schott, das im Unterwuchs des älteren Sekundärwaldes vereinzelt zu beobachten ist, im jungen Sekundärwald jedoch völlig fehlt. 
Tab. 2-3: Artenliste der Baum- und Straucharten im jungen Sekundärwald, Cordillera Talamanca, Costa Rica. Die Deckungsgrade wurden nach der erweiterten Skala von Braun-Blanquet geschätzt.

$+=<1 \% \quad 1=1$ bis $5 \% \quad 2 \mathrm{a}=5$ bis $15 \% \quad 2 \mathrm{~b}=5$ bis $25 \% \quad 3=5$ bis $50 \% \quad 4=50$ bis $75 \% \quad 5=75$ bis $100 \%$

\section{Baum- und Straucharten im jungen Sekundärwald}

\begin{tabular}{|c|c|c|c|}
\hline ARALIACEAE & & LOGANIACEAE & \\
\hline Oreopanax capitatus. (Jacq.) Decne.\& Planch. & $2 \mathrm{a}$ & Buddleja nitida Benth. & 1 \\
\hline Oreopanax xalapensis (Kunth) Decne.\& Planch. & $2 \mathrm{~b}$ & MELASTOMATACEAE & \\
\hline ASTERACEAE & & Monochaetum spec. & $2 b$ \\
\hline Ageratina cf. Subcordata & 1 & & \\
\hline Vernonia cf. patens & 1 & MYRSINACEAE & \\
\hline & & Ardisia spec. & 1 \\
\hline CAPRIFOLIACEAE & & Myrsine coriacea (Sw.) R. Br. Ex Roem. \& Schult & 1 \\
\hline Viburnum costaricanum (Oerst.) Hemsl. & $2 \mathrm{a}$ & Myrsine glanduloso punctata & $2 \mathrm{a}$ \\
\hline CORNACEAE & & ONAGRACEAE & \\
\hline Cornus disciflora Mociño \& Sessé & $2 b$ & Fuchsia microphylla Kunth & 1 \\
\hline CUNONIACEAE & & Fuchsia paniculata Lindl. & 1 \\
\hline Weinmannia pinnata $\mathrm{L}$. & $2 \mathrm{a}$ & PAPAVERACEAE & \\
\hline & & Bocconia frutescens $\mathrm{L}$. & + \\
\hline ERICACEAE & & & \\
\hline Comarostaphylis arbutoides Lindl. & $2 \mathrm{a}$ & POLYGALACEAE & \\
\hline Macleanea rupestris (Kunth) A.C. Sm. & 1 & Monnina cf. xalapensis / crepinii & + \\
\hline Vaccinium consanguineum Klotzsch & 1 & & \\
\hline Vaccinium spec. & 1 & ROSACEAE & \\
\hline & & Acaena elongata $\mathrm{L}$. & 1 \\
\hline ESCALLONIACEAE & & Rubus spec. & + \\
\hline Escallonia myrtilloides L.f. & + & & \\
\hline & & RUTACEA & \\
\hline & & Zanthoxylum melanosticum Schltdl. \& Cham. & 1 \\
\hline FAGACEAE & & & \\
\hline Quercus copeyensis C.H. Müll. & 3 & STYRACACEA & \\
\hline Quercus costaricensis Liebm. & $2 b$ & $\begin{array}{l}\text { Styrax argentus C. Presl. } \\
\text { Styrax glabrescens Benth. }\end{array}$ & $\begin{array}{l}2 \mathrm{~b} \\
+\end{array}$ \\
\hline FLACOURTIACEAE & & & \\
\hline Abatia parviflora Ruiz López \& Pavón & 1 & THEACEAE & $\mathrm{h}$ \\
\hline LAURACEAE & & Cleyera theaeoldes & $\mathrm{E}$ \\
\hline Ocotea spec. & + & & \\
\hline
\end{tabular}

Die Baum- und Krautschicht dieser Untersuchungsfläche wurde bereits von KAPPELLE (1995) floristisch bearbeitet (plot 8). Die Anzahl epiphytisch auf Quercus copeyensis vorkommender Moosarten ist mit 116 höher als im jungen Sekundärwald (HoLZ 2003). Unter den Gefäßepiphyten waren mehrere Farn- und Orchideenarten sowie Piperaceen und die Ericaceae Macleanea rupestris vertreten. Neben regelmäßig vorkommenden BromelienJungpflanzen waren auch vereinzelt mittelgroße und große Exemplare der Bromeliaceae Vriesea orosiensis (Mez) L.B. Sm. \& Pittendr. zu finden. 
Auch im untersuchten Altbestand wurde die Baum- und Krautschicht bereits von KAPPELlE (1995) floristisch untersucht (plot 10). Hier wird die obere Baumschicht ausschließlich von Quercus copeyensis und einzelnen Quercus costaricensis gebildet. Diese Eichen erreichen Höhen von 30 bis $35 \mathrm{~m}$. Das Kronendach der oberen Baumschicht ist zum Teil lückig und nicht dicht geschlossen. Eine zweite, deutlich ausgeprägte Baumschicht erreicht etwa 10 bis $15 \mathrm{~m}$ Höhe. Diese wird durch Arten wie Cleyera theaeoides, Weinmannia pinnata und Schefflera rodriguesiana gebildet. Darunter lässt sich eine weniger deutlich abgegrenzte Strauchschicht erkennen, die von Anthurium concinnatum und Cavendishia bracteata (Ruiz \& Pav.ex J. St.-Hil.) dominiert wird. Auch Baumarten wie Zanthoxylum melanosticum, Palicourea salicifolia Standl. und Quercus copeyensis sind hier häufig anzutreffen, während Chusquea spec. nur vereinzelt auftritt. Viele Pionier- und frühsukzessionale Baumarten wie Bocconia frutescens oder Abatia parviflora treten im Altbestand nicht auf oder sind wie Oreopanax xalapense, Cornus disciflora und Fuchsia paniculata nur noch selten $\mathrm{zu}$ finden. Die Krautschicht ist nur schwach ausgebildet. Im untersuchten Bestand konnten 100 epiphytisch auf Quercus copeyensis vorkommende Moosarten unterschieden werden (HoLz 2003). Aufgrund der unterschiedlichen Anzahl von Vegetationsaufnahmen sind die in den drei Waldstadien gefundenen Artenzahlen epiphytischen Moose jedoch nicht exakt miteinander vergleichbar. Die Gesamtartenzahl epiphytisch auf Quercus copeyensis vorkommender Moosarten liegt in den drei Beständen bei 177 (Holz 2003). Auffallend sind im Altbestand besonders das Polster bildende Moos Leptodontium exasperatum Cardot und epiphytisch vorkommende Gefäßpflanzen wie Macleanea rupestris, Oreopanax capitatus oder Vriesea orosiensis. Neben mehreren epiphytischen Farn- und Orchideenarten sind zahlreiche weitere, nicht näher bestimmte Gefäßepiphyten in den Baumkronen zu finden. Ein Alter läßt sich weder für den Bestand noch für einzelne Bäume angeben, da deutliche Zuwachszonen nur bei besonders scharfen, nicht regelmäßig auftretenden Trockenzeiten ausgebildet werden (BLASER 1987). 


\section{Material und Methoden}

Die Geländearbeiten zum Projekt wurden in der Zeit vom 23.02.1999 bis zum 10.09.2000 in der Umgebung der Ortschaft Jaboncillo de Dota, Cordillera Talamanca, in Costa Rica durchgeführt.

\subsection{Mikrometeorologische Messungen}

\subsubsection{Mikrometeorologische Messungen im Freiland}

Zur Beschreibung der mikroklimatischen Standortsbedingungen der drei untersuchten Bestände wurde auf einer zentral gelegenen Freifläche in der Nähe der Ortschaft Jaboncillo (2900 m ü.M.) eine mikrometeorologische Wetterstation betrieben. Über einen Zeitraum von 17 Monaten wurden Luftfeuchte, Lufttemperatur, Strahlungsbilanz und Windgeschwindigkeit alle zehn Sekunden erfaßt und die Mittelwerte von 60 Messungen in einem Zeittakt von zehn Minuten berechnet und gespeichert. Während einzelner Meßkampagnen wurde auch die potentielle Verdunstung mit Piche-Evaporimetern bestimmt.

Zur Messung von Luftfeuchte und Lufttemperatur in $1.50 \mathrm{~m}$ über dem Boden wurden kombinierte Meßühler (Hygromer MP 100A, Fa. Rotronic, Ettlingen, Deutschland) eingesetzt, die nach einem kapazitiven Meßprinzip arbeiten. Um bei der Messung den Strahlungsfehler möglichst gering zu halten, wurden die Fühler in einem zylindrischen Edelstahlgehäuse mit Lüftungsschlitzen untergebracht. So waren sie auch gegen Niederschläge abgeschirmt, ohne dabei eine ausreichende Luftzirkulation zu unterbinden. Aus der gemessenen relativen Luftfeuchte und der Lufttemperatur konnte das Wasserdampfsättigungsdefizit (Vapor Pressure Deficit, VPD) der Luft über die MagnusFormel (DEFANT 1958) berechnet werden:

(1) $V P D=e_{s}-e_{a}$

(2) $e_{S}=6.1078 \cdot \exp \left(\frac{17.08085 \cdot T}{234.175+T}\right)$

(3) $e_{a}=e_{S} \cdot\left(\frac{r h}{100}\right)$

VPD $=$ Wasserdampfsättigungsdefizit $[\mathrm{hPa}]$

$\mathrm{e}_{\mathrm{s}}=$ Sättigungsdampfdruck der Luft bei gegebener Temperatur [hPa]

$\mathrm{e}_{\mathrm{a}}=$ aktueller Dampfdruck der Luft $[\mathrm{hPa}]$

$\mathrm{T}=$ Lufttemperatur $\left[{ }^{\circ} \mathrm{C}\right]$

$\mathrm{rh}=$ relative Luftfeuchte $[\%]$ 
Die Strahlungsbilanz im kurz- und langwelligen Strahlungsbereich $(0.3$ bis $>30 \mu \mathrm{m})$ wurde mit einem Pyrradiometer (Modell 8111, Fa. Schenk, Wien, Österreich), das über zwei getrennte Hemisphären verfügt, in 1.50 m Bodenhöhe gemessen. Die obere Empfängerfläche dient der Ermittlung der kurzwelligen Globalstrahlung und der langwelligen Strahlung der Atmosphäre gemäß ihrer Temperatur. Mit der unteren Empfängerhälfte werden die reflektierte kurzwellige Strahlung und die langwellige Ausstrahlung gemäß der Oberflächentemperatur des Untergrundes gemessen. Die Strahlungsbilanz (Q) ergibt sich aus der Differenz der oberen und der unteren Empfängerhälfte.

Die Windgeschwindigkeit wurde mit einem Schalen-Anemometer (Modell 4.3519.00, Fa. Thies, Göttingen, Deutschland) in $1.50 \mathrm{~m}$ über dem Boden gemessen.

Die Speicherung der Meßwerte erfolgte mit einem Datalogger (Modell CR 10X, Fa. Campbell, Shepshed, England), der über eine 12-V-Autobatterie mit Strom versorgt wurde.

Die Niederschlagshöhe wurde mit fünf Niederschlagssammlern in wöchentlicher Auflösung aufgezeichnet. Zusätzlich wurden in einzelnen Meßkampagnen tägliche Leerungen durchgeführt. Die Sammler waren aus Kunststofftrichtern mit einem Innendurchmesser von $16.5 \mathrm{~cm}$ gefertigt. Ein senkrecht hochgezogener $1.5 \mathrm{~cm}$ breiter Rand sollte ein Abprallen der Regentropfen von der schrägen Trichterinnenseite und ein anschließendes Herausspritzen des Wassers verhindern. Als Auffanggefäße dienten silberfarbene Kunststoffflaschen (Volumen 4 Liter). Die silberne Farbe sollte ein starkes Aufheizen der Gefäße durch Sonneneinstrahlung unterbinden. Die Gesamthöhe der Niederschlagssammler betrug $70 \mathrm{~cm}$. Um Evaporationsverluste aus den Sammelgefäßen zu reduzieren und eine Verunreinigung der Sammler durch Streufall möglichst gering zu halten, wurden Tischtennisbälle in die Trichter eingelegt. Aufgrund der größeren räumlichen Entfernung des Altbestandes zu den beiden Sekundärwäldern wurde zur Erfassung des Freilandniederschlages eine zweite, an den Altbestand angrenzende Freifläche eingerichtet, auf der ebenfalls fünf Niederschlagssammler betrieben wurden.

Weitere drei Niederschlagssammler waren in etwa $1.5 \mathrm{~km}$ Entfernung $\mathrm{zu}$ den beiden Freiflächen auf der Finca Serrano aufgestellt. Hier wurde der Freilandniederschlag während eines Jahres in täglicher Auflösung aufgezeichnet.

Der auskämmbare Nebelniederschlag im Freiland wurde mit Hilfe von drei Nebelsammlern über einen Zeitraum von neun Monaten wöchentlich quantifiziert. Zusätzlich wurden parallel zum Freilandniederschlag in einzelnen Meßkampagnen tägliche Leerungen durchgeführt. Die Sammler waren aus einem Holzrahmen gefertigt, in dem zwei $40 \mathrm{~cm}$ lange Plexiglas-Kämme in einem Abstand von $50 \mathrm{~cm}$ zueinander angebracht waren. Diese Kämme wurden mit einer $0.7 \mathrm{~mm}$ starken Perlonschnur im Abstand von $1.2 \mathrm{~mm}$ bespannt, so daß die Sammelfläche 0.2 $\mathrm{m}^{2}$ betrug. Gegen vertikale Niederschläge waren die Nebelsammler durch ein Holzdach abgeschirmt. Mit den Perlonschnüren der Bespannung sollten die winzigen Nebeltröpfchen 
ausgekämmt und über eine Abflußrinne in ein geschlossenes Sammelgefäß geleitet werden. Diese flächige Bauweise, wie sie von SCHEMENAUER \& CERECEDA (1994) als Standardmodell vorgeschlagen wird, eignet sich vor allem für windarme Gebiete mit geringer Nebelbildung, ist jedoch anfälliger gegen horizontal verwehten Regen als zylindrische Modelle, die sich vor allem in nebelreichen und sehr windigen Gebieten bewährt haben (BRUIJNZEEL 2002).

Zusätzlich wurden über einen Zeitraum von acht Monaten tägliche Beobachtungen der Nebelhäufigkeit im Altbestand von der gegenüberliegenden Finca Serrano aus durchgeführt. Tage mit mehr als drei Stunden Nebel wurden hierbei als Nebeltage eingestuft. Dieses Kriterium wurde nach einigen Vorbeobachtungen gewählt, um eine geeignete Auflösung bei der Beobachtung der Nebelhäufigkeit zu erreichen.

Zur Messung der potentiellen Verdunstung wurden Evaporimeter nach Piche verwendet. Diese bestehen aus einer einseitig verschlossenen Glasröhre mit 1/10 ml Skala. Die mit destilliertem Wasser gefüllten Glasröhren werden an der offenen Unterseite mit einer grünen Filterpapierscheibe von $5 \mathrm{~cm}$ Durchmesser verschlossen und mit dieser Seite nach unten in $1.50 \mathrm{~m}$ Bodenhöhe befestigt. Die Verdunstung erfolgt über die Filterpapierscheibe, wobei die Menge des verdunsteten Wassers an der Skalierung des Glasröhrchen abgelesen werden kann.

\subsubsection{Mikrometeorologische Messungen in den Beständen}

In jedem der drei Bestände wurden in verschiedenen, jeweils mehrwöchigen Perioden Vertikalgradienten von Lufttemperatur und Luftfeuchte aufgezeichnet. Die Meßperioden wurden dabei so gewählt, daß in jedem Bestand mehrere Wochen in der Regen- und in der Trockenzeit dokumentiert werden konnten (Abb. 3-1).

\begin{tabular}{|c|c|c|c|c|c|c|c|c|}
\hline \multirow[t]{2}{*}{$\begin{array}{c}\text { Mär } \\
1999 \rightarrow\end{array}$} & Apr & Mai & Jun & Jul & Aug & Sep & Okt & Nov \\
\hline & \multicolumn{3}{|c|}{ älterer Sekundärwald } & \multicolumn{3}{|c|}{ junger Sekundärwald } & \multicolumn{2}{|c|}{ Altbestand } \\
\hline
\end{tabular}

\begin{tabular}{|c|c|c|c|c|c|c|c|c|}
\hline Dez & $\underset{2000 ~}{\text { Jan }} \rightarrow$ & Feb & Mär & Apr & Mai & Jun & Jul & Aug \\
\hline & pestand & \multicolumn{3}{|c|}{ ält. Sek. } & \multicolumn{3}{|c|}{ junger Sekundärwald } & \\
\hline
\end{tabular}

Trockenzeit Regenzeit

Abb. 3-1: Standort der Bestandesmeßstation während des Untersuchungszeitraumes von März 1999 bis August 2000 im jungen und älteren Sekundärwald sowie im Altbestand. Die Trockenzeit ist durch die grau unterlegten Bereiche gekennzeichnet. 
Die untersuchten Höhengradienten beinhalten die fünf Straten Stammbasis, Stamm, innere, mittlere und äußere Krone (in Anlehnung an JOHANNSON 1974), die der Diversitätsanalyse der Moose und Flechten der kooperierenden Forschergruppe (Arbeitsgruppe Gradstein, Göttingen) zugrunde gelegt wurden. Zur Installation der Meßfühler wurde die Seil-KletterTechnik (PERRY 1978, LOWMAN \& NADKARNi 1995) angewendet. Dazu mußte mittels einer Armbrust zuerst eine dünne Perlonschnur in die Baumkronen geschossen werden, an der dann eine stabilere Reepschnur und schließlich ein Kletterseil nachgezogen werden konnte. Die Besteigung der Bäume erfolgte mit Hilfe von Steigklemmen und Klettergurt.

Die Meßpunkte im Altbestand lagen in 0.5, 17, 25, 26 und 30 m Höhe (Abb. 3-2) und im älteren Sekundärwald in 0.2, 4, 7, 8 und $11 \mathrm{~m}$ Höhe. Im jungen Sekundärwald wurde der Temperatur- und Feuchtegradient nur in drei unterschiedlichen Höhen $(0.2,4,6 \mathrm{~m})$ gemessen. Die übrigen Fühler wurden dazu verwendet, die horizontale Variabilität auf der Fläche zu dokumentieren und in verschiedenen Himmelsrichtungen in $4 \mathrm{~m}$ Entfernung vom Meßbaum in $0.2 \mathrm{~m}$ Bodenhöhe installiert. Die Messungen erfolgten alle zehn Sekunden, die Mittelwerte aus 60 Messungen wurden im Zeittakt von zehn Minuten aufgezeichnet. Hierzu wurden, wie auch bei den Freilandmessungen, ein Campbell-Datalogger und fünf Rotronic Luftfeuchteund Temperatur-Meßfühler verwendet, die, wie bereits beschrieben, gegenüber Strahlung und Niederschlag abgeschirmt waren.

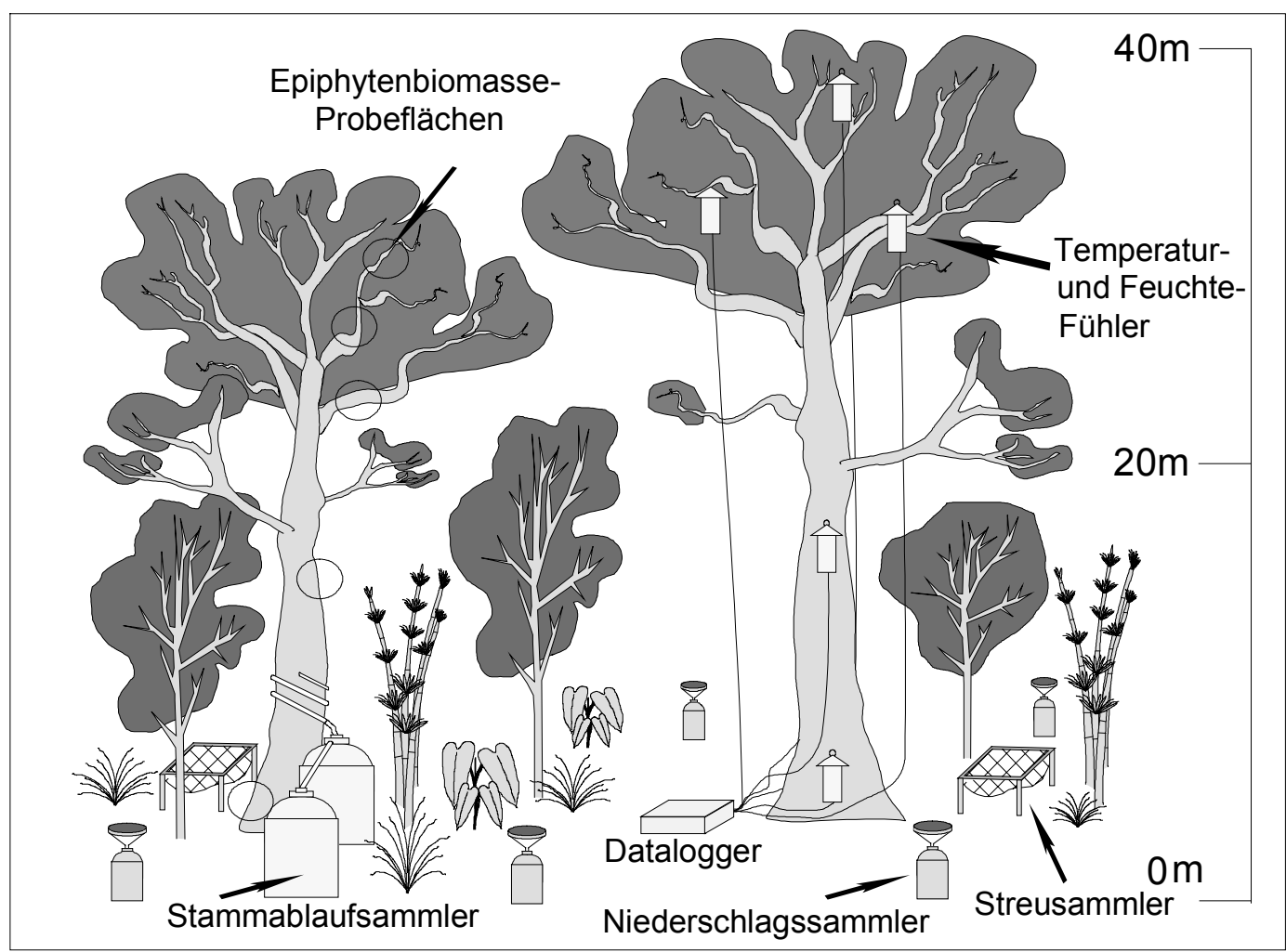

Abb. 3-2: Versuchsaufbau im Altbestand. Dargestellt sind die Bestandesniederschlags-, Stammablauf- und Streusammler sowie die Luftfeuchte- und Lufttemperatursensoren. Die Kreise kennzeichnen die Straten, in denen die Erhebungen der Epiphytenbiomasse durchgeführt wurden. 
In Meßkampagnen wurde sowohl in der Regenzeit als auch in der Trockenzeit parallel zu den Messungen im Freiland die Piche-Evaporation in unterschiedlichen Höhen (29 m, 25 m, 18 m und $1 \mathrm{~m}$ ) im Altbestand aufgezeichnet.

\subsection{Wasserumsatz im Kronenraum}

\subsubsection{Messung des Bestandesniederschlags}

Zur Erfassung des Bestandesniederschlags wurden auf jeder Untersuchungsfläche 30 von den auch im Freiland benutzten Niederschlagssammlern verwendet. Diese waren in drei hangparallelen Reihen mit je zehn Sammlern im Bestand aufgestellt. Untereinander hatten die Reihen einen Abstand von zehn Metern, wobei die Sammler innerhalb einer Reihe fünf Meter voneinander entfernt waren. Die Lage dieses systematischen Rasters wurde vorher per Zufall bestimmt. Diese Methode mit stationären Niederschlagssammlern führt nach BRUIJNZEEL (2002) zu einer Unterschätzung des Bestandesniederschlags, da sogenannte „drip points“, Punkte, an denen sich der abtropfende Niederschlag konzentriert, nicht ausreichend berücksichtigt werden. Um Störungen an den stark geneigten Hängen der Untersuchungsflächen möglichst gering zu halten, wurde jedoch keine Technik mit rotierenden Sammlern (LLOYD \& MARQUES 1988) eingesetzt. Ferner kamen in den meisten bisher in tropischen Bergregenwäldern durchgeführten Niederschlagsmessungen stationäre Niederschlagssammler zum Einsatz, was eine bessere Vergleichbarkeit der eigenen Ergebnisse mit anderen Untersuchungen gewährleistet. Mit der hohen Zahl an Wiederholungen (30 Sammler) sollte der Fehler möglichst gering gehalten werden. Die Leerung der Sammler erfolgte wöchentlich parallel zur Registrierung des Freilandniederschlags. Um eine höhere Auflösung der Niederschlagsereignisse zu erreichen und die Kronenspeicherkapazität der Bestände berechnen zu können, wurden zusätzlich zu den wöchentlich durchgeführten Messungen in einzelnen Meßkampagnen in der Regenzeit und in der Trockenzeit tägliche Leerungen durchgeführt.

\subsubsection{Ermittlung des Stammablaufs}

Zur Erfassung des Stammablaufs wurden aufgeschnittene Kunststoffschläuche benutzt, die etwa eineinhalb Windungen um den unteren Stammabschnitt der Meßbäume gelegt wurden. Vorher mußte der Stamm in diesem Bereich von grober Borke und Epiphyten befreit werden. Die Schläuche wurden mit kleinen Nägeln am Stamm befestigt. Zusätzlich wurde der Ansatzpunkt des Schlauches am Baum mit Silikon verklebt, wodurch eine lückenlose Verbindung zwischen Stamm und Sammler geschaffen werden konnte. Diese Silikonverbindung mußte, besonders bei den schnellwüchsigen Bäumen im jungen Sekundärwald, regelmäßig erneuert werden. Die Schlauchbreite wurde möglichst gering 
gewählt (1 bis $3 \mathrm{~cm}$ ), um ein direktes Auftreffen von Regenwasser zu verhindern. Das ablaufende Wasser wurde in geschlossene Kunststofftonnen geleitet, die ein Fassungsvermögen von bis zu 200 Litern hatten. Die Leerung erfolgte wöchentlich, parallel zur Registrierung des Freilandniederschlags. In einzelnen Meßkampagnen wurden zusätzlich auch tägliche Leerungen durchgeführt. Folgenden Baumarten wurde in die Messungen einbezogen: Quercus copeyensis, Quercus costaricensis, Cleyera theaoides, Styrax glabrescens, Schefflera rodriguesiana, Myrsine spec., Cornus disciflora, Vernonia cf. patens, Styrax argentus, Monochaetum spec. und Weinmannia pinnata. Die Auswahl der Arten erfolgte gemäß ihrer Häufigkeit auf den Untersuchungsflächen. So befanden sich im jungen Sekundärwald drei, im älteren Sekundärwald sieben und im Altbestand fünf Sammler an Eichen. Im Altbestand und im älteren Sekundärwald wurde zwischen Bäumen, die in die obere Kronenschicht reichen (Kronenbäume-KB) und unterständigen Bäumen (UB) unterschieden. Während die Installation von fünf Sammlern je Bestand an den Kronenbäumen bereits zu Beginn der Untersuchung erfolgte, wurden die zusätzlichen Messungen an je fünf unterständigen Bäumen erst später begonnen und im Altbestand über insgesamt 40 Wochen, im älteren Sekundärwald über 26 Wochen durchgeführt. Über das Verhältnis der Sammelleistung der Kronenbäume zu den unterständigen Bäumen (älterer Sekundärwald: $\mathrm{y}=0.19+0.26 \mathrm{x}, \mathrm{r}=0.99, \mathrm{p}<0.001 \%$. Altbestand: $\mathrm{y}=0.11+2.38 \mathrm{x}, \mathrm{r}=0.93, \mathrm{p}<0.001 \%)$ konnte auf den Gesamtstammablauf für den Zeitraum von einem Jahr hochgerechnet werden. Im jungen Sekundärwald reichten aufgrund der einfacheren Bestandesstruktur nahezu alle Bäume in die obere Kronenschicht. Auch hier wurden zu Untersuchungsbeginn fünf Sammler installiert. Später kamen fünf weitere Sammler hinzu, die über 25 Wochen betrieben wurden. Die Berechnung des Stammablaufs auf Bestandesebene [mm] erfolgte durch Multiplikation der gemessenen Stammablaufmengen mit der Anzahl der Stämme, wobei die Position der Bäume (Kronenbaum oder unterständig) berücksichtigt wurde. Die hierfür nötige Stammdichte wurde in den drei Beständen für alle Bäume mit einem Brusthöhendurchmesser $\geq 3 \mathrm{~cm}$ ermittelt, wobei bei mehrstämmigen Bäumen jeder Stamm gezählt wurde. Unterständige Bäume wurden getrennt von Bäumen des oberen Kronenraums erfaßt. Die Stammdichte wurde anschließend auf eine ebene Fläche bezogen.

Um den Einfluß der Baumstruktur auf die Höhe des Stammablaufes zu untersuchen, wurden bei den insgesamt 30 Meßbäumen wichtige Strukturparameter wie Höhe, Brusthöhenumfang und Rindenstruktur bestimmt.

In einem Experiment sollte geklärt werden, ob Zusammenhänge zwischen der Blattfläche und der Menge des Stammablaufes bestehen. An fünf Bäumen im jungen Sekundärwald, an denen Stammablaufsammler installiert waren, wurde eine Totalernte der Laubblätter durchgeführt und deren Trockengewicht bestimmt. Für jede der unterschiedlichen Baumarten wurde ein Teil der Laubblätter mit dem Scanner erfaßt, um ihre Fläche zu bestimmen. Die Gesamtblattfläche für jeden der Bäume konnte somit sehr genau ermittelt werden. Nach dem Entfernen der Laubblätter wurden die Bäume wieder aufgerichtet und exakt in ihrer 
ursprünglichen Position befestigt. An diesen blattlosen Bäumen wurde für zwei weitere Wochen der Stammablauf gemessen.

\subsubsection{Bestimmung der Interzeption und Kronenspeicherkapazität}

Die Interzeption der Bestände wurde als Bilanzgröße bestimmt:

(4) $I=F N-(B N+S)$

$\mathrm{I}=$ Interzeption [mm]

$\mathrm{FN}=$ Freilandniederschlag $[\mathrm{mm}]$

$\mathrm{BN}=$ Bestandesniederschlag $[\mathrm{mm}]$

$\mathrm{S}=$ Stammablauf $[\mathrm{mm}]$

Die Kronenspeicherkapazität der Bestände wurde in Anlehnung an LEYTON et al. (1967) durch die Auftragung des an einzelnen Regenzeittagen ermittelten Nettoniederschlags (Bestandesniederschlag + Stammablauf) gegen den Freilandniederschlag ermittelt. Bei dieser Methode läßt sich im unteren Wertebereich ein sehr flacher Kurvenanstieg beobachten, der auf eine unvollständige Aufsättigung der Krone durch geringe Niederschlagsereignisse zurückgeführt wird. Bei höheren Freilandniederschlägen zeigt sich ein stärkerer Anstieg des Nettoniederschlags. In diesem Bereich lassen hohe Nettoniederschlagswerte einzelne Niederschlagsereignisse erkennen, während niedrigere Werte als Ergebnis verschiedener Benetzungs- und Trocknungszyklen der Baumkronen interpretiert werden. Zur Ermittlung der Kronenspeicherkapazität werden nur die hohen Meßwerte (einzelne Niederschlagsereignisse) herangezogen, die einen stark linearen Zusammenhang zwischen Nettoniederschlag und Freilandniederschlag erkennen lassen. Der Schnittpunkt der Regressionsgeraden dieser Punkte mit der Abzisse ergibt einen Wert für die Kronenspeicherkapazität eines Bestandes.

\subsubsection{Messung des horizontalen Niederschlags}

Mit einem experimentellen Ansatz wurde untersucht, über welches Potential hängende Moose verfügen, horizontale Niederschläge auszukämmen. Dafür wurden oberhalb von sieben im Freiland aufgestellten Niederschlagssammlern Schweife des Hängemooses Pilotrichella flexilis installiert. Als Referenzwerte dienten weitere fünf Sammler ohne Moose. Aus der Differenz beider Sammlertypen wurde die Höhe des durch das Moos zugeleiteten horizontalen Niederschlages berechnet. Dieser Versuch wurde über mehrere Wochen in der Trockenzeit und in der Regenzeit durchgeführt, wobei auch tägliche Leerungen stattfanden. 


\subsubsection{Untersuchung der Wasserspeicherkapazität der Epiphyten}

Die Wasserspeicherkapazität der Epiphytenvegetation und Blattmasse wurde im Labor experimentell durch Beregnung mit unterschiedlichen Wassermengen (fünf bis acht Parallelen je Beregnungsstufe) ermittelt. Die verwendete Methode orientierte sich an den Experimenten von LEUSCHNER (1986), in denen die Wasserspeicherkapazität von Bodenvegetation untersucht wurde. Dazu wurde zuerst das Frischgewicht der Pflanzen bestimmt. Um die für die unterschiedlichen Beregnungsstufen nötige Wassermenge zu berechnen, mußte ferner die Projektionsfläche der Versuchspflanzen ermittelt werden. Anschließend wurden diese in Halterungen aus Draht gemäß ihrer natürlichen Lage befestigt und über Auffangschalen aus Kunststoff gebracht. Die Beregnung erfolgte mit einer Pipette, mit der die entsprechende Wassermenge in einzelnen Tropfen gleichmäßig auf die Pflanzenoberflächen aufgetragen wurde. Die Beregnungsmengen für Polstermoose entsprachen beispielsweise etwa 0.1, 0.5, 1, 2, 5, 10 und $20 \mathrm{~mm}$. Nach jeder Beregnungsstufe wurde eine Abtropfzeit von zehn Minuten (bei Blättern drei Minuten) eingehalten und das dabei abtropfende Wasser aufgefangen. Durch die Bestimmung der abgetropften Wassermenge wurde die Wasseraufnahme durch die Pflanzen ermittelt. Vor Beginn der nächsten Beregnungsstufe wurden die Pflanzen bis zum Erreichen ihres Anfangsgewichts im Freien getrocknet. Nach Durchführung aller Beregnungsstufen wurde die Wasserspeicherkapazität der Epiphyten beziehungsweise die Wasserspeicherkapazität der Blätter bestimmt, indem diese für fünf Minuten unter Wasser aufgesättigt wurden. Nach einer Abtropfzeit von zehn Minuten (bei Blättern drei Minuten) wurden die Pflanzen gewogen. Zum Abschluss wurden die Versuchspflanzen 48 Std. bei $70{ }^{\circ} \mathrm{C}$ getrocknet, um ihr Trockengewicht zu bestimmen.

\subsubsection{Experimentelle Ansätze zur Wasserspeicherung und Wasserabgabe der Epiphyten im Altbestand}

Zur Überprüfung der experimentell ermittelten Wasserspeicherkapazitäten und um Aussagen zu der jeweils aktuell vorhandenen Wasserspeicherkapazität der Epiphyten in der Kronenregion zu treffen, wurden in einem vierwöchentlichen Turnus im Altbestand Messungen des aktuellen Wassergehalts des Polstermooses Leptodontium exasperatum und eines poikilohydren Farnes (Elaphoglossum spec.) durchgeführt. Dazu wurden von Elaphoglossum jeweils sechs bis zehn Einzelpflanzen geerntet und bei Leptodontium aus verschiedenen Moospolstern mit einem Stechzylinder jeweils sieben bis zehn Proben entnommen. Die Probenahme erfolgte jeweils am Vormittag vor den in den Mittagsstunden einsetzenden Niederschlägen. Nach der Bestimmung des Frischgewichts wurden die Proben 48 Std. bei $70^{\circ} \mathrm{C}$ getrocknet, das Trockengewicht bestimmt und der aktuelle Wassergehalt nach Gleichung (5) berechnet. 
(5) $W G=\frac{F G-T G \cdot 100}{T G}$

$$
\begin{aligned}
\mathrm{WG} & =\text { Wassergehalt }[\% \mathrm{TG}] \\
\mathrm{FG} & =\text { Frischgewicht }[\mathrm{g}] \\
\mathrm{TG} & =\text { Trockengewicht }[\mathrm{g}]
\end{aligned}
$$

Die Bestimmung der maximalen Wasserspeicherkapazität von Bromelien (Vriesea orosiensis) unterschiedlicher Größenklassen erfolgte durch künstliche Beregnung. Nach einer Abtropfzeit von drei Minuten wurde die in den Blatttrichtern (Phytotelmen) gespeicherte Wassermenge gemessen. Auf der Basis von Bromelien-Zählungen, die in den drei Beständen durchgeführt wurden, konnte deren Beitrag zur Wasserspeicherkapazität im Kronenraum abgeschätzt werden.

Die experimentell ermittelten Wasserspeicherkapazitäten der Epiphyten dienten wie auch die aktuellen in der Kronenregion des Altbestandes gemessenen Wassergehalte zur Abschätzung der Kronenspeicherkapazität der Bestände.

Um neben der Wasserspeicherung durch die Vegetation auch Aussagen über den zeitlichen Verlauf der Wasserabgabe des interzepierten Wassers treffen zu können, wurde eine experimentelle Austrocknung verschiedener Epiphyten und Eichenborke (Quercus copeyensis) durchgeführt. Zunächst wurde das Frischgewicht der Versuchspflanzen (Leptodontium exasperatum, Elaphoglossum spec., Sticta ferax Müll. Arg.) sowie von Eichenborke bestimmt. Nach einer Aufsättigungszeit von fünf Minuten unter Wasser folgte eine Abtropfphase von zehn Minuten. Nach Ablauf dieser Zeitspanne war nur noch eine geringe Wasserabgabe durch Tropfen zu beobachten (drainage-phase, VENEKLAAS et al. 1990) und das Sättigungsgewicht konnte bestimmt werden. Die aufgesättigten Pflanzenproben wurden im Bestand in etwa $1 \mathrm{~m}$ Höhe exponiert, in Abständen von 30 oder 60 Minuten gewogen und die Gewichtsänderungen aufgezeichnet (evaporation-phase, VENEKLAAS et al. 1990). Da dieser Versuch sowohl in der Regenzeit als auch in der Trockenzeit durchgeführt wurde, konnten neben den artspezifischen Unterschieden auch jahreszeitlich bedingte Differenzen im Verdunstungsgang des interzepierten Wassers dargestellt werden. 


\subsection{Blattflächenindex und Epiphytenbiomasse}

\subsubsection{Messung des Blattflächenindex mit dem LAI 2000}

Die Überschirmung des Bodens durch Pflanzen wurde an den drei Waldstandorten mit dem Blattflächenmessgerät LAI 2000 (Fa. Licor, Lincoln, USA) bestimmt. Der optische Sensor des LAI 2000 besteht aus fünf konzentrischen Ringen, die Strahlung von Wellenlängen unterhalb $0.49 \mu \mathrm{m}$ in unterschiedlichen Hemisphärensegmenten messen. Bei der Messung wurde eine Abdeckkappe für die Linse mit einem Öffnungswinkel von $90^{\circ}$ benutzt, um Streulicht von den Seiten auszuschließen und eine Beeinflussung des Sensors durch die Meßperson zu verhindern. Die Messungen wurden in jedem Bestand an 30 Meßpunkten eines vorher eingemessenen Rasters erhoben. Die Meßpunkte entsprachen den Standorten der Regensammler. So konnte überprüft werden, ob ein direkter Zusammenhang zwischen der räumlichen Heterogenität der Blattfläche und der Höhe des Bestandesniederschlags besteht. Vor und nach jeder Messung im Bestand erfolgte eine Referenzmessung im Freiland, wobei die Zeitspanne zwischen den Messungen so gering wie möglich gehalten wurde und meist unter einer Minute lag. Alle Messungen erfolgten bei wolkenlosem Himmel vor Sonnenaufgang oder bei gleichmäßiger Bewölkung im Februar 2000.

\subsubsection{Untersuchung der Streuproduktion}

Die Menge der Feinstreu wurde in allen drei Beständen mit jeweils zehn Sammlern über einen Untersuchungszeitraum von zwölf Monaten bestimmt. Die Untersuchungen begannen im Mai 1999, und die Leerungen erfolgten in einem vierwöchigen Turnus. Die Sammler bestanden aus einer hölzernen Rahmenkonstruktion aus $5 \mathrm{~cm}$ breiten Kanthölzern mit einer Auffangfläche von $250 \mathrm{~cm}^{2}$ und waren mit Kunststoffgaze (Maschenweite $2 \mathrm{~mm}$ ) bespannt. Sie wurden in etwa $50 \mathrm{~cm}$ Höhe über dem Boden horizontal aufgestellt. Die Anordnung auf den Untersuchungsflächen erfolgte in zwei hangparallelen Reihen von je vier Sammlern, zwei weitere Sammler wurden zwischen diesen Reihen platziert. Die Lage dieses systematischen Rasters im Gelände wurde vorher per Zufall bestimmt. Um an den stark geneigten Hängen der Untersuchungsflächen ein Hineinwehen von Bodenstreu in die Sammler zu verhindern, wurden die Hänge oberhalb der Streufänger zusätzlich mit einer Kunststoffgaze abgespannt. Diese Maßnahme diente außerdem dazu, einen Streueintrag durch eine besonders in den Sekundärwäldern häufige Vogelart (Pezopetes capitalis) zu verhindern, die während der Nahrungssuche am Waldboden mit ihren kräftigen Beinen Laubstreu aufwirft (STILES et al. 1998). Bei der Fraktionierung der Streu erfolgte die Trennung von Baumblättern, epiphytischen Gefäßpflanzen sowie epiphytischen Moosen und Flechten. Laubblätter, die nicht eindeutig epiphytischer Herkunft waren, wurden der Streukomponente Baumblätter zugeordnet. Zweige ( $<2 \mathrm{~cm}$ Durchmesser), Früchte, Blüten, Kronenhumus und nicht näher 
identifizierbares Material wurden in einer Restfraktion zusammengefaßt. Zusätzlich wurden parasitische Sträucher (Mistelgewächse, hauptsächlich Phoradendron) erfaßt. Aus jedem Streusammler wurden bereits während der Arbeiten in Costa Rica monatlich sechs zufällig ausgewählte Laubblätter unterschiedlicher Baumarten mit einem Flachbrettscanner digitalisiert und danach deren Trockengewichte (48 Std. bei $70{ }^{\circ} \mathrm{C}$ ) bestimmt. Die Ermittlung der Flächen der eingescannten Blätter erfolgte mit einem speziellen Analyseprogramm (WinFolia, Régent Instruments Inc., Québec, Canada). Mit bekannter Blattfläche und dem Trockengewicht der Blätter war dann eine Berechnung der spezifischen Blattfläche möglich.

\subsubsection{Ermittlung der Blattlebensdauer von Eichenblättern}

Um die Blattlebensdauer von Quercus copeyensis, der in allen drei Waldstadien häufigsten Baumart, abzuschätzen, wurden in den Beständen phänologische Untersuchungen durchgeführt. Dazu erfolgte gleich nach dem Laubaustrieb die Kennzeichnung der jungen Eichenblätter mit kleinen Klebeetiketten am Blattstiel. Zur leichteren Wiederauffindbarkeit wurden zusätzlich auch die dazugehörigen Zweige mit Kunststoffschildern markiert. Im jungen Sekundärwald erfolgte die Kennzeichnung der Blätter $(n=17)$ in 1 bis 2 m Höhe, im älteren Sekundärwald $(\mathrm{n}=91)$ in 6 bis $9 \mathrm{~m}$ Höhe und im Altbestand $(\mathrm{n}=57)$ in etwa $25 \mathrm{~m}$ Höhe. Zusätzlich wurden im Altbestand in einer mittleren Bodenhöhe von $2 \mathrm{~m}$ auch Blätter von unterständigen Eichen markiert $(n=167)$. In Abständen von mehreren Wochen wurde die Blattzahl protokolliert und gegebenenfalls Markierungen erneuert. Mit der so ermittelten Blattlebensdauer und den Streufalldaten konnte der Blattflächenindex berechnet werden (ROBERTS et al. 1996).

\subsubsection{Bestimmung der Epiphytenbiomasse}

Um die epiphytische Biomasse der Bäume zu erfassen, wurden in jedem Bestand auf sechs in die obere Baumschicht reichenden Eichen (Quercus copeyensis) Biomasseernten durchgeführt. Dazu wurde im älteren Sekundärwald und im Altbestand die bereits beschriebene Seil-Kletter-Technik eingesetzt. Im jungen Sekundärwald war aufgrund der geringen Baumgröße der Einsatz dieser Technik nicht nötig. Hier wurden die Bäume gefällt und dann die Biomasseernten am Boden durchgeführt. Insgesamt wurden etwa 450 Proben in den fünf Straten Stammbasis, Stamm, untere, mittlere und äußere Krone entnommen (Tab. 31). Bei Ästen und Stämmen mit einem Durchmesser von mehr als $15 \mathrm{~cm}$ wurden Flächen von $20 \mathrm{mal} 30 \mathrm{~cm}$ beprobt und die Exposition der Fläche erfaßt. Bei dünneren Ästen und Stämmen wurde ein Abschnitt rundherum abgeerntet und Länge und Umfang der beprobten Fläche notiert.

Die Proben am Stammfuß wurden direkt über dem Boden genommen, die Stammbereiche auf halber Höhe zwischen Stammbasis und Kronenansatz beprobt. Die Biomasseproben der 
inneren Krone wurden im Altbestand in den Hauptastgabeln erhoben. Im älteren Sekundärwald wurde die vertikale Hauptachse (Stammfortsetzung im Kronenbereich) beprobt, da hier die Astgabeln keine ausreichende Probefläche boten und meist auch keinen stärkeren Epiphytenbewuchs zeigten. Die Probenahme erfolgte nach dem Zufallsprinzip. In der mittleren Krone wurden die Biomasseerhebungen im Altbestand in $3 \mathrm{~m}$ und im älteren Sekundärwald in $1.5 \mathrm{~m}$ Entfernung von der vertikalen Hauptachse durchgeführt. Als äußere Krone wurden im Altbestand die äußeren $3 \mathrm{~m}$ der Äste und Zweige definiert und im älteren Sekundärwald die äußeren $1.5 \mathrm{~m}$. Zusätzlich wurde im älteren Sekundärwald innerhalb der äußeren Krone ein unterer und ein oberer Bereich unterschieden. Da die äußere Kronenregion mit der angewendeten Klettertechnik nicht zugänglich war, wurden hier die zu beprobenden Äste herausgeschnitten, die Astabschnitte einzeln verpackt und die Erhebungen der Epiphytenbiomasse im Labor durchgeführt.

Da bei den Eichen im jungen Sekundärwald ein Klettern nicht möglich war, wurden die Bäume gefällt, die zu beprobenden Ast- und Stammabschnitte herausgeschnitten und einzeln verpackt zur späteren Biomassebestimmung abtransportiert. Die Probenahme des Stammfußbereiches erfolgte direkt über dem Boden. Da bei diesen Jungbäumen eine Stammund Kronenregion erst undeutlich ausgeprägt war, wurden von der Stammbasis der vertikalen Hauptachse nach oben folgend in $1 \mathrm{~m}$ Abständen Biomasseproben entnommen (innere Krone). Eine mittlere Kronenregion konnte nicht gesondert abgegrenzt werden. Die Beprobung der äußeren Krone wurde an den äußeren $50 \mathrm{~cm}$ der Seitenäste durchgeführt. Wie im älteren Sekundärwald wurde auch hier ein unterer und ein oberer Bereich unterschieden.

Bei der Aufarbeitung der Proben wurden die Fraktionen epiphytische Gefäßpflanzen und epiphytische Moose und Flechten unterschieden. Im Altbestand wurde außerdem der Kronenhumus erfaßt. Nach der Trocknung der Proben (48 Stunden bei $70{ }^{\circ} \mathrm{C}$ ) erfolgte die Bestimmung des Trockengewichts. Zur Abschätzung der Biomasse epiphytischer Bromelien wurde in den drei untersuchten Beständen auf mehreren Eichen eine Zählung der größeren Bromelien durchgeführt.

Tab. 3-1: Anzahl der Proben zur Ermittlung der epiphytischen Biomasse in den fünf Straten (Stammbasis, Stamm, innere, mittlere und äußere Krone) der drei untersuchten Bestände.

\begin{tabular}{lccc}
\hline & $\begin{array}{c}\text { junger } \\
\text { Sekundärwald }\end{array}$ & $\begin{array}{c}\text { älterer } \\
\text { Sekundärwald }\end{array}$ & Altbestand \\
\hline äußere Krone & obere: 30 & obere: 30 & 60 \\
& untere: 30 & untere: 30 & \\
mittlere Krone & & 30 & 24 \\
innere Krone & 31 & 30 & 10 \\
Stamm & & 13 & 48 \\
Stammbasis & 12 & 12 & 48 \\
\hline \multicolumn{1}{c}{ Summe } & 103 & 145 & 190 \\
\hline
\end{tabular}


Zur Abschätzung der Epiphytenbiomasse auf Bestandesebene erfolgte die Ermittlung der Astund Stammoberflächen in den drei Beständen. Im jungen Sekundärwald dienten die allometrischen Daten der sechs bei der Biomasseerhebung in Meterabschnitten vermessenen Eichen als Berechnungsgrundlage. Über eine Kegelstumpfformel konnte die Oberfläche der einzelnen Stammsegmente berechnet werden. Anhand des BHD und der geschätzten Baumhöhe wurde die Stammoberfläche dann auch für alle übrigen Einzelbäume berechnet und über die Stammzahlen auf den Bestand hochgerechnet. Eine Schätzung der Astoberflächen erfolgte durch Zählung und Vermessung von Ästen bei sechs Einzelbäumen. Im älteren Sekundärwald und im Altbestand erfolgte die Abschätzung der Stammoberflächen über die Stammzahlen, den BHD und die Stammhöhen. Unter der Annahme, daß sich der wasserleitende Querschnitt eines Baumes vom Stamm bis in die äußere Krone nur geringfügig verändert (WEST et al. 1999), konnte für die unterschiedlichen Kronenstraten (innere, mittlere und äußere Krone) bei bekanntem mittlerem Astdurchmesser und mittlerer Astlänge je Stratum die Astoberfläche der Einzelbäume sowie des Bestandes abgeschätzt werden. Durch Multiplikation der Flächengröße mit der in den verschiedenen Straten ermittelten Epiphytenmengen ist so eine grobe Abschätzung der epiphytischen Biomasse auf Bestandesebene möglich. Im älteren Sekundärwald und im Altbestand wurden dabei auch die Untersuchungen zur epiphytischen Biomasse der Strauchschicht (KUNZ 2000) berücksichtigt. In der mittleren Baumschicht des Altbestandes erfolgte keine Bestimmung der epiphytischen Biomasse. Hier wurde ein hypothetischer Wert $\left(0.5 \mathrm{t} \mathrm{ha}^{-1}\right)$ für die Berechnung der GesamtEpiphytenbiomasse des Bestandes verwendet.

\subsection{Nährstoffflüsse}

\subsubsection{Ermittlung der Nährstoffgehalte in den Niederschlägen}

Um den Nährstoffeintrag mit dem Freilandniederschlag und die Bedeutung von Nährstoffauswaschungen (leaching) im ökosystemaren Nährstoffkreislauf zu untersuchen, wurde über einen Zeitraum von mehr als einem Jahr die chemische Zusammensetzung von Freilandniederschlag, Bestandesniederschlag und Stammablauf analysiert. Die Probenahme wurde in einem vierwöchigen Turnus durchgeführt, wobei die Beprobung des Freilandniederschlags auf den an die Sekundärwälder und den Altbestand angrenzenden Freiflächen stattfand. Vor der Probenahme wurden alle Sammler mit Regenwasser gereinigt. Die Entnahme der Proben erfolgte in der Regel zwei, maximal aber vier Tage nach der Reinigung. Dazu wurde aus jedem der jeweils fünf Niederschlagssammler etwas mehr als die eigentliche Probemenge $(100 \mathrm{ml})$ entnommen und die Probegefäße mit der überschüssigen Wassermenge zweimal gründlich gespült. Danach erfolgte die eigentliche Probenahme, wobei die Probeflüssigkeit mit einem feinen Kunststoffsieb grob vorgefiltert wurde. Auf die gleiche Weise erfolgte auch die Probenahme des Stammablaufs. 
Der Bestandesniederschlag wurde monatlich mit 15 Niederschlagssammlern je Bestand beprobt, wobei jeweils der Inhalt aus drei Sammlern aliquotisch zu einer Mischprobe vereinigt wurde. Die Auswahl der Niederschlagssammler erfolgte mit einem Zufallsprogramm. Auch hier wurden die Sammler zuvor gereinigt, die Probegefäße vor der Probenahme gründlich gespült und die Proben vorgefiltert. Die Wasserproben wurden bis zur Analyse im Dunkeln bei $4{ }^{\circ} \mathrm{C}$ gelagert. Zusätzlich fand vor dem Transport nach Deutschland eine Konservierung der Proben mit jeweils $2 \mathrm{ml}$ Chloroform je $100 \mathrm{ml}$ Probe statt. Die Analyse der Proben erfolgte in Deutschland. Dabei wurden die Elemente Calcium, Kalium, Magnesium und Natrium mittels Atomabsorbtions-Spektrometrie (AAS) (Modell Spectra AA-30, Fa. Varian, Darmstadt, Deutschland) gemessen.

Die Nitrat- und Ammoniumkonzentrationen wurden colorimetrisch mittels Continuous flowAuto Analyzer (Fa. Bran \& Luebbe, Norderstedt, Deutschland) bestimmt. Die Berechnung der Nährstoffflüsse erfolgte durch Multiplikation der Elementkonzentrationen mit den monatlichen Niederschlagsmengen. Im Freiland- und Bestandesniederschlag konnten im Monat Oktober 1999 keine Nährstoffanalysen durchgeführt werden. Der Nährstofffluss für diesen Monat wurde durch Mittelung der Flüsse der Monate September und November 1999 bestimmt. Ebenso wurde beim Stammablauf der Kronenbäume in zwei Monaten verfahren, für die keine Nährstoffgehalte vorlagen. Bei unterständigen Bäumen erfolgte die Berechnung der Nährstoffflüsse in Monaten, für die keine Meßwerte der Elementkonzentrationen im Stammablauf verfügbar waren, über das Verhältnis der Nährstoffflüsse der Kronenbäume zu den unterständigen Bäumen in den übrigen Monaten. In allen Niederschlagsproben wurde außerdem der $\mathrm{pH}-$ Wert mit einem $\mathrm{pH}-$ Meßgerät ermittelt.

\subsubsection{Bestimmung der Nährstoffgehalte von Baumblättern und Epiphyten}

Erweiternd zu diesen Messungen wurden im jungen und älteren Sekundärwald Blattproben verschiedener Blattjahrgänge aus der Kronenregion von jeweils zehn Eichen (Quercus copeyensis) gesammelt, um diese chemisch $\mathrm{zu}$ analysieren. Im Altbestand erfolgte die Probenahme bei fünf Einzelbäumen (Quercus copeyensis), wobei zwei Proben je Baum erhoben wurden. Nach der Trocknung (48 Stunden bei $70^{\circ} \mathrm{C}$ ) und dem Mahlen der Proben mit einer Schwing-Scheiben-Mühle wurde ein Druckaufschluß mit $65 \%$ iger $\mathrm{HNO}_{3}$ durchgeführt. Die Elemente Calcium, Kalium, Magnesium und Natrium wurden mittels AAS analysiert. Die Bestimmung der Kohlenstoff- und Stickstoffgehalte erfolgte an einem C/NAnalyzer (Vario EL III, Elementar Analysensysteme GmbH, Hanau, Deutschland). Das Analyseverfahren beruht auf der Verbrennung der Probe und der anschließenden gaschromatographischen Trennung der entstehenden Gase.

Des Weiteren wurden im Altbestand Proben von fünf häufigen Moosarten (Herbertus divergenz (Steph.) Herzog, Pilotrichella flexilis (Hedw.) Ångström, Leptodontium exasperatum, 
Frullania brasilensis Raddi, Plagiochila spec.) sowie Kronenhumus gesammelt, um diese ebenfalls chemisch zu analysieren. Die Aufbereitung und Analyse der Proben erfolgte wie bereits bei den Eichenblättern beschrieben.

Um die Bedeutung der Streu für den Nährstofffluß aus dem Kronenraum in den Boden der drei Bestände zu untersuchen, wurden in den Monaten November 1999 bis April 2000 gesammelte Streuproben der Baumblätter ( $\mathrm{n}=10$ je Monat und Bestand) chemisch analysiert. Zusätzlich wurde die Streu des in der Kronenregion des Altbestandes sehr häufigen parasitischen Gehölzes Phoradendron tonduzii Trel. gesondert analysiert. Die Aufbereitung und Analyse der Proben erfolgte ebenfalls wie bei den frisch geernteten Eichenblättern.

Die Berechnung der Nährstoffflüsse erfolgte für die Streu von Baumblättern und Phoradendron durch Multiplikation der in der Streu gemessenen Elementkonzentration mit der Jahresmenge der jeweiligen Streukomponente. Bei den epiphytischen Moosen und Flechten wurden die mittleren Elementkonzentrationen von fünf in der Kronenregion des Altbestandes geernteten Moosarten zugrunde gelegt und mit der Jahresmenge dieser Streukomponente multipliziert. Dies beruht auf der Annahme, daß bei Epiphyten der Streufall meist nicht durch Senezenz der Pflanzen, sondern durch Störungsereignisse (z.B. Wind) hervorgerufen wird und eine Retranslokation der Nährstoffe von geringer Bedeutung ist.

\subsection{Statistische Auswertung der Daten}

Korrelationen zwischen verschiedenen Parametern wurden mit dem Computerprogramm Xact (Fa. Sci-Lab, Deutschland) untersucht. Für weitergehende statistische Testverfahren wurde das Computerprogramm SAS verwendet. Dazu wurde zuerst mit dem Anpassungstest von Shapiro \& Wilk geprüft, ob bei den zu testenden Meßdaten Normalverteilung vorliegt. Waren die Daten normalverteilt, konnte zur Ermittlung signifikanter Mittelwertunterschiede der Test von Scheffé für unbalancierte, unabhängige Stichproben durchgeführt werden. Häufig lag jedoch keine Normalverteilung vor, so daß nichtparametrische (= verteilungsunabhängige) Testverfahren angewendet wurden. Die Ermittlung signifikanter Unterschiede zwischen zwei Stichproben wurde mit dem Wilcoxon-U-Test von Mann \& Whitney für unbalancierte, unabhängige Stichproben durchgeführt. 


\section{Ergebnisse}

\subsection{Bestandesstruktur und Epiphytenbiomasse}

\subsubsection{Struktur der Baumschicht der Bestände}

In Tab. 4-1 sind wichtige Daten zur Struktur der drei untersuchten Bestände zusammengestellt. Auf die mittleren Baumhöhen und das Bestandesalter der Untersuchungsflächen wurde bereits in Kapitel 2.4.3 eingegangen. Im jungen Sekundärwald wurden 31 Baum- und Straucharten gefunden. Die von KAPPELLE (1995) ermittelte Baumartenzahl liegt im älteren Sekundärwald bei 24 und im Altbestand bei 18 Arten und ist damit niedriger als im jungen Sekundärwald. Dies könnte darauf zurückzuführen sein, daß in der zitierten Untersuchung nur Arten mit einem Brusthöhendurchmesser von mindestens $3 \mathrm{~cm}$ berücksichtigt wurden, während im jungen Sekundärwald im Rahmen der vorliegenden Arbeit alle Baum- und Straucharten unabhängig von deren Größe aufgenommen wurden.

Tab. 4-1: Bestandesstruktur der drei untersuchten Bestände. Die Stammzahl der Bäume und Sträucher mit einem Brusthöhendurchmesser (BHD) $\geq 3 \mathrm{~cm}$ wurde auf eine ebene Fläche projiziert. *Anzahl der Baumarten mit einem Brusthöhendurchmesser $\geq 3 \mathrm{~cm}$ im älteren Sekundärwald und im Altbestand nach KAPPELLE (1995).

\begin{tabular}{|c|c|c|c|}
\hline & $\begin{array}{c}\text { junger } \\
\text { Sekundärwald }\end{array}$ & $\begin{array}{c}\text { älterer } \\
\text { Sekundärwald }\end{array}$ & Altbestand \\
\hline Mittlere Baumhöhe [m] & 5 bis 9 & 11 bis 15 & 30 bis 35 \\
\hline Bestandesalter [Jahre] & 10 bis 15 & ca. 40 & unbekannt \\
\hline Anzahl der Baum- und Straucharten & 31 & $24 *$ & $18^{*}$ \\
\hline Stammzahl $\left[\mathrm{n} \mathrm{ha}^{-1}\right]$ & 5730 & 4800 & 3460 \\
\hline $\begin{array}{l}\text { Häufigkeit der in die obere Krone } \\
\text { reichenden Stämme [\%] }\end{array}$ & 94 & 39 & 7 \\
\hline $\begin{array}{l}\text { Häufigkeit der mehrstämmigen } \\
\text { Bäume und Sträucher [\%] }\end{array}$ & 32 & 17 & 2 \\
\hline $\begin{array}{l}\text { Anzahl der Baum- und } \\
\text { Strauchschichten }\end{array}$ & 1 & 2 & 3 \\
\hline
\end{tabular}

Zur Ermittlung der Stammzahlen der drei untersuchten Bestände wurden in der vorliegenden Arbeit ebenfalls nur Bäume und Sträucher mit einem Brusthöhendurchmesser von $3 \mathrm{~cm}$ und mehr berücksichtigt und die Werte auf eine ebene Fläche projiziert. Der junge Sekundärwald weist von den drei Beständen mit 5730 Stämmen je Hektar die höchste Stammdichte auf. Im älteren Sekundärwald und im Altbestand liegen die Werte mit 4800 Stämmen beziehungsweise 3460 Stämmen je Hektar wesentlich niedriger. Beim Vergleich der Stammzahlen mit einem BHD von $10 \mathrm{~cm}$ und mehr zeigen sich im jungen Sekundärwald mit 
446 Stämmen je Hektar die niedrigsten Werte, während der ältere Sekundärwald mit 1398 Stämmen je Hektar eine etwa dreimal höhere Stammdichte aufweist. Im Altbestand liegen die Werte mit 840 Stämmen je Hektar wieder deutlich niedriger (ohne Abb.).

Auffallend große Unterschiede zwischen den drei Beständen läßt das Verhältnis der Kronenbäume zu den unterständigen Bäumen erkennen. Während im jungen Sekundärwald 94\% und im älteren Sekundärwald 39\% der Stämme in die obere Krone reichen, sind es im Altbestand lediglich 7\%. Ferner liegt in den Sekundärwäldern der Anteil der mehrstämmigen Bäume mit 32\% beziehungsweise 17\% deutlich über den im Altbestand ermittelten Werten (2\%). Mit zunehmendem Bestandesalter ist eine Ausbildung mehrerer Baum- und Strauchschichten zu beobachten. Diese wurden bereits in Kapitel 2.4.3 besprochen.

Die Verteilung der Stammzahlen nach Größenklassen des Brusthöhendurchmessers zeigt in allen drei Beständen eine Abnahme der Häufigkeiten mit zunehmender DurchmesserGrößenklasse des Brusthöhendurchmessers (Abb. 4-1). Der Vergleich der Bestände untereinander macht deutlich, daß die beiden kleinsten BHD-Größenklassen (3-5 cm, 5$10 \mathrm{~cm}$ ) besonders im jungen Sekundärwald stark vertreten sind. In der Durchmesserklasse 10$20 \mathrm{~cm}$ zeigen sich die höchsten Werte im älteren Sekundärwald, während im jungen Sekundärwald in diesem Bereich ein starker Rückgang der Stammzahlen zu beobachten ist und sich ähnlich niedrige Werte wie im Altbestand zeigen. Stämme mit 40 bis $80 \mathrm{~cm}$ Durchmesser sind nur noch im älteren Sekundärwald und im Altbestand $\mathrm{zu}$ finden. Die Größenklasse über $80 \mathrm{~cm}$ ist ausschließlich im Altbestand vertreten. Der höchste gemessene BHD lag hier bei $178 \mathrm{~cm}$ (inklusive Brettwurzeln). Mit zunehmendem Bestandesalter ist also erwartungsgemäß eine Verschiebung zu größeren Brusthöhendurchmessern sowie eine ausgeglichenere Verteilung der Stammzahlen auf die einzelnen Größenklassen zu erkennen.

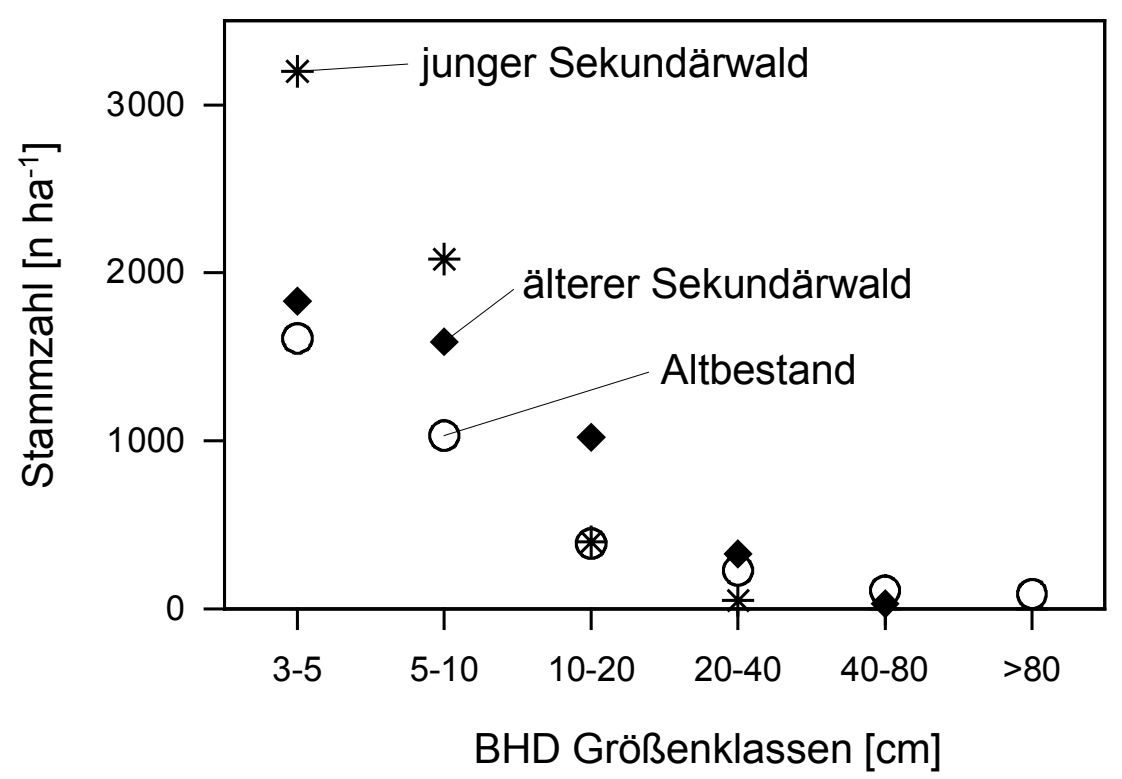

Abb. 4-1: Verteilung der Stammzahlen nach Größenklassen des Brusthöhendurchmessers (BHD) bei Stämmen $\geq 3 \mathrm{~cm}$ in den drei untersuchten Beständen. Die Stammzahlen wurden auf eine ebene Fläche projiziert. 


\subsubsection{Spezifische Blattfläche}

Die mittlere spezifische Blattfläche unterschiedlicher Baumarten zeigt im Jahresverlauf in den drei untersuchten Beständen nur eine geringe saisonale Variabilität (ohne Abb.). Insgesamt wurden in jedem Bestand etwa 650 Blätter aus den Streusammlern entnommen und analysiert, wobei sich im Jahresmittel im jungen Sekundärwald eine mittlere spezifische Blattfläche von $74.5 \mathrm{~cm}^{2} \mathrm{~g}^{-1}$ und im älteren Sekundärwald von $72.8 \mathrm{~cm}^{2} \mathrm{~g}^{-1}$ ergab. Im Altbestand wurden mit $71.1 \mathrm{~cm}^{2} \mathrm{~g}^{-1}$ etwas niedrigere Werte gemessen. Diese Befunde lassen sich statistisch jedoch nicht absichern, da die Bestimmung des Trockengewichts nicht für Einzelblätter, sondern für Mischproben aus drei bis sechs Blättern erfolgte.

Beim Vergleich der spezifischen Blattfläche verschiedener Baumarten des jungen Sekundärwaldes zeigen sich deutliche Unterschiede zwischen den einzelnen Arten (Tab. 4-2). Monochaetum spec. (Melastomataceae) weist mit $234.2 \mathrm{~cm}^{2} \mathrm{~g}^{-1}$ die mit Abstand größte spezifische Blattfläche auf. Die geringste spezifische Blattfläche ist mit nur $46.5 \mathrm{~cm}^{2} \mathrm{~g}^{-1}$ bei Comarostaphylis arbutoides (Ericaceae) $\mathrm{zu}$ beobachten. Der für Quercus copeyensis ermittelte Wert $\left(74.1 \mathrm{~cm}^{2} \mathrm{~g}^{-1}\right)$ liegt im Bereich der oben genannten mittleren spezifischen Blattfläche unterschiedlicher Baumarten in den drei Beständen. Dies ist darauf zurückzuführen, daß die Gattung Quercus (fast ausschließlich Quercus copeyensis) mit Werten von zum Teil über $90 \%$ an der Gesamtmasse der Blattstreu beteiligt ist und somit unter allen Baumarten die mit Abstand höchste Streuproduktion aufweist.

Tab. 4-2: Spezifische Blattfläche verschiedener Baumarten des jungen Sekundärwaldes. Die Blattproben wurden in unterschiedlichen Monaten aus den Streusammlern entnommen. Angegeben sind Mittelwerte und Standardabweichungen. Unterschiedliche Buchstaben kennzeichnen signifikante Unterschiede zwischen den Arten; Signifikanztest nach Scheffé $(\mathrm{p}<0.05)$.

\begin{tabular}{lccc}
\hline \multirow{2}{*}{ Baumart } & \multicolumn{3}{c}{ spezifische Blattfläche } \\
& Mw & Stabw & $\mathrm{n}$ \\
\hline Buddleja nitida & $76.7^{\mathrm{a}}$ & 16.8 & 13 \\
Comarostaphylis arbutoides & $46.5^{\mathrm{b}}$ & 7.3 & 18 \\
Monochaetum spec. & $234.2^{\mathrm{c}}$ & 45.2 & 7 \\
Quercus copeyensis & $74.1^{\mathrm{a}}$ & 17.5 & 124 \\
Quercus costaricensis & $67.6^{\mathrm{a}}$ & 50.0 & 25 \\
Viburnum costaricanum & $108.6^{\mathrm{d}}$ & 19.1 & 10 \\
\hline
\end{tabular}




\subsubsection{Streuproduktion}

Der monatliche Streufall der Baumblätter läßt in allen drei Waldstadien eine Jahresdynamik erkennen (Abb. 4-2). Während der Regenzeit bleiben die Werte meist deutlich unter $100 \mathrm{~g} \mathrm{~m}^{-2}$ und es sind nur geringe monatliche Schwankungen $\mathrm{zu}$ beobachten. In den TrockenzeitMonaten Januar bis März können die Streufallmengen ein Mehrfaches der während der Regenzeit gemessenen Werte erreichen. Im jungen Sekundärwald ist die saisonale Variabilität des Streufalls der Baumblätter jedoch deutlich geringer ausgeprägt als in den beiden älteren Beständen.
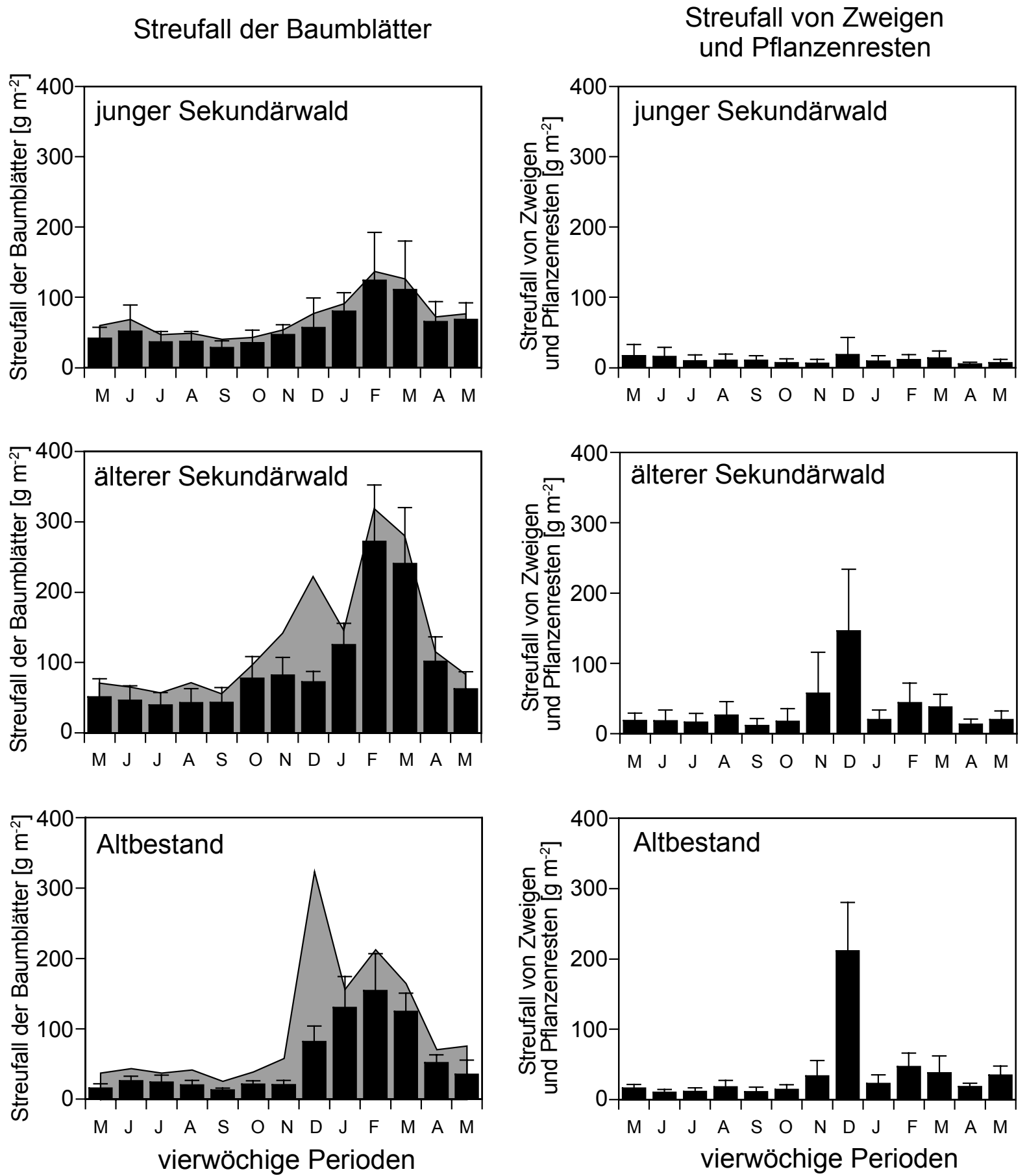

Abb. 4-2: Monatlicher Streufall der Baumblätter sowie der Zweige und Pflanzenreste in den drei untersuchten Beständen. Die grau unterlegten Flächen zeigen den Gesamtstreufall (Baumblätter, Zweige und Pflanzenreste, epiphytische Moose und Flechten sowie epiphytische Gefäßpflanzen). Alle Angaben wurden auf eine ebene Fläche bezogen (10 Streusammler je Bestand und Monat). 
Auffallend hohe Streumengen werden mit $273 \mathrm{~g} \mathrm{~m}^{-2}$ und $241 \mathrm{~g} \mathrm{~m}^{-2}$ in den Monaten Februar und März im älteren Sekundärwald erreicht. Der Anteil der Eichenblätter an der gesamten Blattstreu liegt hier mit etwa $95 \%$ besonders hoch.

Die grau unterlegten Flächen zeigen den monatlichen Gesamtstreufall. Auch hier läßt sich eine sehr ähnliche Jahresdynamik erkennen, was den großen Einfluß des Streufalls der Baumblätter auf den Gesamtstreufall verdeutlicht. Nur im Monat Dezember weichen die Gesamtstreumengen stark von denen der Baumblätter ab. Die Ursache hierfür liegt in erster Linie in dem starken Anstieg der Streumengen von Zweigen und Pflanzenresten im Dezember (rechte Grafiken), was wiederum auf die vergleichsweise hohen Windgeschwindigkeiten, die in diesem Monat auftraten (Kap. 4-2), zurückzuführen ist. Auffällig ist ferner, daß die Auswirkungen des Windes auf den Streufall der Zweige und Pflanzenreste mit steigender Bestandeshöhe zunehmen. So zeigen sich die insgesamt höchsten Werte im Monat Dezember im Altbestand und übertreffen hier sogar den Streufall der Baumblätter. Auch im älteren Sekundärwald wurden im Dezember sehr hohe Streumengen gemessen, während im jungen Sekundärwald kein klarer Einfluß des Windes auf den Streufall zu beobachten ist. Eine Saisonalität läßt der Streufall von Zweigen und Pflanzenresten in keinem der drei Bestände erkennen.

Der Streufall der epiphytischen Gefäßpflanzen zeigt in keinem der drei Bestände eine durch Regen- und Trockenzeit geprägte Jahresdynamik (Abb. 4-3). Hinsichtlich der Streumengen werden jedoch große Unterschiede zwischen den Beständen deutlich. So liegen die höchsten monatlichen Streumengen im jungen Sekundärwald bei etwa $0.5 \mathrm{~g} \mathrm{~m}^{-2}$, während im älteren Sekundärwald mehr als doppelt so hohe Werte gemessen wurden. Die höchste insgesamt in den drei Beständen ermittelte Streumenge war mit über $15 \mathrm{~g} \mathrm{~m}^{-2}$ im Dezember im Altbestand zu verzeichnen. Hier wird wiederum der Einfluß des Windes in diesem Monat deutlich. Nicht berücksichtigt wurde bei dieser Darstellung eine einzelne größere Bromelie (Trockengewicht etwa $150 \mathrm{~g}$ ), die sich im Mai 2000 in einem der Streusammler befand. Im Gegensatz zum Altbestand, in dem kontinuierlich ein Streufall epiphytischer Gefäßpflanzen verzeichnet werden konnte, sind in beiden Sekundärwäldern mehrere Monate ohne meßbaren Streufall zu beobachten. Allen Beständen gemeinsam ist die große Heterogenität des Streufalls der epiphytischen Gefäßpflanzen, die in der hohen Standardabweichung der Monatswerte zum Ausdruck kommt.

Auch der Streufall der Moose und Flechten läßt keine saisonal geprägte Dynamik erkennen (Abb. 4-3, rechte Grafiken). Bezüglich der Streumengen unterscheiden sich auch hier die drei Bestände deutlich voneinander. Dabei bewegen sich die Werte etwa in der gleichen Größenordnung wie die epiphytischen Gefäßpflanzen. Nur im älteren Sekundärwald übertreffen die maximalen monatlichen Streumengen der Moose und Flechten den höchsten monatlichen Streufall der epiphytischen Gefäßpflanzen um das Doppelte. Der Monat Dezember zeichnet sich im älteren Sekundärwald und im Altbestand wiederum durch besonders hohe Streumengen aus. Während im älteren Sekundärwald $2.9 \mathrm{~g} \mathrm{~m}^{-2}$ gemessen 
wurden, zeigte sich im Altbestand mit $14.4 \mathrm{~g} \mathrm{~m}^{-2}$ ein um den Faktor fünf höherer Wert. Im Gegensatz zu den epiphytischen Gefäßpflanzen konnte bei den Moosen und Flechten in allen drei Beständen kontinuierlich ein monatlicher Streufall registriert werden, was die größere zeitliche Homogenität dieser Streukomponente widerspiegelt. Eine höhere räumliche Homogenität wird durch die geringeren Standardabweichungen im Vergleich zu den monatlichen Streumengen der epiphytischen Gefäßpflanzen deutlich.
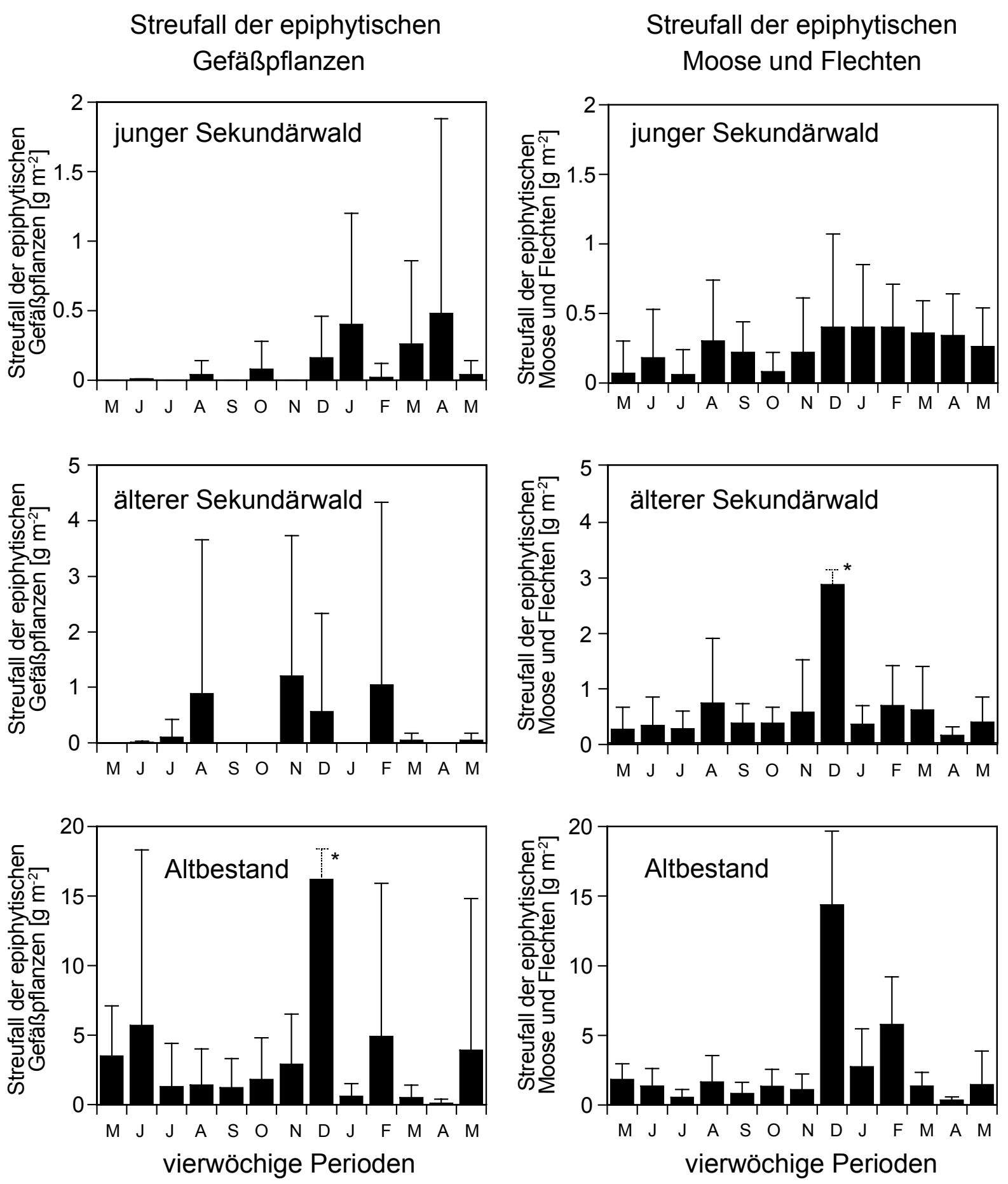

Abb. 4-3: Monatlicher Streufall der epiphytischen Gefäßpflanzen sowie der epiphytischen Moose und Flechten in den drei untersuchten Beständen. Alle Angaben wurden auf eine ebene Fläche bezogen (10 Streusammler je Bestand und Monat). * Um aus Gründen der Übersichtlichkeit den Maßstab beizubehalten, wurde die Standardabweichung um den Faktor 10 gestaucht dargestellt. 
Die Jahressummen der einzelnen Feinstreu-Komponenten zeigen, daß die Baumblätter in allen drei Beständen mengenmäßig den größten Anteil an der Gesamtstreumenge ausmachen (Tab. 4-3). Ihr prozentualer Anteil nimmt jedoch mit steigendem Bestandesalter ab. So betragen die Werte im jungen Sekundärwald 84\%, im älteren Sekundärwald 73\% und im Altbestand 56\% der Gesamtstreu. Die absoluten Streumengen der Baumblätter liegen im älteren Sekundärwald mit $1258.9 \mathrm{~g} \mathrm{~m}^{-2} \mathrm{a}^{-1}$ deutlich über den Werten der beiden anderen Bestände. Bei den epiphytischen Moosen und Flechten ist zwischen jungem und älterem Sekundärwald eine Zunahme der Streumenge um den Faktor $2.4 \mathrm{zu}$ beobachten. Im Altbestand liegen die Werte 4.2 mal höher als im älteren Sekundärwald.

Tab. 4-3: Jahressumme der Feinstreu der Baumblätter, der epiphytischen Moose und Flechten, der epiphytischen Gefäßpflanzen sowie der Zweige und Pflanzenreste in den drei untersuchten Beständen. Die Fraktion Zweige und Pflanzenreste umfaßt außerdem alle nicht näher zuzuordnenden Streukomponenten. Zusätzlich ist die Gesamtjahresstreuproduktion angegeben. 10 Streusammler je Bestand. Unterschiedliche Buchstaben kennzeichnen signifikante Unterschiede zwischen den Beständen innerhalb einer Streufraktion; bei epiphytischen Gefäßpflanzen U-Test nach Wilcoxon $(\mathrm{p}<0.05)$, alle übrigen Signifikanztest nach Scheffé $(\mathrm{p}<0.05)$.

\begin{tabular}{|c|c|c|c|c|c|c|}
\hline & \multicolumn{6}{|c|}{ Streufall $\left[\mathrm{g} \mathrm{m}^{-2} \mathrm{a}^{-1}\right]$} \\
\hline & \multicolumn{2}{|c|}{$\begin{array}{c}\text { junger } \\
\text { Sekundärwald }\end{array}$} & \multicolumn{2}{|c|}{$\begin{array}{c}\text { älterer } \\
\text { Sekundärwald }\end{array}$} & \multicolumn{2}{|c|}{ Altbestand } \\
\hline & $\mathrm{Mw}$ & Stabw & Mw & Stabw & Mw & Stabw \\
\hline Baumblätter & $786.5^{\mathrm{a}}$ & 237.3 & $1258.9^{b}$ & 275.9 & $719.5^{\mathrm{a}}$ & 144.8 \\
\hline $\begin{array}{l}\text { Epiphytische Moose } \\
\text { und Flechten }\end{array}$ & $3.3^{\mathrm{a}}$ & 2.2 & $8.1^{\mathrm{a}}$ & 6.3 & $34.5^{b}$ & 5.7 \\
\hline Epiphytische Gefäßpflanzen & $1.5^{\mathrm{a}}$ & 1.9 & $3.9^{\mathrm{a}}$ & 5.1 & $44.0^{\mathrm{b}}$ & 28.6 \\
\hline Zweige und Pflanzenreste & $142.1^{\mathrm{a}}$ & 80.6 & $449.0^{\mathrm{b}}$ & 182.2 & $489.0^{\mathrm{b}}$ & 116 \\
\hline Gesamtstreufall & $933.3^{\mathrm{a}}$ & 282.4 & $1719.7^{\mathrm{b}}$ & 426.9 & $1287.0^{\mathrm{a}}$ & 220.2 \\
\hline
\end{tabular}

Die Streumengen der epiphytischen Gefäßpflanzen lassen ebenfalls einen Anstieg mit zunehmendem Bestandesalter erkennen. Zwischen dem jungen und dem älteren Sekundärwald kommt es zu einer Erhöhung der Werte um den Faktor 2.6, während zwischen dem älteren Sekundärwald und dem Altbestand eine Zunahme des Streufalls um das 11.3fache $\mathrm{zu}$ beobachten ist. Auffallend ist ferner, daß in den Sekundärwäldern die Streumengen der epiphytischen Moose und Flechten die der epiphytischen Gefäßpflanzen um mehr als das Doppelte übertreffen, während sie im Altbestand hinter den Gefäßpflanzen zurückbleiben. Die Gesamtmenge der Epiphytenstreu beträgt im jungen Sekundärwald $4.8 \mathrm{~g} \mathrm{~m}^{-2} \mathrm{a}^{-1}$, im älteren Sekundärwald $12 \mathrm{~g} \mathrm{~m}^{-2} \mathrm{a}^{-1}$ und im Altbestand $78.5 \mathrm{~g} \mathrm{~m}^{-2} \mathrm{a}^{-1}$. So tragen die Epiphyten mit $0.5 \%, 0.7 \%$ und $6.1 \%$ nur zu einem vergleichsweise geringen Anteil zum Gesamtstreufall der Bestände bei. Eine deutlich höhere Streuproduktion zeigt sich bei den Zweigen und Pflanzenresten. Hier ist wiederum eine Zunahme der Werte mit steigendem Bestandesalter zu beobachten. Dabei bleibt der junge Sekundärwald mit $142.1 \mathrm{~g} \mathrm{~m}^{-2} \mathrm{a}^{-1}$ 
deutlich hinter den beiden älteren Beständen zurück, in denen mehr als dreimal höhere Werte gemessen wurden. Auch der relative Anteil der Zweige und Pflanzenreste am Gesamtstreufall läßt einen stetigen Anstieg von 15.2\% im jungen Sekundärwald auf 26.1\% im älteren Sekundärwald und 38\% im Altbestand erkennen. Für die parasitisch in den Baumkronen lebenden Mistelgewächse (meist Phoradendron) wurde im Altbestand im Jahresmittel eine Streumenge von $60 \mathrm{~g} \mathrm{~m}^{-2} \mathrm{a}^{-1}$ gemessen, in den anderen Beständen spielten sie mit Werten von weniger als $1 \mathrm{~g} \mathrm{~m}^{-2} \mathrm{a}^{-1}$ mengenmäßig eine untergeordnete Rolle. In Tab. 4-3 wurde die parasitische Streu der Fraktion Zweige und Pflanzenreste zugeordnet. Bedingt durch die hohen Streumengen der Baumblätter liegen die Gesamtstreumengen im älteren Sekundärwald mit $1719.7 \mathrm{~g} \mathrm{~m}^{-2} \mathrm{a}^{-1}$ deutlich über den Werten des jungen Sekundärwaldes $\left(933.3 \mathrm{~g} \mathrm{~m}^{-2} \mathrm{a}^{-1}\right)$ und des Altbestandes (1287 $\left.\mathrm{g} \mathrm{m}^{-2} \mathrm{a}^{-1}\right)$.

\subsubsection{Blattlebensdauer}

Bei der zur Untersuchung der Blattlebensdauer von Quercus copeyensis durchgeführten Markierung von Blättern läßt der relative Anteil der lebenden Blätter mit steigendem Blattalter in allen drei Beständen eine stetige Abnahme erkennen (Abb. 4-4). Nach einer Beobachtungsdauer von neun Monaten beträgt der Anteil der lebenden Eichenblätter im jungen Sekundärwald noch fast 95\% der zu Beginn der Untersuchung markierten Blätter. Im älteren Sekundärwald ist ein etwas schnelleres Absterben der Blätter zu beobachten. 13 Monate nach Versuchsbeginn liegt der relative Anteil der markierten Blätter hier bei $82 \%$. Im Altbestand zeigt sich anfangs eine verhältnismäßig hohe Blattsterblichkeit. Nach 15 Monaten liegt der Anteil der lebenden Eichenblätter mit 84.2\% über den nach 13 Monaten im älteren Sekundärwald gemessenen Werten. Die höchste Blattlebensdauer ist im Unterwuchs des Altbestandes zu beobachten. Nach 17 Monaten liegt der Anteil der lebenden Eichenblätter hier bei $91.6 \%$.

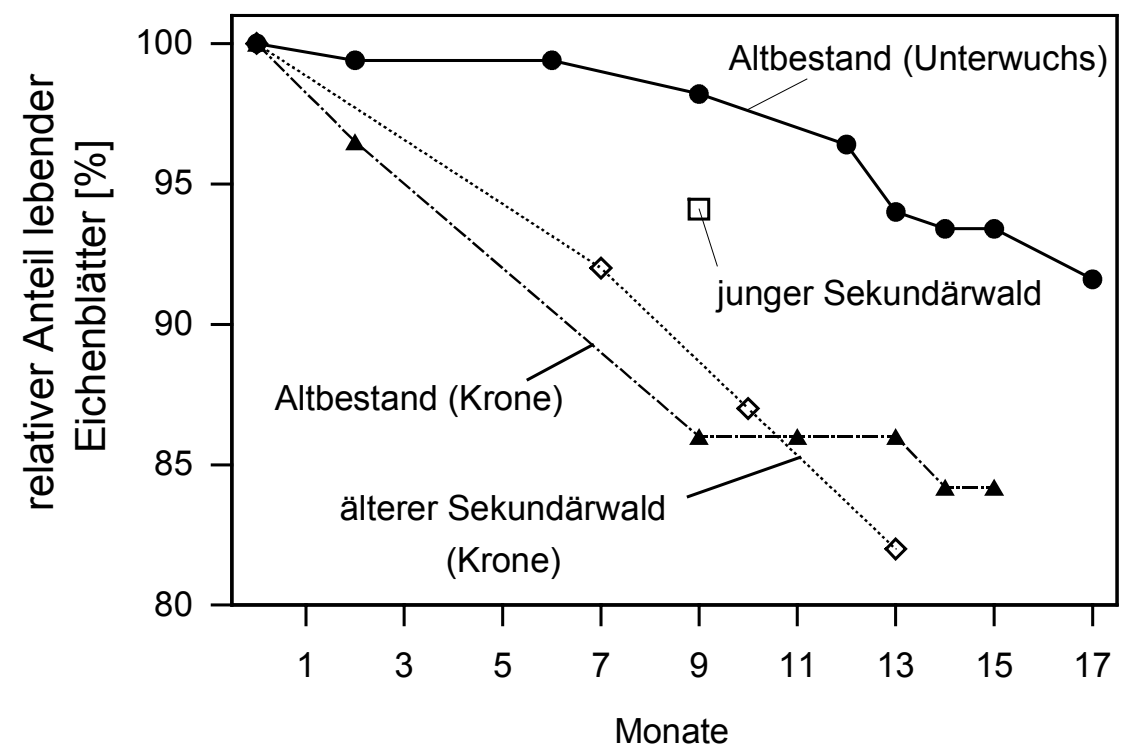

Abb. 4-4: Relativer Anteil der lebenden Eichenblätter (Quercus copeyensis) an der Gesamtzahl einer markierten Blattpopulation in den drei untersuchten Beständen. Junger Sekundärwald $n=17$ Blätter, älterer Sekundärwald $n=91$ Blätter sowie Altbestand (Kronenregion) $n=57$ Blätter und Altbestand (Unterwuchs) n=167 Blätter. 
Mit zunehmender Entfernung vom Waldboden (Kronenregion des älteren Sekundärwaldes und des Altbestandes) scheint die Blattsterblichkeit höher als in Bodennähe (junger Sekundärwald, Unterwuchs des Altbestandes) zu sein. Die Ursache hierfür könnte in der stärkeren mechanischen Belastung der windexponierten Kronenblätter liegen. Diese Untersuchungen zeigen, daß ein Beobachtungszeitraum von 17 Monaten nicht ausreicht, um genaue Angaben zur mittleren Blattlebensdauer von Quercus copeyensis zu machen.

\subsubsection{Blattflächenindex der Bestände}

Der mit dem Blattflächenmeßgerät LAI 2000 bestimmte Blattflächenindex (LAI) beträgt im jungen Sekundärwald und im Altbestand $3.8 \mathrm{~m}^{2} \mathrm{~m}^{-2}$, während im älteren Sekundärwald mit $4.7 \mathrm{~m}^{2} \mathrm{~m}^{-2}$ ein signifikant höherer Wert gemessen wurde (Tab. 4-4). Eine mögliche Ursache für diese verhältnismäßig niedrigen Indizes liegt darin, daß die Messungen im Februar zur Zeit des stärksten Laubfalls stattfanden. Zusätzlich zu den mit dem LAI 2000 ermittelten Werten wurde eine Berechnung des Blattflächenindex anhand der Streufalldaten und der mittleren Blattlebensdauer durchgeführt. Wie bereits in Kapitel 4.1 .4 besprochen, war eine Beobachtungsperiode von 17 Monaten zur Ermittlung der Blattlebensdauer der in allen drei Beständen dominierenden Baumart Quercus copeyensis nicht ausreichend. Daher wurden die Berechnungen des Blattflächenindex für eine hypothetische Blattlebensdauer von ein, eineinhalb und zwei Jahren durchgeführt. Für die Annahme von eineinhalb Jahren ergibt sich so beispielsweise im jungen Sekundärwald ein Wert von $8.8 \mathrm{~m}^{2} \mathrm{~m}^{-2}$, im älteren Sekundärwald von $13.8 \mathrm{~m}^{2} \mathrm{~m}^{-2}$ und im Altbestand von $7.7 \mathrm{~m}^{2} \mathrm{~m}^{-2}$. Die nach diesem Verfahren ermittelten Werte lassen erkennen, daß trotz der absoluten Unterschiede die Relation zwischen den Beständen erhalten bleibt.

Tab. 4-4: Blattflächenindex ( $\mathrm{m}^{2}$ Blattfläche je $\mathrm{m}^{2}$ Bodenfläche) der drei untersuchten Bestände. Dargestellt ist der mit dem LAI 2000 ermittelte Wert (30 Messungen je Bestand) sowie die anhand des Blattstreufalls berechneten Werte. Die Berechnung wurde für eine angenommene Blattlebensdauer von ein, eineinhalb und zwei Jahren durchgeführt und auf eine ebene Fläche bezogen. Unterschiedliche Buchstaben kennzeichnen signifikante Unterschiede zwischen den Beständen; Signifikanztest nach Scheffé $(p<0.05)$.

\begin{tabular}{|c|c|c|c|c|c|c|}
\hline & \multicolumn{2}{|c|}{$\begin{array}{c}\text { junger } \\
\text { Sekundärwald }\end{array}$} & \multicolumn{2}{|c|}{$\begin{array}{c}\text { älterer } \\
\text { Sekundärwald }\end{array}$} & \multicolumn{2}{|c|}{ Altbestand } \\
\hline & $\mathrm{Mw}$ & Stabw & $\mathrm{Mw}$ & Stabw & $\mathrm{Mw}$ & Stabw \\
\hline LAI 2000 & $3.8^{\mathrm{a}}$ & 1 & $4.7^{b}$ & 0.5 & $3.8^{\mathrm{a}}$ & 0.5 \\
\hline Streufall (1 Jahr) & 5.9 & - & 9.2 & - & 5.1 & - \\
\hline Streufall (1.5 Jahre) & 8.8 & - & 13.8 & - & 7.7 & - \\
\hline Streufall (2 Jahre) & 11.7 & - & 18.3 & - & 10.2 & - \\
\hline
\end{tabular}


Wird der anhand des Streufalls errechnete Blattflächenindex nicht auf eine ebene Fläche, sondern auf die geneigte Hangfläche bezogen, ergeben sich niedrigere LAI-Werte, die für eine mittlere Blattlebensdauer von eineinhalb Jahren im jungen Sekundärwald $7.6 \mathrm{~m}^{2} \mathrm{~m}^{-2}$, im älteren Sekundärwald $12.5 \mathrm{~m}^{2} \mathrm{~m}^{-2}$ und im Altbestand $6.6 \mathrm{~m}^{2} \mathrm{~m}^{-2}$ betragen.

\subsubsection{Epiphytenbiomasse der Bestände}

Im jungen Sekundärwald zeigt die Biomasse der epiphytisch auf Quercus copeyensis vorkommenden Moose und Flechten eine stetige Abnahme mit steigender Baumhöhe (Tab. 45). Die höchsten Werte sind im Bereich der Stammbasen zu beobachten. In der inneren Krone ist die größte epiphytische Biomasse in $1 \mathrm{~m}$ Höhe zu finden und nimmt um mehr als das Vierfache bis in $6 \mathrm{~m}$ Höhe ab. Die äußeren Zweigabschnitte (äußere Krone) weisen in einem Meter Bodenhöhe eine mehr als neunmal höhere Biomasse epiphytischer Moose und Flechten auf als in sechs Metern Höhe.

Im älteren Sekundärwald sind an den Stammbasen der bestandesbildenden Eichen deutlich größere Mengen epiphytischer Moose und Flechten zu finden als im Stammbereich. Die insgesamt höchste epiphytische Biomasse befindet sich jedoch in der inneren Krone und beträgt mehr als das Doppelte der an den Stämmen gemessenen Werte. Zur mittleren Krone hin ist erneut eine Abnahme der Biomasse zu beobachten. Die insgesamt geringsten Mengen epiphytischer Moose und Flechten sind im oberen Bereich der äußeren Krone zu verzeichnen, während die unteren Bereiche etwa viermal höhere Werte aufweisen. Hier gleicht das Bild den bereits im jungen Sekundärwald beobachteten Verhältnissen.

Im Altbestand sind an den Stammbasen der bestandesbildenden Eichen (Quercus copeyensis) etwas geringere Mengen epiphytischer Moose und Flechten als im Bereich der Stämme zu finden. Im Gegensatz zu den Sekundärwäldern zeigt der Epiphytenbewuchs der Stamm- und Stammfußregion im Altbestand sehr starke expositionsbedingte Unterschiede. Über weite Bereiche weisen die nach Nordosten gerichteten, hangabwärts geneigten Seiten der Eichenstämme keinen meßbaren Epiphytenbewuchs auf. Wie im älteren Sekundärwald ist auch im Altbestand die stärkste Epiphytenbesiedlung in der inneren Krone zu beobachten. Die Bryophyten machen dabei etwa 95\% der durch Flechten und Moose gebildeten Biomasse aus. Da hier jedoch Astgabeln beprobt wurden, die im Vergleich zur übrigen inneren Krone einen besonders starken Epiphytenbewuchs aufweisen, sind die verhältnismäßig hohen Werte nicht auf die gesamte innere Kronenregion des Altbestandes übertragbar. In der mittleren Krone nehmen die Werte auf weniger als ein Viertel ab. Auf den Astoberseiten, die, wie auch in den Sekundärwäldern, einen deutlich höheren Epiphytenbewuchs als die Unterseiten der Äste aufweisen, wird die epiphytische Biomasse zu über 80\% durch Bryophyten gebildet. Die Astunterseiten sind häufig frei von Epiphyten oder stärker durch Flechten besiedelt. Die geringsten, innerhalb der Kronenregion des Altbestandes gemessenen Werte sind in der äußeren Krone zu beobachten. Sie betragen im Mittel $82 \%$ der in der mittleren Krone gemessenen Biomasse epiphytischer Moose und Flechten. Der Anteil der LeptodontiumMoospolster an der Gesamtbiomasse der auf den bestandesbildenden Eichen zu findenden nichtvaskulären Epiphyten wird auf mindestens 30\% geschätzt. 
Im jungen Sekundärwald zeigt sich nur eine sehr geringe Besiedlung der untersuchten Eichen durch epiphytische Gefäßpflanzen. So wurden in weniger als $6 \%$ der in diesem Bestand durchgeführten Biomasseerhebungen vaskuläre Epiphyten gefunden. Diese sind ausschließlich auf den unteren Bereich der äußeren Krone beschränkt.

Im älteren Sekundärwald liegt die Biomasse der epiphytischen Gefäßpflanzen im Stammbereich etwa doppelt so hoch wie an den Stammbasen. In der inneren Krone sind auffallend niedrige Werte zu beobachten. In der mittleren Krone steigt die Biomasse um mehr als das Siebenfache an. Die niedrigsten Werte sind in der äußeren Krone zu finden. Während im unteren Bereich die Biomasse die Hälfte der in der inneren Krone gemessenen Werte beträgt, wurden in der oberen Region der äußeren Krone keine vaskulären Epiphyten gefunden.

Tab. 4-5: Biomasse epiphytischer Moose und Flechten sowie epiphytischer Gefäßpflanzen in verschiedenen Straten unterschiedlich alter Eichen (Quercus copeyensis) in den drei untersuchten Beständen. Die Angaben [g TG] beziehen sich auf $\mathrm{m}^{2}$ Ast- oder Stammoberfläche.

\begin{tabular}{|c|c|c|c|c|c|c|}
\hline \multirow[t]{2}{*}{ Bestand } & \multirow[t]{2}{*}{ Stratum } & \multirow[t]{2}{*}{$\begin{array}{l}\text { Baum- } \\
\text { Höhe } \\
{[\mathrm{m}]}\end{array}$} & \multicolumn{2}{|c|}{$\begin{array}{l}\text { Moose und Flechten } \\
\qquad\left[\mathrm{g} \mathrm{m}^{-2}\right]\end{array}$} & \multicolumn{2}{|c|}{$\begin{array}{c}\text { Epiphytische } \\
\text { Gefäßpflanzen } \\
{\left[\mathrm{g} \mathrm{m}^{-2}\right]}\end{array}$} \\
\hline & & & $\mathrm{Mw}$ & Stabw & $\mathrm{Mw}$ & Stabw \\
\hline junger & äußere Krone & 6 & 2.1 & 2.8 & 0 & - \\
\hline \multirow[t]{8}{*}{ Sekundärwald } & & 1 & 19.3 & 17.7 & 0.4 & 1.1 \\
\hline & innere Krone & 6 & 6.5 & 0.2 & 0 & - \\
\hline & & 5 & 10.7 & 8.7 & 0 & - \\
\hline & & 4 & 14.6 & 16.7 & 0 & - \\
\hline & & 3 & 17.8 & 21.4 & 0 & - \\
\hline & & 2 & 16.8 & 17.9 & 0 & - \\
\hline & & 1 & 27.4 & 24.4 & 0 & - \\
\hline & Stammbasis & 0.2 & 43.7 & 24.7 & 0 & - \\
\hline älterer & äußere Krone & $10-13$ & 14.8 & 8.9 & 0 & - \\
\hline \multirow[t]{5}{*}{ Sekundärwald } & & $3-6$ & 61.4 & 46.3 & 0.2 & 0.9 \\
\hline & mittlere Krone & $6-10$ & 44.9 & 24.3 & 2.9 & 15.2 \\
\hline & innere Krone & $6-10$ & 56.6 & 25.4 & 0.4 & 1.1 \\
\hline & Stamm & $3-6$ & 27.5 & 10.6 & 1.3 & 4.5 \\
\hline & Stammbasis & $0-0.5$ & 39.8 & 14.2 & 0.6 & 1.7 \\
\hline \multirow[t]{5}{*}{ Altbestand } & äußere Krone & $25-30$ & 174.3 & 218.5 & 3 & 8.1 \\
\hline & mittlere Krone & $20-25$ & 212.6 & 81.8 & 94.6 & 134.5 \\
\hline & innere Krone & $20-25$ & 825 & 911.4 & 259.5 & 474.3 \\
\hline & Stamm & $8-10$ & 25.1 & 22.7 & 3.8 & 12.9 \\
\hline & Stammbasis & $0-0.5$ & 20.1 & 14 & 0.1 & 0.3 \\
\hline
\end{tabular}


Im Altbestand zeigen die epiphytischen Gefäßpflanzen das gleiche Verteilungsmuster wie die epiphytischen Moose und Flechten. Von der Stammbasis über den Stammbereich hin zur inneren Krone ist eine starke Anreicherung der epiphytischen Biomasse zu beobachten. In der inneren Krone (Astgabeln) zeigt sich ein etwa 68mal höherer Wert als im Stammbereich. Von der inneren Krone über die mittlere bis hin zur äußeren Krone ist wiederum eine starke Abnahme der Menge an epiphytischen Gefäßpflanzen um den Faktor $87 \mathrm{zu}$ erkennen. Auffallend ist bei den vaskulären Epiphyten die sehr hohe Standardabweichung der Meßwerte.

Kronenhumus wurde nur im Altbestand gefunden. In der mittleren Krone wurden im Mittel $150 \mathrm{~g} \mathrm{~m}^{-2}$ gemessen, während der Wert in der inneren Krone (Astgabeln) mit im Mittel $2100 \mathrm{~g} \mathrm{~m}^{-2}$ deutlich höher lag. Allen drei Beständen gemeinsam ist, daß die Biomasse der Moose und Flechten die der epiphytischen Gefäßpflanzen übertrifft und eine wesentlich homogenere Verteilung aufweist. Im Altbestand zeigen die Epiphyten eine wesentlich stärkere Klumpung als in den Sekundärwäldern. Ferner kommt es mit zunehmendem Bestandesalter zu einer immer stärkeren Verlagerung der epiphytischen Biomasse von der Stammbasis und der Stammregion in die Kronenregion der Eichen.

Dies wird auch beim Vergleich der einzelnen Straten der drei untersuchten Bestände hinsichtlich der Biomasse epiphytischer Moose und Flechten deutlich (Abb. 4-5). Mit steigendem Bestandesalter kommt es in der Kronenregion der Eichen zu einer immer stärkeren Zunahme der Epiphytenbiomasse, wobei die höchsten Werte in der inneren Krone zu beobachten sind.

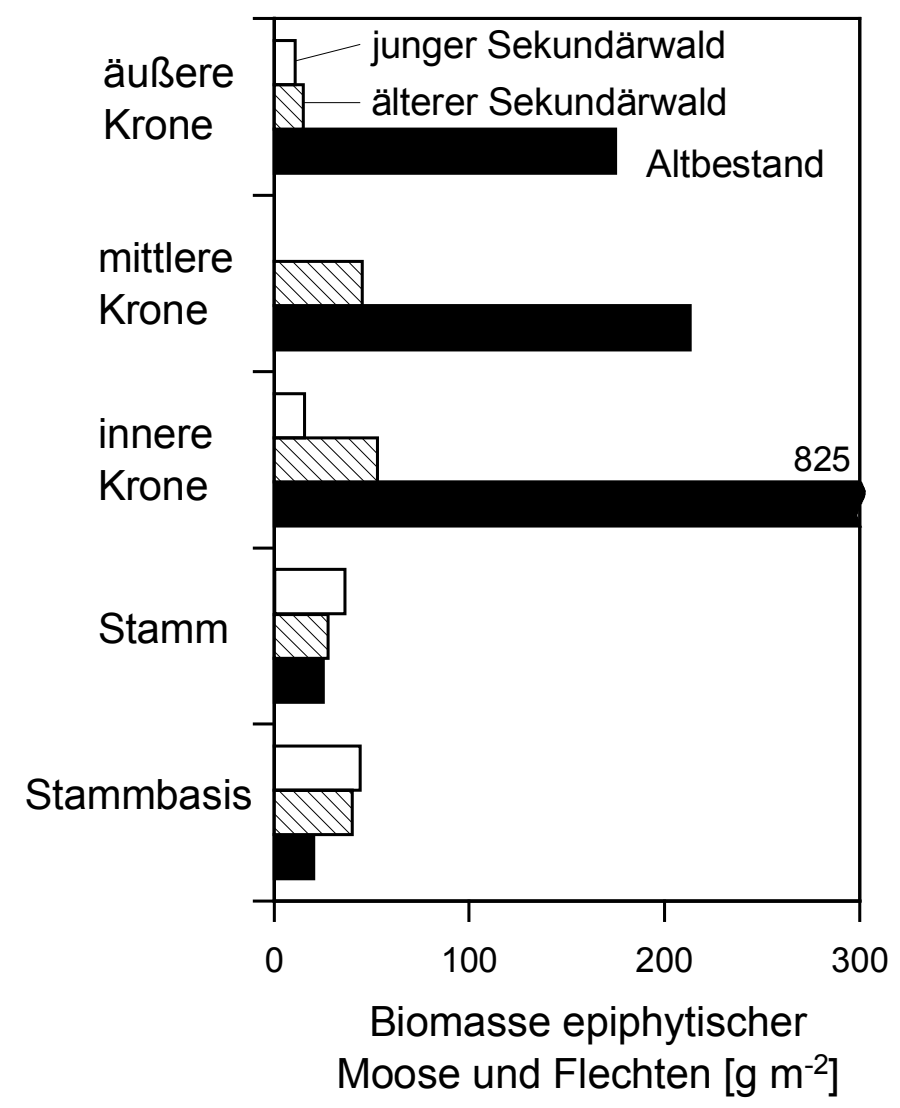

Abb. 4-5: Biomasse der epiphytischen Moose und Flechten in verschiedenen Straten von Quercus copeyensis in den drei untersuchten Beständen. Die Angaben [g Trockengewicht] beziehen sich auf $\mathrm{m}^{2}$ Ast- oder Stammoberfläche. Auf die Darstellung der teilweise hohen Standardabweichungen wurde aus Gründen der Übersichtlichkeit verzichtet. Für die Straten der äußeren und inneren Krone wurden bei den Sekundärwäldern zum Teil Mittelwerte aus unterschiedlichen Baumhöhen dargestellt. Da sich bei den Eichen des jungen Sekundärwaldes noch keine klare Stammregion abgrenzen lässt, wurde hier der Mittelwert aus Stammbasis $(0.2 \mathrm{~m})$ und $1 \mathrm{~m}$ Baumhöhe aufgetragen. 
Der mit $825 \mathrm{~g} \mathrm{~m}^{-2}$ besonders hohe Wert im Altbestand ist auf die Beprobung der Astgabeln zurückzuführen und nicht direkt mit den Erhebungen in der inneren Kronenregion der Sekundärwälder vergleichbar. Im Stammbereich und an den Stammbasen ist im Vergleich zur Kronenregion ein gegenläufiger Trend zu beobachten. Hier ist die höchste Epiphytenbiomasse im jungen Sekundärwald zu verzeichnen, während mit zunehmendem Bestandesalter ein stetiger Rückgang der Werte festzustellen ist. So übertrifft die Biomasse epiphytischer Moose und Flechten an den Stammbasen im jungen Sekundärwald die im Altbestand gemessenen Werte etwa um das Doppelte.

Aus den in Tab. 4-5 dargestellten epiphytischen Biomassen und der geschätzten Ast- und Stammoberfläche der drei Bestände ist eine grobe Abschätzung der Epiphytenbiomasse auf Bestandesebene möglich. Im jungen Sekundärwald wird die Biomasse der Epiphyten auf 160 $\mathrm{kg} \mathrm{ha}^{-1}$ geschätzt. Dabei handelt es sich fast ausschließlich um Moose und Flechten. Größere Mengen an epiphytischen Gefäßpflanzen sind nur an Überhältern zu beobachten, die jedoch nicht berücksichtigt wurden. Im älteren Sekundärwald wird die gesamte Epiphytenmenge auf $520 \mathrm{~kg} \mathrm{ha}{ }^{-1}$ geschätzt. Auch hierbei handelt es sich in erster Linie um Moose und Flechten, wobei der Anteil der Gefäßpflanzen (in erster Linie Bromelien) jedoch höher als im jungen Sekundärwald liegt. Der Altbestand weist mit Abstand den stärksten Epiphytenbewuchs auf. Die Gesamtmenge inklusive Kronenhumus wird auf etwa $3400 \mathrm{~kg} \mathrm{ha}^{-1}$ geschätzt, wobei der überwiegende Teil in der oberen Kronenregion zu finden ist. Moose und Flechten übertreffen den Biomasseerhebungen zufolge auch im Altbestand mengenmäßig die epiphytischen Gefäßpflanzen. 


\subsection{Wasserumsatz und Mikroklima in den Beständen}

\subsubsection{Klimabedingungen im Untersuchungszeitraum}

Mit der mikrometeorologischen Meßstation auf einer zentral gelegenen Freifläche bei Jaboncillo in 2900 m Meereshöhe konnten kontinuierliche Klimadaten über einen Zeitraum von mehr als 17 Monaten aufgezeichnet werden. Diese sind zur Charakterisierung des Regionalklimas sowie als Referenz für die Temperatur- und Feuchtemessungen in den Beständen von großer Bedeutung. Abb. 4-6 A, B veranschaulicht den monatlichen Niederschlagsgang sowie den Verlauf der mittleren monatlichen Lufttemperatur und des mittleren monatlichen Wasserdampfsättigungsdefizites im Freiland für den Zeitraum von April 1999 bis August 2000.
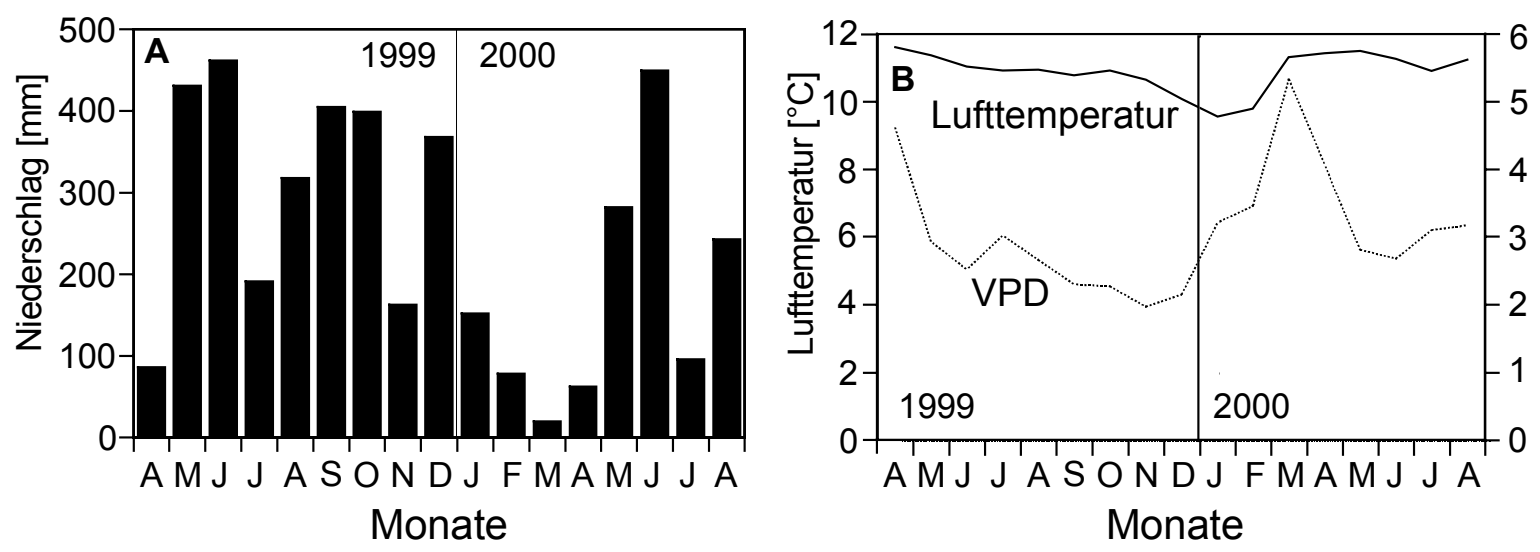

Abb. 4-6 A, B: Monatliche Niederschlagssummen im Freiland (A) sowie mittlere monatliche Lufttemperatur und mittleres monatliches Wasserdampfsättigungsdefizit (VPD) (B) in $1.5 \mathrm{~m}$ über dem Boden auf einer zentral gelegenen Freifläche des Untersuchungsgebietes (2900 m ü.M.) von April 1999 bis August 2000.

Der Jahresniederschlag im Untersuchungsgebiet betrug von April 1999 bis März 2000 $3074 \mathrm{~mm}$. Die Monate Mai bis November sind zur Regenzeit (Invierno) zu rechnen, wobei im Juli 1999 und Juli bis August 2000 eine typische niederschlagsärmere Periode (Veranillo) zu beobachten war. In der ersten Hälfte des Monats Dezember, der häufig einen Übergang zwischen Regen- und Trockenzeit darstellt, wurden verhältnismäßig hohe Niederschläge gemessen. Ab Mitte Dezember mit dem Beginn der Trockenzeit (Verano) war eine deutliche Abnahme der Niederschläge zu beobachten. 1999 erstreckte sich die Trockenzeit bis Ende April, während im Jahr 2000 erst Mitte Mai ein starker Anstieg der Niederschlagstätigkeit zu beobachten war. Niederschlagsreichster Monat in der Untersuchungsperiode war der Monat Juni 1999 mit $462 \mathrm{~mm}$, die geringsten Niederschläge wurden mit $20 \mathrm{~mm}$ im Monat März 2000 gemessen. Auf einer zweiten Freifläche in der Nähe des untersuchten Altbestandes wurde mit $3041 \mathrm{~mm}$ eine sehr ähnliche Jahressumme der Niederschläge registriert. Die monatlichen Niederschlagsmengen konnten jedoch bis zu etwa $100 \mathrm{~mm}$ von den in Abb. 4-6, A dargestellten Werten abweichen. Auf einer weiteren Freifläche der Finca Serrano wurden 
die Niederschläge von Oktober 1999 bis September 2000 in täglicher Auflösung aufgezeichnet. Meist betrugen die Tagesniederschläge hier weniger als 5 mm (123 Tage). Niederschlagsmengen unter $20 \mathrm{~mm}$ trugen etwa 50\% zum Gesamtjahresniederschlag bei. Die maximalen Tagesniederschläge lagen zwischen 50 und 60 mm (3 Tage). An 115 Tagen wurde kein Niederschlag verzeichnet.

Die eigenen Niederschlags-Meßergebnisse zeigen einen sehr ähnlichen Jahresgang wie die in Kapitel 2 dargestellten, auf mehrjährigen Datensätzen basierenden Niederschlagsdiagramme der meteorologischen Stationen Ojo de Agua und Villa Mills.

Die mittleren Lufttemperaturen in 1.50 m Bodenhöhe schwankten im Freiland zwischen dem wärmsten Monat (April 1999) und dem kältesten Monat (Januar 2000) um nur 2 K (Abb. 4-6, B). Die Jahresmitteltemperatur von April 1999 bis März 2000 betrug $10.7{ }^{\circ} \mathrm{C}$. Als absolutes Temperaturmaximum im Untersuchungszeitraum wurden $23.1{ }^{\circ} \mathrm{C}$ (März 2000) gemessen. Das absolute Temperaturminimum lag mit $2.3{ }^{\circ} \mathrm{C}$ in den Monaten April 1999 und Januar 2000.

Die mittlere monatliche relative Luftfeuchte lag zwischen etwa 67\% in der Trockenzeit und über 87.5\% in der Regenzeit. Der Jahresmittelwert von April 1999 bis März 2000 betrug etwa 80\%. Aussagekräftiger ist jedoch das Sättigungsdefizit der Luft (VPD) (Abb. 4-6, B). Die Monatsmittel schwankten im Jahresverlauf zwischen 2 und $5.3 \mathrm{hPa}$, wobei der Jahresmittelwert für den oben genannten Zeitraum etwa $3 \mathrm{hPa}$ betrug. Werte über $4 \mathrm{hPa}$ traten dabei nur in den Trockenzeitmonaten März und April auf. Das absolute Sättigungsdefizitmaximum wurde mit fast $23 \mathrm{hPa}$ im Monat März 2000 gemessen.

Die Strahlungsbilanz (Nettostrahlung) lag im Untersuchungszeitraum im Freiland über kurzem Rasen im Monatsmittel zwischen 81 und $130 \mathrm{~W} \mathrm{~m}^{-2}$ (Abb. 4-7, A). Werte über $100 \mathrm{~W}$ $\mathrm{m}^{-2}$ wurden dabei nur in der wolkenärmeren Trockenzeit (Mitte Dezember bis Mitte Mai) und der Zwischentrockenzeit (Juli, August) erreicht. Im Jahresmittel (April 1999 bis März 2000) ergab sich eine Strahlungsbilanz von $101 \mathrm{~W} \mathrm{~m}^{-2}$.

Die mittlere monatliche Windgeschwindigkeit lag im Freiland des Untersuchungsgebietes meist zwischen 0.4 und $1 \mathrm{~m} \mathrm{~s}^{-1}$ (Abb. 4-7, B). Nur in den Trockenzeitmonaten Dezember bis Februar wurden deutlich höhere Werte gemessen. Im Januar traten mit fast $1.6 \mathrm{~m} \mathrm{~s}^{-1}$ die im Mittel größten Windgeschwindigkeiten auf. Die höchsten insgesamt gemessenen Werte (zehnminütige Mittelwerte) lagen bei etwa $5 \mathrm{~m} \mathrm{~s}^{-1}$ im Monat Dezember. Vermutlich können auch kurzfristig wesentlich höhere Windgeschwindigkeiten auftreten, die zwischen den Meßintervallen jedoch nicht erfaßt oder durch die Mittelwertbildung nivelliert wurden. 

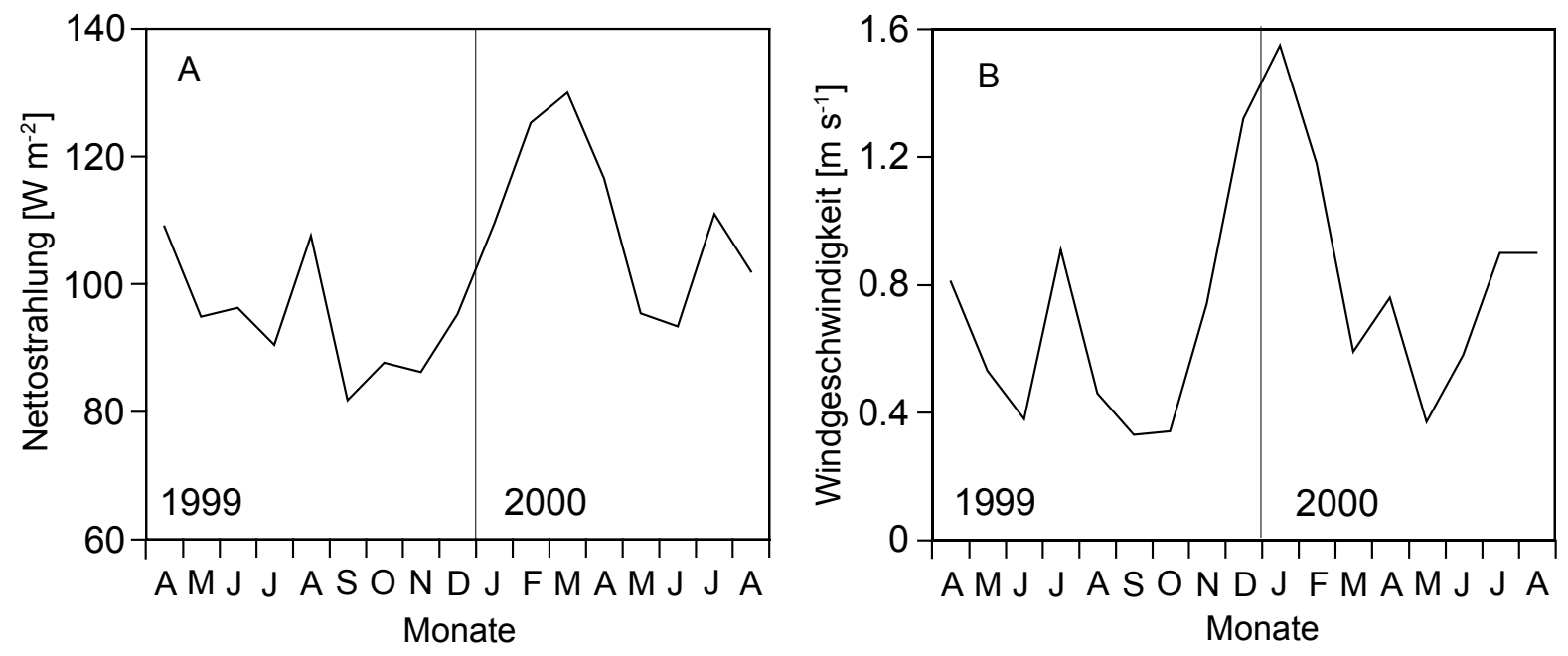

Abb. 4-7 A, B: Mittlere monatliche Nettostrahlung (A) sowie mittlere monatliche Windgeschwindigkeit (B) in $1.5 \mathrm{~m}$ über dem Boden auf einer zentral gelegenen Freifläche des Untersuchungsgebietes von April 1999 bis August 2000.

Bei der Beobachtung der Nebelhäufigkeit im Altbestand wurden im Monat Februar 2000 nur fünf Tage mit mehr als drei Stunden Nebel verzeichnet (Abb. 4-8). Im März und April war eine leichte Zunahme der Nebelhäufigkeit zu beobachten. Der Mai war mit 22 Nebeltagen der nebelreichste Monat der Beobachtungsperiode. Danach zeigte sich eine erneute Abnahme der Werte, wobei während der Zwischentrockenzeit im Monat Juli mit elf Nebeltagen ein weiteres Minimum zu beobachten war. In den Monaten August und September kam es erneut zu einer Zunahme der Nebelhäufigkeit.

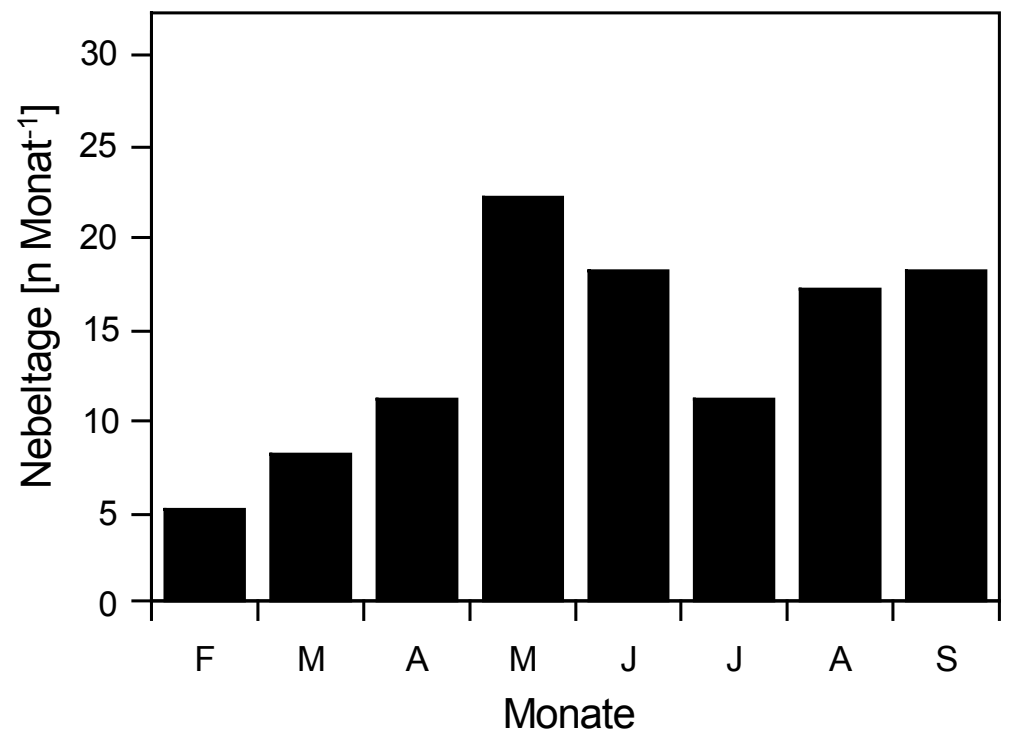

Abb. 4-8: Anzahl der monatlichen Nebeltage (Tage mit mindestens drei Stunden Nebel) von Februar bis September $2000 \mathrm{im}$ untersuchten Altbestand. 
Die mit den Nebelsammlern gemessenen Niederschlagsmengen (horizontaler Niederschlag) zeigen eine starke Abhängigkeit von der Höhe der vertikalen Freilandniederschläge. An regenfreien Nebeltagen konnten keine horizontalen Niederschläge registriert werden, während die Sammelleistung der Nebelsammler mit der Höhe des vertikalen Freilandniederschlags zunahm. Besonders hohe Niederschlagsmengen wurden allerdings während der DerrameWetterlage im Januar 2000 (Trockenzeit) bei vergleichsweise geringen vertikalen Regenmengen von den Nebelsammlern ausgekämmt. Bei diesem feinen Sprühregen, der in Verbindung mit relativ hohen Windgeschwindigkeiten von im Mittel $2.8 \mathrm{~m} \mathrm{~s}^{-1}$ auftrat, wurden mit den Nebelsammlern etwa um den Faktor 23 höhere Werte gemessen als bei ähnlicher Niederschlagshöhe in der Regenzeit (Abb. 4-9).

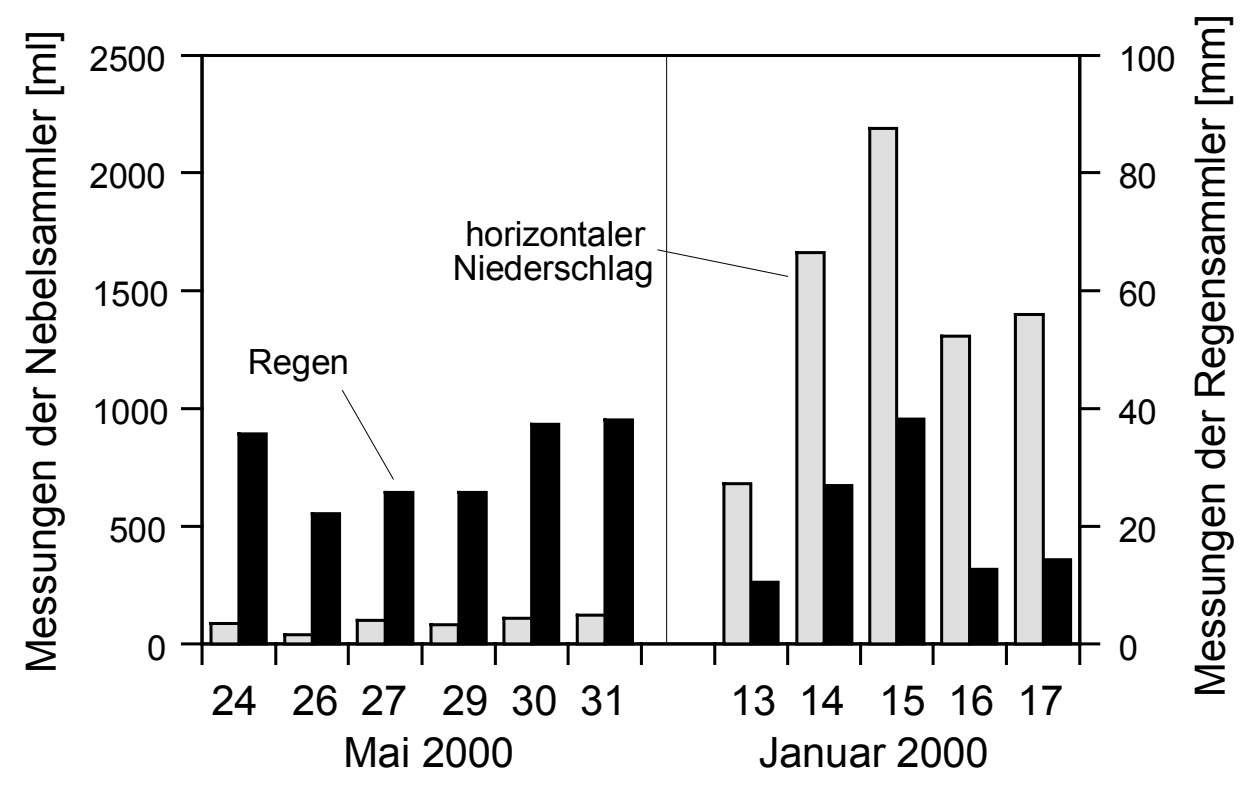

\begin{abstract}
Abb. 4-9: Messungen der Regensammler (vertikaler Freilandniederschlag) und mit den Nebelsammlern gemessener horizontaler Niederschlag an einzelnen Tagen der Regenzeit im Mai 2000 und in der Trockenzeit im Januar 2000 während einer Derrame-Wetterlage.
\end{abstract}

Da trotz der Dachkonstruktion der Nebelsammler ein seitliches Eintreten von Regen nicht zu verhindern war und so eine Trennung von vertikalen und horizontalen Niederschlägen nicht möglich ist, werden diese Messungen in der weiteren Auswertung nicht berücksichtigt.

\title{
4.2.2 Temperatur und Luftfeuchte in den Beständen
}

Die Messungen der Lufttemperatur in fünf unterschiedlichen Bestandeshöhen des Altbestandes während vier Wochen in der Trockenzeit (Abb. 4-10) zeigen eine kontinuierliche Zunahme der Meßwerte vom Stammfußbereich $(0.5 \mathrm{~m})$ zur äußeren Kronenregion (30 m). Von der mittleren (25, $26 \mathrm{~m}$ ) zur äußeren Krone (30 m), in der der Hauptenergieumsatz der eingestrahlten Sonnenenergie stattfindet, ist dabei ein besonders starker Temperaturanstieg zu beobachten. In der Regenzeit zeigt sich ein fast identischer 
Kurvenverlauf, wobei die Werte aufgrund der sehr geringen Trockenzeittemperaturen im Januar und Februar im Mittel um 0.5 K höher liegen. Die Temperaturdifferenzen zwischen Stammfußbereich und äußerer Kronenregion betragen im vierwöchigen Mittel in der Regenund in der Trockenzeit etwa $1 \mathrm{~K}$. Die maximalen Temperaturdifferenzen, die zwischen diesen beiden Straten gemessen wurden, betrugen $7.7 \mathrm{~K}$ in der Trockenzeit und $5.3 \mathrm{~K}$ in der Regenzeit (ohne Abb.).

Auch bei dem parallel zur Lufttemperatur gemessenen Wasserdampfsättigungsdefizit ist im Altbestand in der Regenzeit ein Anstieg der Werte von $0.2 \mathrm{hPa}$ im Stammfußbereich auf 1.1 $\mathrm{hPa}$ in der äußeren Kronenregion zu beobachten (Abb. 4-10). In der Trockenzeit zeigt sich ein sehr ähnlicher Kurvenverlauf, wobei die Werte im Mittel jedoch um 2.7 hPa höher liegen. Die Unterschiede des Sättigungsdefizites zwischen Stammfußbereich und äußerer Kronenregion betragen im vierwöchigen Mittel in der Regen- und in der Trockenzeit etwa 0.9 hPa. Die maximalen Differenzen des Sättigungsdefizites, die zwischen diesen beiden Straten gemessen wurden, betrugen $7.5 \mathrm{hPa}$ in der Trockenzeit und $4.9 \mathrm{hPa}$ in der Regenzeit.

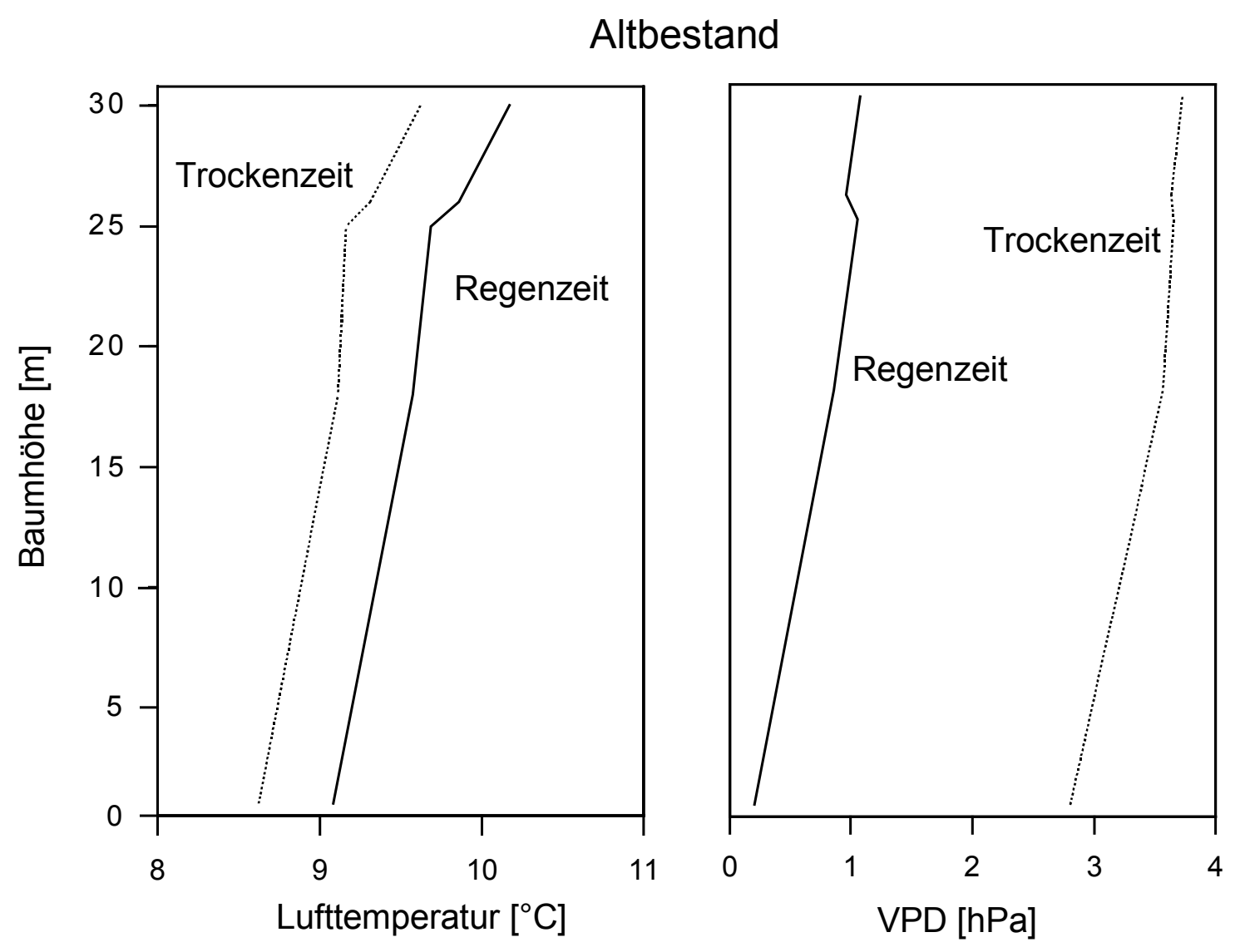

Abb. 4-10: Höhengradient der Lufttemperatur und des Sättigungsdefizites (VPD) in fünf verschiedenen Baumhöhen des Altbestandes. Dargestellt sind die Mittelwerte aus vier Regenzeit- und vier Trockenzeitwochen. 
Allgemein ist die äußere Kronenregion durch größere Schwankungen der Lufttemperatur und des Sättigungsdefizites gekennzeichnet. So wurden in $30 \mathrm{~m}$ Höhe im Altbestand Schwankungen der Lufttemperatur bis zu $12.7 \mathrm{~K}$ und des VPD bis zu $15.7 \mathrm{hPa}$ registriert, während sich in $0.5 \mathrm{~m}$ Bestandeshöhe mit einer Amplitude von maximal $10.4 \mathrm{~K}$ und $11.4 \mathrm{hPa}$ ein ausgeglicheneres Mikroklima zeigte (ohne Abb.).

Höhengradienten der Lufttemperatur und des Sättigungsdefizites sind auch in den untersuchten Sekundärwaldbeständen zu beobachten, wobei hier nur die Sättigungsdefizite grafisch dargestellt werden (Abb. 4-11). Im jungen Sekundärwald ist während vier Wochen in der Regen- und in der Trockenzeit im Mittel eine Zunahme der Lufttemperaturen mit steigender Baumhöhe zu erkennen. In der Regenzeit wurden im Stammfußbereich $9.5{ }^{\circ} \mathrm{C}$ gemessen, während die Werte in der äußeren Krone bei $10.2{ }^{\circ} \mathrm{C}$ lagen. In der Trockenzeit wurden um etwa $0.3 \mathrm{~K}$ höhere Temperaturen gemessen. Wie im Altbestand zeigt sich bei beiden Kurven der stärkste Temperaturanstieg von der mittleren zur äußeren Kronenregion. Die Temperaturunterschiede zwischen Stammfußbereich und äußerer Kronenregion betragen im vierwöchigen Mittel in der Regenzeit $0.8 \mathrm{~K}$ und in der Trockenzeit $0.7 \mathrm{~K}$. Die maximalen Temperaturdifferenzen zwischen diesen Straten betrugen $4.3 \mathrm{~K}$ in der Regenzeit und $5.8 \mathrm{~K}$ in der Trockenzeit (ohne Abb.).

Die Sättigungsdefizite im jungen Sekundärwald lassen im vierwöchigen Mittel in der Regenzeit einen fast linearen Anstieg von $0.4 \mathrm{hPa}$ im Stammfußbereich auf $1.1 \mathrm{hPa}$ in der äußeren Kronenregion erkennen (Abb. 4-11). In der Trockenzeit zeigt sich ein sehr ähnlicher Kurvenverlauf, wobei die Meßwerte um 2 hPa höher liegen. Die Unterschiede des Sättigungsdefizites zwischen Stammfußbereich und der äußeren Kronenregion betragen im vierwöchigen Mittel in der Regenzeit $0.7 \mathrm{hPa}$ und in der Trockenzeit 0.6 hPa. Die maximalen Differenzen des Sättigungsdefizites, die zwischen diesen beiden Straten auftraten, betrugen in der Regen- und in der Trockenzeit $5.2 \mathrm{hPa}$.

Anders als im Altbestand sind im jungen Sekundärwald die Schwankungen der Lufttemperatur und des Sättigungsdefizites am Waldboden größer als in der äußeren Krone. So wurden in $6 \mathrm{~m}$ Höhe Änderungen der Temperatur bis zu $15.4 \mathrm{~K}$ und des VPD bis zu 15.2 $\mathrm{hPa}$ registriert, während sich in $0.2 \mathrm{~m}$ Bestandeshöhe eine Amplitude von maximal $16.9 \mathrm{~K}$ und $15.5 \mathrm{hPa}$ und damit ein heterogeneres Mikroklima zeigte (ohne Abb.). Die starken Temperaturschwankungen im Stammfußbereich sind auf die zum Teil niedrigen Temperaturen in Bodennähe zurückzuführen. 

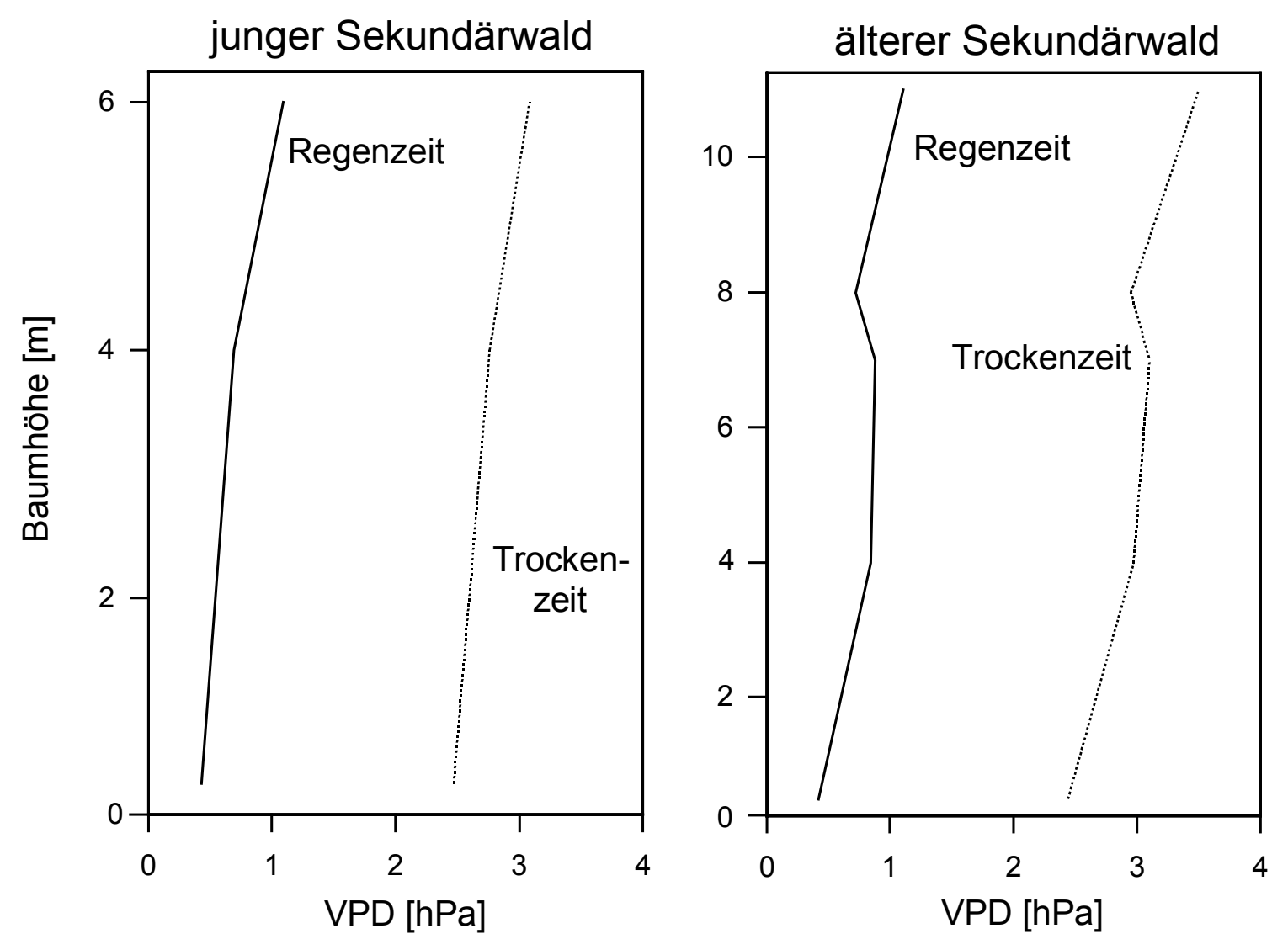

Abb. 4-11: Höhengradient des mittleren Sättigungsdefizites (VPD) in drei verschiedenen Baumhöhen im jungen Sekundärwald und fünf verschiedenen Baumhöhen im älteren Sekundärwald. Dargestellt sind die Mittelwerte aus vier Regenzeit- und vier Trockenzeitwochen.

Im älteren Sekundärwald ist im vierwöchigen Mittel sowohl in der Regen- als auch in der Trockenzeit eine Zunahme der Lufttemperaturen mit steigender Bestandeshöhe zu erkennen. Zwischen 7 und $8 \mathrm{~m}$ Baumhöhe ist jedoch ein geringer Temperaturrückgang zu beobachten. Auch hier zeigt sich ein besonders starker Anstieg der Werte von der mittleren zur äußeren Kronenregion. Die Trockenzeitwerte liegen im Stammfußbereich um $0.2 \mathrm{~K}$ und in der äußeren Kronenregion um $0.5 \mathrm{~K}$ über den Meßwerten der Regenzeit. Die Temperaturunterschiede zwischen diesen beiden Straten betragen im vierwöchigen Mittel in der Regenzeit $1.0 \mathrm{~K}$ und in der Trockenzeit $1.4 \mathrm{~K}$, die maximalen Temperaturdifferenzen betrugen $3.8 \mathrm{~K}$ in der Regenzeit und $6.2 \mathrm{~K}$ in der Trockenzeit.

Die zeitgleich gemessenen Sättigungsdefizite steigen in der Regenzeit im älteren Sekundärwald von $0.4 \mathrm{hPa}$ im Stammfußbereich auf $1.1 \mathrm{hPa}$ in der äußeren Krone an (Abb. 411). Ein ähnlicher Kurvenverlauf ist während der Trockenzeit zu beobachten, wobei die Werte im Mittel jedoch um $2.2 \mathrm{hPa}$ höher liegen. Wie auch die Temperaturen lassen die Sättigungsdefizite eine leichte Abnahme zwischen 7 und $8 \mathrm{~m}$ Baumhöhe erkennen, bevor die Werte zur äußeren Krone hin erneut ansteigen. Die Unterschiede des Sättigungsdefizites zwischen Stammfußbereich und oberer Kronenregion betragen im vierwöchigen Mittel in der Regenzeit $0.7 \mathrm{hPa}$ und in der Trockenzeit $1.1 \mathrm{hPa}$. Die maximalen Differenzen des 
Sättigungsdefizites, die zwischen diesen beiden Straten gemessen wurden, betrugen $3.4 \mathrm{hPa}$ in der Regenzeit und $5.3 \mathrm{hPa}$ in der Trockenzeit (ohne Abb.).

Im älteren Sekundärwald sind in der äußeren Krone größere Schwankungen der Lufttemperatur und des Sättigungsdefizites als am Waldboden zu beobachten. So wurden in 11 m Höhe Änderungen der Lufttemperatur bis zu 14.9 K und des VPD bis zu $13.3 \mathrm{hPa}$ registriert, während in $0.5 \mathrm{~m}$ Bestandeshöhe die Werte maximal um $13.3 \mathrm{~K}$ und $11.2 \mathrm{hPa}$ schwankten (ohne Abb.).

Somit zeigen sich interessanterweise in allen drei Beständen, trotz der sehr unterschiedlichen Bestandeshöhen, zwischen Stammbasis und äußerer Krone im Mittel ähnliche Differenzen der Lufttemperatur und des VPD. Diese Unterschiede sind in der Trockenzeit meist etwas stärker ausgeprägt als in der Regenzeit.

Im jungen Sekundärwald lassen die mittleren Wasserdampfsättigungsdefizite im Freiland während 45 Tagen in der Trockenzeit in den frühen Morgenstunden keine Unterschiede zu den Bestandeswerten erkennen (Abb. 4-12). Bedingt durch den Sonnenaufgang um sechs Uhr morgens steigen sowohl die Sättigungsdefizite im Freiland als auch im Bestand deutlich an und erreichen zwischen 9 und 10 Uhr vormittags die höchsten Werte. Danach fallen alle Kurven kontinuierlich bis etwa 18.30 Uhr. Im weiteren Tagesverlauf ist nach Sonnenuntergang ein erneutes Ansteigen der Sättigungsdefizite im Freiland und im Bestand zu erkennen. Innerhalb des Bestandes sind im gesamten Tagesverlauf die geringsten VPDs an der Stammbasis $(0.2 \mathrm{~m}) \mathrm{zu}$ beobachten. Die untersuchten Straten lassen eine deutliche Abhängigkeit der mittleren Sättigungsdefizite von der Bestandeshöhe erkennen, wobei die Werte zur äußeren Kronenregion $(6 \mathrm{~m})$ hin zunehmen. Zwischen Stammfußbereich und äußerer Kronenregion treten Differenzen von bis zu $3 \mathrm{hPa}$ auf.

In den frühen Morgenstunden liegen die mittleren Sättigungsdefizite während 34 Tagen in der Trockenzeit in der Kronenregion des älteren Sekundärwaldes über den im Freiland gemessenen Werten. Im weiteren Tagesverlauf zeigen sich sehr ähnliche Verhältnisse wie im jungen Sekundärwald. Auch hier bewegen sich die Sättigungsdefizite in der äußeren Kronenregion $(11 \mathrm{~m})$ deutlich über den Werten im Stammfußbereich $(0.2 \mathrm{~m})$, wobei Differenzen von bis zu $2.5 \mathrm{hPa}$ auftreten. Innerhalb der einzelnen Straten zeigen sich trotz hoher Freilandwerte im Vergleich zum jungen Sekundärwald nur relativ geringe Schwankungen. Nach Sonnenuntergang ist bei den Freiland- wie auch bei den Bestandeswerten ein erneuter Anstieg der mittleren Sättigungsdefizite zu beobachten. 

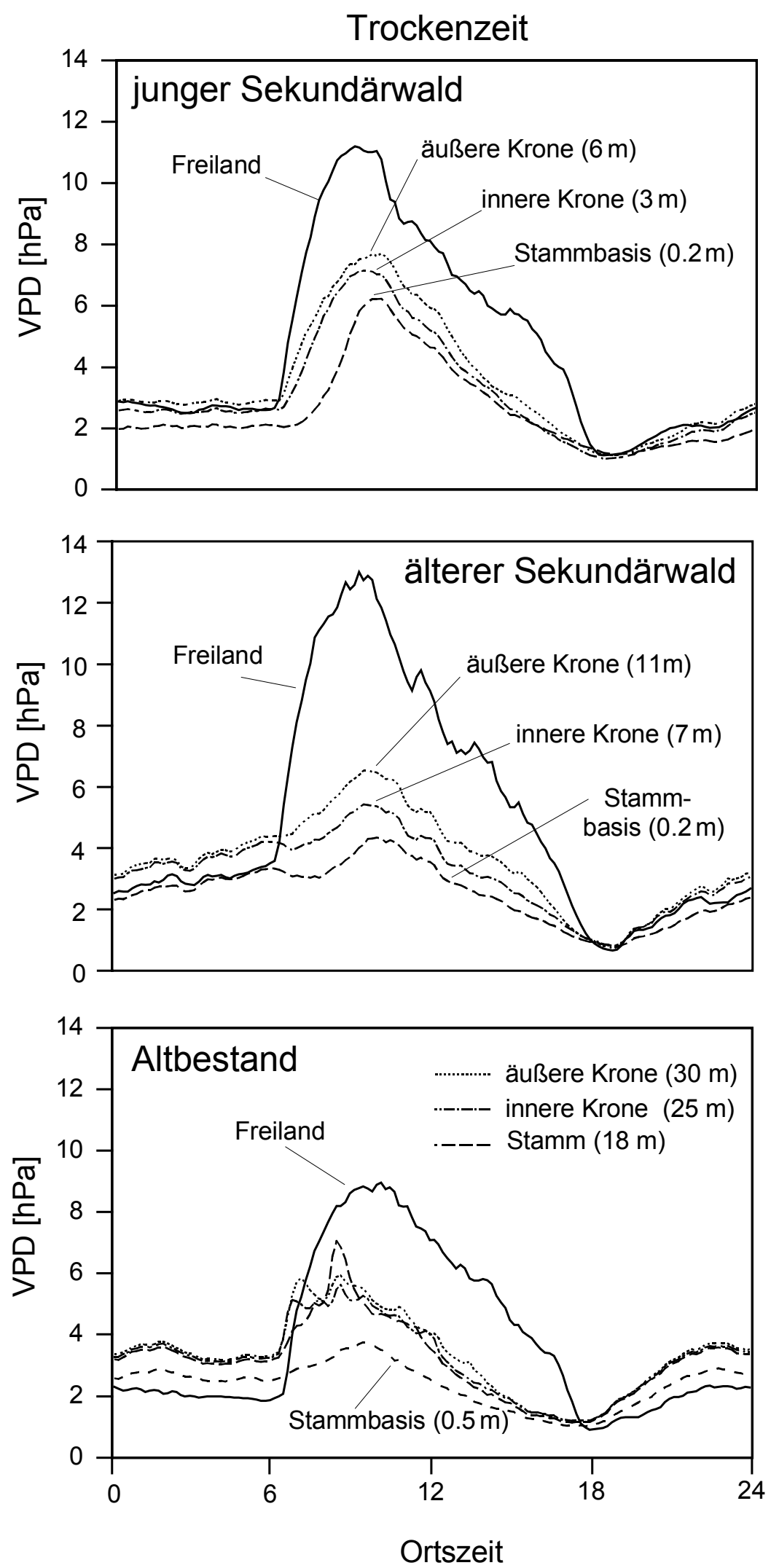

Abb. 4-12: Mittlerer Tagesverlauf der Sättigungsdefizite (VPD) in unterschiedlichen Baumhöhen der untersuchten Bestände sowie Tagesverlauf der jeweiligen Freilandwerte. Dargestellt sind verschiedene Perioden der Trockenzeit 1999/2000 mit einem Freiland-Wochenniederschlag unter 20 mm. Im jungen Sekundärwald: 45 Tage mit im Mittel $4.5 \mathrm{~mm}$ pro Woche und im älteren Sekundärwald: 34 Tage mit im Mittel $3.3 \mathrm{~mm}$ Freilandniederschlag pro Woche. Im Altbestand: 49 Tage mit im Mittel $8 \mathrm{~mm}$ Freilandniederschlag pro Woche. 
Die Tagesverläufe des mittleren Sättigungsdefizites, die während 49 Tagen in der Trockenzeit im Altbestand gemessen wurden, lassen erkennen, daß die Bestandeswerte in den frühen Morgenstunden über den zeitgleich gemessenen Freilandwerten liegen (Abb. 4-12). Um sechs Uhr morgens ist ein steiler Anstieg der Freilandwerte zu beobachten, die maximalen Sättigungsdefizite treten um 10 Uhr vormittags auf. Auch im Bestand zeigt sich ein Anstieg der Werte nach Sonnenaufgang, die im weiteren Tagesverlauf allerdings hinter den Freilandwerten zurückbleiben. Daß die Höchstwerte im Altbestand gegen 8.30 Uhr und damit etwa eineinhalb Stunden früher als im Freiland erreicht werden, ist vermutlich auf die NOExposition dieser Untersuchungsfläche zurückzuführen. Nach Sonnenuntergang sind im Freiland erneut niedrigere Werte als im Bestand zu beobachten, was durch einen stärkeren Anstieg der Bestandeswerte gegenüber den Freilandwerten verursacht wird. Innerhalb des Altbestandes lassen die Sättigungsdefizite im Bereich der Stammbasis $(0.5 \mathrm{~m})$ die geringsten Schwankungen im Tagesverlauf erkennen. Im Stammbereich $(18 \mathrm{~m})$ sowie in der inneren und äußeren Krone $(25 \mathrm{~m}, 30 \mathrm{~m})$ zeigt das Sättigungsdefizit sehr ähnliche Kurvenverläufe. Die starken Schwankungen der Meßwerte zwischen sechs und neun Uhr vormittags im Kronenund vor allem im Stammbereich sind vermutlich auf das relativ offene Kronendach des Altbestandes und eine direkte Sonneneinstrahlung zurückzuführen. Außerhalb dieser Zeitspanne treten im mehrwöchigen Mittel die größten Differenzen des Sättigungsdefizites mit $3.7 \mathrm{hPa}$ zwischen Stammbasis und Stamm auf.

Analog zu diesen Untersuchungen wurden auch in der Regenzeit Messungen des Wasserdampfsättigungsdefizites im Freiland und in den drei Beständen durchgeführt (Abb. 413). Dabei zeigte sich, daß sowohl die Freiland- als auch die Bestandeswerte in der Regenzeit deutlich niedriger als in der Trockenzeit liegen. Die Maxima der Sättigungsdefizite werden aufgrund der im Verlauf des Vormittags aufziehenden Bewölkung im Freiland bereits zwischen 8 und 9 Uhr morgens erreicht. Dementsprechend treten auch die im Bestand gemessenen Höchstwerte in der Regenzeit früher als während der Trockenzeit auf. Im jungen Sekundärwald liegen die mittleren Sättigungsdefizite während 35 Tagen in der Regenzeit im gesamten Tagesverlauf über den Bestandeswerten. Wie in der Trockenzeit ist bei allen Kurven ein Anstieg nach Sonnenaufgang zu beobachten. Allerdings ist im Vergleich zur Trockenzeit keine klare Zunahme der Sättigungsdefizite nach Sonnenuntergang zu erkennen. Innerhalb des Bestandes zeigt sich im Gegensatz zum Altbestand erneut eine deutliche Abstufung der gemessenen Werte mit den niedrigsten Sättigungsdefiziten an der Stammbasis $(0.2 \mathrm{~m})$ und den höchsten Werten in der äußeren Krone $(6 \mathrm{~m})$, wobei maximale Differenzen von $1.8 \mathrm{hPa}$ zu beobachten sind.

Sehr ähnliche Verhältnisse sind während 35 Tagen in der Regenzeit im älteren Sekundärwald zu erkennen. Es zeigt sich die gleiche Abstufung der Sättigungsdefizite zwischen den untersuchten Straten mit den niedrigsten Werten an der Stammbasis (0.2 m) und den höchsten Werten in der äußeren Krone $(11 \mathrm{~m})$. Dabei werden maximale Differenzen von $1.3 \mathrm{hPa}$ erreicht. Innerhalb dieser Straten treten im älteren Sekundärwald trotz vergleichbarer Freilandwerte jedoch geringere Schwankungen als im jungen Sekundärwald auf. 


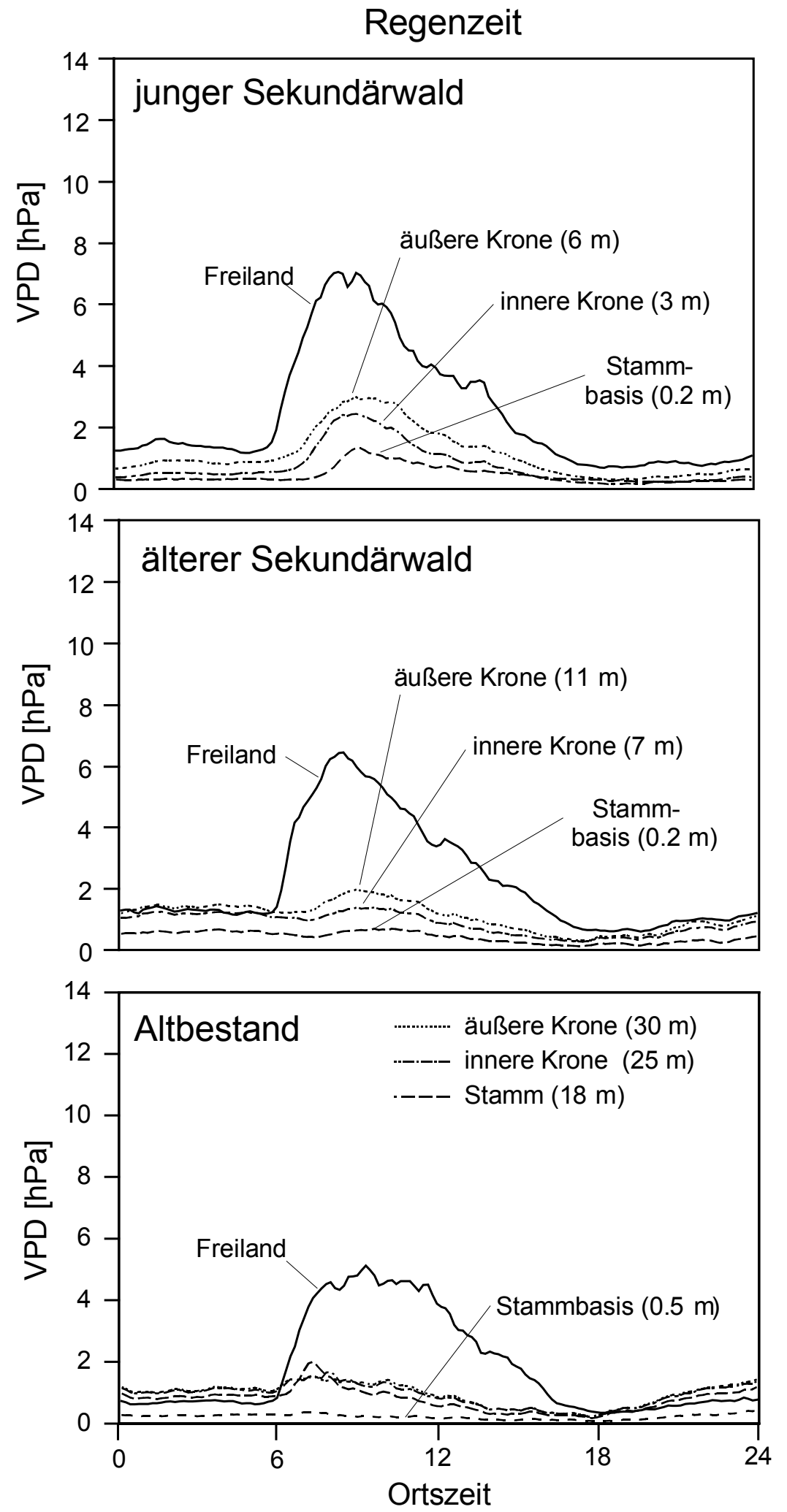

Abb. 4-13: Mittlerer Tagesverlauf der Sättigungsdefizite (VPD) in unterschiedlichen Baumhöhen der untersuchten Bestände sowie Tagesverlauf der jeweiligen Freilandwerte. Dargestellt sind verschiedene Perioden der Regenzeit 1999/2000 mit einem FreilandWochenniederschlag über $100 \mathrm{~mm}$. Im Altbestand: 26 Tage mit im Mittel $124 \mathrm{~mm}$ FreilandWochenniederschlag, im jungen Sekundärwald: 35 Tage mit im Mittel $126 \mathrm{~mm}$ und im älteren Sekundärwald: 35 Tage mit im Mittel 132 mm Freilandniederschlag pro Woche. 
Im Altbestand liegen die mittleren Sättigungsdefizite während 26 Tagen in der Regenzeit vor Sonnenaufgang innerhalb der Spanne der Bestandeswerte (Abb. 4-13). Die Freilandwerte lassen nach Sonnenaufgang ein starkes Ansteigen erkennen, während die Sättigungsdefizite im Bestand nur geringe Schwankungen zeigen. Nur im Stammbereich $(18 \mathrm{~m})$ ist ein etwas stärkerer Anstieg der Werte zu beobachten. Um 18 Uhr treten sowohl bei den Freiland- als auch bei den Bestandeswerten die Tagesminima auf. Nach Sonnenuntergang läßt sich bei allen Kurven ein erneuter Anstieg erkennen. Innerhalb des Bestandes zeigt sich im Altbestand das schon in der Trockenzeit beobachtete Bild mit nur geringfügig unterschiedlichen Werten vom Stammbereich $(18 \mathrm{~m})$ bis zur äußeren Krone $(30 \mathrm{~m})$. Deutlich niedriger liegen die Werte hingegen an der Stammbasis $(0.5 \mathrm{~m})$. Die größten Differenzen zwischen den untersuchten Bestandeshöhen treten im mehrwöchigen Mittel der Sättigungsdefizite zwischen Stammbasis und Stamm auf und betragen $1.7 \mathrm{hPa}$.

Da die hier dargestellten Mikroklima-Untersuchungen der drei Waldbestände nicht parallel durchgeführt wurden, sondern an unterschiedlichen Terminen stattfanden, konnten während der Bestandesmessung jeweils unterschiedliche mikroklimatische Bedingungen im Freiland auftreten. Ein direkter Vergleich der Bestände ist daher erst nach Subtraktion der zeitgleich gemessenen Freilandwerte von den Bestandeswerten möglich (Abb. 4-14). Stark negative Werte bedeuten dabei eine starke Abweichung der im Bestand gemessenen Sättigungsdefizite von den Freilandwerten, wobei die Bestandeswerte niedriger als die Freilandwerte waren. Bei positiven Werten lagen die Sättigungsdefizite im Waldesinneren über den im Freiland gemessenen Werten. Aus Gründen der Übersichtlichkeit wird hier für jeden Bestand nur die innere Krone, der Hauptlebensraum der Epiphyten, graphisch dargestellt.

Beim Vergleich der Tagesverläufe der in den drei Beständen gemessenen und um die jeweiligen Freilandwerte bereinigten Sättigungsdefizite zeigen sich in der Trockenzeit relativ stark voneinander abweichende Kurvenverläufe (Abb. 4-14, Trockenzeit). Im jungen Sekundärwald sind während des gesamten Tages in der inneren Krone (3 m) ausschließlich negative Werte zu erkennen (VPD Bestand < VPD Freiland). Diese liegen mit Ausnahme einiger Stunden (10 bis $15 \mathrm{Uhr}$ ) unterhalb der im Altbestand gemessenen Werte. Dies bedeutet, daß unter Berücksichtigung der jeweiligen Freilandwerte im jungen Sekundärwald die meiste Zeit des Tages niedrigere Sättigungsdefizite als im Altbestand auftraten.

Die größten Abweichungen von den jeweiligen Feuchtebedingungen im Freiland zeigen sich im älteren Sekundärwald. Während vor Sonnenaufgang und nach Sonnenuntergang in der inneren Kronenregion ( $7 \mathrm{~m}$ ) leicht positive Werte zu beobachten sind (VPD Bestand > VPD Freiland), verläuft die Kurve zwischen 6 und 18 Uhr im stark negativen Bereich. Dies bedeutet, daß die im Bestand gemessenen Sättigungsdefizite weit hinter den Freilandwerten zurückbleiben, was vermutlich auf den relativ hohen LAI des älteren Sekundärwaldes zurückzuführen ist.

Im Altbestand sind in der inneren Krone $(25 \mathrm{~m})$ bis Sonnenaufgang positive Werte zu beobachten (VPD Bestand > VPD Freiland). Der gegen sechs Uhr morgens auftretende Peak ist auf eine zeitliche Verschiebung des morgendlichen Anstiegs der Sättigungsdefizite zwischen Bestandes- und der Freilandkurve und die dadurch kurzfristig entstehenden großen 
positiven Differenzen zurückzuführen. Nach Sonnenaufgang ist ein starkes Abfallen der Kurve zu beobachten. Bis zum Sonnenuntergang gegen $18 \mathrm{Uhr}$ treten ausschließlich negative Werte auf (VPD Bestand < VPD Freiland). In den positiven Werten nach Sonnenuntergang spiegeln sich die höheren Sättigungsdefizite im Bestand gegenüber niedrigeren Freilandwerten wider.

In der Regenzeit zeigt sich im Wesentlichen die gleiche Abstufung der drei untersuchten Waldstadien (Abb. 4-14, Regenzeit). Die zwischen den Beständen auftretenden Unterschiede sind jedoch deutlich geringer als in der Trockenzeit. Bestandesspezifisch bedingte Unterschiede scheinen durch die Regenzeit nivelliert zu werden.

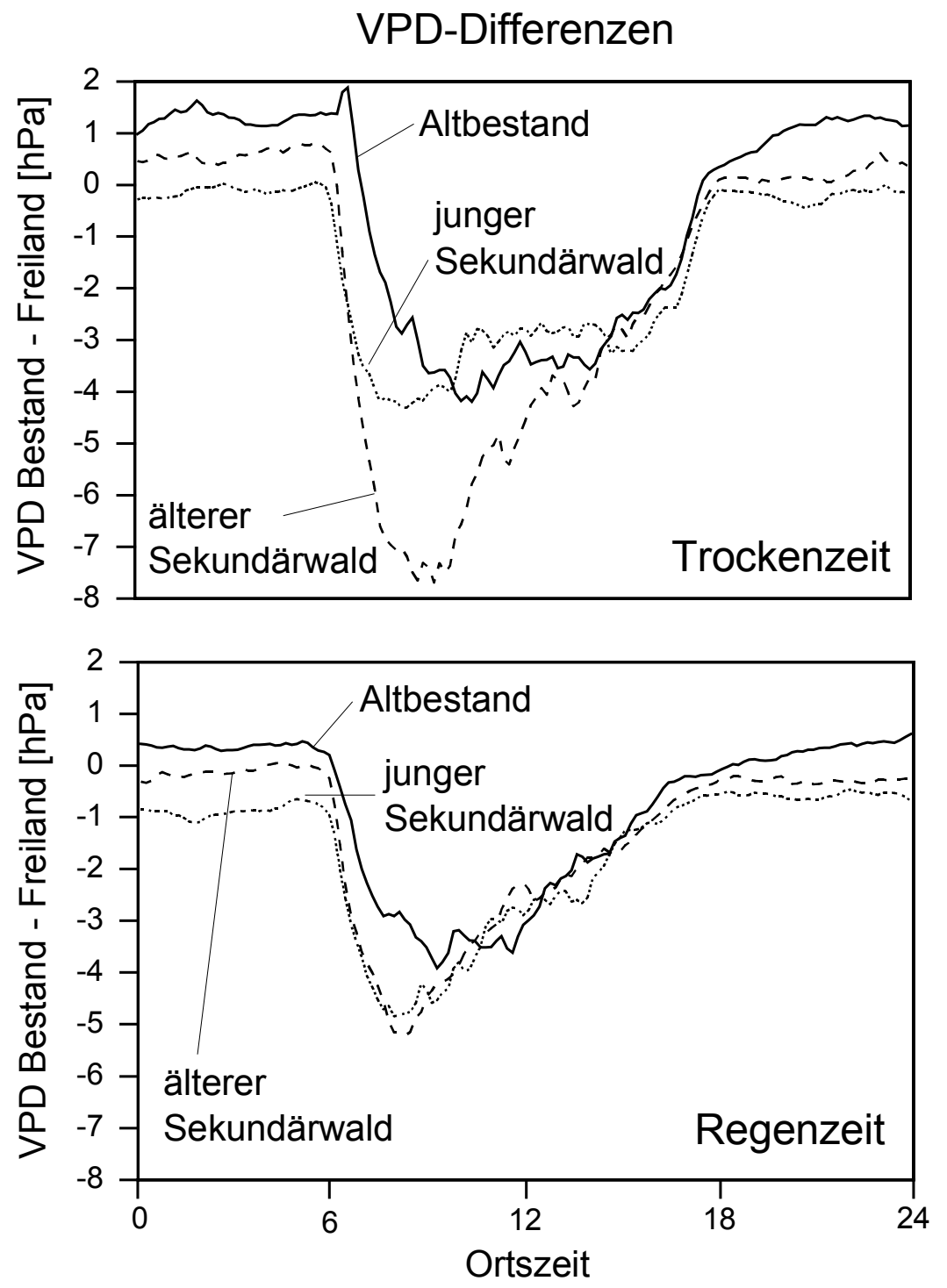

Abb. 4-14: Differenzen zwischen den mittleren Sättigungsdefiziten (VPD) im Freiland und den drei Beständen (innere Kronenregionen). Dargestellt sind für den jungen Sekundärwald die mittleren Tagesverläufe in $3 \mathrm{~m}$ Baumhöhe, für den älteren Sekundärwald in $6 \mathrm{~m}$ Baumhöhe und für den Altbestand in $25 \mathrm{~m}$ Baumhöhe, während der Regen- und der Trockenzeit. 
Die mittlere Piche-Evaporation während drei Tagen in der Trockenzeit liegt im Freiland mit $1.3 \mathrm{~cm}^{3} \mathrm{~h}^{-1}$ deutlich über den im Altbestand gemessenen Werten (Abb. 4-15). Beim Vergleich der unterschiedlichen Bestandeshöhen zeigen sich oberhalb $18 \mathrm{~m}$ sehr einheitliche Bedingungen der potentiellen Verdunstung. So liegen die Werte im Stammbereich $(18 \mathrm{~m})$, sowie in der inneren und äußeren Krone $(25 \mathrm{~m}, 30 \mathrm{~m})$ bei etwa $0.6 \mathrm{~cm}^{3} \mathrm{~h}^{-1}$. Eine um die Hälfte geringere Evaporation wurde hingegen mit $0.3 \mathrm{~cm}^{3} \mathrm{~h}^{-1}$ an der Stammbasis ermittelt. Dies steht im Einklang mit den weiter oben im Kapitel dargestellten mittleren Tagesverläufen der Wasserdampfsättigungsdefizite, bei denen sich in den oberen Straten des Altbestandes ebenfalls ein sehr einheitliches Bild zeigte.

In der Regenzeit waren deutlich geringere Evaporationswerte zu beobachten. So wurden an zwei Tagen im Monat Juni in der inneren Krone des Altbestandes im Mittel $0.26 \mathrm{~cm}^{3} \mathrm{~h}^{-1}$ gemessen, während die entsprechenden Freilandwerte mit $0.37 \mathrm{~cm}^{3} \mathrm{~h}^{-1}$ deutlich höher lagen (ohne Abb.). Während einer zwölftägigen Periode in der Regenzeit, in der bei der Mittelwertberechnung auch die Nachtstunden berücksichtigt wurden, zeigte sich im Bereich der Stammbasen des Altbestandes eine potentielle Verdunstung von $0.02 \mathrm{~cm}^{3} \mathrm{~h}^{-1}$ und von 0.14 $\mathrm{cm}^{3} \mathrm{~h}^{-1}$ im Freiland.

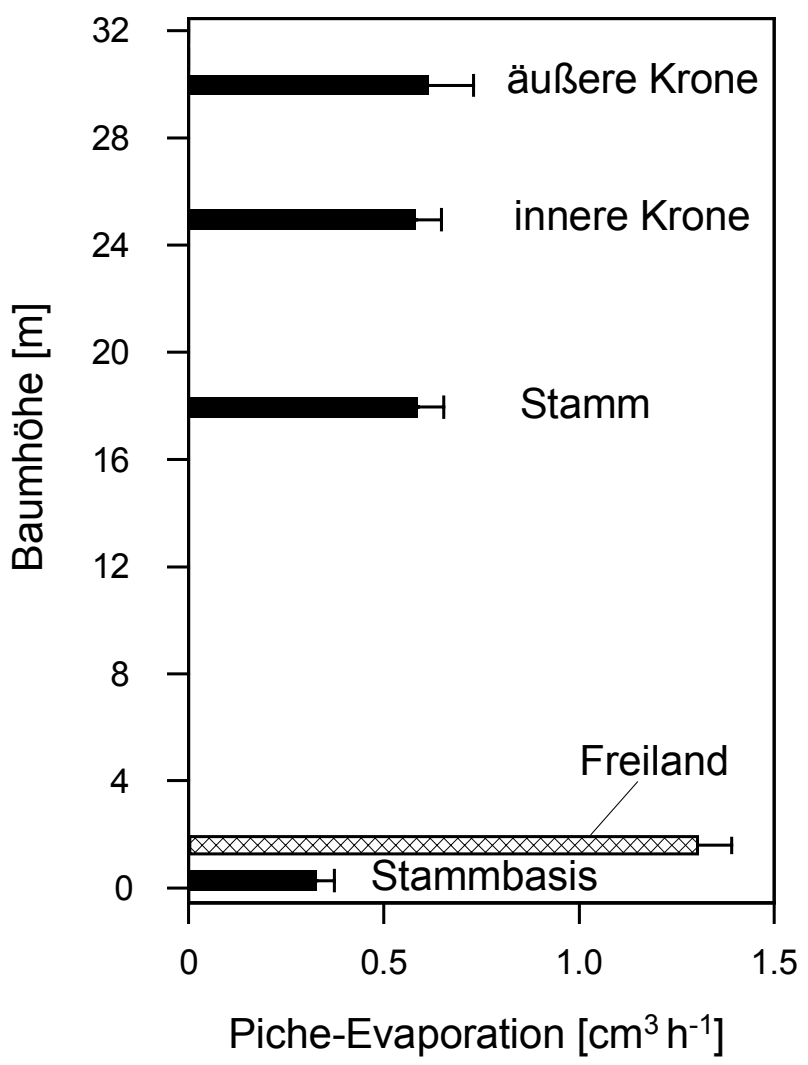

Abb. 4-15: Mittlere Piche-Evaporation in vier unterschiedlichen Baumhöhen des Altbestandes sowie im Freiland. Dargestellt sind die Mittelwerte der Messungen während drei einzelner Tage in der Trockenzeit. Je Meßhöhe wurden zwei bis drei Evaporimeter eingesetzt. Die Evaporationswerte pro Stunde wurden ermittelt, indem jeweils die Gesamtevaporation von $8 \mathrm{Uhr}$ morgens bis $17 \mathrm{Uhr}$ nachmittags durch die Anzahl der Stunden geteilt wurde. 


\subsubsection{Wasserumsatz in den Beständen}

\subsubsection{Bestandesniederschlag, Stammablauf und Interzeption in Jahresmittel}

Die kontinuierliche Aufzeichnung von Freilandniederschlag, Bestandesniederschlag und Stammablauf erfolgte in den drei untersuchten Beständen über einen Zeitraum von mehr als 17 Monaten. Bei der Analyse der jährlichen Niederschlagsverteilung wird hier zunächst der Zeitraum von zwölf Monaten betrachtet, um die Dauer von Trockenzeit und Regenzeit angemessen zu berücksichtigen (Tab. 4-6).

Tab. 4-6: Freilandniederschlag (FN), Bestandesniederschlag (BN), Stammablauf (S) und Interzeption (I) in den drei untersuchten Beständen von Juni 1999 bis Mai 2000. * Angabe der Standardabweichung nicht möglich, da die Berechnung des Gesamt-Stammablaufes auf getrennter Berechnung für Kronenbäume und unterständige Bäume und einer Hochrechnung der Werte für die unterständigen Bäume beruht. Die Standardabweichung beim Stammablauf im jungen Sekundärwald bezieht sich auf $\mathrm{n}=5$ Sammler. Unterschiedliche Buchstaben kennzeichnen signifikante Unterschiede zwischen den Beständen; U-Test nach Wilcoxon ( $<<0.05)$.

\begin{tabular}{lcccccccccccc}
\hline & \multicolumn{3}{c}{ FN [mm] } & \multicolumn{3}{c}{ BN [\% FN] } & \multicolumn{3}{c}{ S [\% FN] } & \multicolumn{2}{c}{ I [\% FN] } \\
& Mw & Stabw & $\mathrm{n}$ & Mw & Stabw & n & Mw & Stabw & n & Mw \\
\hline jung. Sekw. & 2900 & 37.7 & 5 & $69.2^{\mathrm{a}}$ & 32.6 & 30 & 16.1 & 8.9 & $\begin{array}{c}5- \\
10\end{array}$ & 14.7 \\
ält. Sekw. & 2900 & 37.7 & 5 & $74.9^{\mathrm{a}}$ & 23.1 & 30 & 16.5 & $*$ & 10 & 8.6 \\
Altbestand & 2830 & 67.6 & 5 & $72.8^{\mathrm{a}}$ & 18.8 & 30 & 2.2 & $*$ & 10 & 25.0 \\
\hline
\end{tabular}

Der mit jeweils 30 systematisch angeordneten Sammlern gemessene Bestandesniederschlag zeigt im Jahresmittel in allen Beständen Werte zwischen $69 \%$ und $75 \%$ des Freilandniederschlags (Tab 4-6).

Wesentlich größere Unterschiede sind hingegen beim Stammablauf zu beobachten. Im jungen Sekundärwald wurde ein Jahresstammablauf von 16.1\% des Freilandniederschlags gemessen $(n=5-10)$. Überträgt man die etwas höhere Sammelleistung der später installierten fünf zusätzlichen Sammler auf das gesamte Jahr, so beträgt der Stammablauf im jungen Sekundärwald 18.2\%. Im älteren Sekundärwald zeigt sich mit insgesamt 16.5\% ebenfalls ein sehr hoher Wert, wobei die Kronenbäume mit 12.8\% einen deutlich höheren Anteil am Gesamtwert des Stammablaufs als die unterständigen Bäume (3.7\%) aufwiesen. Im Altbestand wurde mit nur $2.2 \%$ des Freilandniederschlags ein deutlich niedrigerer Gesamtwert gemessen. Im Gegensatz zum älteren Sekundärwald tragen hier jedoch die unterständigen Bäume aufgrund ihrer Abundanz mit 1.6\% stärker zum Gesamtstammablauf bei als die Kronenbäume (0.6\%).

Für den jungen Sekundärwald ergibt sich eine Interzeption von $14.7 \%$ des Freilandniederschlags. Der ältere Sekundärwald weist mit 8.6\% die niedrigste, der Altbestand mit $25 \%$ die höchste Interzeption auf. Nach diesen Ergebnissen ist im Altbestand die 
Verdunstung nach Interzeption im Jahresmittel also deutlich höher als in den Sekundärwäldern.

Wird der Stammablauf nicht, wie in Tab. 4-6 dargestellt, auf die Bestandesfläche bezogen, sondern für einzelne in die obere Baumschicht reichende Bäume (Kronenbäume) betrachtet, zeigen sich im Altbestand mit 7491 je Baum und im jungen Sekundärwald mit 7861 je Baum sehr ähnliche Jahressummen ( $\mathrm{n}=5$ je Bestand). Im älteren Sekundärwald weisen die einzelnen Kronenbäume hingegen mit 19691 je Baum $(n=5)$ einen deutlich höheren jährlichen Stammablauf auf.

\subsubsection{Bestandesniederschlag und Stammablauf in monatlicher Auflösung}

Aus dem Vergleich des relativen monatlichen Bestandesniederschlags wird deutlich, daß von April bis November 1999 die Werte in allen drei Beständen zwischen 60\% und $80 \%$ des Freilandniederschlags schwanken (Abb. 4-16). Im Monat Dezember zeigt sich im Altbestand mit fast $85 \%$ der insgesamt höchste Wert. Von Dezember bis Februar sind auffallend große Unterschiede zwischen den beiden Sekundärwäldern $\mathrm{zu}$ beobachten, wobei der Bestandesniederschlag im jungen Sekundärwald deutlich unter den im älteren Bestand gemessenen Werten liegen. In der gleichen Periode zeigen sich auch im monatlichen Stammablauf (Abb. 4-17) im jungen Sekundärwald besonders niedrige Werte im Vergleich zum älteren Sekundärwald.

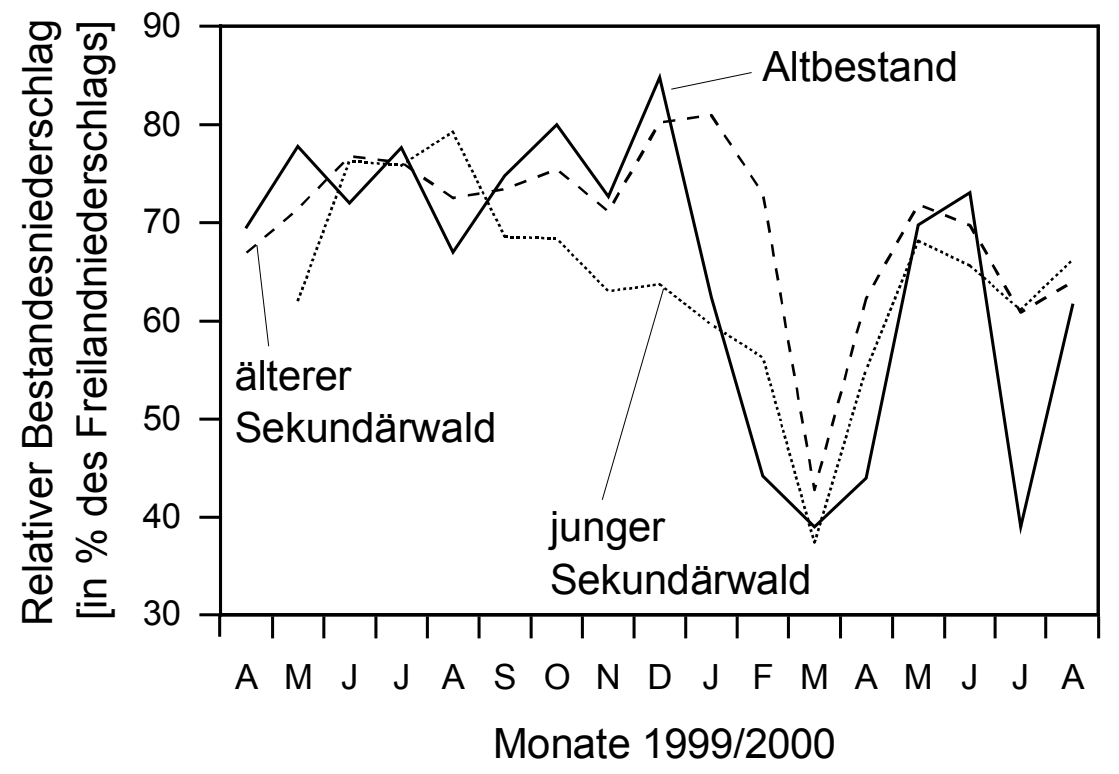

Abb. 4-16: Monatlicher Bestandesniederschlag in den beiden Sekundärwäldern sowie im Altbestand in Prozent des Freilandniederschlags. Dargestellt ist der Untersuchungszeitraum von April 1999 bis August 2000. $\mathrm{n}=30$ je Bestand. 
Allen drei Beständen gemeinsam ist der niedrige relative Bestandesniederschlag in den Trockenzeitmonaten Februar bis April 2000, wobei im März Minima von etwa 40\% erreicht werden (Abb. 4-16). Danach ist ein erneuter Anstieg der Werte zu erkennen. Im Monat Juli 2000, während der Zwischentrockenzeit, zeigt sich ein erneutes Absinken des relativen Bestandesniederschlags mit besonders niedrigen Werten im Altbestand, die vermutlich auf Expositionsunterschiede zwischen den Sekundärwaldflächen und dem Altbestand zurückzuführen sind. Beim Vergleich der beiden Sekundärwaldflächen zeigt sich, daß die Werte im älteren Bestand mit Ausnahme von zwei Monaten höher als im jungen Sekundärwald liegen. Dies entspricht den in Tab. 4-6 dargestellten Verhältnissen der Jahresmittelwerte. Zwischen Altbestand und Sekundärwäldern sind aufgrund der starken monatlichen Variabilität der Werte keine klaren Tendenzen hinsichtlich der Höhe des relativen Bestandesniederschlags zu erkennen.

Der relative monatliche Stammablauf im jungen Sekundärwald zeigt einen ähnlichen Jahresverlauf wie der Stammablauf der Kronenbäume im älteren Sekundärwald (Abb. 4-17). Die Maxima werden mit 23\% im Mai beziehungsweise 20.3\% im Dezember 1999 erreicht. Im Altbestand bleibt der monatliche Stammablauf der Kronenbäume während des gesamten Untersuchungszeitraumes unter einem Prozent des Freilandniederschlags. Wie schon der Bestandesniederschlag zeigt auch der Stammablauf in der Trockenzeit im Monat März die niedrigsten relativen Werte.

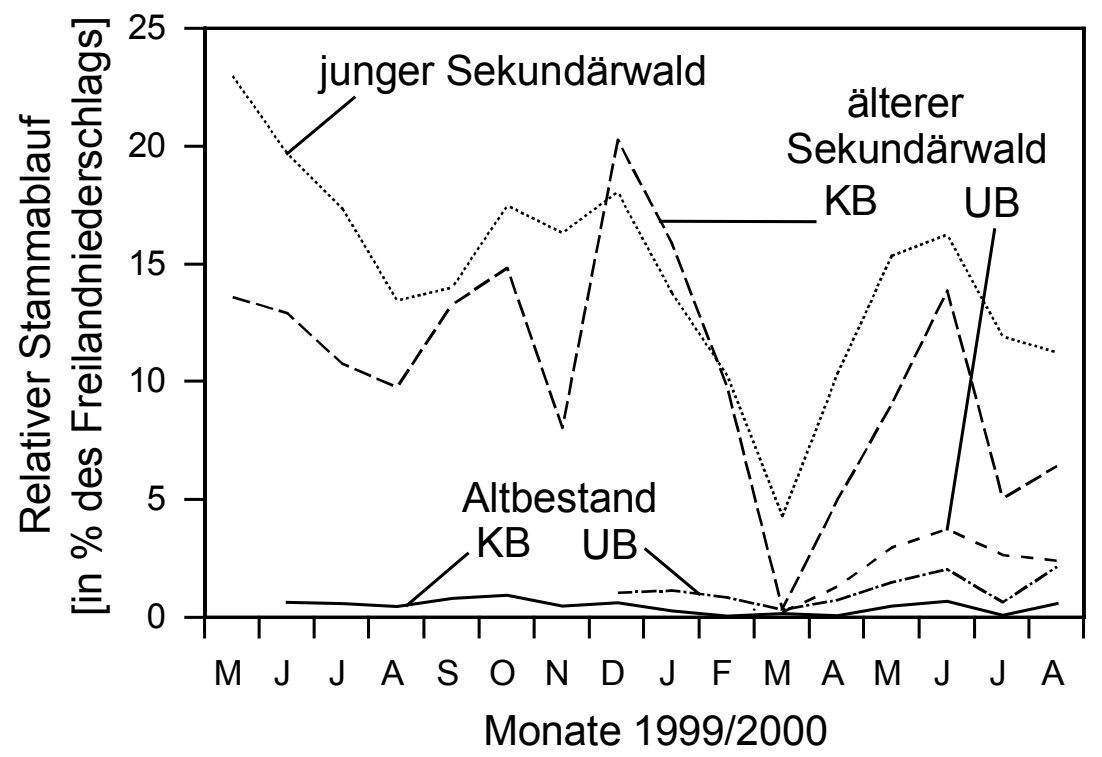

\begin{abstract}
Abb. 4-17: Monatlicher Stammablauf in den drei untersuchten Beständen in Prozent des Freilandniederschlags. Dargestellt ist der Untersuchungszeitraum von Mai 1999 bis August 2000. Im älteren Sekundärwald und im Altbestand wurde zwischen Kronenbäumen (KB) und unterständigen Bäumen (UB) unterschieden, im jungen Sekundärwald reichten alle untersuchten Bäume in die Kronenregion. Die Messungen an unterständigen Bäumen wurden erst ab Dezember bzw. März 2000 durchgeführt. $n=5$ je dargestellter Kurve (beim jungen Sekundärwald ab März $2000 \mathrm{n}=10$ ).
\end{abstract}


Danach ist in allen Beständen ein erneutes Ansteigen der Kurven zu beobachten. In der Zwischentrockenzeit im Juli und August 2000 zeigt sich in allen Waldstadien ein zweites Minimum des relativen Stammablaufs. Im älteren Sekundärwald ist bei den unterständigen Bäumen in allen Monaten ein deutlich höherer relativer Stammablauf als im Altbestand zu erkennen. Im Unterschied zum älteren Sekundärwald übertreffen im Altbestand die Stammablaufwerte der unterständigen Bäume die der Kronenbäume wesentlich. Auch bei den unterständigen Bäumen sind die niedrigsten Werte im Monat März zu finden, wobei ein weiteres Minimum in der Zwischentrockenzeit auftritt.

\subsubsection{Ermittlung der Kronenspeicherkapazität}

Der Zusammenhang zwischen dem täglich gemessenen Nettoniederschlag (= Bestandesniederschlag + Stammablauf) und dem Freilandniederschlag läßt im Altbestand im unteren Wertebereich einen flach ansteigenden Kurvenverlauf erkennen, der eine unvollständige Aufsättigung der Baumkronen widerspiegelt (Abb. 4-18). Bei höheren Freilandniederschlägen ist ein deutlich stärkeres Ansteigen des Nettoniederschlags zu beobachten. Die höheren Nettoniederschlagswerte (einzelne Niederschlagsereignisse, dargestellt als Punkte) lassen einen engen linearen Zusammenhang zwischen Nettoniederschlag und Freilandniederschlag erkennen $(\mathrm{y}=-3.47+0.98 \mathrm{x}, \mathrm{r}=0.999$, $\mathrm{p}=0.02 \%)$.

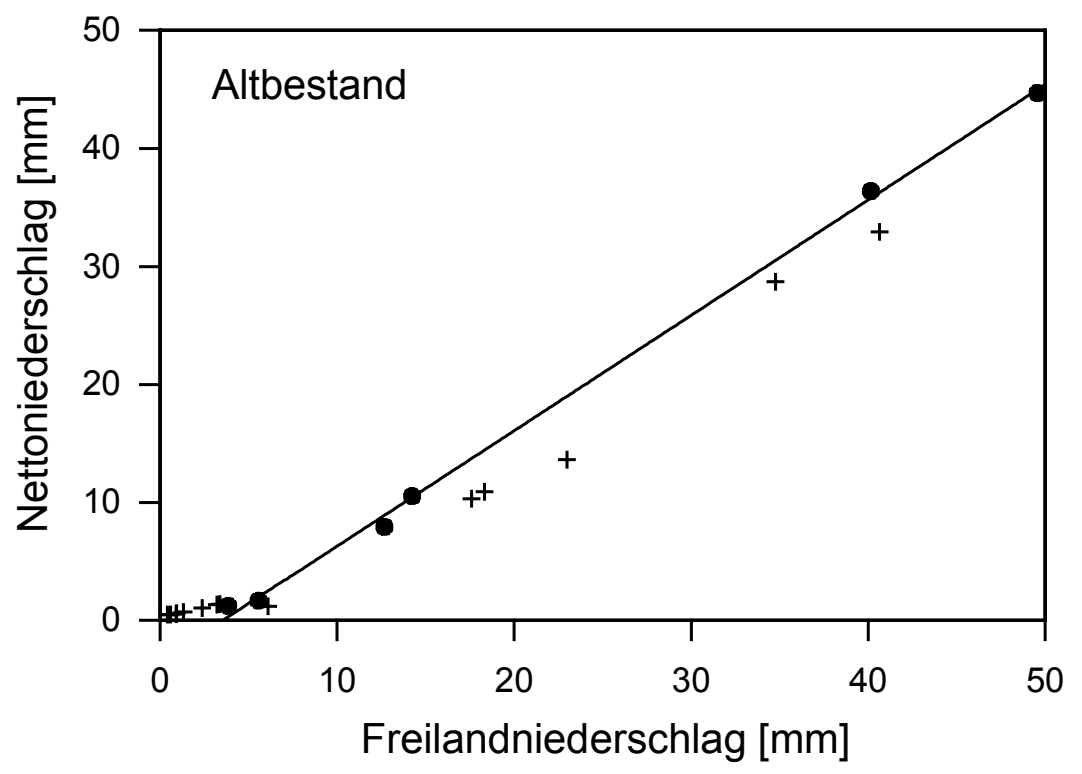

\footnotetext{
Abb. 4-18: Zusammenhang zwischen Freilandniederschlag und Nettoniederschlag im Altbestand während 19 Tagen in der Regenzeit und Zwischentrockenzeit. Die Punkte kennzeichnen Meßwerte, die zur Ermittlung der Kronenspeicherkapazität herangezogen wurden. Werte, die eine unvollständige Kronensättigung oder einzelne Regen- und Trocknungszyklen vermuten lassen (dargestellt durch Kreuze), wurden bei der Berechnung nicht berücksichtigt.
} 
Die Extrapolation dieser Geraden auf die Abzisse ergibt eine Kronenspeicherkapazität von 3.5 $\mathrm{mm}$. Diese Wassermenge kann bei einem Niederschlagsereignis von der trockenen Krone aufgenommen und von dort verdunstet werden, ohne im Bestand einen meßbaren Niederschlag zu bewirken. In den beiden Sekundärwaldstadien ergaben sich geringere Kronenspeicherkapazitäten von $1.6 \mathrm{~mm}$ im jungen Sekundärwald $(\mathrm{y}=-1.62+1.01 \mathrm{x}$, $\mathrm{r}=0.999, \mathrm{p}=0.004 \%)$ und $2.4 \mathrm{~mm}$ im älteren Sekundärwald $(\mathrm{y}=-2.33+0.95 \mathrm{x}, \mathrm{r}=0.999$, $\mathrm{p}=0.018 \%$ ).

\subsubsection{Räumliche Variabilität des Bestandesniederschlags}

Die Häufigkeitsverteilung des Bestandesniederschlags nach Größenklassen des Freilandniederschlags ist in Abb. 4-19 dargestellt. Im jungen Sekundärwald liegt der Bestandesniederschlag während einer vierzehntägigen Periode in der Regenzeit zu 40\% in der Größenklasse 40 bis $60 \%$. Im älteren Sekundärwald hingegen ist die Klasse 60 bis $80 \%$ mit über $40 \%$ am stärksten vertreten. Das gleiche Bild zeigt sich auch im Altbestand, wobei hier jedoch die Häufigkeit des innerhalb dieses Bereichs auftretenden Bestandesniederschlags deutlich höher liegt. Die Ergebnisse lassen erkennen, daß es mit zunehmendem Bestandesalter $\mathrm{zu}$ einer Verschiebung des Verteilungsmusters des Bestandesniederschlags in Richtung höherer Größenklassen kommt, wobei die größte Schwankungsbreite des Bestandesniederschlags im jungen Sekundärwald $\mathrm{zu}$ beobachten ist. So beträgt der Variationskoeffizient in diesem Bestand 53\%, während er im älteren Sekundärwald (30\%) und im Altbestand (26\%) deutlich niedriger liegt.

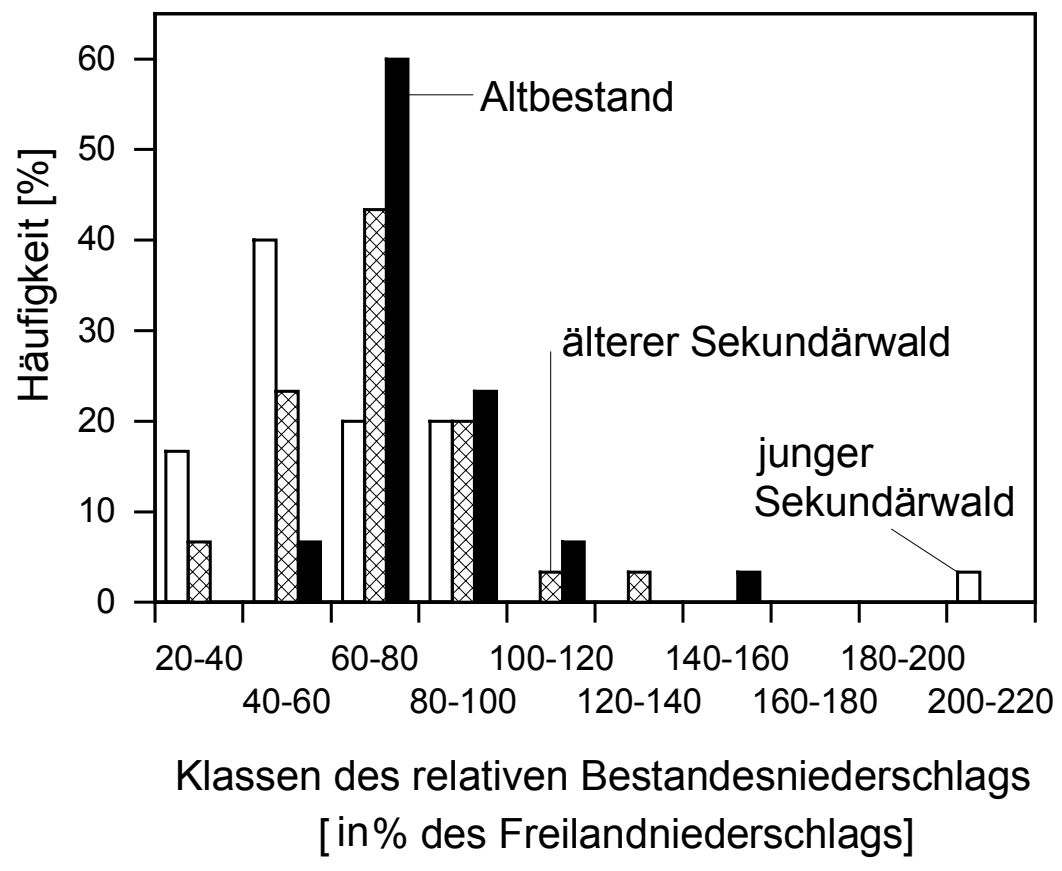

Abb. 4-19: Häufigkeitsverteilung des Bestandesniederschlags nach Größenklassen [in \% des Freilandniederschlags] in den drei untersuchten Beständen. Dargestellt sind die Mittelwerte von 14 täglich durchgeführten Niederschlagsmessungen während der Regenzeit. $\mathrm{n}=30$ Sammler je Bestand. 
Die Variabilität des Bestandesniederschlags ist in der Regel von der Höhe des Freilandniederschlags abhängig. So zeigen sich die größten Schwankungen bei geringem Freilandniederschlag, während starke Niederschlagsereignisse im Freiland meist eine homogenere Verteilung des Bestandesniederschlags zur Folge haben (ohne Abb.).

\subsubsection{Zusammenhang zwischen Bestandesstruktur und Niederschlag}

Eine negative Korrelation zwischen dem in jedem einzelnen Sammler gemessenen Bestandesniederschlag und der direkt darüber ermittelten Blattfläche konnte im Monat Februar 2000 zur Zeit der LAI-Messungen im jungen Sekundärwald gefunden werden $(\mathrm{y}=4.56-0.02 \mathrm{x}, \mathrm{r}=-0.54, \mathrm{p}=0.23 \%)$. Ein ähnlicher Zusammenhang zwischen dem LAI und dem Bestandesniederschlag zeigt sich auch im Jahresmittel. Im älteren Sekundärwald und im Altbestand konnte hingegen keine Abhängigkeit des Bestandesniederschlags je Sammler von der darüber gemessenen Blattfläche gefunden werden.

Um Zusammenhänge zwischen der Blattfläche und der Höhe des Stammablaufs zu untersuchen, wurde im jungen Sekundärwald bei vier Bäumen eine Totalernte der Blätter durchgeführt. Im belaubten Zustand wiesen die Bäume im zweiwöchigen Mittel einen Stammablauf von etwa 11\% (Stabw 6.8) des Freilandniederschlags auf (Abb. 4-20). Nach der Entlaubung fiel dieser Wert im Mittel von zwei Wochen um fast das Achtfache auf 1.4\% (Stabw 1.1) des Freilandniederschlags. Als Referenz dienten fünf weitere Bäume (Kontrollvariante), an denen zeitgleich der Stammablauf gemessen wurde, aber keine Entlaubung stattfand.

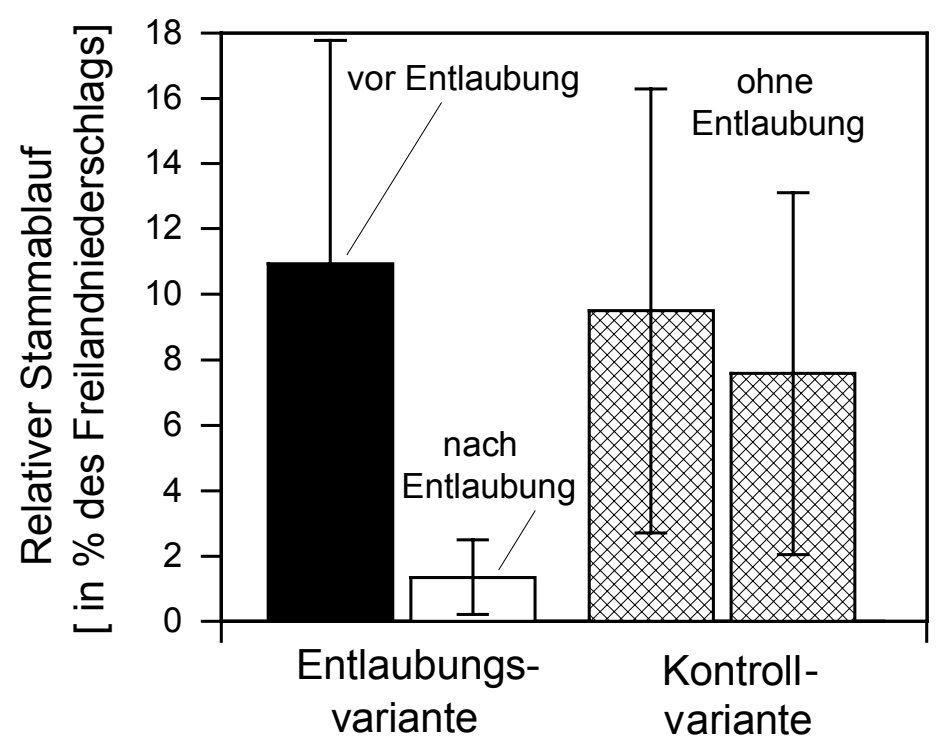

Abb. 4-20: Relativer Stammablauf im jungen Sekundärwald während zwei Wochen vor und zwei Wochen nach Entlaubung der Bäume ( $\mathrm{n}=$ 4). Schraffiert dargestellt ist eine zeitgleich gemessene Kontrollvariante $(\mathrm{n}=5)$. 
Im zweiwöchigen Mittel wurde ein Stammablauf von 9.5\% (Stabw 6.8) registriert. In den zwei darauffolgenden Wochen war allerdings auch hier eine Abnahme der Werte auf 7.6\% (Stabw 5.5) zu beobachten, obwohl keine Blatternte durchgeführt wurde. Dies deutet darauf hin, daß im Fall der entlaubten Varianten nicht die gesamte Verminderung des Stammablaufs auf den Blattverlust zurückgeführt werden kann, sondern daß hier auch andere Faktoren wie beispielsweise die relativ geringen Niederschläge in den beiden letzten Untersuchungswochen eine Rolle spielten. Da die Abnahme des Stammablaufs im Fall der nicht entlaubten Varianten jedoch wesentlich geringer war, deuten die Untersuchungsergebnisse auf einen positiven Zusammenhang zwischen der Blattmasse und der Höhe des Stammablaufs hin.

Bei fünf Bäumen wurden nach der Totalernte der Blattmasse die Blattfläche und das Trockengewicht der Blätter bestimmt. Auch hier zeigte sich, daß Bäume, an denen zuvor ein hoher Stammablauf gemessen wurde, über eine tendenziell größere Blattfläche und Blattmasse verfügten als Bäume mit geringem Stammablauf (ohne Abb.). Diese Befunde lassen sich jedoch nicht statistisch absichern.

Ein wichtiger Faktor, der die Menge des Stammablaufs an Einzelbäumen bestimmt, ist dessen Position im Bestand (Kronenbaum oder unterständiger Baum). An Kronenbäumen wurde im älteren Sekundärwald ein im Mittel um den Faktor 5.5 höherer und im Altbestand ein 5.3mal größerer Wasserfluß als an unterständigen Bäumen des jeweiligen Bestandes gemessen. Daß die unterständigen Bäume im Altbestand auf Bestandesebene mehr zum Gesamtstammablauf beitragen als die Kronenbäume (Kap. 4.2.3.1), ist auf deren große Häufigkeit zurückzuführen. Bei Bäumen der oberen Baumschicht wurde der höchste Stammablauf im älteren Sekundärwald an einem Quercus copeyensis-Baum mit 2907 Litern im Zeitraum eines Jahres gemessen. Hier wurde auch die höchste wöchentliche Wassermenge mit 400 Litern verzeichnet. Im jungen Sekundärwald zeigte sich die höchste Sammelleistung bei Myrsine spec. mit 1428 Litern in einem Jahr. Im Altbestand betrug der an einem Baum (Quercus copeyensis) gemessene maximale Stammablauf 1097 Liter im Zeitraum eines Jahres, wobei es sich hier ebenfalls um einen Kronenbaum handelte.

Im älteren Sekundärwald und im Altbestand zeigt sich eine positive Korrelation zwischen dem BHD und des Höhe des Stammablaufs $(\mathrm{y}=18.35+0.06 \mathrm{x}, \mathrm{r}=0.89, \mathrm{p}=0.1 \%$ und $\mathrm{y}=-$ $2.45+0.9 \mathrm{x}, \mathrm{r}=0.92, \mathrm{p}=0.04 \%$ ), während im jungen Sekundärwald dieser Zusammenhang nicht zu beobachten ist (ohne Abb.). Im Altbestand ist außerdem eine positive Abhängigkeit des Stammablaufs von der Baumhöhe zu beobachten $(\mathrm{y}=7.69+0.1 \mathrm{x}, \mathrm{r}=0.89, \mathrm{p}=0.09 \%)$. $\mathrm{Da}$ diese Zusammenhänge nur innerhalb der einzelnen Bestände und nicht bestandesübergreifend bestehen, deutet ebenfalls darauf hin, daß in erster Linie die Position der Bäume (Krone oder unterständig) für die Höhe des Stammablaufs entscheidend ist und die Strukturparameter BHD und Baumhöhe nur in indirektem Zusammenhang mit der Höhe des Stammablaufs stehen. Zwischen der Rindenstruktur der Meßbäume und dem Stammablauf ist keine eindeutige Abhängigkeit zu erkennen. Anhand der Beobachtungen läßt sich ferner keine klare Aussage bezüglich der unterschiedlichen Sammeleffizienz der verschiedenen Baumarten treffen. 


\subsection{Wasserhaushalt der Epiphyten, Blattmasse und Eichenborke}

\subsubsection{Potentielle Wasseraufnahme der Epiphyten im Altbestand}

Die experimentelle Beregnung des Hängemooses Pilotrichella flexilis und des Polstermooses Leptodontium exasperatum mit unterschiedlichen Wassermengen von 0.6 bis $111 \mathrm{ml}$ zeigt den Verlauf einer Sättigungskurve (Abb. 4-21). Bezogen auf die projizierte Fläche, die diese Epiphyten in ihrer natürlichen Lagerung überdecken, entsprechen die Beregnungsmengen etwa Niederschlägen von 0.1 bis $20 \mathrm{~mm}$.

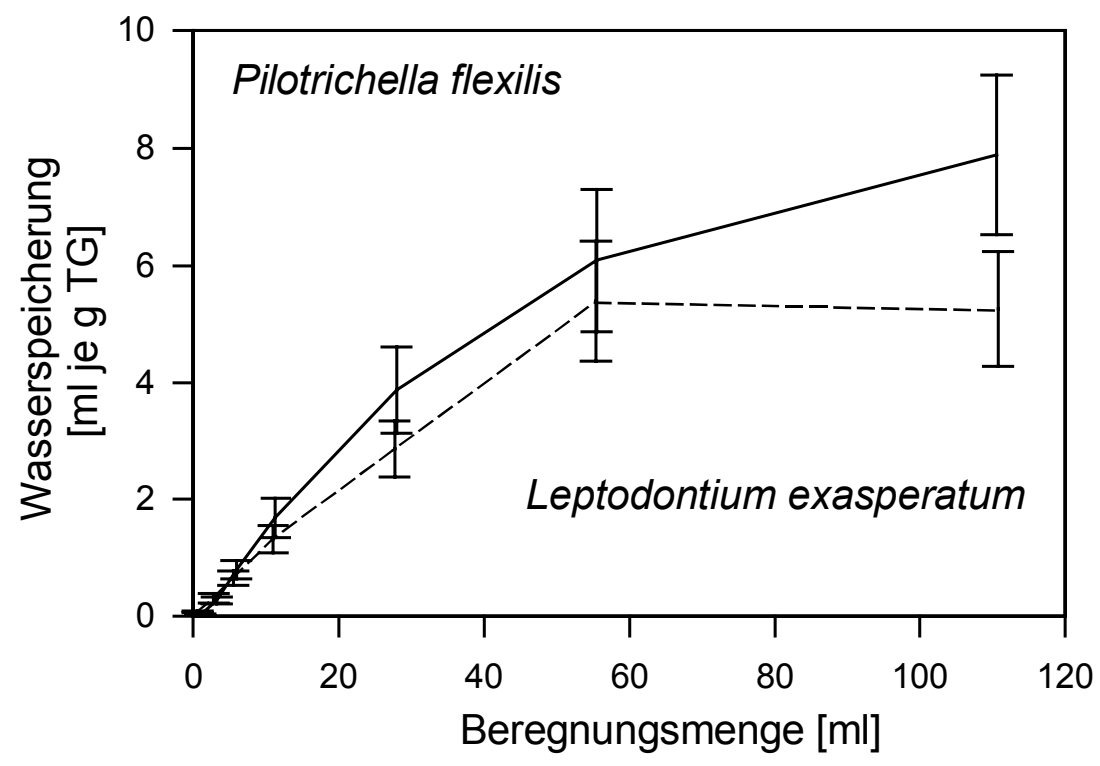

Abb. 4-21: Wasserspeicherung der Moosarten Pilotrichella flexilis und Leptodontium exasperatum bei experimenteller Beregnung mit unterschiedlichen Regenmengen. $\mathrm{n}=8$ je Art und Beregnungsstufe.

Beide Kurven zeigen zu Beginn einen steilen Anstieg und werden im weiteren Verlauf zunehmend flacher. Bei allen Beregnungsstufen weist Pilotrichella eine höhere Wasserspeicherung als Leptodontium auf. Die Interpolation des linearen Kurvenabschnittes auf die Ordinate ergibt die maximale Wasserspeicherkapazität der Epiphyten. Diese beträgt bei Leptodontium etwa $5.5 \mathrm{ml}$ je Gramm Trockengewicht. Bei Pilotrichella liegt der Achsenschnittpunkt bei etwa $8 \mathrm{ml}$ je Gramm Trockengewicht und damit deutlich höher, obwohl die Kurve noch keinen vollständigen Sättigungsverlauf zeigt. 
Analog zu der experimentellen Beregnung der Moose wurde die Beregnung bei Trieben von Quercus copeyensis und Blättern von Oreopanax spec. durchgeführt (Abb. 4-22). Im Gegensatz zu den Moosen reichen hier Wassermengen von $15 \mathrm{ml}$ bereits aus, um eine Sättigung zu bewirken. Die maximale Wasserspeicherkapazität je Gramm Trockengewicht beträgt bei Oreopanax, bedingt durch das hohe spezifische Blattgewicht, nur etwa $0.6 \mathrm{ml}$, während sie bei Quercus bei etwa $1 \mathrm{ml}$ liegt.

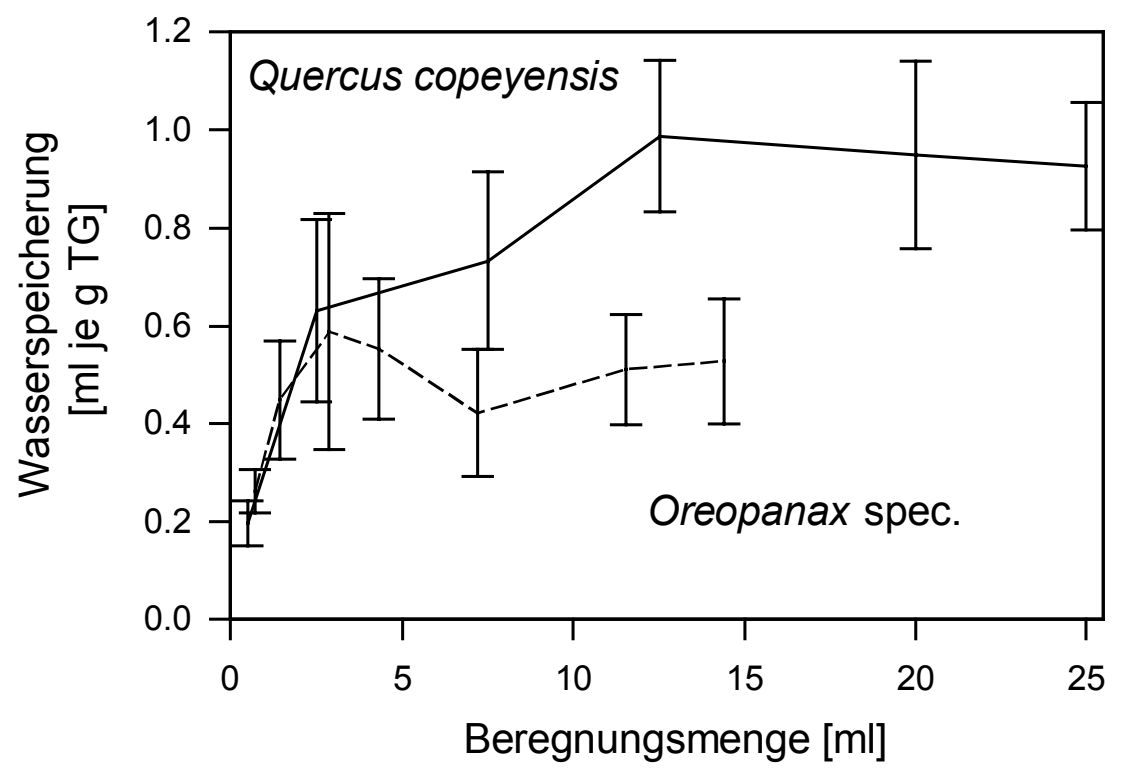

\begin{abstract}
Abb. 4-22: Wasserspeicherung der Blätter von Oreopanax spec. und der Triebe von Quercus copeyensis bei experimenteller Beregnung mit unterschiedlichen Regenmengen. Bei Oreopanax $\mathrm{n}=8$, bei Quercus $\mathrm{n}=5$ je Beregnungsstufe.
\end{abstract}

Auf die Blattfläche der Versuchspflanzen bezogen, ergibt sich bei Quercus eine maximale Wasserspeicherkapazität von etwa $0.14 \mathrm{~mm}$ und bei Oreopanax von $0.11 \mathrm{~mm}$. Auffällig sind die Wendepunkte im Kurvenverlauf. Diese kommen zustande, wenn bei einer Beregnungsstufe die kritische Wassermenge, die auf einem Blatt gespeichert werden kann, überschritten wird. Das Blatt neigt sich dann soweit, daß ein Großteil des auf der Oberfläche befindlichen Wassers abfließen kann, was eine geringere Speicherung bei höherer Beregnung zur Folge hat. 


\subsubsection{Aktuelle Wassergehalte der Epiphyten im Altbestand}

Der aktuelle monatliche Wassergehalt des epiphytischen Polstermooses Leptodontium exasperatum, gemessen in der Kronenregion des Altbestandes, zeigt deutliche saisonale Schwankungen (Abb. 4-23). Im Monat Dezember wurde mit einem Wassergehalt von 406\% der insgesamt höchste Wert gemessen. Danach ist eine stetige Abnahme der Werte zu beobachten, wobei das Minimum mit 24\% im Trockenzeitmonat März erreicht wird. In den Folgemonaten ist ein erneuter Anstieg der Werte zu erkennen. In der Zwischentrockenzeit im Monat Juli treten mit nur 38\% ähnlich niedrige Werte wie in der Trockenzeit auf. Im Monat August ist wieder ein deutlich höherer Wassergehalt zu beobachten. Ein sehr ähnliches Bild zeigt der aktuelle monatliche Wassergehalt des epiphytischen Farnes Elaphoglossum spec. Allerdings sind hier im Jahresverlauf geringere Schwankungen des Wassergehalts zu erkennen. Der höchste Wert wird mit 267\% im Dezember erreicht, während das Minimum mit 42\% im Monat März gemessen wurde. So liegt der aktuelle Wassergehalt von Elaphoglossum in der Trockenzeit von Januar bis März und in der Zwischentrockenzeit im Juli über den bei Leptodontium gemessenen Werten. In den übrigen Monaten zeigt sich ein gegensätzliches Bild mit höheren Werten bei Leptodontium.

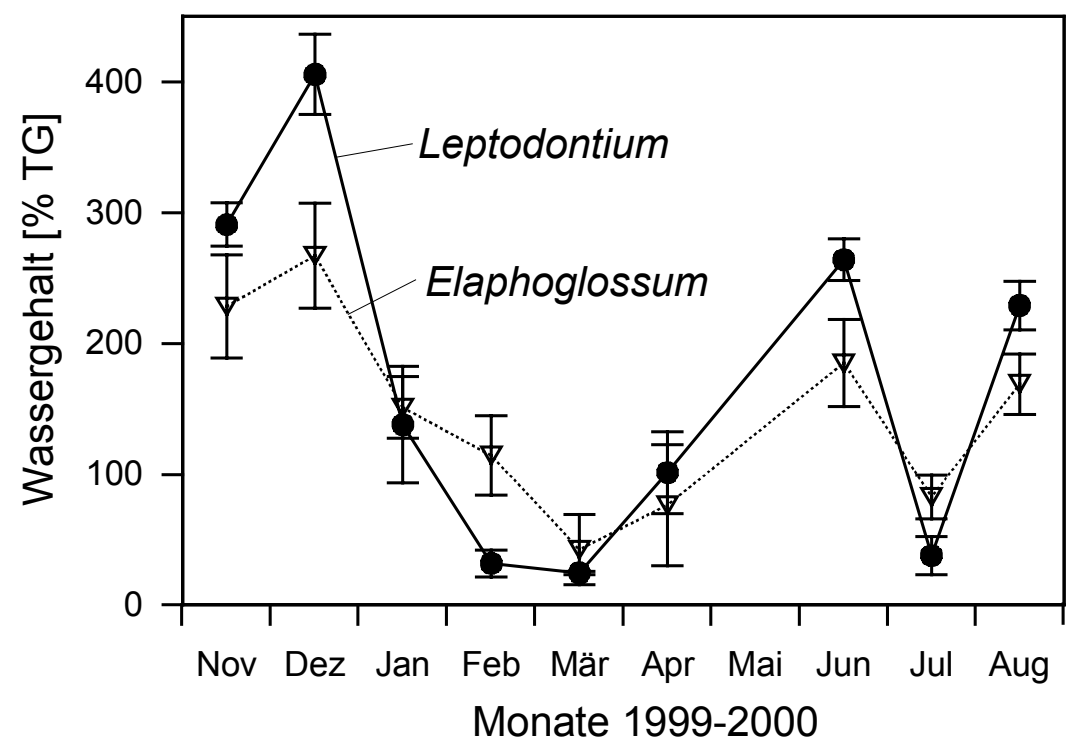

Abb. 4-23: Aktueller monatlicher Wassergehalt des epiphytischen Polstermooses Leptodontium exasperatum und des epiphytischen Farnes Elaphoglossum spec. in der Kronenregion des Altbestandes von November 1999 bis August 2000. $n=6-10$ je Probetermin und Art. 
Neben der saisonalen Variabilität des aktuellen Wassergehalts der Epiphytenvegetation können auch die einzelnen Epiphytenarten in ihren verschiedenen Pflanzenteilen sehr unterschiedliche Wassergehalte speichern (Abb. 4-24, A, B). So zeigt der Humus- und Rhizoid-Anteil eines Leptodontium-Moospolsters in der Trockenzeit einen etwa viermal höheren Wassergehalt als der photosynthetisch aktive Bereich. Ähnliches gilt auch für Blätter der Bromelie Vriesea orosiensis. Die unteren, chlorophyllosen Bereiche der Blätter weisen einen deutlich höheren Blattwassergehalt als die oberen photosynthetisch aktiven Blattabschnitte auf. Insgesamt liegen die Wassergehalte von Vriesea in der Trockenzeit um ein Vielfaches über den bei Leptodontium gemessenen Werten. Die Ursache hierfür ist vermutlich, daß Vriesea über ein effektiveres Abschlußgewebe verfügt und so zu einer besseren Regulation des internen Wasserhaushaltes fähig ist, während Leptodontium als poikilohydrer Organismus sich weniger gut gegen Austrocknung schützen kann.
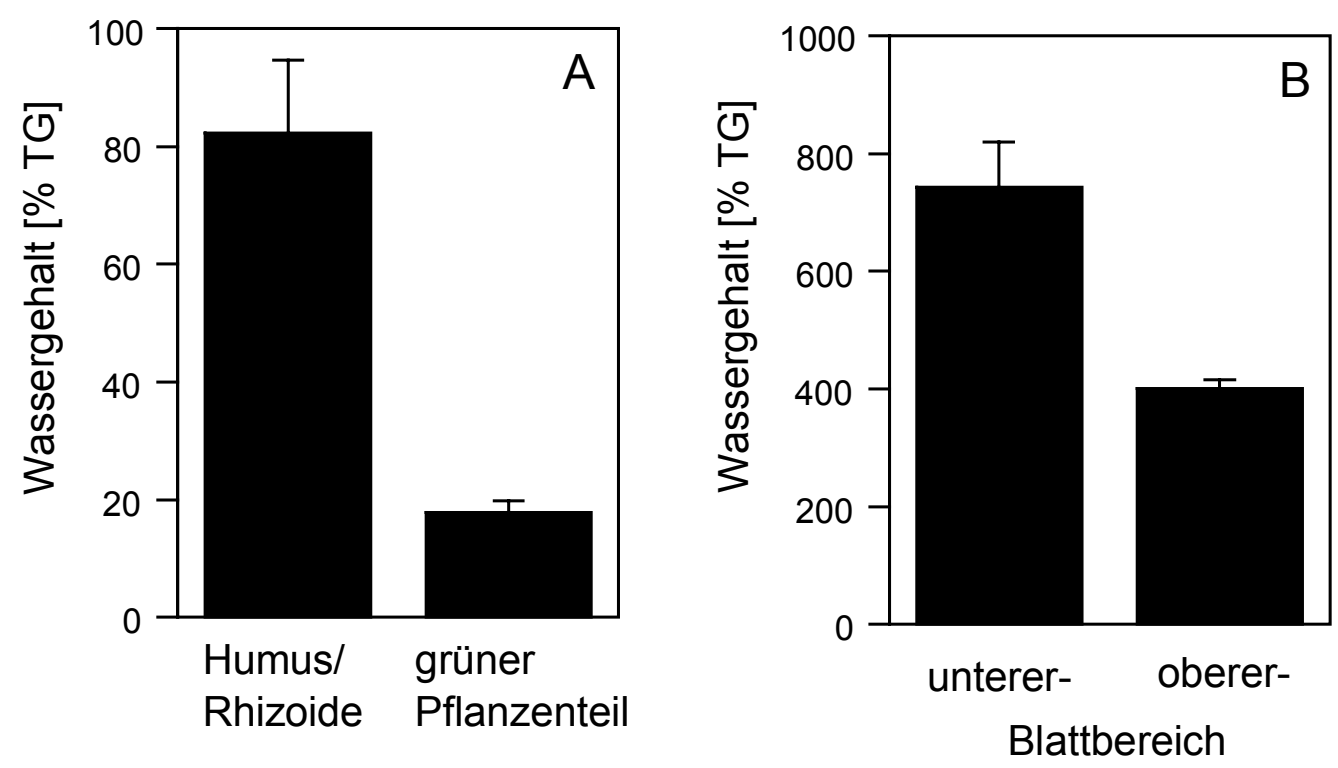

Abb. 4-24 A, B: Aktueller Wassergehalt mehrerer Leptodontium-Moospolster im Februar 2000 (Trockenzeit) im Altbestand $(n=5)(A)$. Der Wassergehalt ist für den Humus- und Rhizoid-Anteil und den photosynthetisch aktiven, grünen Teil der Polster gesondert dargestellt. In Grafik B ist für den gleichen Monat der Blattwassergehalt der unteren Bereiche von Bromelienblättern (Vriesea orosiensis) und der photosynthetisch aktiven oberen Blattabschnitte dargestellt. $\mathrm{n}=5$. 


\subsubsection{Wasserspeicherkapazität von Bromelien}

Zwischen dem Durchmesser der Blattrosetten von Vriesea orosiensis (Bromeliaceae) und der experimentell ermittelten Wasserspeicherkapazität der Phytotelmen ist eine positiv exponentielle Abhängigkeit $\mathrm{y}=(0.025 \mathrm{x}+1)^{8.5} \mathrm{zu}$ beobachten (Abb. 4-25). Bei den größten Individuen wurde dabei eine maximale Wasserspeicherkapazität von $750 \mathrm{ml}$ gemessen. Nach einer Auszählung der Bromelien in der oberen Baumschicht des Altbestandes wird die Anzahl der großen Exemplare ( $>40 \mathrm{~cm}$ Rosettendurchmesser) auf $4484 \mathrm{ha}^{-1}$, die der mittelgroßen Exemplare (10-40 cm Durchmesser) auf 2596 ha $^{-1}$ geschätzt. Unter Berücksichtigung der mittleren maximalen Wasserspeicherkapazität dieser Größenklassen ergibt die Hochrechnung auf Bestandesebene eine maximale Speicherkapazität der Bromelien im Altbestand von 0.25 mm. Diese Wassermenge kann während eines einzigen Niederschlagsereignisses in den Phytotelmen gespeichert werden. Im älteren Sekundärwaldbestand wird die maximale Wasserspeicherkapazität der Bromelien auf unter $0.05 \mathrm{~mm}$ geschätzt, während sie im jungen Sekundärwald vernachlässigt werden kann.

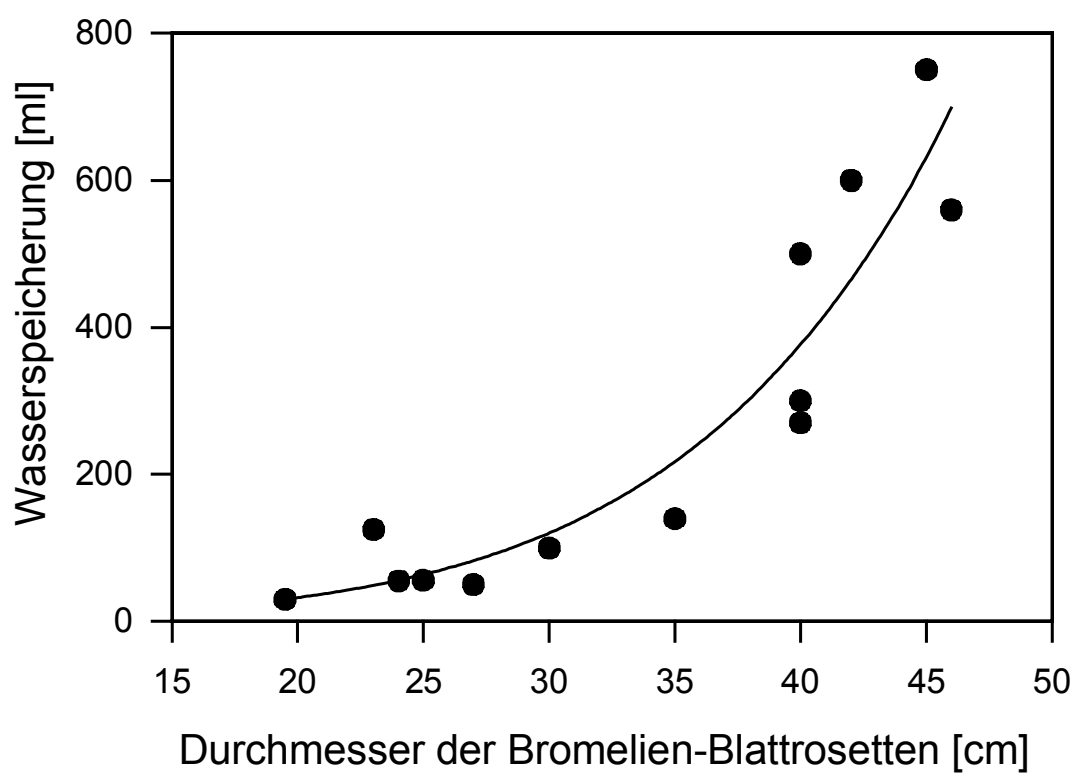

Abb. 4-25: Experimentell ermittelte Wasserspeicherkapazität der Phytotelmen von Vriesea orosiensis (Bromeliaceae) in der Kronenregion des Altbestandes. $\mathrm{y}=(0.025 \mathrm{x}+1)^{8.5}, \mathrm{r}^{2}=0.87, \mathrm{p}=$ $0.003 \% . \mathrm{n}=13$. 


\subsubsection{Auskämmen von Nebel und horizontalem Regen durch die Moosvegetation}

Die Niederschlagsmenge in Regensammlern mit experimentell angebrachten Hängemoosen (Pilotrichella flexilis) auf der Freifläche des Altbestandes unterscheidet sich zum Teil deutlich von der in Regensammlern ohne Moose gemessenen Niederschlagsmenge (Abb. 4-26). Im Januar 2000 (Trockenzeit) schwanken die Werte während einer Derrame-Wetterlage mit horizontalen Niederschlägen zwischen $35 \%$ und $185 \%$ des Freilandniederschlags. Unter diesen Bedingungen bewirken die Moose durch ihre große Oberfläche einen zusätzlichen Wassereintrag. Bei vertikalem Niederschlag während mehrerer Regenzeittage im Mai 2000 liegen alle im Versuch gemessenen Niederschlagsmengen deutlich unter den Freilandwerten, da durch die Interzeption der Moose ein Teil des Wassers verloren geht. Diese Ergebnisse zeigen, daß die Moose bei bestimmten Wetterlagen zu einer deutlichen Erhöhung des Niederschlags führen können. Im nahegelegenen Altbestand wurde während derselben Derrame-Wetterlage an zwei Tagen ein hoher mittlerer Bestandesniederschlag von 110 und $114 \%$ des Freilandniederschlags gemessen, während in der in Abb. 4-26 dargestellten Regenzeitperiode der täglich im Altbestand quantifizierte Bestandesniederschlag $89 \%$ nicht überschritt. So konnte der im Experiment ermittelte zusätzliche Wassereintrag durch horizontalen Niederschlag auch im Bestand gemessen werden.

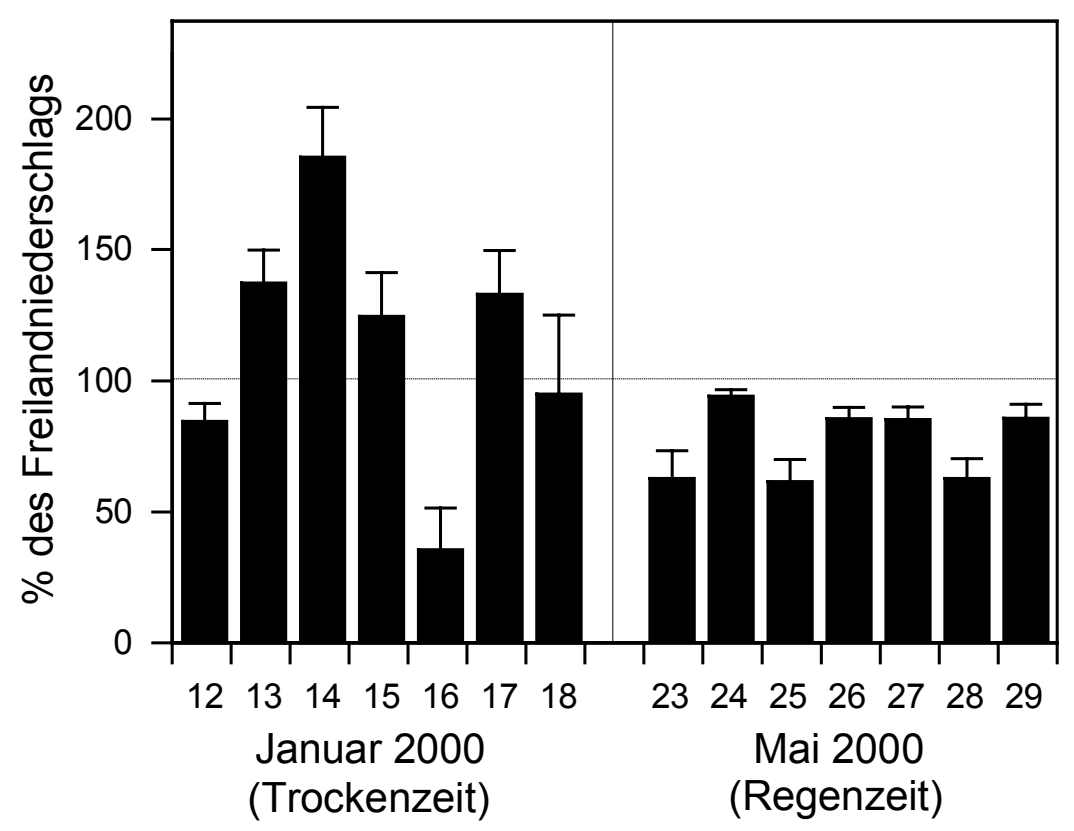

Abb. 4-26: Niederschlag in Regensammlern mit experimentell angebrachten Moosen (Pilotrichella flexilis) im relativen Verhältnis zum Niederschlag in Regensammlern ohne Moose (=Freilandniederschlag) während einzelner Tage in der Trockenzeit (Januar, Derrame-Wetterlage) und in der Regenzeit (Mai). $\mathrm{n}=5$ in der Trockenzeit, $\mathrm{n}=7$ in der Regenzeit. 
Ausgeprägte Derrame-Wetterlagen, bei denen es $\mathrm{zu}$ einem meßbaren zusätzlichen Wassereintrag durch horizontale Niederschläge kommt, traten im Untersuchungsgebiet jedoch nur relativ selten auf (Abb. 4-27). Während 25 Untersuchungswochen lag der Niederschlag in den Regensammlern mit experimentell angebrachten Moosen nur bei zwei wöchentlichen Leerungsterminen über den im Freiland ermittelten Werten. Auffallend ist, daß beide Termine in der Trockenzeit lagen, die sich sonst durch besonders niedrige relative Niederschlagsmengen auszeichnet. Außerhalb der Trockenzeit überwiegen Werte zwischen 75\% und 95\% des wöchentlichen Freilandniederschlags.

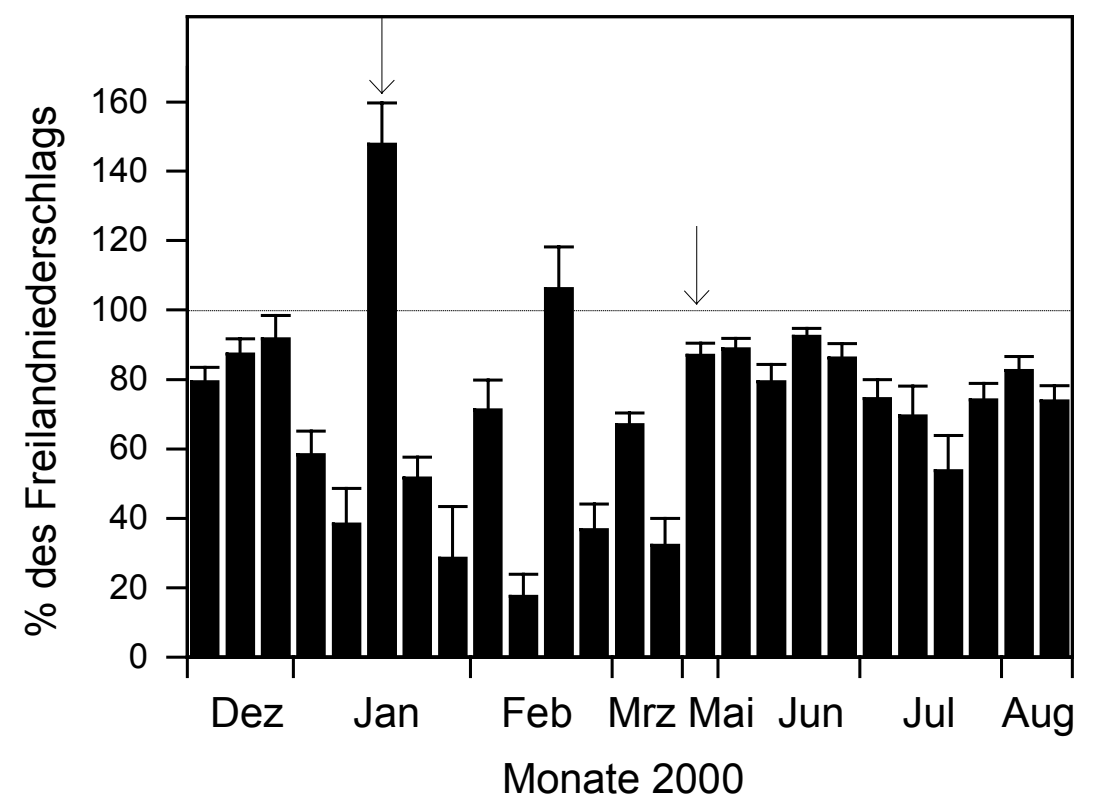

Abb. 4-27: Niederschlag in Regensammlern mit experimentell angebrachten Moosen (Pilotrichella flexilis) im relativen Verhältnis zum Niederschlag in Regensammlern ohne Moose (=Freilandniederschlag) in wöchentlicher Auflösung. Die Pfeile kennzeichnen die in Abb. 4-26 dargestellten Untersuchungsperioden im Januar und Mai 2000.

\subsubsection{Wasserrückhaltevermögen der Moose, Flechten und Baumborke}

Die Austrocknungskurven verschiedener Epiphyten des Altbestandes lassen in der Regenzeit und in der Trockenzeit deutliche Unterschiede in ihrem Kurvenverlauf erkennen (Abb. 4-28). Das Hängemoos Pilotrichella flexilis ist in der Trockenzeit bereits nach vier Stunden auf etwa 6\% seiner maximalen Wasseraufnahmekapazität ausgetrocknet. Danach bleiben die Werte auf einem konstanten Niveau und es ist keine weitere Austrocknung zu erkennen. In der Regenzeit ist ein wesentlich flacherer Kurvenverlauf und damit eine langsamere Wasserabgabe zu beobachten, wobei der Wassergehalt nur bis auf 26\% des Ausgangswertes absinkt. Eine weitere Austrocknung wurde durch den in den Mittagsstunden einsetzenden Regen verhindert. Sehr ähnliche Austrocknungskurven zeigen sich bei der Makroflechte 
Sticta ferax. In der Trockenzeit werden bereits nach kurzer Zeit Wassergehalte von etwa 11\% der maximalen Wasseraufnahmekapazität erreicht, danach findet keine weitere Wasserabgabe statt. In der Regenzeit bleiben die Werte bei etwa 40\% auf einem konstanten Niveau und zeigen trotz ausbleibenden Regens keine weitere Abnahme.

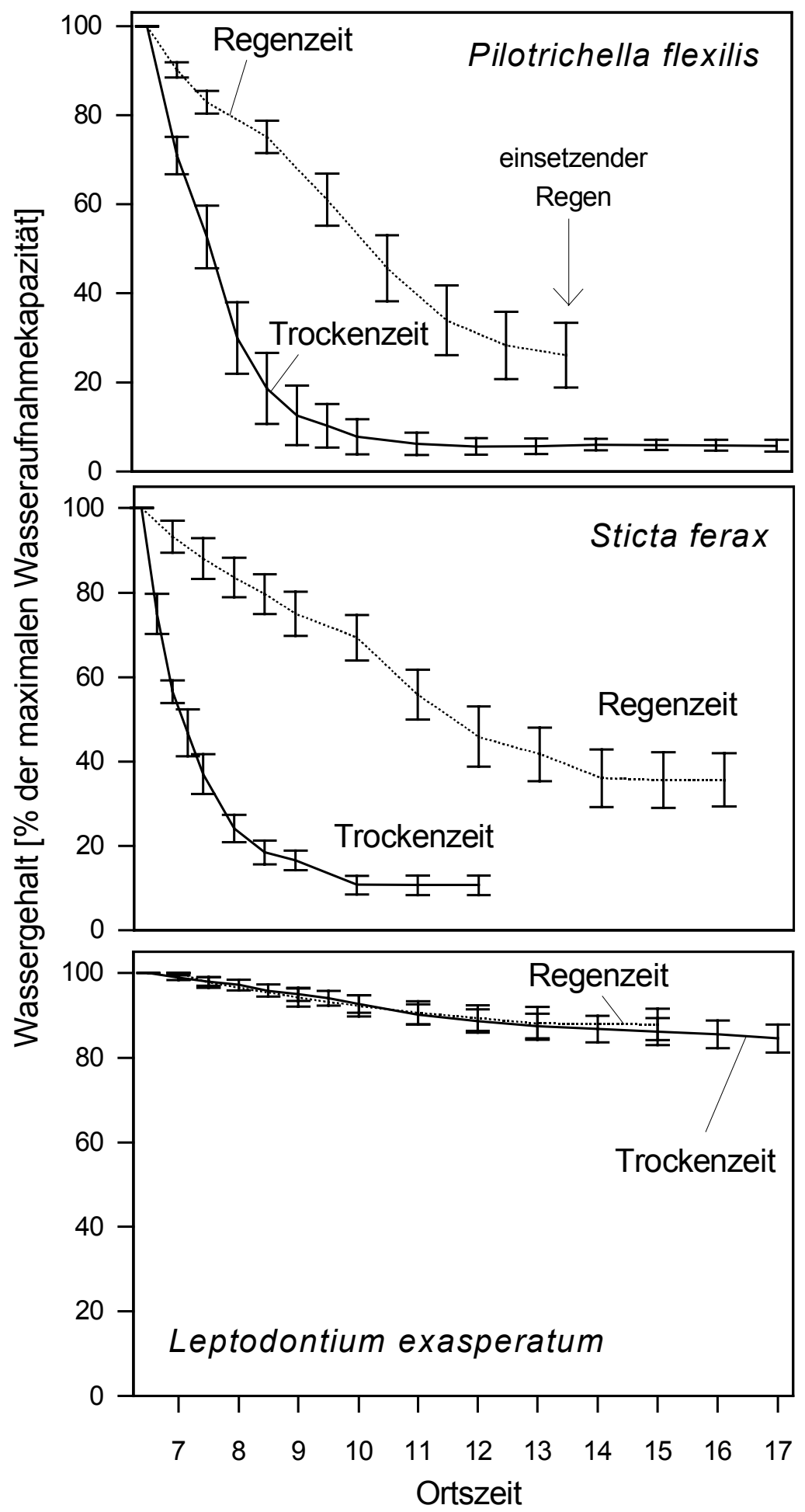

Abb. 4-28: Austrocknungskurven verschiedener Epiphyten des Altbestandes aufgenommen in situ am Standort. Dargestellt ist der zeitliche Verlauf der Austrocknung nach Wasseraufsättigung für das Hängemoos Pilotrichella flexilis $(\mathrm{n}=7)$, die Makroflechte Sticta ferax $(\mathrm{n}=8)$ und das Polstermoos Leptodontium exasperatum $(\mathrm{n}=7)$ an einem Tag in der Regen- und in der Trockenzeit im Altbestand. 
Ein gänzlich anderes Bild läßt sich bei dem Polstermoos Leptodontium exasperatum erkennen. Hier zeigen sich in der Regen- und in der Trockenzeit nahezu identische Kurvenverläufe. Die Wasserabgabe erfolgt sehr gleichmäßig und deutlich langsamer als bei den anderen Epiphytenarten. Selbst in der Trockenzeit werden im Verlauf eines Tages im Mittel nur 16\% des gespeicherten Wassers durch Verdunstung wieder abgegeben.

Bei der Borke von Quercus copeyensis ist ein deutlicher Unterschied der Austrocknungskurven während der Regen- und der Trockenzeit zu beobachten (Abb. 4-29). In der Regenzeit ist die Borke nach etwa sieben Stunden bis auf 30\% der maximalen Aufnahmekapazität ausgetrocknet. Danach ist keine weitere Abnahme der Werte mehr zu erkennen. In der Trockenzeit liegen die Werte schon nach fünf Stunden bei etwa $6 \%$ des Ausgangswassergehaltes und bleiben danach konstant.

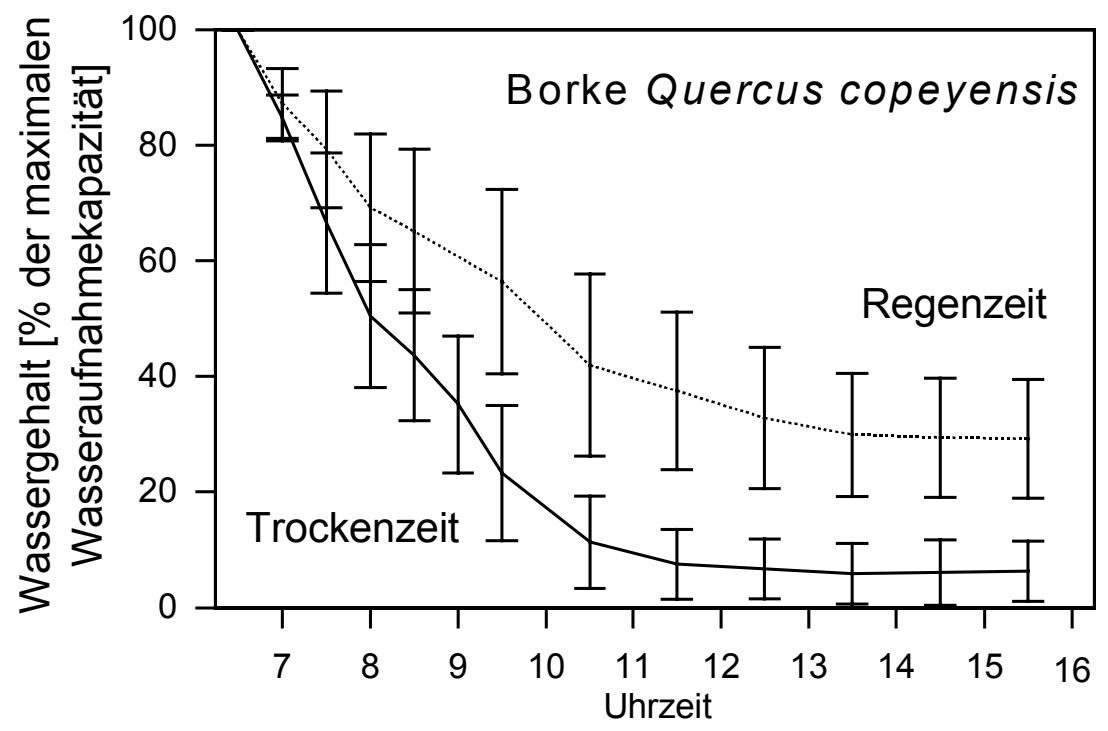

\begin{abstract}
Abb. 4-29: Austrocknungskurven von Eichenborke (Quercus copeyensis $)(\mathrm{n}=8)$. Dargestellt ist der zeitliche Verlauf der Austrocknung nach Wasseraufsättigung an einem Tag in der Regenund in der Trockenzeit in situ im Altbestand.
\end{abstract}

Das Wasserabgabeverhalten verschiedener Epiphyten der Kronenregion des Altbestandes sowie der Borke von Quercus copeyensis läßt deutliche Unterschiede erkennen (Tab. 4-7). So zeigt das Polstermoos Leptodontium exasperatum in der Regenzeit nur eine sehr geringe Austrocknung, wobei ein Wassergehalt von 50\% der maximalen Speicherkapazität nicht erreicht wird. Bei Pilotrichella flexilis, Sticta ferax und bei Borke von Quercus copeyensis wird der 50\%-Wert nach drei bis fünf Stunden erreicht. Wie bereits in den Austrocknungskurven (Abb. 4-28, 4-29) deutlich wurde, wird in der Trockenzeit ein Wassergehalt von 50\% wesentlich schneller erreicht. 
Tab. 4-7: Kenngrößen des Wasserhaushalts verschiedener Epiphyten der Kronenregion des Altbestandes sowie der Borke von Quercus copeyensis. Angegeben ist die Zeitdauer, nach der beim Austrocknungsversuch ein Wassergehalt von $50 \%$ der maximalen Wasserspeicherkapazität erreicht wurde. Die mittlere maximale Speicherkapazität wurde aus Werten der Regen- und der Trockenzeit berechnet. (Mittlere maximale Speicherkapazität [\%] = Sättigungsgewicht- Trockengewicht /Trockengewicht*100). Unterschiedliche Buchstaben kennzeichnen signifikante Unterschiede zwischen den Arten. U-Test nach Mann \& Whitney $(\mathrm{p}<0.05)$.

\begin{tabular}{|c|c|c|c|c|c|c|}
\hline & \multicolumn{2}{|c|}{$\begin{array}{l}\text { Wassergehalt } 50 \% \\
\text { erreicht nach x min. }\end{array}$} & \multicolumn{2}{|c|}{$\begin{array}{l}\text { mittlere maximale } \\
\text { Speicherkapazität }\end{array}$} & \multirow[b]{2}{*}{ Stabw } & \multirow[b]{2}{*}{$\mathrm{n}$} \\
\hline & Regenzeit & Trockenzeit & {$[\% \mathrm{TG}]$} & {$\left[\mathrm{ml} \mathrm{g} \mathrm{TG}^{-1}\right]$} & & \\
\hline Leptodontium & $>1000$ & $>1000$ & $722^{a}$ & 7.2 & 217 & 14 \\
\hline Pilotrichella & 220 & 65 & $671^{a}$ & 6.7 & 99 & 14 \\
\hline Sticta & 305 & 40 & $200^{b}$ & 2.0 & 41 & 16 \\
\hline Elaphoglossum & - & 160 & $105^{b c}$ & 1.1 & 6 & 8 \\
\hline $\begin{array}{l}\text { Borke } \\
\text { Quercus cop. }\end{array}$ & 200 & 90 & $14^{\mathrm{c}}$ & 0.1 & 5 & 16 \\
\hline
\end{tabular}

Bei Leptodontium hingegen reicht auch ein Tag in der Trockenzeit nicht aus, um den Wassergehalt auf diesen Wert absinken zu lassen. Dieses Moos besitzt von allen untersuchten Epiphyten mit Abstand das höchste Haltevermögen für Wasser. Die mittlere maximale Wasserspeicherkapazität wurde aus den Anfangswassergehalten (nach Aufsättigung) des in der Regen- und in der Trockenzeit durchgeführten Austrocknungsexperimentes ermittelt. Beide untersuchten Moosarten (Leptodontium, Pilotrichella) lassen ähnlich hohe Werte erkennen. Diese weichen allerdings von den bei der experimentellen Beregnung (Abb. 4-21) für diese Arten ermittelten Werten ab. Bei Sticta und Elaphoglossum liegen die hier dargestellten Wassergehalte deutlich niedriger. Die Eichenborke besitzt erwartungsgemäß die geringste Wasserspeicherkapazität und unterscheidet sich damit stark von Pilotrichella, obwohl beide ein sehr ähnliches Wasserabgabeverhalten zeigen. 


\section{4 Ökosystemare Nährstoffflüsse}

\subsubsection{Nährstoffgehalte im Freilandniederschlag, Bestandesniederschlag und Stammablauf}

Die im Freilandniederschlag gemessenen Elementkonzentrationen zeigen im Jahresmittel auf den beiden Freiflächen keine signifikanten Unterschiede (Tab. 4-8). In fast allen Fällen liegen die Werte unter den im Bestandesniederschlag und Stammablauf gemessenen Konzentrationen. Nur bei Nitrat $\left(\mathrm{NO}_{3}-\mathrm{N}\right)$ lassen sich im Freilandniederschlag höhere Gehalte als im Bestandesniederschlag beobachten. Im Bestandesniederschlag sind bei fünf der untersuchten Elemente die höchsten Konzentrationen im Altbestand und in vier Fällen die niedrigsten Werte im älteren Sekundärwald zu finden. Besonders deutliche Unterschiede zeigen sich bei Ammonium $\left(\mathrm{NH}_{4}-\mathrm{N}\right)$. Hier liegt der Wert im Altbestand etwa dreimal höher als in den Sekundärwäldern. Meist sind die Nährstoffkonzentrationen im Bestandesniederschlag niedriger als im Stammablauf. Eine Ausnahme zeigte sich bei einigen Elementen im jungen Sekundärwald, wo die sehr niedrigen Gehalte im Stammablauf unter den im Bestandesniederschlag gemessenen Werten lagen. Besonders große Unterschiede zwischen den Beständen lassen die im Stammablauf der Kronenbäume gemessenen Nährstoffkonzentrationen erkennen. Bei den Elementen Kalium, Calcium und Magnesium zeigen sich signifikante Unterschiede zwischen allen drei Beständen mit den jeweils niedrigsten Werten im jungen Sekundärwald und den höchsten Werten im Altbestand. Auch die Natrium- und Ammoniumkonzentrationen liegen im Altbestand signifikant über den in den Sekundärwäldern gemessenen Werten. Hingegen weisen die $\mathrm{NO}_{3}$-N-Konzentrationen nur geringe Unterschiede zwischen den Beständen auf. Die im Stammablauf der unterständigen Bäume im älteren Sekundärwald und im Altbestand gemessenen Nährstoffgehalte lassen meist nur geringe Unterschiede zwischen den Beständen erkennen. Signifikante Unterschiede sind nur bei $\mathrm{K}$ und $\mathrm{NO}_{3}-\mathrm{N}$ zu beobachten. Ferner liegen die im Stammablauf der unterständigen Bäume gemessenen Nährstoffkonzentrationen oftmals deutlich niedriger als die bei den Kronenbäumen ermittelten Werte.

Die Ergebnisse zeigen, daß es in allen drei Beständen im Jahresmittel während der Kronenpassage zu einer Anreicherung der Nährstoffe vom Freilandniederschlag zum Bestandesniederschlag und Stammablauf kommt. Nur bei Nitrat ist in einigen Fällen eine Abreicherung zu beobachten. Auffällig sind in allen Niederschlagsfraktionen die großen zeitlichen und räumlichen Schwankungen insbesondere der Konzentrationen von $\mathrm{Na}, \mathrm{NH}_{4}-\mathrm{N}$ und $\mathrm{NO}_{3}-\mathrm{N}$, die durch die hohen Standardabweichungen zum Ausdruck kommen. Bei diesen drei Elementen lagen die Gehalte in den analysierten Proben häufig unterhalb der Nachweisgrenze und gingen als Nullwert in die Berechnungen ein. Bei den Stickstoffverbindungen kann auch eine Verfälschung der Meßwerte durch mikrobiellen Einfluß nicht ausgeschlossen werden.

Meist zeigte der Bestandesniederschlag eine deutliche Jahresdynamik mit zum Teil erheblich höheren Nährstoffkonzentrationen in der Trockenzeit. Dies ist vermutlich auf stärkere 
Tab. 4-8: Jahresmittelwerte der Elementkonzentrationen im Freilandniederschlag, Bestandesniederschlag und Stammablauf der drei untersuchten Bestände. Außerdem ist der mittlere $\mathrm{pH}-$ Wert der einzelnen Niederschlagsfraktionen dargestellt. Unterschiedliche Buchstaben kennzeichnen signifikante Unterschiede zwischen den Beständen innerhalb der einzelnen Niederschlagsfraktionen. $\mathrm{KB}=$ Kronenbäume, $\mathrm{UB}=$ unterständige Bäume. U-Test nach Mann \& Whitney $(\mathrm{p}<0.05)$.

\begin{tabular}{lrrrrrrrr}
\hline & \multicolumn{2}{c}{ K } & \multicolumn{2}{c}{ Ca } & \multicolumn{2}{c}{ Mg } & \multicolumn{2}{c}{ Na } \\
& \multicolumn{1}{c}{ Mw } & Stabw & Mw & Stabw & Mw & Stabw & Mw & Stabw \\
\hline Freilandniederschlag & & & & & & & & \\
Sekundärwälder & $5.5^{\mathrm{a}}$ & 8.4 & $4.0^{\mathrm{a}}$ & 2.8 & $1.1^{\mathrm{a}}$ & 0.6 & $5.4^{\mathrm{a}}$ & 6.1 \\
Altbestand & $6.2^{\mathrm{a}}$ & 7.8 & $4.0^{\mathrm{a}}$ & 2.7 & $1.5^{\mathrm{a}}$ & 1.0 & $7.1^{\mathrm{a}}$ & 7.4 \\
Bestandesniederschlag & & & & & & & & \\
junger Sekundärwald & $112.4^{\mathrm{a}}$ & 86.9 & $21.7^{\mathrm{a}}$ & 13.9 & $12.9^{\mathrm{a}}$ & 11.4 & $6.6^{\mathrm{a}}$ & 7.4 \\
älterer Sekundärwald & $73.8^{\mathrm{b}}$ & 54.7 & $15.4^{\mathrm{b}}$ & 7.0 & $8.5^{\mathrm{a}}$ & 5.0 & $11.9^{\mathrm{a}}$ & 32.4 \\
Altbestand & $147.0^{\mathrm{a}}$ & 118.8 & $24.5^{\mathrm{c}}$ & 11.9 & $18.7^{\mathrm{b}}$ & 14.5 & $11.9^{\mathrm{b}}$ & 15.5 \\
Stammablauf (KB) & & & & & & & & \\
junger Sekundärwald & $119.8^{\mathrm{a}}$ & 95.4 & $10.9^{\mathrm{a}}$ & 7.5 & $3.8^{\mathrm{a}}$ & 2.8 & $18.0^{\mathrm{a}}$ & 21.7 \\
älterer Sekundärwald & $129.3^{\mathrm{b}}$ & 58.0 & $44.4^{\mathrm{b}}$ & 32.0 & $22.1^{\mathrm{b}}$ & 11.5 & $16.2^{\mathrm{a}}$ & 20.3 \\
Altbestand & $428.0^{\mathrm{c}}$ & 254.5 & $80.6^{\mathrm{c}}$ & 68.5 & $62.9^{\mathrm{c}}$ & 42.9 & $36.1^{\mathrm{b}}$ & 44.0 \\
Stammablauf (UB) & & & & & & & & \\
älterer Sekundärwald & $115.3^{\mathrm{a}}$ & 95.0 & $21.7^{\mathrm{a}}$ & 17.4 & $14.9^{\mathrm{a}}$ & 12.8 & $29.1^{\mathrm{a}}$ & 9.1 \\
Altbestand & $246.5^{\mathrm{b}}$ & 143.3 & $37.4^{\mathrm{a}}$ & 40.7 & $29.3^{\mathrm{a}}$ & 27.0 & $26.1^{\mathrm{a}}$ & 14.8 \\
\hline
\end{tabular}

\begin{tabular}{lrrrrrr}
\hline & \multicolumn{2}{c}{$\mathrm{NH}_{4}-\mathrm{N}$} & $\mathrm{NO}_{3}-\mathrm{N}$ & $\mathrm{pH}$ & \\
& \multicolumn{5}{c}{$\left.[\mu \mathrm{mol})^{-1}\right]$} \\
& $\mathrm{Mw}$ & $\mathrm{Stabw}$ & $\mathrm{Mw}$ & $\mathrm{Stabw}$ & - & $\mathrm{n}$ \\
\hline Freilandniederschlag & & & & & & \\
Sekundärwälder & $5.5^{\mathrm{a}}$ & 10.8 & $4.9^{\mathrm{a}}$ & 5.7 & 5.6 & 53 \\
Altbestand & $4.2^{\mathrm{a}}$ & 7.3 & $4.0^{\mathrm{a}}$ & 5.3 & 5.3 & 55 \\
Bestandesniederschlag & & & & & & \\
junger Sekundärwald & $10.8^{\mathrm{a}}$ & 12.9 & $4.3^{\mathrm{a}}$ & 5.8 & 6.5 & 55 \\
älterer Sekundärwald & $10.2^{\mathrm{a}}$ & 12.0 & $3.6^{\mathrm{a}}$ & 5.2 & 6.1 & 54 \\
Altbestand & $31.1^{\mathrm{b}}$ & 48.6 & $2.6^{\mathrm{a}}$ & 4.7 & 6.0 & 55 \\
Stammablauf (KB) & & & & & & \\
junger Sekundärwald & $6.8^{\mathrm{a}}$ & 13.1 & $6.6^{\mathrm{a}}$ & 7.3 & 5.7 & 62 \\
älterer Sekundärwald & $10.0^{\mathrm{a}}$ & 12.8 & $4.4^{\mathrm{a}}$ & 6.3 & 4.5 & 50 \\
Altbestand & $152.6^{\mathrm{b}}$ & 223.2 & $4.2^{\mathrm{a}}$ & 6.3 & 4.2 & 49 \\
Stammablauf (UB) & & & & & & \\
älterer Sekundärwald & $12.2^{\mathrm{a}}$ & 10.1 & $13.0^{\mathrm{a}}$ & 3.0 & 4.8 & 15 \\
Altbestand & $33.9^{\mathrm{a}}$ & 81.3 & $6.7^{\mathrm{b}}$ & 7.6 & 5.7 & 25 \\
\hline
\end{tabular}


Trockendepositionen und geringere Verdünnungseffekte in der Trockenzeit zurückzuführen und zeigt sich in schwächerer Ausprägung auch beim Stammablauf (ohne Abb.).

Sowohl die im Bestandesniederschlag als auch die im Stammablauf der Kronenbäume gemessenen $\mathrm{pH}-$ Werte lassen im Jahresmittel eine Abnahme der Werte mit zunehmendem Bestandesalter erkennen. Im Altbestand wurden im Stammablauf mit $\mathrm{pH} 4.2$ besonders niedrige Werte gemessen. Dies ist in erster Linie auf Quercus copeyensis-Altbäume zurückzuführen, deren Stammablauf teilweise sehr niedrige $\mathrm{pH}$-Werte von nur 3.3 aufwies. Der Stammablauf der unterständigen Bäume zeigt sowohl im älteren Sekundärwald als auch im Altbestand höhere $\mathrm{pH}-$ Werte als die Kronenbäume des jeweiligen Bestandes.

\subsubsection{Nährstoffflüsse mit dem Niederschlag}

Bei fast allen untersuchten Elementen ist eine Anreicherung vom Freilandniederschlag zum Nettoniederschlag während der Kronenpassage $\mathrm{zu}$ beobachten (Tab. 4-9). Die Anreicherungsfaktoren (Nettoniederschlag / Freilandniederschlag) betragen 1-3 $\left(\mathrm{NH}_{4}-\mathrm{N}\right), 10$ 12 (K), 3-4 (Ca) und 6-8 (Mg) (ohne Abb.).

Tab. 4-9: Nährstoffflüsse mit dem Freilandniederschlag (FN), Bestandesniederschlag (BN) und Stammablauf (S) in den drei untersuchten Beständen. Aus Bestandesniederschlag und Stammablauf ergibt sich der Nettoniederschlag (N).

\begin{tabular}{|c|c|c|c|c|c|c|c|c|}
\hline & Fluß & $\begin{array}{c}\mathrm{H}_{2} \mathrm{O} \\
{\left[\mathrm{mm} \mathrm{a}^{-1}\right]}\end{array}$ & $\mathrm{K}$ & $\mathrm{Ca}$ & $\begin{array}{l}\mathrm{Mg} \\
{[\mathrm{mm}}\end{array}$ & $\begin{array}{c}\mathrm{Na} \\
\left.\mathrm{m}^{-2} \mathrm{a}^{-1}\right]\end{array}$ & $\mathrm{NH}_{4}-\mathrm{N}$ & $\mathrm{NO}_{3}-\mathrm{N}$ \\
\hline \multicolumn{9}{|l|}{ Freiflächen } \\
\hline Sekundärwälder & $\mathrm{FN}$ & 2900 & 14.3 & 13.0 & 3.2 & 10.4 & 15.7 & 13.7 \\
\hline Altbestand & $\mathrm{FN}$ & 2830 & 15.2 & 9.7 & 3.0 & 13.4 & 9.5 & 12.1 \\
\hline \multirow{3}{*}{$\begin{array}{l}\text { Bestände } \\
\text { junger } \\
\text { Sekundärwald }\end{array}$} & $\mathrm{BN}$ & 2003 & 140.3 & 32.4 & 17.3 & 10.2 & 16.6 & 6.1 \\
\hline & $\mathrm{S}$ & 466 & 29.3 & 3.8 & 1.0 & 3.5 & 1.7 & 1.0 \\
\hline & $\mathrm{N}$ & 2469 & 169.6 & 36.2 & 18.3 & 13.7 & 18.3 & 7.1 \\
\hline \multirow{3}{*}{$\begin{array}{l}\text { älterer } \\
\text { Sekundärwald }\end{array}$} & $\mathrm{BN}$ & 2171 & 104.8 & 30.9 & 13.8 & 18.2 & 41.3 & 7.5 \\
\hline & $\mathrm{S}$ & 480 & 36.7 & 14.9 & 7.0 & 3.5 & 3.1 & 0.7 \\
\hline & $\mathrm{N}$ & 2651 & 141.5 & 45.8 & 20.8 & 21.7 & 44.4 & 8.2 \\
\hline \multirow[t]{3}{*}{ Altbestand } & $\mathrm{BN}$ & 2058 & 157.7 & 37.5 & 22.3 & 14.0 & 24.2 & 3.5 \\
\hline & $\mathrm{S}$ & 63 & 8.6 & 1.9 & 1.4 & 0.7 & 0.4 & 0.1 \\
\hline & $\mathrm{N}$ & 2121 & 166.3 & 39.4 & 23.7 & 14.7 & 24.6 & 3.6 \\
\hline
\end{tabular}


Ein anderes Bild zeigt sich bei $\mathrm{NO}_{3}-\mathrm{N}$, bei dem die Anreicherungsfaktoren in den drei untersuchten Beständen zwischen 0.3 und 0.6 liegen, wodurch eine Abnahme der Stoffflüsse vom Freilandniederschlag zum Nettoniederschlag zum Ausdruck kommt. Die Ursache hierfür sind die geringen $\mathrm{NO}_{3}-\mathrm{N}-$ Konzentrationen, die im Bestandesniederschlag gemessen wurden (Tab. 4-8).

Obwohl die Elementkonzentrationen im Bestandesniederschlag meist deutlich niedriger als im Stammablauf liegen, ist der Nährstoffeintrag mit dem Bestandesniederschlag aufgrund der größeren Wasserflußraten wesentlich höher als mit dem Stammablauf. Besonders ausgeprägt ist dies im Altbestand. Hier ist der durch den Bestandesniederschlag bedingte Stofftransport im Mittel aller Elemente 28mal höher als mit dem Stammablauf. In den Sekundärwäldern ist hingegen nur eine etwa sechs- bis achtmal höhere Nährstofffracht mit dem Bestandesniederschlag zu beobachten. Dies kommt in erster Linie durch die geringen Nährstoffflüsse mit dem Stammablauf im Altbestand zustande. So zeigen sich hier beispielsweise wesentlich geringere Kaliumflüsse als in den Sekundärwäldern, obwohl die Kaliumkonzentration im Altbestand deutlich höher als in den Sekundärwäldern liegt. Nur etwa 5\% des über die Nettoniederschläge eingetragenen Kaliums entfallen im Altbestand auf den Stammablauf, während die Werte im jungen Sekundärwald bei $17 \%$ und im älteren Sekundärwald bei $26 \%$ liegen. Im älteren Sekundärwald wurden bei allen analysierten Elementen die höchsten Stoffflüsse an Bäumen der oberen Kronenschicht gemessen, während sich im Altbestand ein uneinheitliches Bild zeigte.

Die Untersuchungen lassen erkennen, daß die bestandesinternen Nährstoffflüsse mit den Nettoniederschlägen in den drei Beständen nur geringe Differenzen aufweisen. Es bestehen jedoch große Unterschiede zwischen den Sekundärwäldern und dem Altbestand hinsichtlich der mit dem Stammablauf transportierten Nährstofffracht. 


\subsubsection{Nährstoffgehalte der Baumblätter und Epiphyten}

Die Nährstoffgehalte von Eichenblättern (Quercus copeyensis), die in der Kronenregion der drei Bestände geerntet wurden, zeigen mit Ausnahme von Ca und Mn keine signifikanten Unterschiede zwischen den Beständen (Tab. 4-10). Auffallend sind vor allem die besonders niedrigen Calciumkonzentrationen der Blätter im Altbestand.

Der Vergleich der Nährstoffgehalte von fünf im Altbestand häufigen Moosarten mit den aus diesem Bestand stammenden Eichenblättern läßt bei fast allen Elementen deutlich geringere Werte bei den Moosen erkennen. Ein gegensätzliches Bild ist bei Calcium zu beobachten, wo die in den Moosen gemessenen Elementkonzentrationen die verhältnismäßig niedrigen Blattgehalte übertreffen. Kronenhumus zeichnet sich besonders durch hohe Stickstoffgehalte aus, während die Borke von Quercus copeyensis relativ hohe Calciumgehalte aufweist.

Tab. 4-10: Elementgehalte von Eichenblättern (Quercus copeyensis) aus der Sonnenkrone der drei untersuchten Bestände. Dargestellt sind außerdem die Elementgehalte verschiedener Moosarten der Kronenregion des Altbestandes sowie Kronenhumus und Borke von Quercus copeyensis (Altbestand). Bei den Borkenproben $n=5$; alle übrigen $n=10$. Unterschiedliche Buchstaben kennzeichnen bei den Eichenblättern signifikante Unterschiede zwischen den Beständen, bei den Moosen Unterschiede zwischen den Arten; U-Test nach Mann \& Whitney $(p<0.05)$.

\begin{tabular}{|c|c|c|c|c|c|c|c|c|c|c|}
\hline & \multicolumn{2}{|c|}{$\mathrm{K}$} & \multicolumn{2}{|c|}{$\mathrm{Ca}$} & \multicolumn{2}{|c|}{$\begin{array}{c}\mathrm{Mg} \\
{\left[\mathrm{mmol} \mathrm{kg}^{-1}\right]}\end{array}$} & \multicolumn{2}{|c|}{$\mathrm{Mn}$} & \multicolumn{2}{|c|}{$\mathrm{N}$} \\
\hline & $\mathrm{Mw}$ & Stabw & $\mathrm{Mw}$ & Stabw & $\mathrm{Mw}$ & Stabw & $\mathrm{Mw}$ & Stabw & $\mathrm{Mw}$ & Stabw \\
\hline \multicolumn{11}{|c|}{ Blätter (Quercus copeyensis) } \\
\hline jung. Sekw. & $160^{\mathrm{a}}$ & 41.7 & $195^{\mathrm{a}}$ & 33.5 & $59.7^{\mathrm{a}}$ & 9.57 & $20.1^{\mathrm{a}}$ & 8.2 & $976^{\mathrm{a}}$ & 96 \\
\hline ält. Sekw. & $159^{\mathrm{a}}$ & 72.5 & $207^{\mathrm{a}}$ & 82.5 & $70.6^{\mathrm{a}}$ & 13.9 & $31.4^{b}$ & 9.3 & $990^{\mathrm{a}}$ & 113 \\
\hline Altbestand & $199^{\mathrm{a}}$ & 75.0 & $71^{b}$ & 37.3 & $63.2^{\mathrm{a}}$ & 14.0 & $17.5^{\mathrm{a}}$ & 6.3 & $1031^{\mathrm{a}}$ & 172 \\
\hline \multicolumn{11}{|l|}{ Moosarten } \\
\hline Frullania & $122^{\mathrm{ac}}$ & 39.6 & $76.4^{\mathrm{a}}$ & 18.5 & $50.9^{\mathrm{a}}$ & 17.4 & $10.7^{\mathrm{a}}$ & 3.3 & $738^{\mathrm{a}}$ & 78.8 \\
\hline Herbertus & $98.3^{\mathrm{a}}$ & 18.5 & $97.1^{\mathrm{b}}$ & 12.5 & $64.4^{\mathrm{b}}$ & 7.3 & $11.3^{\mathrm{ac}}$ & 2.4 & $497^{\mathrm{b}}$ & 92.3 \\
\hline Leptodontium & $70.8^{\mathrm{b}}$ & 10.6 & $71.7^{\mathrm{a}}$ & 10.5 & $31.2^{\mathrm{c}}$ & 3.7 & $8.8^{\mathrm{ab}}$ & 3.6 & $599^{\mathrm{cd}}$ & 80.5 \\
\hline Pilotrichella & $94.2^{\mathrm{a}}$ & 10.8 & $93.5^{\mathrm{ab}}$ & 24.6 & $61.1^{\mathrm{ab}}$ & 12.8 & $7.2^{\mathrm{b}}$ & 1.4 & $577^{\mathrm{d}}$ & 60.4 \\
\hline Plagiochila & $136^{\mathrm{c}}$ & 10.5 & $97.1^{b}$ & 22.4 & $38.7^{\mathrm{d}}$ & 5.4 & $4.5^{c}$ & 0.9 & $993^{\mathrm{e}}$ & 128 \\
\hline Kronenhumus & 24.2 & 9.0 & 69.3 & 15.6 & 21.6 & 7.5 & 9.2 & 7.0 & 1290 & 128 \\
\hline Querc.-Borke & 25.2 & 27.9 & 177 & 142 & 24.0 & 11.7 & 3.6 & 2.7 & 286 & 80 \\
\hline
\end{tabular}


Die Nährstoffgehalte der Blattstreu weisen bei den meisten Elementen deutliche Unterschiede zwischen den Beständen auf (Tab. 4-11). Da bei lebenden Blättern von Quercus copeyensis nur geringe Unterschiede $\mathrm{zu}$ finden waren (Tab. 4-10), ist dies vermutlich auf die verschiedenartige Baumartenzusammensetzung in den drei Beständen oder die unterschiedliche Retranslokation der Nährstoffe vor dem Blattfall zurückzuführen. Allerdings läßt sich hinsichtlich der Höhe der Nährstoffkonzentrationen kein einheitliches Muster erkennen. Meist liegen die Elementkonzentrationen in der Blattstreu unter den in frischen Eichenblättern gefundenen Werten. Eine Ausnahme bildet hier Calcium, das in der Streu in deutlich höherer Konzentration auftritt. Eine Ursache hierfür liegt möglicherweise in der Immobilität des $\mathrm{Ca}^{2+}$ - Ions im Phloem, die dazu führt, daß sich Calcium kontinuierlich in den Blättern anreichert und vor dem Blattfall im Gegensatz $\mathrm{zu}$ anderen Nährstoffen nicht wieder zurückgeführt werden kann. Eine weitere Erklärung wäre, daß Quercus copeyensis im Vergleich zu anderen Baumarten relativ geringe Calciumgehalte aufweist. Besonders hohe Konzentrationen von Stickstoff und Kalium sind in der Streu des parasitisch in der Kronenregion des Altbestandes vorkommenden Phoradendron zu finden. Die Kaliumgehalte übertreffen die in der Blattstreu verschiedener Baumarten gefundenen Werte um mehr als das Achtfache. Kalium als wichtiges osmotisch wirksames Ion ist vermutlich für parasitisch lebende Pflanzen von großer Bedeutung, da sie ein niedrigeres Wasserpotential als ihr Wirtsbaum erzeugen müssen.

Tab. 4-11: Elementgehalte der Blattstreu der drei untersuchten Bestände. Die Proben wurden monatlich aus 10 Streusammlern je Bestand entnommen. Junger Sekundärwald $n=60$, älterer Sekundärwald $\mathrm{n}=58$ und Altbestand $\mathrm{n}=61$. Außerdem sind die Elementgehalte der Streu von Phoradendron tonduzii aus dem Altbestand dargestellt $\mathrm{n}=5$. Unterschiedliche Buchstaben kennzeichnen signifikante Unterschiede zwischen den Beständen. Signifikante Unterschiede zwischen Phoradendron und der Blattstreu Altbestandes sind durch Sterne gekennzeichnet; U-Test nach Mann \& Whitney $(\mathrm{p}<0.05)$.

\begin{tabular}{|c|c|c|c|c|c|c|c|c|c|c|}
\hline & \multicolumn{2}{|c|}{$\mathrm{K}$} & \multicolumn{2}{|c|}{$\mathrm{Ca}$} & \multicolumn{2}{|c|}{$\begin{array}{c}\mathrm{Mg} \\
{\left[\mathrm{mmol} \mathrm{kg}^{-1}\right]}\end{array}$} & \multicolumn{2}{|c|}{$\mathrm{Mn}$} & \multicolumn{2}{|c|}{$\mathrm{N}$} \\
\hline & Mw & Stabw & $\mathrm{Mw}$ & Stabw & $\mathrm{Mw}$ & Stabw & Mw & Stabw & Mw & Stabw \\
\hline \multicolumn{11}{|l|}{ Blattstreu } \\
\hline $\begin{array}{l}\text { junger } \\
\text { Sekundärwald }\end{array}$ & $106^{\mathrm{a}}$ & 41.8 & $458^{\mathrm{a}}$ & 131 & $89.1^{\mathrm{ab}}$ & 43.1 & $18.5^{\mathrm{a}}$ & 7.3 & $650^{\mathrm{a}}$ & 123 \\
\hline $\begin{array}{l}\text { älterer } \\
\text { Sekundärwald }\end{array}$ & $73.5^{b}$ & 18.0 & $249^{b}$ & 45.5 & $67.7^{\mathrm{a}}$ & 17.9 & $37.7^{\mathrm{b}}$ & 7.1 & $676^{b}$ & 78 \\
\hline Altbestand & $95.5^{\mathrm{ac}}$ & 19.6 & $224^{\mathrm{c}}$ & 36.9 & $79.9^{b}$ & 15.3 & $24.8^{\mathrm{c}}$ & 5.1 & $757^{\mathrm{c}}$ & 101 \\
\hline \multicolumn{11}{|c|}{ Streu (Phoradendron) } \\
\hline Altbestand & $781^{*}$ & 88.7 & 191 & 72.6 & 82.5 & 5.6 & $34.7 *$ & 10.7 & $1031^{*}$ & 108 \\
\hline
\end{tabular}




\subsubsection{Nährstoffflüsse durch den Streufall von Blättern und Epiphyten}

Bei fast allen untersuchten Elementen sind die bestandesinternen Nährstoffflüsse mit der Blattstreu im älteren Sekundärwald am höchsten (Tab. 4-12). Dies ist in erster Linie auf die hohen jährlichen Streumengen in diesem Bestand zurückzuführen. Abweichend hiervon zeigt sich bei Calcium der höchste Stofffluß im jungen Sekundärwald, was auf die relativ hohe CaKonzentration in der Blattstreu dieses Bestandes zurückzuführen ist. Auffällig sind ferner die vergleichsweise geringen Calciumflüsse mit der Blattstreu im Altbestand (Tab. 4-12).

Der in den Sekundärwäldern über Phoradendron stattfindende Nährstoffeintrag ist aufgrund der niedrigen Streumengen dieser Art nur sehr gering. Im Gegensatz dazu zeigen sich im Altbestand vergleichsweise hohe Stickstoff- und Kaliumflüsse. Der Kaliumeintrag über Phoradendron beläuft sich hier auf etwa $68 \%$ bezüglich des durch die Streu der Baumblätter eingebrachten Kaliums.

Tab. 4-12: Nährstoffflüsse mit der Streu der Baumblätter, des parasitischen Phoradendron tonduzii sowie epiphytischer Moose und Flechten in den drei untersuchten Beständen. Die den Berechnungen zugrunde liegenden Elementgehalte beruhen bei Phoradendron auf Analysen von im Altbestand gesammelter Streu. Bei den Moosen und Flechten wurde der mittlere Nährstoffgehalt von fünf im Altbestand häufigen Moosarten (Tab. 4-10) zugrunde gelegt.

\begin{tabular}{lccccc}
\hline & $\mathrm{K}$ & $\mathrm{Ca}$ & $\begin{array}{c}\mathrm{Mg} \\
{\left[\mathrm{mmol} \mathrm{m}^{-2} \mathrm{a}^{-1}\right]}\end{array}$ & $\mathrm{Mn}$ & $\mathrm{N}$ \\
\hline Blattstreu & & & & & \\
junger Sekundärwald & 83.4 & 360.2 & 70.1 & 14.6 & 511.2 \\
älterer Sekundärwald & 92.5 & 313.5 & 85.2 & 47.5 & 851.0 \\
Altbestand & 68.7 & 161.2 & 57.5 & 17.8 & 544.7 \\
Streu (Phoradendron) & & & & & \\
junger Sekundärwald & 0.7 & 0.2 & 0.1 & 0.03 & 0.9 \\
älterer Sekundärwald & 0.2 & 0.04 & 0.02 & 0.01 & 0.2 \\
Altbestand & 46.9 & 11.5 & 5.0 & 2.1 & 61.9 \\
Streu der Moose und Flechten & & & & & \\
junger Sekundärwald & 0.3 & 0.3 & 0.2 & 0.03 & 2.2 \\
älterer Sekundärwald & 0.8 & 0.7 & 0.4 & 0.1 & 5.5 \\
Altbestand & 3.6 & 3.0 & 1.7 & 0.3 & 23.5 \\
\hline
\end{tabular}

Der bestandesinterne Kaliumfluß mit der Streu von Phoradendron ist im Altbestand damit etwa um den Faktor 13 höher als die durch die Streu der epiphytischen Moose und Flechten transportierten Kaliummengen. Auch bei allen anderen analysierten Elementen ist im Altbestand der Stofftransport über die Streu von Phoradendron höher als durch die epiphytischen Moose und Flechten. Nur in den Sekundärwäldern sind die Moose und Flechten für den Nährstofftransport mit der Streu von größerer Bedeutung als Phoradendron. 


\section{Diskussion}

\subsection{Unterschiedliche Epiphytenbiomassen in Bergregenwäldern und deren Ursachen}

Tropische Bergregenwälder sind gegenüber Wäldern des Tieflandes durch eine andersartige Bestandesstruktur und Artenzusammensetzung sowie vor allem durch ihren Epiphytenreichtum gekennzeichnet. Vaskuläre Epiphyten erreichen ihre größte Diversität und Biomasse in Wäldern der praemontanen bis mittleren montanen Stufe (BENZING 1998). Nach FREIBERG \& FREIBERG (2000) besteht jedoch kein signifikanter Zusammenhang zwischen ihrer Biomasse und der Meereshöhe. Auch nichtvaskuläre Epiphyten erreichen ihre größte Diversität und Häufigkeit, je nach geographischer Lage, auf unterschiedlicher Meereshöhe; diese steht jedoch meist in Übereinstimmung mit der Bildungszone der Wolken. Dennoch wurde in den meisten in den Tropen durchgeführten Studien eine deutliche Zunahme der Biomasse nichtvaskulärer Epiphyten mit steigender Meereshöhe beobachtet, wobei die größten Werte in Wolkenwäldern der oberen montanen Stufe und in den kleinwüchsigen sogenannten Elfenwäldern erreicht werden (VAN REENEN \& GRADSTEIN 1983, 1984, FRAHM 1987, 1990a, 1990b, WoLF 1993a).

Die am häufigsten diskutierten Ursachen des Epiphytenreichtums tropischer Bergregenwälder sind hohe Luftfeuchte, niedrige Temperaturen sowie hohe Niederschlagsmengen in den Bergregionen. Nach FRAHM (1987) liefert jedoch keiner dieser Faktoren eine zufriedenstellende Erklärung für die Höhenabhängigkeit der epiphytischen Moosbiomasse in den Tropen. RichARDS (1984) vermutet, daß sich die hohen Temperaturen im tropischen Tiefland sowie die geringen Lichtintensitäten in Tieflandregenwäldern nachteilig auf die Entwicklung der Bryophytenflora auswirken. Untersuchungen von FRAHM (1987), ZOTZ \& WinTER (1994) und ZoTZ (1999) bestätigen diese Hypothese und kommen zu dem Ergebnis, daß nichtvaskuläre Epiphyten oftmals während des Tages austrocknen, was einen stark reduzierten Kohlenstoffgewinn zur Folge hat. Eine erneute Hydratisierung der Epiphyten während der Nacht kann dann bei den hohen Lufttemperaturen im Tiefland zu starken Respirationsverlusten führen. Dies resultiert häufig in einer negativen Kohlenstoffbilanz und macht das Wachstum und Überleben der Epiphyten im Tiefland schwierig, wenn nicht sogar unmöglich.

In der vorliegenden Untersuchung im Bergregenwald Costa Ricas konnte mit zunehmendem Bestandesalter auch innerhalb einer Höhenstufe ein deutlicher Anstieg der Epiphytenbiomasse in der Kronenregion der drei untersuchten Bestände beobachtet werden. Die höchsten Werte zeigten die epiphytischen Moose und Flechten mit $0.83 \mathrm{~kg}$ je Quadratmeter Astoberfläche in der inneren Krone des Altbestandes, während in der mittleren und äußeren Krone die Werte auf 0.21 und $0.17 \mathrm{~kg} \mathrm{~m}^{-2}$ abnahmen und am Stamm bei nur 0.03 $\mathrm{kg} \mathrm{m}^{-2}$ lagen. Ein sehr ähnliches Verteilungsmuster der epiphytischen Bryophytenbiomasse 
fanden MÜLLER \& FRAHM (1998) in einem Bergregenwald in Ecuador, jedoch lagen die dort gefundenen Werte mit $1.87 \mathrm{~kg} \mathrm{~m}^{-2}$ im Astbereich, $1.23 \mathrm{~kg} \mathrm{~m}^{-2}$ im Zweigbereich und mit 0.08 $\mathrm{kg} \mathrm{m}^{-2}$ am Stamm wesentlich höher. In zwei Bergregenwäldern in Ecuador ermittelten Freiberg \& Freiberg (2000) Biomassen epiphytischer Moose und Flechten von 0.28, 0.32, $0.32 \mathrm{~kg} \mathrm{~m}^{-2}$ und $0.71,0.72,0.54 \mathrm{~kg} \mathrm{~m}^{-2}$ in der inneren, mittleren und äußeren Krone, wobei nur die lebende Biomasse berücksichtigt wurde. In einem Bergregenwald der oberen montanen Stufe in Kolumbien war ebenfalls eine Abnahme der Gesamt-Epiphytenbiomasse von der inneren zur mittleren und äußeren Krone zu beobachten, wobei die Werte in der inneren Krone um den Faktor 4 und in der mittleren Krone um den Faktor 7 über den in der vorliegenden Arbeit gefundenen Phytomassen (einschließlich Kronenhumus) lagen (Hofstede et al. 1993). In einem Elfenwald in Monteverde in Costa Rica ermittelte NADKARNI (1984) auf einer 13 m hohen Clusia alata eine Gesamt-Epiphytenmasse von 142 $\mathrm{kg}$, wobei wiederum eine Abnahme der Werte von den inneren über die mittleren und äußeren Ästen beobachtet werden konnte. In der vorliegenden Untersuchung lag die im Altbestand geschätzte mittlere Gesamt-Epiphytenmasse mit etwa $12 \mathrm{~kg}$ je Kronenbaum trotz der größeren Baumhöhe deutlich niedriger. In einigen Studien wurde nur die epiphytische Moosbiomasse im Stammbereich berücksichtigt. So konnte FrAHM (1990a, 1990b, 1994) auf Borneo sowie in Peru, Malaysia und Zaire in Meereshöhen um $3000 \mathrm{~m}$ Werte ermitteln, die deutlich über der Moos- und Flechtenbiomasse lagen, die im Stammbereich von Quercus copeyensis in der vorliegenden Untersuchung gefunden wurden.

Wie aus dieser Gegenüberstellung ersichtlich, liegen die Literaturangaben meist deutlich über den in der vorliegenden Arbeit gefundenen Epiphytenbiomassen. Nur in der Untersuchung von FreIBERG \& FREIBERG (2000) wurden zum Teil niedrigere Werte als in der vorliegenden Arbeit gefunden. Diese Studie wurde in nur $2000 \mathrm{~m}$ Meereshöhe durchgeführt, was die geringere Epiphytenbiomasse erklären könnte.

Bisher liegen nur wenige Literaturangaben zur Epiphytenbiomasse in montanen Sekundärwäldern der Tropen vor. KUNZ (2000) ermittelte in der Strauchschicht (bis $2 \mathrm{~m}$ Höhe) der Untersuchungsflächen der vorliegenden Arbeit im älteren Sekundärwald eine Biomasse epiphytischer Kryptogamen von $0.05 \mathrm{~kg} \mathrm{~m}^{-2}$ Stammoberfläche, während die Werte im Altbestand mit $0.18 \mathrm{~kg} \mathrm{~m}^{-2}$ deutlich höher lagen. Auffällig ist, daß die in der Strauchschicht des Altbestandes gefundenen Werte damit das Neunfache der an der Stammbasis der Alteichen in diesem Bestand gemessenen Biomasse betragen. Ebenfalls an der Pazifikabdachung der Cordillera Talamanca ermittelte SchIMANNEK (1999) in einem 30jährigen Sekundärwald der unteren montanen Stufe eine achtmal geringere Epiphytenmenge als in einem Primärwaldbestand. Diese Untersuchungen stehen in Übereinstimmung mit dem Ergebnis der vorliegenden Arbeit, daß in den untersuchten Sekundärwäldern geringere epiphytische Biomassen als im Altbestand zu finden sind.

Die Literaturangaben zur epiphytischen Biomasse in tropischen Primärwäldern der praemontanen und montanen Stufe bezogen auf die Bestandesfläche reichen von $370 \mathrm{~kg} \mathrm{ha}^{-1}$ (TANNER 1980a, 1985) bis $44000 \mathrm{~kg} \mathrm{ha}^{-1}$ (Hofstede et al. 1993) (Tab. 5-1). Unter 
Berücksichtigung der großen Meereshöhe sind die in der vorliegenden Untersuchung im Altbestand ermittelten Werte vergleichsweise gering. Die in den beiden Sekundärwäldern gefundenen epiphytischen Biomassen liegen ähnlich niedrig wie der von TANNER 1980a, 1985 mit $370 \mathrm{~kg} \mathrm{ha}{ }^{-1}$ in Jamaika ermittelte Wert. Auf Bestandesebene liegen bisher keine Literaturangaben zur Epiphytenbiomasse von Sekundärwäldern tropischer Bergregionen vor.

Tab. 5-1: Übersicht der Literaturangaben zur epiphytischen Gesamtbiomasse in tropischen Primärwäldern der praemontanen und montanen Stufe im Vergleich zu den in den drei untersuchten Beständen der vorliegenden Arbeit ermittelten Werten.

\begin{tabular}{lccl}
\hline Ort & $\begin{array}{c}\text { Höhe } \\
{[\mathbf{m} \text { ü.M.] }}\end{array}$ & $\begin{array}{c}\text { epiphytische } \\
\left.\text { Biomasse [kg ha }{ }^{-1}\right]\end{array}$ & Autoren \\
\hline Kolumbien & 3700 & 44000 & HOFSTEDE et al. 1993 \\
Kolumbien & 3370 & 12000 & VENEKLAAS et al. 1990 \\
Neu Guinea & 2500 & 5200 & EDWARDS \& GRUBB 1977 \\
Tansania & 1415 & 2130 & PÓCS 1980 \\
Tansania & 2120 & 13650 & PÓCS 1980 \\
Costa Rica & 1700 & 4730 & NADKARNI 1984 \\
Jamaika (Mor) & 1550 & 2100 & TANNER 1980a, 1985 \\
Jamaika (Mull) & 1550 & 370 & TANNER 1980a, 1985 \\
Panama & $500 ?$ & 1440 & GoLLEY et al. 1971 \\
Puerto Rico & 1000 & 7360 & WEAVER 1972 \\
Puerto Rico & 1015 & 4350 & WEAVER 1972 \\
Puerto Rico & 930 & 4750 & WEAVER 1972 \\
Costa Rica & & & \\
Altbestand & 2900 & 3400 & vorliegende Arbeit \\
junger Sekundärwald & 2900 & 520 & vorliegende Arbeit \\
älterer Sekundärwald & 2900 & & \\
\hline & & & \\
\hline
\end{tabular}

Angaben zur Epiphytenbiomasse von Waldbeständen sollten jedoch generell nur als grobe Schätzungen betrachtet werden. Die heterogene Verteilung der Epiphyten und die eingeschränkte Zugänglichkeit der Baumkronen machen eine genaue Quantifizierung der epiphytischen Biomasse sehr schwierig. Besonders auf Bestandesebene bezogene Angaben beinhalten vermutlich ein hohes Fehlerpotential. Ferner wird die Vergleichbarkeit von Literaturwerten häufig durch eine unterschiedliche Methodik eingeschränkt. Dennoch läßt die 
Gegenüberstellung der eigenen Ergebnisse mit Literaturangaben vergleichsweise niedrige epiphytische Biomassen in den untersuchten Waldbeständen erkennen.

Als mögliche Ursachen hierfür scheinen die klimatischen Bedingungen im Untersuchungsgebiet von besonderer Bedeutung zu sein.

Bei einem Jahresniederschlag von etwa $2800 \mathrm{~mm}$ im mehrjährigen Mittel scheint eine Limitierung des Epiphytenwachstums aufgrund unzureichender Wasserversorgung unwahrscheinlich. Von größerer ökologischer Bedeutung als die Jahressumme des Niederschlags ist jedoch dessen jahreszeitliche Verteilung sowie die Niederschlagsmenge im trockensten Monat. So weisen Gebiete mit hohem, aber ungleichmäßig verteiltem Jahresniederschlag meist eine geringere Epiphytenhäufigkeit auf als solche mit geringerem, aber gleichmäßig übers Jahr verteiltem Niederschlag (BENZING 1998). Auch im Untersuchungsgebiet konnte in den Monaten Februar bis April 2000 eine längere niederschlagsarme Periode beobachtet werden, in der ein Freilandniederschlag von nur 160 $\mathrm{mm}$ registriert wurde; ein Wert, der sich auch in den niedrigen Wassergehalten der Epiphyten in der Kronenregion des Altbestandes widerspiegelt. Das Polstermoos Leptodontium exasperatum ließ eine besonders starke Austrocknung erkennen. Da Moose als poikilohydre Organismen über eine vergleichsweise einfache Epidermis verfügen, sind sie nur eingeschränkt zur Regulation ihres Wasserhaushalts fähig. Sie reagieren daher sehr empfindlich gegenüber Trockenphasen und sind auf ausreichende Feuchtperioden angewiesen, um zu überleben (BENZING 1998). Aus diesem Grund sind Trockenperioden besonders für das Wachstum epiphytischer Bryophyten, die auf exponierten Ästen und Zweigen wachsen, von großer ökologischer Bedeutung (RICHARDS 1984). Es kann daher vermutet werden, daß die im oberen Savegre-Tal auftretenden Trockenperioden eine bedeutende Rolle für das Wachstum der Epiphyten spielen. Daß im Untersuchungsgebiet noch wesentlich ausgeprägtere Trockenzeiten als in den Jahren 1999/2000 auftreten können, belegen die mehrjährigen Niederschlagsaufzeichnungen der meteorologischen Station Villa Mills, wonach bereits dreimonatige Perioden mit weniger als $20 \mathrm{~mm}$ Niederschlag registriert wurden (IMN 1988).

Die im Rahmen der vorliegenden Arbeit durchgeführten hydrologischen Messungen deuten auf einen insgesamt geringen Nebeleinfluß im Untersuchungsgebiet hin. Einzelne hohe Nettoniederschläge in den Beständen ließen sich meist auf Derrame-Wetterlagen mit horizontal verwehtem Regen zurückführen. Ferner ließ die Beobachtung der Nebelhäufigkeit eine abnehmende Tendenz in den Trockenzeitmonaten erkennen. Der Nebel kann daher im Vergleich zu anderen Gebieten (Vogelmann 1973, Sugden \& Robins 1979, Cavelier \& GOLdSTEIN 1989, GORDON et al. 1994a, CAVELIER et al. 1996) vermutlich nur zu einer geringen Abschwächung der Trockenheit führen. Generell zeichnet sich die Pazifikabdachung der Cordillera Talamanca, bedingt durch den Massenerhebungseffekt und die windgeschützte Lage, durch ein relativ warmes und trockenes Lokalklima aus (BRUIJNZEEL \& HAMILTON 2000) und unterscheidet sich somit von typischen Wolkenwaldgebieten. Zwar können auch in typischen Wolkenwaldgebieten saisonale Trockenzeiten auftreten und $\mathrm{zu}$ kurzzeitigem 
Trockenstreß der Vegetation führen (LABAstille \& POOL 1978), dennoch sind häufig deutlich luftfeuchtere Bedingungen als im Savegre-Tal zu beobachten. So lag beispielsweise die im Freiland gemessene relative Luftfeuchte in einem Elfenwaldgebiet in Puerto Rico im Jahresmittel bei $98.5 \%$ (BAYNTON 1968), während in der eigenen Untersuchung mit etwa $80 \%$ ein deutlich geringerer Jahresmittelwert gemessen wurde und die Monatsmittelwerte in der Trockenzeit nur $67 \%$ betrugen. In einem sehr epiphytenreichen Wolkenwaldgebiet der oberen montanen Stufe der kolumbianischen Anden maßen VenEKLAAS et al. (1990) im Jahresmittel im Freiland ein Wassersättigungsdefizit von $1.6 \mathrm{hPa}$, während dagegen in der vorliegenden Untersuchung mit $3 \mathrm{hPa}$ ein fast doppelt so hoher Wert gefunden wurde. Ferner ist im oberen Savegre-Tal in der Trockenzeit nach Sonnenuntergang ein erneuter Anstieg der Wassersättigungsdefizite zu beobachten, was die Epiphyten einer zusätzlichen Trockenheitsbeanspruchung in den Nachtstunden aussetzt. Ähnliche Beobachtungen wurden in Kolumbien von WOLF (1993a) und VAN DER HAMMEN (1984) gemacht und werden dort auf trockene Luftmassen, die in den Nachtstunden aus höheren Gebirgsregionen absinken, zurückgeführt.

Die klimatischen Verhältnisse im Untersuchungsgebiet spiegeln sich außer in den geringen epiphytischen Biomassen auch im Lebensformenspektrum der in den Eichenkronen zu findenden Bryophyten wider. So läßt der hohe Anteil von Moosdecken und das fast vollständige Fehlen von Wedel- und Schweifmoosen in der Kronenregion der Eichenwälder des oberen Savegre-Tals die große Bedeutung der Trockenzeit in diesem Gebiet erkennen (HoLz et al. 2002)

Auch historische Prozesse könnten eine mögliche Ursache für geringe Epiphytenbiomassen darstellen. Da besonders in der Kronenregion von Primärwäldern die Wiederbesiedlung durch Epiphyten nach Störungseinflüssen ein sehr langsamer Prozeß ist (NADKARNI 2000), können sich häufige Störungen (z.B. Starkwindereignisse) ebenfalls negativ auf die epiphytische Biomasse in der Kronenregion von Waldbeständen auswirken. Wie in der vorliegenden Untersuchung gezeigt wird, ließ sich besonders im Altbestand, vermutlich bedingt durch die große Bestandeshöhe, ein deutlicher Einfluß des Windes auf den Streufall der Epiphyten beobachten. Allerdings bleibt ungeklärt, ob Starkwindereignisse auf der eher windgeschützten Pazifikabdachung der Cordillera Talamanca einen bedeutenden Störungsfaktor bei der Akkumulation von epiphytischer Biomasse in den Baumkronen darstellen.

Zusammenfassend läßt sich jedoch feststellen, daß sich das Untersuchungsgebiet durch für Epiphyten relativ ungünstige klimatische Bedingungen auszeichnet, die vermutlich die Hauptursache für die verhältnismäßig geringe epiphytische Biomasse des untersuchten Altbestandes im Vergleich zu anderen Primärwäldern darstellen. Kleinräumig können sich expositionsbedingt oder an „Sonderstandorten“, wie beispielsweise in feuchten Bachtälern, dennoch deutlich günstigere Bedingungen für das Epiphytenwachstum ergeben. 


\subsubsection{Ursachen der unterschiedlichen Epiphytenbiomassen in den drei Waldstadien}

Sekundärwaldbestände können sich mikroklimatisch stark von Primärwaldbeständen unterscheiden. So betrug das Wassersättigungsdefizit in einem submontanen 15jährigen Sekundärwald in Bolivien während 40 Tagen in der Regenzeit im Mittel $6.5 \mathrm{hPa}$, während in zwei Primärwaldparzellen mit 3.4 und $3.5 \mathrm{hPa}$ deutlich luftfeuchtere Klimate registriert wurden (ACEBEY et al. 2002). In der vorliegenden Untersuchung lassen die mittleren Tagesverläufe des Wassersättigungsdefizites in der inneren Kronenregion des älteren Sekundärwaldes während der Trockenzeit luftfeuchtere Bedingungen als im Altbestand erkennen. Trotz der höheren Luftfeuchte ist die epiphytische Biomasse hier jedoch wesentlich niedriger als im Altbestand. Ein mikroklimatischer Gradient wurde auch innerhalb der einzelnen Bestände beobachtet, wobei Lufttemperatur und Wassersättigungsdefizit von der Stammbasis zur äußeren Krone einen deutlichen Anstieg zeigten. Somit sind die Epiphyten in der Kronenregion der Bestände größeren Extremen von Temperatur und VPD und einer höheren Verdunstungsbeanspruchung ausgesetzt. Mikroklimatische Faktoren scheinen daher nicht bestimmend für die unterschiedliche Epiphytenbiomasse der drei Waldstadien sowie deren vertikale Verteilung im Bestand zu sein.

Wahrscheinlich ist, daß eine Zeitspanne von 15 und 40 Jahren in den untersuchten Sekundärwäldern nicht ausgereicht hat, um eine mit dem Altbestand vergleichbare epiphytische Biomasse zu bilden. Epiphyten zeigen häufig ein sehr langsames Wachstum (JACOBSEN 1978) und ihre Biomasse steigt in der Regel im Sukzessionsverlauf an (HALE 1967 in COXON \& NADKARNI 1995), so daß die Epiphytenbiomasse vom Bestandesalter abhängig ist (MCCUNE 1993). In Übereinstimmung mit vielen anderen Untersuchungen zeigte sich in der vorliegenden Arbeit eine Abnahme der epiphytischen Biomasse von den breiten Ästen der inneren Krone zu den dünneren Ästen der äußeren Krone. Auch hierbei spielt der Zeitfaktor eine wichtige Rolle, da die Astabschnitte im Kroneninneren ein höheres Alter aufweisen und größere Etablierungsmöglichkeiten für Epiphyten bieten als die jüngeren Bereiche der äußeren Krone. So zeigte sich in Monteverde in Costa Rica eine enge positive Korrelation zwischen der epiphytischen Biomasse und dem Astumfang (INGRAM \& NADKARNI 1993). Steile Astwinkel haben nach dieser Untersuchung hingegen eine Abnahme des Epiphytenbewuchses zur Folge. Die Neigung der Rindenoberfläche hat Auswirkungen auf die Etablierungsmöglichkeiten, die Wasser- und Nähstoffversorgung sowie den Lichtgenuß und ist deshalb ebenfalls von großer Bedeutung für Epiphyten (RICHARDS 1984). Da die Eichen der oberen Baumschicht des Altbestandes anders als in den Sekundärwäldern häufig flache Aststellungswinkel und teilweise horizontale Äste aufweisen, dürfte auch dies zu der im Vergleich zu den Sekundärwäldern großen epiphytischen Biomasse in der Kronenregion des Altbestandes beitragen.

Eine gegenläufige Entwicklung läßt sich im Stammbereich der untersuchten Bestände beobachten. Mit zunehmendem Baumalter zeigt sich hier ein Rückgang der epiphytischen Biomasse. Eine mögliche Ursache dafür könnte sein, daß Quercus copeyensis mit dem Alter eine zunehmend rauhere und stärker schuppende Borke aufweist. Nach WHITMORE (1962, 
1963) weist glatte, wenig stark schuppende Borke häufig einen stärkeren Epiphytenbewuchs auf. Andere Untersuchungen fanden den größten Epiphytenbewuchs auf rauher Borke und führen dies auf ihr höheres Wasserspeichervermögen zurück (TER STEEGE \& CORNELISSEN 1989). Eine hohe Wasserspeicherkapazität der Borke ist auch nach CALLAWAY et al. (2002) der entscheidende Faktor für die Epiphytenbesiedlung, wobei der Rindenstruktur eine geringere Bedeutung zugeschrieben wird. Allgemein läßt sich jedoch feststellen, daß schuppende Borken von Epiphyten gemieden werden (SCHLESINGER \& MARKS 1977, RichARDS 1984, CALLAWAY et al. 2002).

Mit zunehmendem Baumalter können sich neben den physikalischen auch die chemischen Eigenschaften der Borke ändern (RICHARDS 1984). Die Untersuchungen von Holz (2003) zeigen, daß die Borke von Quercus copeyensis bei Jungbäumen einen $\mathrm{pH}$-Wert von im Mittel 5.1 aufweist, während bei Altbäumen mit pH 4.1 deutlich niedrigere Werte gemessen wurden. Auch die im Rahmen der vorliegenden Arbeit durchgeführten chemischen Niederschlagsanalysen lassen bei Eichen einen Zusammenhang zwischen dem Baumalter und dem pH-Wert der Borke erkennen. So ist mit zunehmendem Alter der Bäume eine deutliche Abnahme der $\mathrm{pH}-$ Werte des Stammablaufes zu beobachten, wobei die niedrigsten Werte $(\mathrm{pH}$ 3.3) bei Altbäumen von Quercus copeyensis gemessen wurden. Ob sich die zunehmende Azidität der Borke jedoch auf die epiphytische Biomasse auswirkt, ist ungewiß. WOLF (1993b) untersuchte den Einfluß des pH-Wertes von Astborke auf die Besiedlung durch Epiphyten. Bedingt durch die Humusakkumulation auf den Astoberflächen war jedoch kein direkter Einfluß zu beobachten. MÜLLER \& FRAHM (1998) fanden höhere Artenzahlen von epiphytischen Bryophyten bei niedrigeren pH-Werten der Borke, machen jedoch keine Angaben über die Moosbiomasse.

Im Altbestand fällt ferner auf, daß die Eichenstämme auf ihrer nach Nordosten gerichteten, hangabwärts geneigten Seite größtenteils fast völlig frei von Epiphytenbewuchs sind. Diese Stammbereiche sind vermutlich zu stark gegen Niederschlag und Stammabfluß abgeschirmt, um ein Epiphytenwachstum zu ermöglichen. Eine mangelnde Wasserversorgung der Epiphyten könnte aber auch im übrigen Stammbereich der Alteichen eine Rolle spielen. Der bei fünf oberständigen Eichen im Altbestand gemessene Stammabfluß liegt im Mittel bei 749 1 pro Jahr und entspricht damit in etwa den bei Kronenbäumen des jungen Sekundärwaldes gemessenen Werten (786 1). Wird diese Wassermenge jedoch mit dem Baumumfang in Brusthöhe in Beziehung gesetzt, ergibt sich eine etwa zehnmal geringere Wasserversorgung des unteren Stammbereiches im Altbestand. Auch FrAHM (1990a) sieht in einem hohen Stammablauf eine mögliche Ursache für große epiphytische Moosbiomassen im Stammbereich.

Die drei untersuchten Waldbestände zeigten deutliche Unterschiede in der Artenzusammensetzung epiphytischer Bryophyten (HoLz 2003). So lag der Anteil der im jungen Sekundärwald und im Altbestand gemeinsam vorkommenden Moosarten bei nur etwa 45\% der Gesamtartenzahl, während das Arteninventar des älteren Sekundärwaldes etwa 50\% 
Übereinstimmung mit dem Altbestand aufwies. Mehrere Arten, die im Altbestand eine große epiphytische Biomasse bilden, sind in den Sekundärwäldern noch nicht vorhanden. Das Fehlen dieser Arten könnte eine weitere mögliche Ursache für die geringen epiphytischen Biomassen in den Sekundärwäldern im Vergleich zum Altbestand darstellen.

Die Ergebnisse lassen erkennen, daß für die unterschiedlichen Epiphytenbiomassen der Bestände und das vertikale Verteilungsmuster der Epiphyten das Bestandesalter und die Bestandesstruktur von größerer Bedeutung zu sein scheinen als die mikroklimatischen Unterschiede zwischen den Beständen. 


\subsection{Die Bedeutung der Epiphyten für den ökosystemaren Wasserumsatz und das Bestandesmikroklima}

\subsubsection{Der Kronenwasserumsatz der drei Bestände}

Der auf einen Waldbestand auftreffende Freilandniederschlag unterteilt sich im Bestandesinneren als Bestandesniederschlag und Stammablauf. Die Summe aus diesen beiden Niederschlagskomponenten wird auch als Nettoniederschlag bezeichnet. In der vorliegenden Untersuchung konnte gezeigt werden, daß die drei untersuchten Bestände im Jahresmittel einen sehr ähnlichen Bestandesniederschlag aufwiesen. So wurden im Altbestand $73 \%$ und in den beiden Sekundärwäldern 69\% und 75\% des Freilandniederschlags (2830 mm bzw. 2900 $\mathrm{mm})$ gemessen. Literaturwerte des Bestandesniederschlags in primären Bergregenwäldern bewegen sich innerhalb einer sehr breiten Spanne von im Jahresmittel 49\% (ATAROFF \& RADA 2000) bis 179\% (STADTMÜLlER \& AGUdELO 1990), wobei hohe Werte auf einen Einfluß von Nebel oder horizontalem Niederschlag hindeuten. Noch höhere Prozentwerte (281\%) wurden in Wolkenwäldern in Honduras gemessen, wobei sich der Untersuchungszeitraum in dieser Studie jedoch über weniger als ein Jahr erstreckte (BROWN et al. 1996 in BRUIJNZEEL 2002). Angaben aus Sekundärwäldern sind dagegen selten. HÖLSCHER (1995) ermittelte im östlichen Amazonasgebiet in einem zwei- und einem zehnjährigen Sekundärwald Bestandesniederschläge von $65 \%$ und $41 \%$. MCDONALD \& HEALEY (2000) fanden in montanen Sekundärwäldern in Jamaika ebenfalls sehr geringe Bestandesniederschläge von nur 50\% des Freilandniederschlags. FALLAS (1996) ermittelte dagegen in einem schmalen Sekundärwaldfragment in Costa Rica mit 108\% deutlich höhere Werte.

Deutliche Unterschiede zwischen den untersuchten Bestände ließen sich hingegen bezüglich des Stammablaufs beobachten. Während im Altbestand im Jahresmittel $2 \%$ des Freilandniederschlags gemessen wurden, liegen die Werte im jungen und älteren Sekundärwald mit 16\% bzw. 17\% deutlich höher. Ähnlich niedrige Werte wie im Altbestand wurden auch in anderen primären Bergregenwäldern der Tropen gefunden (LUNDGREN \& LundGREN 1979, SteINHARDT 1979, CACERES 1981, EdWARDS 1982, VENEKLAAS \& VAN EK 1990, CAVElier et al. 1997, AtArofF 1998, AtArofF \& RADA 2000). In zwei Sekundärwaldbeständen in Ost-Amazonien konnten HöLSCHER et al. (1998) mit 23\% und $41 \%$ hingegen extrem hohe Stammablaufwerte messen. Die Autoren führen die hohen Werte auf die große Sammeleffizienz der häufigsten Sekundärwaldarten zurück. In einigen Untersuchungen wurden jedoch auch in Primärwaldbeständen deutlich höhere Werte festgestellt. So ermittelte JORDAN (1978) in einem Tieflandregenwald in Venezuela Stammablaufmengen von $7 \%$ bis $8 \%$, wobei die zahlreichen unterständigen Bäume (BHD < $10 \mathrm{~cm}$ ) mehr als 80\% der Gesamtmenge ausmachten. Auch WEAVER (1972) verzeichnete in Puerto Rico in einem Elfenwald mit hoher Stammdichte einen Stammablauf von bis zu 10\% des Freilandniederschlags. HAFKENSCHEID (2000) konnte in Bergregenwäldern Jamaikas noch 
höhere Stammabflußwerte von $13 \%$ und $18 \%$ messen und führt dies auf die hohe Stammdichte und die große Anzahl vielstämmiger und krummwüchsiger Bäume zurück.

Wird der in der vorliegenden Untersuchung ermittelte Stammablauf nicht auf die Bestandesfläche bezogen, sondern für einzelne Bäume der oberen Baumschicht betrachtet, unterscheiden sich der Altbestand und der junge Sekundärwald nur geringfügig voneinander (Abb. 5-1, A). Hingegen wurden an den oberständigen Eichen des älteren Sekundärwaldes deutlich höhere Wassermengen gemessen, wobei sich dieser Befund aufgrund der hohen Standardabweichung jedoch nicht statistisch absichern läßt. Der höhere Wasserfluß im älteren Sekundärwald scheint in erster Linie in Zusammenhang mit den steilen Astwinkeln der Eichen in diesem Altersstadium zu stehen, wodurch die Niederschläge effektiv zum Stamm geleitet werden und dadurch den Stammablauf erhöhen. Die bestandesbildenden Eichen im Altbestand weisen hingegen deutlich flachere Astwinkel bis hin zu waagerechten Ästen auf. Eine solche Kronenstruktur hat nach JORDAN (1978) und HUBER \& IrOUMÉ (2001) eine Verminderung des Stammablaufs zur Folge. Zwar zeigten die Einzelbäume im Altbestand einen ähnlich hohen Stammablauf wie Bäume des jungen Sekundärwaldes, relativ zur Kronenfläche ist der Stammablauf im Altbestand jedoch deutlich geringer.

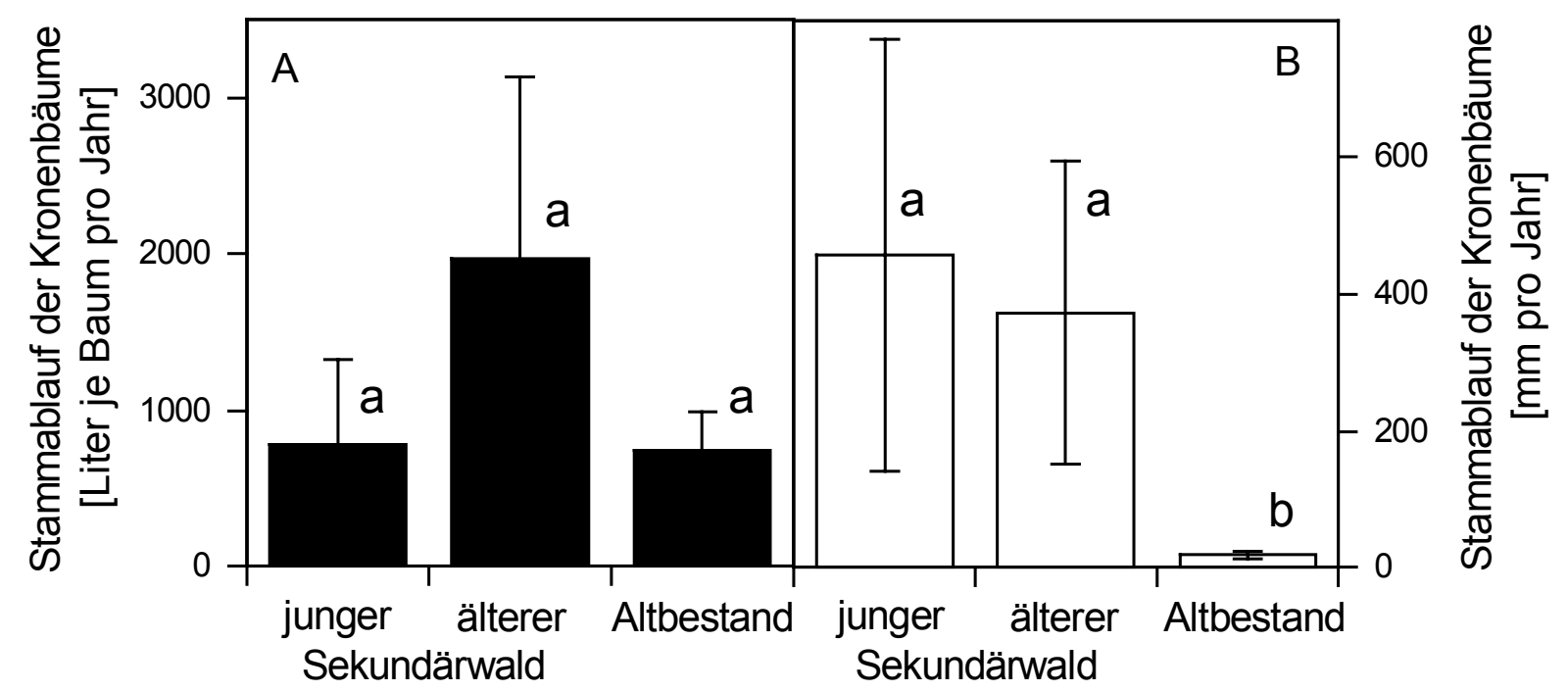

\begin{abstract}
Abb. 5-1, A, B: Stammablauf in den drei untersuchten Waldstadien. Dargestellt sind die mittleren Jahressummen der Kronenbäume (A) sowie der mittlere, auf die Bestandesebene bezogene Stammablauf der Kronenbäume (B). $\mathrm{n}=5$ je Bestand. Unterschiedliche kleine Buchstaben kennzeichnen signifikante Unterschiede zwischen den Beständen innerhalb einer Graphik. U-Test nach Mann \& Whitney $(\mathrm{p}<0.05)$. Im jungen Sekundärwald ergeben sich Abweichungen zu dem in Tab. 4-6 (für $\mathrm{n}=5-10$ ) angegebenen Wert.
\end{abstract}

Daß der Stammablauf der Kronenbäume auf Bestandesebene im jungen Sekundärwald dennoch die höchsten Werte aufweist (Abb. 5-1, B), ist auf die hohe Anzahl von Kronenbäumen in diesem Bestand (5413 Stämme ha ${ }^{-1}$ ) zurückzuführen. Im älteren Sekundärwald zeigt sich trotz der deutlich geringeren Anzahl an Kronenbäumen 
(1890 Stämme $\mathrm{ha}^{-1}$ ), bedingt durch die große Sammeleffizienz der Bäume, auch auf Bestandesebene ein hoher Stammablauf. Im Altbestand ist aufgrund der geringen Anzahl oberständiger Bäume (236 Stämme $\mathrm{ha}^{-1}$ ) auf Bestandesebene mit Abstand der geringste Stammablauf zu verzeichnen.

Damit bestätigt sich auch in der vorliegenden Arbeit die Beobachtung anderer Autoren, wonach ein hoher Stammablauf auf Bestandesebene auf eine hohe Stammdichte zurückzuführen ist. Die Ergebnisse zeigen ferner, daß die Position der Bäume (Kronenbaum oder unterständiger Baum) ein wichtiger, den Stammablauf bestimmender Faktor ist, der maßgeblich zu den hohen, in den Sekundärwäldern gemessen Werten beiträgt.

Zum geringen Stammablauf im Altbestand könnte die sehr grobe, schuppende Borke der älteren Exemplare von Quercus copeyensis beigetragen haben. Zwar wurde keine eindeutige Abhängigkeit zwischen dem Stammablauf und der Rindenstruktur der Meßbäume gefunden, es ist jedoch nicht auszuschließen, daß am Stamm herablaufendes Wasser zum Teil durch abstehende Borkenstücke oberhalb der Stammabflußmanschette vom Stamm abgeleitet wird und so nicht bei der Stammablaufmessung erfaßt werden konnte. Sowohl die große räumliche Variabilität des Stammablaufs sowie dessen Abschätzung auf Bestandesebene beinhalten vermutlich ein weiteres hohes Fehlerpotential.

In vielen Bergregenwäldern werden die hydrologischen Prozesse durch das häufige Auftreten von Nebel oder tiefliegenden Wolken beeinflußt (Wolkenwälder). Das Auskämmen dieser horizontalen Niederschläge durch die Vegetation kann in Wolkenwäldern zu einem zusätzlichen Wassereintrag führen. Obwohl die hydrologische und ökologische Bedeutung dieser zusätzlichen Niederschlagsquelle seit langem bekannt ist, ist die genaue Quantifizierung problematisch (KERFOOT 1968). Die mit Nebelsammlern unterschiedlicher Bauart gemessenen Wassereinträge durch Nebel liegen in tropischen Wolkenwaldgebieten meist zwischen 1-2 mm Tag ${ }^{-1}$ (BRUIJNZEEL \& PROCTOR 1995). Eine weitere Möglichkeit zur Abschätzung horizontaler Niederschläge besteht in dem Vergleich des Nettoniederschlags mit dem Freilandniederschlag. Nach BRUIJNZEel \& PROCTOR (1995) liegt der Nettoniederschlag in primären tropischen Wolkenwäldern der oberen montanen Stufe im Mittel bei 112\%. Dies ist gleichbedeutend mit einem zusätzlichen Niederschlagseintrag von $12 \%$ plus dem Interzeptionsverlust und läßt den starken Nebeleinfluß erkennen. Der in der vorliegenden Untersuchung im Altbestand gemessene Nettoniederschlag betrug im Jahresmittel jedoch nur $75 \%$ (Interzeption $=25 \%$ ), was dem typischen Wert für Bergregenwälder der unteren montanen Stufe entspricht, die nur wenig von Nebel beeinflußt werden. Dementsprechend wurden höhere Interzeptionswerte innerhalb tropischer Gebirgsregionen meist in der unteren montanen Stufe gemessen (z.B. EdWARds 1982, CAVELIER et al. 1997, ATAROFF 1998, CLARK et al. 1998b). Bemerkenswert ist der mit 51\% extrem hohe Interzeptionswert, der von ATAROFF \& RADA (2000) trotz beträchtlicher Wassereinträge durch Nebel in einem venezuelanischen Wolkenwald gemessen wurde. Die Autoren führen diesen hohen Wert auf die komplexe Bestandesstruktur und die großen Epiphytenmengen zurück. 
$\mathrm{Zu}$ den hohen, im Altbestand gemessenen Interzeptionswerten könnte, wie bereits weiter oben im Kapitel angedeutet, die Kronenstruktur der bestandesbildenden Eichen beigetragen haben, da flache Aststellungswinkel zu einer Erhöhung der Interzeptionkapazität der Bäume führen (Huber \& Iroumé 2001). Dieselben Autoren sehen auch in der Mehrschichtigkeit von Waldbeständen eine Ursache für eine höhere Gesamtinterzeption im Vergleich zu einfacher strukturierten Beständen, was ebenfalls die großen, in der vorliegenden Arbeit gefundenen Interzeptionsunterschiede zwischen dem Altbestand und den einfacher strukturierten Sekundärwäldern erklären könnte. Auch eine große Bestandeshöhe wird in manchen Untersuchungen als eine mögliche Ursache für hohe Interzeptionswerte gesehen (CAVELIER et al. 1997), weil mit der Höhe eines Bestandes auch dessen Rauhigkeit und somit die Evaporation ansteigt. Ferner wird vermutet, daß auch Baumborke in tropischen Regenwäldern einen bedeutenden Wasserspeicher darstellen kann (HERWITZ 1985). Den Ergebnissen dieser Studie zufolge, kann die Borke über $80 \%$ des Gesamtspeichers der kronendachbildenden Bäume ausmachen. Da die oberständigen Eichen im Altbestand meist über eine besonders grob strukturierte Borke und aufgrund der großen Bestandeshöhe über große Ast- und Stammoberflächen verfügen, trägt auch dies vermutlich zu den Interzeptionsunterschieden zwischen Altbestand und Sekundärwäldern bei. Hierbei muß jedoch berücksichtigt werden, daß die Borke zwischen zwei Niederschlagsereignissen vermutlich nicht immer vollständig austrocknet und daher besonders in der Regenzeit die Wasserspeicherkapazität nicht für jedes Niederschlagsereignis zur Verfügung steht.

Die in den beiden Sekundärwaldbeständen gemessene Interzeption liegt mit 15\% im jungen Sekundärwald und $9 \%$ im älteren Sekundärwald deutlich niedriger als im Altbestand. Interzeptionswerte von $12 \%$ und $21 \%$ wurden in Sekundärwäldern in Ost-Amazonien gefunden (HöLSCHER et al. 1998). MCDONALD \& HEALEY (2000) ermittelten in montanen Sekundärwäldern in Jamaika ungewöhnlich hohe Interzeptionswerte von 50\%, wobei in dieser Studie jedoch nicht der Stammablauf berücksichtigt wurde, der, wie die Ergebnisse der vorliegenden Arbeit zeigen, gerade in Sekundärwäldern eine bedeutende Rolle spielen kann. $\mathrm{Da}$ im älteren Sekundärwald trotz des höchsten LAI die niedrigste Interzeption gemessen wurde, deutet hingegen auf den Einfluß von horizontalen Niederschlägen, weil in Gebieten ohne Nebeleinfluß die Interzeption in der Regel mit der Blattfläche ansteigt (McNaughton \& Jarvis 1983). Tatsächlich zeigten sich die größten Interzeptionsunterschiede zwischen den beiden Sekundärwaldbeständen während sogenannter Derrame-Wetterlagen, die durch das Auftreten horizontaler Niederschläge gekennzeichnet sind. Auffallend ist, daß während dieser Perioden im älteren Sekundärwald sehr niedrige Interzeptionswerte $(10 \mathrm{~mm}$ zusätzlicher Niederschlagseintrag) gemessen wurden, während zeitgleich im nahegelegenen jungen Sekundärwald sehr hohe Werte von $18 \mathrm{~mm}$ und $47 \mathrm{~mm}$ verzeichnet wurden (Abb. 5-2). Die niedrigen Werte sind vermutlich auf die größere Bestandeshöhe und Blattfläche sowie die exponiertere Lage des älteren Sekundärwaldes zurückzuführen, was während der DerrameWetterlage dazu führt, daß der Nettoniederschlag den Freilandniederschlag übertrifft. Der junge Sekundärwald wird aufgrund seiner geringeren Bestandeshöhe und der etwas geschützteren Lage vermutlich nicht mehr vom horizontalen Niederschlag erreicht, sondern 
steht unter dem Einfluß der warmen Fallwinde, die sich während dieser Wetterlagen im Windschatten der Gebirge bilden und dort zu hohen Interzeptionswerten führen. Dies kann extreme Interzeptionsunterschiede auf engstem Raum zur Folge haben. Werden diese beiden Meßtermine, an denen solche klimatologischen Ereignisse beobachtet wurden, bei der Berechnung des Jahresmittelwertes nicht berücksichtigt, verringern sich die Interzeptionsunterschiede zwischen den beiden Sekundärwaldbeständen deutlich und betragen im Jahresmittel nur noch etwa 3\%. Mit Ausnahme der zwei Derrame-Ereignisse zeigen die beiden Bestände in der hier dargestellten Periode nur geringe Interzeptionsunterschiede, die aufgrund der großen räumlichen und zeitlichen Variabilität von Bestandesniederschlag und Stammablauf mit Vorsicht interpretiert werden sollten.

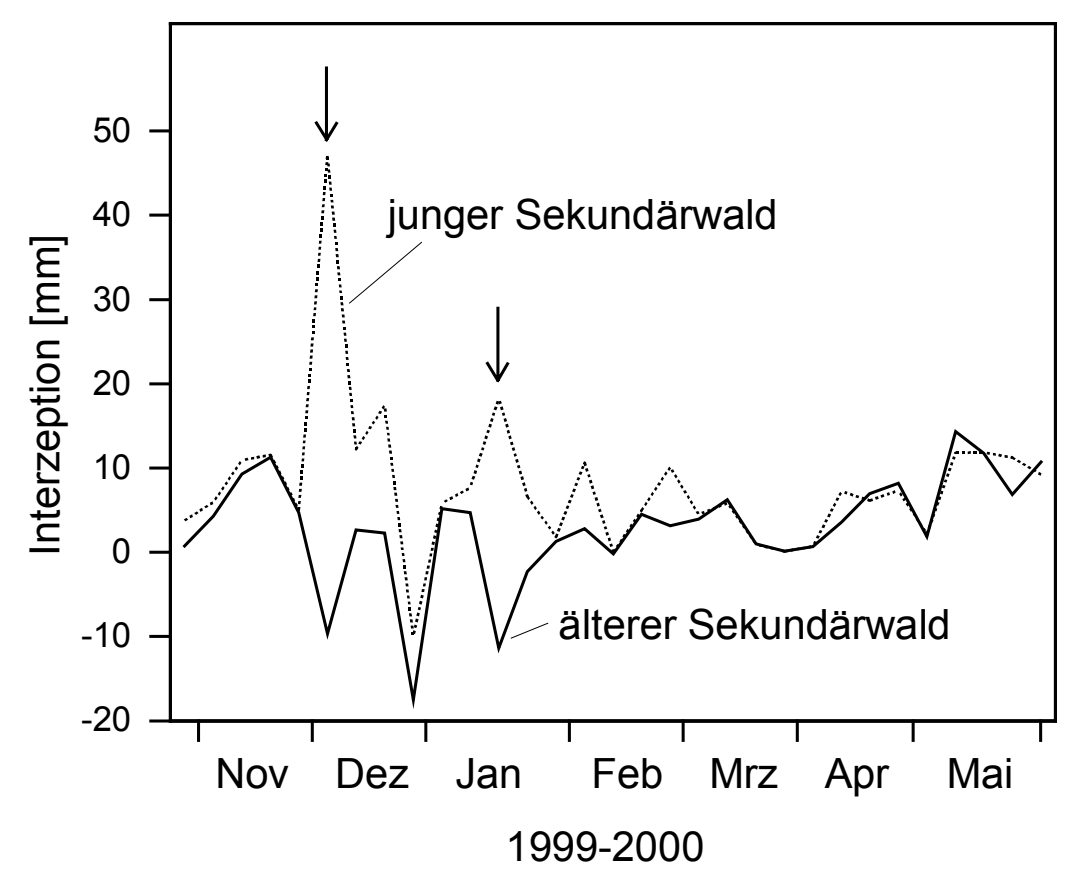

\begin{abstract}
Abb. 5-2: Interzeption im jungen und älteren Sekundärwald in wöchentlicher Auflösung von November 1999 bis Mai 2000. Die Pfeile kennzeichnen das Auftreten von Derrame-Wetterlagen. Der Freilandniederschlag während der dargestellten Periode betrug 1140 mm.
\end{abstract}

\title{
5.2.2 Die Bedeutung der Epiphyten für den Kronenwasserumsatz
}

Mehrere Autoren haben die Hypothese aufgestellt, daß die hydrologischen Prozesse in Bergregenwäldern durch die Häufigkeit der Epiphyten modifiziert werden können (PóCS 1980, VENEKLAAS \& VAN EK 1990). Über deren genaue Funktion im Interzeptionsprozeß ist jedoch wenig bekannt.

Die Kronenspeicherkapazität von Waldbeständen wird häufig als Differenz von Netto- und Freilandniederschlag für einzelne Niederschlagsereignisse ermittelt. Nach dieser Methode 
ergab sich in der vorliegenden Arbeit im Altbestand eine Speicherkapazität von etwa $3.5 \mathrm{~mm}$, die innerhalb der Spanne der in anderen Bergregenwäldern gefundenen Werte liegt. In zwei Wolkenwäldern in Kolumbien ermittelten VENEKLAAS \& VAN EK (1990) Kronenspeicherkapazitäten von 2 bis $5 \mathrm{~mm}$, wobei der höhere Wert im epiphytenreicheren der beiden Bestände gemessen wurde. Mit steigender Epiphytenmasse ist also eine Erhöhung der Kronenspeicherkapazität eines Bestandes zu erwarten. So sind in epiphytenarmen Tieflandregenwäldern häufig Werte von nur 0.8 bis $1 \mathrm{~mm}$ zu finden (BRUIJNZEEL \& PROCTOR 1995). Deutlich niedrigere Werte als im Altbestand ergaben sich in der vorliegenden Arbeit mit $1.6 \mathrm{~mm}$ für den jungen und mit $2.4 \mathrm{~mm}$ für den älteren Sekundärwald. Die nach dieser Methode ermittelte Kronenspeicherkapazität von Waldbeständen gibt jedoch keine Auskunft darüber, welchen Beitrag die einzelnen Kronenkompartimente zur Gesamtwasserspeicherkapazität der Krone leisten.

Mit der folgenden Hochrechnung soll versucht werden, eine grobe Abschätzung der Bedeutung einzelner Kronenkompartimente im Interzeptionsproze $\beta$ vorzunehmen. Mit dem Blattflächenmeßgerät LAI 2000 wurden für alle drei untersuchten Bestände verhältnismäßig niedrige Blattflächenindizes ermittelt. Eine mögliche Ursache hierfür könnte darin liegen, daß die Messungen im Monat Februar zur Zeit des Hauptlaubfalls durchgeführt wurden. Ferner kommen verschiedene Studien zu dem Ergebnis, daß die optische LAI-Bestimmung mit dem LAI-2000 im Vergleich zur direkten allometrischen Ermittlung der Blattfläche zu einer Unterschätzung des Blattflächenindex führt (HERBERT \& FOWNES 1997, PRSKAWETZ \& LEXER 2000). Für die folgenden Hochrechnungen der Wasserspeicherkapazität des Altbestandes soll daher der anhand des Blattstreufalls berechnete LAI verwendet werden. So betrug der jährliche Streufall von Baumblättern im Altbestand $7.2 \mathrm{t} \mathrm{ha}^{-1} \mathrm{a}^{-1}$, wobei der Anteil der Eichenblätter bei mehr als 90\% lag. Nach GRUBB (1977) beträgt die Lebensdauer von Blättern in der oberen montanen Stufe 14 bis 18 Monate. In der vorliegenden Untersuchung konnte gezeigt werden, daß die mittlere Lebensspanne der Blätter von Quercus copeyensis in der Kronenregion des Altbestandes mehr als 15 Monate beträgt. Geht man von einer mittleren Blattlebensdauer von 18 Monaten aus, ergibt sich bei der gemessenen spezifischen Blattfläche für Quercus copeyensis $\left(74.1 \mathrm{~cm}^{-2} \mathrm{~g}^{-1}\right)$ in Kombination mit den Streufalldaten für den Altbestand ein Blattflächenindex von $7.7 \mathrm{~m}^{2} \mathrm{~m}^{-2}$ auf eine ebene Grundfläche bezogen. Wird die durch künstliche Beregnungsexperimente ermittelte maximale Wasserspeicherkapazität von Eichenblättern $(0.14 \mathrm{~mm})$ zugrunde gelegt, ergibt sich bei diesem LAI im Altbestand eine Speicherkapazität der Baumblätter von $1.08 \mathrm{~mm}$.

Die Biomasse der epiphytischen Moose und Flechten der oberen Baumschicht des Altbestandes wird auf etwa $1.92 \mathrm{t} \mathrm{ha}^{-1}$ geschätzt, wobei der Anteil der LeptodontiumMoospolster bei mindestens 30\% lag. Der höchste mittlere Wassergehalt, der in der Kronenregion des Altbestandes in Leptodontium-Polstern gemessen wurde, betrug 406\%. Wird dieser Wert für die Berechnung der Wasserspeicherkapazität aller epiphytischen Moose und Flechten im Altbestand zugrunde gelegt, resultiert daraus eine maximale Wasserspeicherkapazität von $0.78 \mathrm{~mm}$ in der oberen Baumschicht. Die Anzahl größerer Tankbromelien (Vriesea orosiensis) wird im Altbestand auf 7080 Exemplare je Hektar mit 
einer maximalen Wasserspeicherkapazität von $0.25 \mathrm{~mm}$ geschätzt. Insgesamt ergeben die genannten Kronenkompartimente eine Speicherkapazität von $2.1 \mathrm{~mm}$, wobei etwa 50\% dieses Wertes den Epiphyten zugeschrieben werden können. Diese Hochrechnung, bei der die übrigen Kronenkompartimente unberücksichtigt bleiben, verdeutlicht, daß die Epiphyten eine bedeutende Rolle im Kronenwasserumsatz spielen dürften. Auch in anderen Bergregenwäldern wird den Epiphyten eine große hydrologische Bedeutung zugesprochen. So schätzt Pócs (1980) die Wasserspeicherkapazität der Epiphytenbiomasse eines Elfenwaldes in Tansania auf $5 \mathrm{~mm}$ während eines einzigen Niederschlagsereignisses, wobei allein die Moosvegetation ein Speichervermögen von $3 \mathrm{~mm}$ aufweisen soll.

Die im Rahmen der vorliegenden Arbeit durchgeführten ökophysiologischen Experimente belegten ebenfalls, daß sich einige Epiphyten durch eine sehr hohe Wasserspeicherkapazität auszeichnen. Besonders Moose (Leptodontium) zeigten ein sehr hohes Wasserspeichervermögen von bis zu über 700\% ihres Trockengewichtes. Die stufenweise Beregnung von Leptodontium führte zu niedrigeren Werten (550\%), die näher an den im Freiland gemessenen Wassergehalten liegen. Die in anderen Untersuchungen durch künstliche Aufsättigungsexperimente unterschiedlicher Methodik gefundenen Werte bestätigen diese Befunde. So kann nach VENEKLAAS et al. (1990) die wassergesättigte Epiphytenmasse etwa das Sechsfache ihres Trockengewichtes speichern. Ebenfalls sehr hohe Werte fand Pócs (1980), wobei sich auch hier besonders Moose durch eine hohe Wasserspeicherkapazität von über 500\% auszeichneten. Nach FrAHM (1990b) sind epiphytische Moose in der Lage, das 2.6 bis 5.4 fache ihres Trockengewichtes an Wasser aufzunehmen.

Die im Rahmen der vorliegenden Untersuchung in der Kronenregion des Altbestandes durchgeführte Bestimmung der aktuellen Wassergehalte von Leptodontium läßt jedoch erkennen, daß die experimentell ermittelte hohe Wasserspeicherkapazität im Bestand nicht oder vermutlich nur direkt nach starken Niederschlagsereignissen erreicht wird. Dieser Befund steht in Übereinstimmung mit den Beobachtungen von VENEKLAAS et al. (1990), wonach die Beurteilung der Rolle der Epiphyten im Interzeptionsprozeß nur mit Kenntnis der Wasseraufnahme und -abgaberaten unter Freilandbedingungen möglich ist.

$\mathrm{Da}$ die im Freiland beobachteten Wassergehalte der Epiphyten unter der potentiellen Wasserspeicherkapazität lagen, läßt sich darauf zurückführen, daß die Proben zur Bestimmung des Wassergehaltes nicht unmittelbar während oder direkt nach einem Niederschlagsereignis entnommen wurden, so daß ein Teil des aufgenommenen Wassers bereits durch Abfließen oder Verdunstung wieder abgegeben war. Außerdem treffen die Niederschläge zuerst auf das Blätterdach, während die Epiphyten, die sich in der Regel darunter befinden, erst bei stärkeren oder länger anhaltenden Niederschlagsereignissen benetzt werden. Auch führt die heterogene, stark geklumpte Verteilung der Epiphyten dazu, daß diese nur von einem Teil der Niederschläge erreicht werden (VENEKLAAS et al. 1990, HÖLSCHER et al. 2003). 
Die experimentelle Untersuchung des Wasserabgabeverhaltens von LeptodontiumMoospolstern zeigte, daß die Austrocknung der Polster sehr langsam erfolgt, und selbst in der Trockenzeit im Mittel nur etwa 16\% des aufgenommenen Wassers im Laufe eines Tages durch Verdunstung wieder abgegeben werden. Die langsame Wasserabgabe hat zur Folge, daß beim nächsten Niederschlagsereignis, das in der Regenzeit meist am folgenden Tag eintritt, nur ein Teil des Moosspeichers für eine erneute Wasseraufnahme zur Verfügung steht. Die zum Teil unvollständige Aufsättigung und die anschließende langsame Wasserabgabe der Moospolster hat insgesamt niedrige Wasserumsatzraten zur Folge.

Andererseits traten während der Trockenzeit mehrwöchige Perioden ohne meßbaren Niederschlag auf, die eine starke Austrocknung der Moospolster bis auf einen Wassergehalt von $42 \%$ des Trockengewichts zur Folge hatten. Auch in dieser Zeit kommt das potentiell hohe Wasserspeichervermögen der Moose nicht zum Tragen.

Auch VenEKLAAs \& VAN EK (1990) vermuteten, daß die Epiphyten den Interzeptionsprozeß zwar beeinflussen, daß die dabei beteiligten Wassermengen jedoch relativ gering sind. Hochrechnungen der Wasserspeicherkapazität von Epiphyten für längere Zeitperioden sind daher irreführend, da sie auf der Annahme beruhen, daß die hohe Wasserspeicherkapazität der Moose ständig zur Verfügung steht (FRAHM 2002).

Diese bisher nur auf Beobachtungen gestützten Vermutungen konnten für den in der vorliegenden Arbeit untersuchten Altbestand auch mit einer hydrologischen Modellrechnung bestätigt werden (HÖLSCHER et al. 2003). Mit einem erweiterten Interzeptionsmodell (basierend auf VAN DiJK \& BRUIJNZEEL 2001) konnte die Interzeption im Kronenraum des Altbestandes für eine Periode von 46 Wochen mit gutem Erfolg nachgestellt werden. Diesen Ergebnissen zufolge beträgt der Beitrag der epiphytischen Moose an der Gesamtinterzeption des Altbestandes nur 6\%, während der Anteil der Baumblätter bei etwa 71\%, der der übrigen Kronenkomponenten bei $23 \%$ liegt.

Diese Ergebnisse lassen auch für die untersuchten Sekundärwaldbestände, die eine vielfach geringere epiphytische Biomasse als der untersuchte Altbestand aufweisen, nur eine sehr geringe hydrologische Bedeutung der Epiphyten annehmen. Die große Bedeutung der Baumblätter im Interzeptionsprozeß ist darauf zurückzuführen, daß Niederschläge zuerst auf das Blätterdach treffen. Ferner sind die Blattoberflächen einer schnelleren Entleerung des Speichers und damit einem häufigerem Wechsel von Benetzungs- und Verdunstungsphasen als die Epiphyten ausgesetzt, was höhere Wasserumsatzraten zur Folge hat (VENEKLAAs et al. 1990).

Die eigenen Untersuchungen haben deutliche Unterschiede im Wasserabgabeverhalten verschiedener Moosarten erkennen lassen. Das Schweifmoos Pilotrichella wies eine wesentlich schnellere Wasserabgabe als das polsterbildende Moos Leptodontium auf. Daher sollten die Befunde über die hydrologische Bedeutung der Epiphyten nicht ohne weiteres auf andere Waldbestände übertragen werden, die ein anderes Spektrum epiphytischer Lebensformen aufweisen. Auch in sehr epiphytenreichen Waldbeständen könnten die Epiphyten eine größere Bedeutung für die bestandesinternen Wasserflüsse haben. Ein starker Epiphytenbewuchs kann durch Aufnahme und Ableitung des Wassers vom Stamm zu einer 
Erniedrigung des Stammablaufs führen. So fand StEINHARDT (1979) in einem andinen Wolkenwald in Venezuela nach Entfernung der Epiphyten einen deutlich erhöhten Stammablauf, wobei sich dieser Befund aufgrund der hohen Streuung der Werte jedoch nur in einem Monat statistisch absichern ließ. Da in dieser Untersuchung der Stammablauf im Jahresmittel nur $0.7 \%$ des Freilandniederschlags betrug, sind die absoluten Wassermengen jedoch nur gering.

In der vorliegenden Untersuchung konnte gezeigt werden, daß Hängemoose bei bestimmten Wetterlagen durch Auskämmen von horizontalem Niederschlag einen zusätzlichen Niederschlagseintrag bewirken können. Dies spielt in den drei Waldstadien keine bedeutende Rolle, da derartige Wetterlagen im Untersuchungsgebiet nicht sehr häufig auftreten und Hängemoose in den untersuchten Beständen in größerer Anzahl nur im Unterwuchs vorkommen. In nebelreichen und windexponierteren Waldbeständen, wie sie beispielsweise auf der Atlantikabdachung der Cordillera Talamanca in Costa Rica zu finden sind, könnte diesen Epiphyten durch Auskämmen von Nebel eine besondere hydrologische Bedeutung zukommen.

Außerdem wird vermutet, daß Epiphyten bei starken Niederschlagsereignissen eine wichtige hydrologische Pufferfunktion übernehmen können. Wird die Wasseraufnahmekapazität der Epiphytenpolster während starker Regenfälle überschritten, so erfolgt die Wasserabgabe hauptsächlich durch Ablaufen des überschüssigen Wassers. Da dieser zeitverzögerte Prozeß noch bis mehrere Stunden nach dem Niederschlagsereignis andauern kann, könnten die Epiphyten besonders in niederschlagsreichen Gebieten eine wichtige Rolle bei der Dämpfung von Abflußspitzen spielen (VAN EK 1995).

\subsubsection{Die Beeinflussung des Bestandesmikroklimas durch die Epiphyten}

Für das Wachstum von Epiphyten sind die regionalklimatischen und mikroklimatischen Bedingungen von besonderer Bedeutung. Andererseits wird vermutet, daß die Epiphyten selbst das Bestandesmikroklima beeinflussen können, indem sie gespeichertes Wasser in Trockenperioden durch Verdunstung abgeben und dadurch auch lange nach einem Niederschlagsereignis eine hohe Luftfeuchtigkeit in der Kronenregion aufrechterhalten können (RHOADES 1995). In der vorliegenden Untersuchung zeigten sich in der Regenzeit in der inneren Kronenregion der drei untersuchten Bestände trotz der sehr unterschiedlichen Epiphytenbiomassen nur geringe Unterschiede im mittleren Tagesverlauf des Wassersättigungsdefizits. Der Altbestand wies trotz der größten Epiphytenbiomasse sogar die lufttrockensten Verhältnisse auf. Dies steht in Übereinstimmung mit der Beobachtung, daß die Wasserabgabe der im Altbestand häufigen Moospolster nur sehr langsam erfolgt und so gegenüber den übrigen wassergesättigten Kronenkomponenten vermutlich nicht ins Gewicht fällt. In der Trockenzeit sind im älteren Sekundärwald deutlich niedrigere Wassersättigungsdefizite als im Altbestand $\mathrm{zu}$ beobachten, die Bestandesluft war also feuchter, obwohl die Epiphytenmasse viel geringer war. Der höhere Blattflächenindex des älteren Sekundärwaldes scheint also für das Bestandesmikroklima von größerer Bedeutung zu 
sein als die höhere Epiphytenbiomasse des Altbestandes. Die Ursache hierfür liegt vermutlich darin, daß die Epiphyten in der Trockenzeit häufig nur geringe Wassergehalte aufweisen und wiederum keine meßbare Änderung des Bestandesmikroklimas bewirken können. Ferner lassen die Untersuchungen von FREIBERG (2001) vermuten, daß sich der mikroklimatisch durch Epiphyten beeinflußte Bereich auf die unmittelbare Umgebung der Äste beschränkt und auf das Bestandesmikroklima insgesamt nur geringen Einfluß hat. 


\subsection{Oberirdische Nährstoffflüsse in den Beständen und die Bedeutung der Epiphyten}

\subsubsection{Nährstoffflüsse mit dem Niederschlag}

Die im vorhergehenden Kapitel diskutierten hydrologischen Flüsse sind auch für die ökosystemaren Nährstoffflüsse von großer Bedeutung. Der Freilandniederschlag ist ein wichtiger Transportweg, mit dem neue Nährstoffe ins Ökosystem gelangen. Während der Kronenpassage des Niederschlags kommt es meist $\mathrm{zu}$ einer Erhöhung der Elementkonzentrationen. Dabei sind verschiedene Prozesse wie die Auswaschung von Nährstoffen aus Pflanzengeweben (leaching), gasförmige und trockene Deposition sowie als gegenläufiger Prozeß die Nährstoffaufnahme durch Pflanzen beteiligt (PARKER 1983, SCHAEFER \& REINERS 1990).

Die Nährstoffeinträge mit dem Freilandniederschlag liegen im Untersuchungsgebiet im Jahresmittel innerhalb der in der Literaturübersicht von HAFKENSCHEID (2000) für tropische Bergregenwälder angegebenen Werte. Nur für Magnesium wurden in der vorliegenden Arbeit niedrigere Werte gemessen.

Wie die in Tab. 5-2 dargestellten Anreicherungsfaktoren (das Verhältnis der Nährstoffflüsse mit dem Nettoniederschlag im Verhältnis der Flüsse mit dem Freilandniederschlag) zeigen, kommt es in den drei untersuchten Beständen bei allen Elementen mit Ausnahme von Nitrat im Jahresmittel zu einer Anreicherung im Niederschlag während der Kronenpassage. Die Elementanreicherung liegt dabei innerhalb der Spanne der in anderen Tropenwäldern gefundenen Werte.

In der eigenen Untersuchung zeigt sich beim Element Kalium die größte Anreicherung im jungen Sekundärwald. Dieser Befund könnte auf die nährstoffreichen Blätter frühsukzessionaler Baumarten (KAPPELLE \& LEAL 1996) zurückzuführen sein. Obwohl eine große Blattfläche eine starke Elementauswaschung erwarten ließe, weist der ältere Sekundärwald trotz seines signifikant höheren Blattflächenindex nur eine vergleichsweise geringe Kaliumanreicherung auf. Die hohen Kaliumgehalte des im Altbestand häufigen parasitischen Gehölzes Phoradendron scheinen nur geringe Auswirkungen auf die Anreicherung dieses Elements im Nettoniederschlag in diesem Bestand zu haben. Eine starke Kaliumanreicherung in den Niederschlägen während der Kronenpassage ist auch in allen übrigen Studien zu beobachten, was auf die leichte Auswaschbarkeit dieses Elements aus den Blättern zurückzuführen ist (TUKEY 1970).

Bei den Elementen Calcium und Magnesium zeigt sich in der vorliegenden Arbeit eine zunehmende Anreicherung mit steigendem Bestandesalter. Dabei stehen die vergleichsweise hohen $\mathrm{Ca}$-Werte im Altbestand jedoch im Widerspruch zu den geringen Ca-Konzentrationen der Eichenblätter in diesem Bestand. Möglicherweise könnte hier eine Auswaschung von Calcium und Magnesium aus den Epiphytenpolstern eine Rolle spielen, da mit zunehmendem Bestandesalter auch ein Anstieg der epiphytischen Biomasse in den drei untersuchten Beständen beobachtet wurde. 
$\mathrm{NH}_{4}-\mathrm{N}$, das im Vergleich zu K, Ca und $\mathrm{Mg}$ als widerstandfähiger gegen Auswaschung gilt (TUKEY 1970), zeigte in der vorliegenden Arbeit im Gegensatz zu den Untersuchungen von CLARK et al. (1998b) und HAFKENSCHEID (2000) eine Anreicherung im Niederschlag während der Kronenpassage.

Tab. 5-2: Anreicherungsfaktoren der Nährstoffflüsse während der Kronenpassage vom Freilandniederschlag zum Nettoniederschlag in tropischen Sekundär- und Primärwäldern vergleichbarer Standorte sowie in montanen Primärwäldern (Altbeständen) der Tropen nach Angaben verschiedener Autoren.

\begin{tabular}{|c|c|c|c|c|c|c|c|c|}
\hline Ort & $\begin{array}{c}\text { Bestandesalter } \\
{[\mathrm{a}]}\end{array}$ & $\begin{array}{c}\text { Höhe } \\
\text { [m ü.M.] }\end{array}$ & K & $\mathrm{Ca}$ & $\mathrm{Mg}$ & $\mathrm{NH}_{4}-\mathrm{N}$ & $\mathrm{NO}_{3}-\mathrm{N}$ & Ref. \\
\hline Venezuela & Primärwald & 2300 & 26.8 & 1.2 & 0.6 & - & - & 1 \\
\hline Neu Guinea* ${ }^{\boldsymbol{\nabla}}$ & Primärwald & 2450 & 10.7 & 6.3 & 9.4 & - & - & 2 \\
\hline Kolumbien * & Primärwald & 3370 & 4.8 & 2.6 & 2.8 & 1.0 & - & 3 \\
\hline Kolumbien* & Primärwald & 2550 & 12.1 & 2.7 & 3.3 & 1.2 & - & 3 \\
\hline Panama* & Primärwald & 1200 & 4.7 & 1.3 & 1.9 & - & - & 4 \\
\hline Costa Rica* & Primärwald & 1500 & 21.2 & 4.1 & 3.3 & 0.8 & 0.4 & 5 \\
\hline Jamaika & $\begin{array}{c}\text { Primärwald } \\
\text { (tall=Mull) }\end{array}$ & 1810 & 5.1 & 1.4 & 2.6 & 1.2 & 0.4 & 6 \\
\hline Jamaika & $\begin{array}{l}\text { Primärwald } \\
\text { (stunted=Mor) }\end{array}$ & 1810 & 3.7 & 1.2 & 2.5 & 0.9 & 0.3 & 6 \\
\hline Ecuador & $\begin{array}{l}\text { Primärwald } \\
\text { (plot MC3) }\end{array}$ & 1900 & 39.2 & 7.3 & 17.7 & 1.6 & 4.1 & 7 \\
\hline Brasilien & 3 & 40 & 7.6 & 1.7 & 1.1 & - & - & 8 \\
\hline Brasilien & 10 & 40 & 8.5 & 1.9 & 2.6 & - & - & 8 \\
\hline Brasilien & Primärwald & 25 & 11.6 & 1.7 & 2.1 & 1.7 & 31.6 & 9 \\
\hline Costa Rica & $10-15$ & 2900 & 11.9 & 2.8 & 5.7 & 1.2 & 0.5 & 10 \\
\hline Costa Rica & 40 & 2900 & 9.6 & 3.5 & 6.5 & 2.8 & 0.6 & 10 \\
\hline Costa Rica & Altbestand & 2900 & 10.9 & 4.1 & 7.9 & 2.6 & 0.3 & 10 \\
\hline
\end{tabular}

1) Steinhardt 1979, 2) Edwards 1982, 3) VeneKLaAs 1990, 4) CAVELIER et al. 1997, 5) ClARK et al. 1998b, 6) HAFKENSCHEID 2000, 7) YASIN 2001, 8) HÖLSCHER et al. 1998, 9) KLINGE 1998, 10) vorliegende Untersuchung

* ohne Berücksichtigung des Stammablaufs. $\mathbf{v}$ Mittelwert aus vier Waldbeständen

Bei Nitrat zeigt sich in der eigenen sowie den meisten anderen Untersuchungen eine Abnahme der mit den Niederschlägen transportierten Stoffmengen während der Kronenpassage. Mögliche Ursachen hierfür werden später diskutiert. Die starke Nitratanreicherung in der Untersuchung von KLINGE (1998) ist auf die meist unter der Nachweisgrenze liegenden Konzentrationen im Freilandniederschlag zurückzuführen. Auch in der vorliegenden Arbeit lagen die in den Niederschlägen gemessenen Konzentrationen bei 
Ammonium und Nitrat häufig unterhalb der Nachweisgrenze, weshalb diese Ergebnisse mit Vorsicht interpretiert werden sollten.

Insgesamt lassen die in der vorliegenden Untersuchung gefundenen Anreicherungsfaktoren nur geringe Unterschiede zwischen den drei untersuchten Beständen erkennen. Der Einfluß einzelner Kronenkomponenten ist daher vermutlich nicht besonders groß. Sicherlich kommt es aber auch zu einer Überlagerung verschiedener Prozesse.

Der auffallendste Unterschied zwischen den untersuchten Waldbeständen ist der relative Anteil des Stammablaufs an den Nährstoffflüssen mit dem Nettoniederschlag. So trägt der Stofftransport über die Stämme im jungen Sekundärwald im Jahresmittel beispielsweise 17\% und im älteren Sekundärwald $26 \%$ des mit dem Nettoniederschlag transportierten Kaliums bei, während der Anteil im Altbestand bei nur 5\% liegt. Wird die Kaliumfracht mit dem Stammablauf nicht auf Bestandesebene betrachtet, sondern auf einzelne Bäume der oberen Baumschicht bezogen, zeigen sich im Altbestand häufig wesentlich höhere Stoffflüsse als im gleichen Stratum der Sekundärwälder (Abb. 5-3). Die starken Kaliumflüsse der Einzelbäume im Altbestand kommen durch die hohen Elementkonzentrationen im Stammablauf zustande, während die hohen Bestandeswerte in den Sekundärwäldern auf die große Stammdichte beider Sekundärwaldparzellen und eine hohe Wassersammeleffizienz der Kronenbäume im älteren Sekundärwald zurückzuführen ist. Wie bereits in Kapitel 5.2. dargestellt, verteilt sich der Stammablauf der Einzelbäume und die mit ihm transportierten Nährstoffe im Altbestand jedoch auf eine wesentlich größere Stammoberfläche. So werden die Epiphyten der Sekundärwälder von größeren Wasser- und Nährstoffflüssen erreicht, sind aber zusätzlich auch einem stärkeren leaching ausgesetzt als im Altbestand.

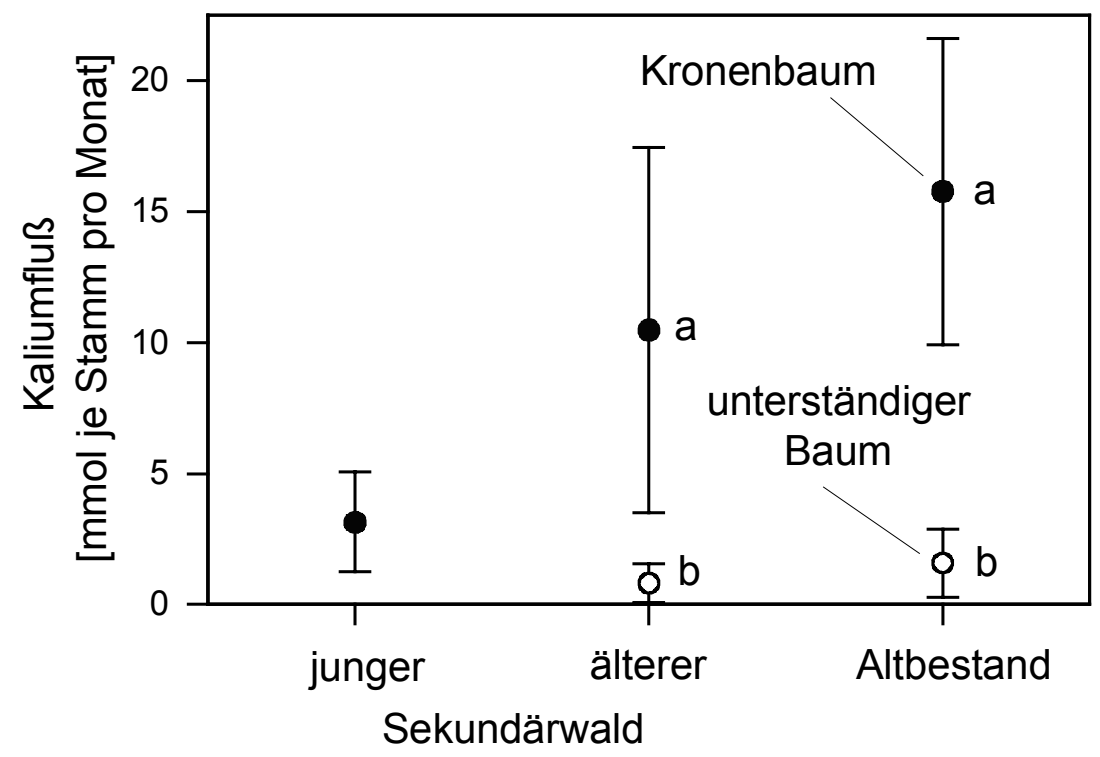

\footnotetext{
Abb. 5-3: Kaliumfluß mit dem Stammablauf in den drei untersuchten Beständen im Monat Mai 2000. Dargestellt sind Mittelwert und Standardabweichung. Im älteren Sekundärwald und im Altbestand wurde zwischen Kronenbäumen und unterständigen Bäumen unterschieden $(\mathrm{n}=5)$. Im einfacher strukturierten jungen Sekundärwald waren alle Sammler an Kronenbäumen angebracht $(\mathrm{n}=10)$. Unterschiedliche Buchstaben kennzeichnen signifikante Unterschiede zwischen Kronenbäumen und unterständigen Bäumen; U-Test nach Wilcoxon $(\mathrm{p}<0.05)$.
} 
Große Nährstoffflußraten durch einen ebenfalls sehr hohen Stammablauf auf Bestandesebene fanden HöLSCHER et al. (1998) in Sekundärwäldern Ost-Amazoniens. Auch SCHROTH et al. (2001) konnten in Sekundärwäldern Zentral-Amazoniens hohe Stoffflußraten mit dem Stammablauf (besonders für Kalium) messen und schlussfolgern, daß der Stammablauf besonders in Beständen mit hoher Stammdichte einen bedeutenden Transportweg für Nährstoffe darstellt. Auch in primären Bergwäldern auf Jamaika, die ebenfalls eine große Stammdichte aufweisen, wurden hohe Nährstoffflüsse mit dem Stammablauf von bis zu 35\% des Nettoniederschlags festgestellt (HAFKENSCHEID 2000). So kann vermutet werden, daß nicht in erster Linie das Bestandesalter, sondern vielmehr die Anzahl der Stämme eines Bestandes für die Bedeutung der Wasser- und Nährstoffflüsse via Stammablauf eine Rolle spielt (HÖLSCHER et al. 2002). Die räumlich sehr heterogene Verteilung des Wassers durch den Stammablauf kann auch eine beträchtliche Veränderung der chemischen Bodeneigenschaften im Stammfußbereich zur Folge haben (GERSPER \& HOLOWAYCHUK 1971). So könnten sich die großen Unterschiede der hydrochemischen Flüsse im Kronenraum der drei untersuchten Waldstadien auch auf die Bodenbedingungen der Bestände auswirken.

Der geringe Nebeleinfluß im Untersuchungsgebiet könnte neben der bereits diskutierten hydrologischen Bedeutung auch einen Einfluß auf den Nährstoffkreislauf der untersuchten Bestände haben. Wie Untersuchungen aus Monteverde in Costa Rica belegen, können die im Nebel enthaltenen Elementkonzentrationen die Nährstoffmengen des Regens um ein Vielfaches übersteigen (CLARK et al. 1998c) und so eine wichtige zusätzliche Nährstoffquelle darstellen. Dies zeigen auch Untersuchungen in anderen tropischen Gebirgsregionen ASBURY et al.1994, GORDON et al. 1994b).

\subsubsection{Nährstoffflüsse mit dem Streufall}

Der Streufall stellt einen der wichtigsten Transportwege für Nährstoffe von der Vegetation zum Boden dar und ist der am häufigsten gemessene Nährstofffluß in Waldökosystemen (Proctor et al. 1983, Vitousek 1984).

Der im Altbestand ermittelte Jahresgesamtstreufall ist mit $1287 \mathrm{~g} \mathrm{~m}^{-2} \mathrm{a}^{-1}$ der höchste bisher in primären tropischen Bergregenwäldern gemessene Wert. Eine sehr ähnliche Streumenge konnte LAMBERT et al. (1980) in einem Tieflandregenwald in Belize messen. Wie ein Vergleich der in den beiden Sekundärwäldern ermittelten Werte mit der Literaturübersicht von MCDONALD \& HEALEY (2000) zeigt, rangiert die im jungen Sekundärwald gemessene Streumenge mit $933 \mathrm{~g} \mathrm{~m}^{-2} \mathrm{a}^{-1}$ im unteren Mittel der Literaturangaben. Der im älteren Sekundärwald gefundene Wert ist mit $1720 \mathrm{~g} \mathrm{~m}^{-2} \mathrm{a}^{-1}$ hingegen als sehr hoch einzustufen. Nur in einem praemontanen Sekundärwald in Costa Rica wurden in einer von FOURNIER \& CAMACHO DE CASTRO (1973) durchgeführten Untersuchung mit $2700 \mathrm{~g} \mathrm{~m}^{-2} \mathrm{a}^{-1}$ (davon $1550 \mathrm{~g}$ $\mathrm{m}^{-2} \mathrm{a}^{-1}$ Blattstreu) noch höhere Werte gemessen. 
Eine mögliche Fehlerquelle bei der Streumessung könnte die Rahmenkonstruktion der Streusammler darstellen, da nicht auszuschließen ist, daß auf den Holzrahmen gefallene Streu anschließend in den Sammler geweht wurde und so zu einer Überschätzung der Werte geführt hat. Andererseits wurden Sammler des gleichen Konstruktionsprinzips auch im jungen Sekundärwald eingesetzt, wo jedoch keine besonders hohen Streuwerte ermittelt wurden. Aufgrund unterschiedlicher Methodik sind Streufalldaten verschiedener Autoren häufig nur schwer miteinander zu vergleichen (PROCTOR 1983, 1984). Die Blattfraktion ist hierbei die am besten abzugrenzende Streukomponente, die außerdem für den Nährstofftransport von entscheidender Bedeutung ist.

Die in der Blattstreu gemessenen Elementkonzentrationen liegen in der vorliegenden Untersuchung innerhalb der Spanne der für primäre tropische Bergregenwälder gemessenen Werte (HEANEY \& PROCTOR 1989). Nur im jungen Sekundärwald wurden deutlich höhere Calciumkonzentrationen ermittelt, während die Magnesiumgehalte im älteren Sekundärwald leicht unterhalb des genannten Bereichs lagen.

Bedingt durch die hohen Streumengen zeigen sich bei allen untersuchten Elementen in der vorliegenden Arbeit sehr hohe Nährstoffflüsse mit der Blattstreu. Die in den drei Beständen ermittelten Stickstoffflüsse liegen höher als in allen bisher in primären tropischen Bergregenwäldern durchgeführten Untersuchungen. Dies ist insofern von Bedeutung, da Stickstoff in tropischen Bergregenwäldern häufig als ein wachstumslimitierender Faktor angesehen wird (EDWARDS 1982). Die Kaliumfrachten mit der Blattstreu sind in den Sekundärwäldern höher als im Altbestand und werden nur von wenigen anderen Untersuchungen übertroffen. Wird im Altbestand jedoch die kaliumreiche Streu des parasitischen Gehölzes Phoradendron berücksichtigt, ergibt sich hier mit $115.6 \mathrm{mmol} \mathrm{m} \mathrm{m}^{2} \mathrm{a}^{-1}$ ein noch höherer Kaliumeintrag als in den beiden anderen Waldstadien. Höhere Calciumflüsse als im untersuchten Altbestand wurden von NADKARNI \& MATELSON (1992a, b) und EDWARDS $(1977,1982)$ gemessen, doch auch diese Werte bleiben deutlich hinter den im jungen und älteren Sekundärwald ermittelten Flüssen zurück. Hingegen liegt der im Altbestand ermittelte Magnesiumfluß innerhalb der Spanne der Literaturangaben, während die in den Sekundärwäldern gemessenen Werte wiederum als sehr hoch einzustufen sind. 
Tab. 5-3: Vergleich der Blattstreumengen und Nährstoffflüsse mit der Blattstreu der drei untersuchten Bestände mit den Angaben anderer Autoren aus Untersuchungen verschiedener primärer Bergregenwälder.

\begin{tabular}{|c|c|c|c|c|c|c|c|}
\hline Ort & $\begin{array}{c}\text { Höhe } \\
\text { [m ü.M.] }\end{array}$ & $\begin{array}{l}\text { Blattstreu } \\
{\left[\mathrm{g} \mathrm{m}^{-2} \mathrm{a}^{-1}\right]}\end{array}$ & \multicolumn{5}{|c|}{$\left[\mathrm{mmol} \mathrm{m}^{-2} \mathrm{a}^{-1}\right]$} \\
\hline Venezuela & 2300 & 338 & 278.3 & 49.5 & 61.9 & 36.2 & 1 \\
\hline Kolumbien & 2550 & 461 & 364.5 & 104.7 & - & - & 2 \\
\hline Kolumbien & 3370 & 282 & 155.9 & 25.1 & - & - & 2 \\
\hline Malaysia & 1310 & 570 & 330.8 & 53.4 & 27.0 & 41.5 & 3 \\
\hline Malaysia & 1860 & 230 & 121.3 & 10.3 & 10.6 & 18.8 & 3 \\
\hline Puerto Rico & 1000 & 245 & 134.7 & 8.6 & 32.2 & 24.6 & 4 \\
\hline $\begin{array}{l}\text { Jamaika } \\
\text { (Mmor) }\end{array}$ & 1824 & 462 & 201.0 & 15.9 & 79.5 & 40.3 & 5 \\
\hline (Pmull) & 1809 & 512 & 282.7 & 22.5 & 100.8 & 45.5 & 5 \\
\hline $\begin{array}{l}\text { Jamaika } \\
\text { (Mor Ridge) }\end{array}$ & 1550 & 490 & 209.9 & 28.8 & 70.9 & 66.5 & 6 \\
\hline (Mull Ridge) & 1550 & 530 & 317.9 & 80.0 & 120.3 & 69.8 & 6 \\
\hline (Wet Slope) & 1550 & 440 & 207.3 & 46.1 & 110.9 & 76.0 & 6 \\
\hline (Gap) & 1550 & 550 & 365.2 & 83.0 & 130.4 & 63.4 & 6 \\
\hline Neu Guinea & 2500 & 620 & 511.9 & 82.9 & 193.1 & 72.0 & 7 \\
\hline Costa Rica & 1500 & 476 & 499.6 & 14.6 & 226.8 & 52.9 & 8 \\
\hline Costa Rica* & 1000 & 550 & 431.9 & 19.7 & 98.8 & 43.2 & 9 \\
\hline Costa Rica* & 2000 & 480 & 308.4 & 27.0 & 131.7 & 37.5 & 9 \\
\hline Costa Rica* & 2600 & 460 & 223.3 & 35.3 & 119.4 & 43.5 & 9 \\
\hline Costa Rica & & & & & & & \\
\hline jung. Sekw. & 2900 & 787 & 511.2 & 83.4 & 360.2 & 70.1 & 10 \\
\hline ält. Sekw. & 2900 & 1259 & 851.0 & 92.5 & 313.5 & 85.2 & 10 \\
\hline Altbestand & 2900 & 720 & 544.7 & 68.7 & 161.2 & 57.5 & 10 \\
\hline
\end{tabular}

1) Steinhardt 1979, 2) VeneKlaAs 1991, 3) Proctor et al. 1983, 4) Weaver et al. 1986, 5) HAFKENSCHEID 2000, 6) TANNER 1977, 1980b, 7) EDWARDS 1977, 1982 berechnet nach HAFKENSCHEID 2000, 8) NADKARNi \& MATELSON 1992b, 9) HEANEY \& PROCTOR 1989, 10) vorliegende Arbeit. (* nichtholzige Feinstreu). 
Eine mögliche Ursache für die in der vorliegenden Untersuchung gefundenen sehr hohen Streumengen (und damit auch für die hohen Nährstoffflüsse) könnte die starke Dominanz der Eichenarten darstellen. Die Gattung Quercus trägt mit Werten von zeitweise über $90 \%$ in einem hohen Maße zur gesamten Blattstreu bei. WiLliams-LinerA \& TOLOME (1996) konnten zeigen, daß in einem mexikanischen Bergwald holarktischen Baumgattungen wie Quercus einen höheren Streufall als Arten tropischer Herkunft aufweisen und daß der Streufall unterschiedlicher Baumarten positiv mit deren Dominanz korreliert ist. So könnte die starke Dominanz der Eichen auch in der eigenen Untersuchung eine mögliche Ursache für die sehr hohen Streumengen darstellen und damit eine zentrale Rolle im Nährstoffumsatz der Bestände spielen.

Im Vergleich zu den durch die Blattstreu bedingten Stoffflüssen sind die Elementdepositionen mit dem Nettoniederschlag als gering einzustufen. So liegen die mit der Blattstreu transportierten Nährstoffmengen um den Faktor 16-20 (N), 4-10 (Ca) und 2-4 (Mg) höher als beim Nettoniederschlag. Eine Ausnahme hiervon zeigt sich bei dem Element Kalium, bei dem die Stoffflüsse mit der Blattstreu im Mittel der drei Bestände etwa um die Hälfte geringer als mit dem Nettoniederschlag sind. Die Ursache hierfür ist vermutlich die leichte Auswaschbarkeit dieses Elementes aus den Streusammlern, die zu einer Unterschätzung der tatsächlichen Konzentrationen in der Blattstreu führt (PROCTOR 1983), während im Nettoniederschlag eine starke Kaliumanreicherung zu beobachten ist.

\subsubsection{Die Bedeutung der Epiphyten im Nährstoffkreislauf}

Gemäß Definition beziehen Epiphyten keine Nährstoffe direkt von ihrem Trägerbaum. Dennoch können sie ihrerseits durch Aufnahme, Speicherung und Freisetzung von Mineralstoffen den ökosystemaren Nährstoffkreislauf beeinflussen. In ihrer Nährstoffversorgung sind Epiphyten zu einem großen Teil auf atmosphärische Ressourcen, zu denen Feucht- und Trockendepositionen wie auch gasförmige Elementeinträge zählen, angewiesen (NADKARNI \& MATELSON 1991). Kryptogamische Epiphyten verfügen, bezogen auf ihre Grundfläche, über eine große Oberfläche, an der sich Regen, Nebel und Stäube niederschlagen können. Die Nährstoffaufnahme erfolgt über die gesamte Pflanzenoberfläche. Weitere physiologische und morphologische Eigenschaften, die der Aufnahme von Nährstoffen dienen, sind beispielsweise die Phytotelmen und Schildhaare bei Bromelien (BENZING 1981). Ferner wird vermutet, daß die organische Substanz von Epiphytenpolstern eine hohe Austauschkapazität für Ionen besitzt und diese aus dem Bestandesniederschlag und Stammablauf zurückhalten kann (NADKARNI 1984). Da auf diese Weise Nährstoffe aus dem ökosystemaren Nährstoffkreislauf entzogen werden können, werden Epiphyten von manchen Autoren auch als ,nutritional pirates“ (BENZING \& SEEMAN 1978) bezeichnet.

Neben der Nutzung atmosphärischer Ressourcen können Epiphyten Nährstoffe auch aus Streu und zersetzter Borke beziehen oder im Niederschlag angereicherte Nährstoffe, die zuvor aus anderen Pflanzen ausgewaschen wurden, aufnehmen (NADKARNI \& MATELSON 1991). 
Interessanterweise zeigen die Nitratflüsse in den drei untersuchten Beständen in Übereinstimmung mit den meisten anderen genannten Untersuchungen eine Abnahme vom Freilandniederschlag zum Nettoniederschlag (Tab. 5-2). HAFKENSCHEID (2000) vermutet, daß $\mathrm{NO}_{3}-\mathrm{N}$ und $\mathrm{NH}_{4}-\mathrm{N}$ von Epiphyten aufgenommen und so dem Nährstoffkreislauf entzogen werden können. VANCE \& NADKARNI (1990) fanden in einem Waldbestand in Monteverde, Costa Rica, eine hohe mikrobielle Biomasse und Aktivität in der organischen Substanz von Epiphytenpolstern. Die Stickstoffmenge, die durch Mikroorganismen in der Kronenregion immobilisiert werden kann, wird auf $0.7 \mathrm{~kg} \mathrm{ha}^{-1}$ geschätzt, was deren Bedeutung und Einfluß auf die Stickstoffverfügbarkeit des Waldes verdeutlicht. Auch in der vorliegenden Untersuchung wäre eine Nitrataufnahme durch Mikroorganismen in der Kronenregion oder durch die Epiphyten selber denkbar. Da sich auch im epiphytenarmen jungen Sekundärwald eine deutliche Abnahme der $\mathrm{NO}_{3}-\mathrm{N}$ Stoffflüsse zeigte, ist auch eine Nitrataufnahme durch die Blätter selbst (PARKER 1983) nicht auszuschließen. Die in den Niederschlägen gemessenen $\mathrm{NO}_{3}$-N-Konzentrationen lagen jedoch häufig unterhalb der Nachweisgrenze und zeigten eine sehr hohe zeitliche und räumliche Variabilität, weshalb diese Ergebnisse mit Vorsicht interpretiert werden sollten.

Eine weitere Möglichkeit, wie Epiphyten den Stickstoffkreislauf beeinflussen können, ist die Fixierung von Stickstoff aus der Luft. BENTLEY \& CARPENTER (1984) und FrEIBERG (1998) konnten zeigen, daß Epiphylle (auf Blattoberflächen lebende Epiphyten) durch Stickstofffixierung einen zusätzlichen Eintrag dieses Elements ins Ökosystem bewirken können. Epiphylle kamen in den untersuchten Beständen im oberen Savege-Tal aufgrund der großen Meereshöhe jedoch nur selten vor, weshalb ihre Bedeutung für den Stickstofffluß in der vorliegenden Arbeit vernachlässigt werden kann.

Epiphyten können einen bedeutenden Nährstoffpool darstellen. So schätzt NADKARNI (1984) die in der Epiphytenvegetation eines Elfenwaldes in Costa Rica gespeicherten Nährstoffvorräte auf bis zu 45\% der in der Blattmasse gespeicherten Nährstoffmenge, obwohl die Epiphyten weniger als zwei Prozent des Trockengewichtes des gesamten Ökosystems ausmachen. Nach HOFSTEDE et al. (1993) übersteigen die in einem kolumbianischen Wolkenwald in der Epiphytenbiomasse festgelegten Stoffmengen die der Blattmasse sogar um den Faktor $7.4(\mathrm{~N}), 6.5(\mathrm{P}), 3.5$ (K) bzw. 2.8 (Ca) und stellen einen beträchtlichen Teil des oberirdischen Nährstoffpools dar.

Aus diesem oberirdischen Nährstoffpool können die Mineralstoffe a) durch epiphytischen Streufall oder b) durch Auswaschung aus Epiphytenpolstern (leaching) wieder freigesetzt werden. 


\section{a) Epiphytischer Streufall}

Der Streufall von Epiphyten unterscheidet sich besonders durch eine hohe zeitliche und räumliche Variabilität vom Streufall terrestrisch wurzelnder Pflanzen und weist kein klar erkennbares saisonales Muster auf (TANNER 1980b, VENEKLAAS 1991, NADKARNI \& MATELSON 1992a). Dies steht im Einklang mit den eigenen Beobachtungen. In den wenigen Untersuchungen, in denen der Epiphytenstreufall in tropischen Primärwäldern gemessen wurde, reicht die Spanne der ermittelten Jahreswerte von $0 \mathrm{~g} \mathrm{~m}^{-2} \mathrm{a}^{-1}$ (PROCTOR et al. 1989) bis $50 \mathrm{~g} \mathrm{~m}^{-2} \mathrm{a}^{-1}$ (NADKARNI \& MATELSON 1992a). Die in der vorliegenden Arbeit im Altbestand gemessenen Streumengen liegen mit $79 \mathrm{~g} \mathrm{~m}^{-2} \mathrm{a}^{-1}$ deutlich darüber. Besonders vor dem Hintergrund der im Vergleich $\mathrm{zu}$ anderen primären Bergregenwäldern geringen Epiphytenbiomasse in diesem Bestand ist dies erstaunlich. Der Streufall der Epiphyten zeigt jedoch keine zwangsläufig lineare Abhängigkeit von der Epiphytenbiomasse, sondern kann durch Artenzusammensetzung der Epiphyten, Baumstruktur, Bestandesrauhigkeit und Windgeschwindigkeit beeinflußt werden. So fielen in der vorliegenden Untersuchung etwa 39\% des im Altbestand gemessenen hohen Jahreswertes auf den Monat Dezember 2000. In diesem Monat wurden auch die höchsten im Untersuchungszeitraum gemessenen Windgeschwindigkeiten verzeichnet. Vermutlich aufgrund der großen Bestandeshöhe zeigten sich im Altbestand größere Auswirkungen des Windes auf den Streufall als in den Sekundärwaldbeständen. Auch wenn der Streufall der Epiphyten von unterschiedlichen Faktoren beeinflußt wird, ist unter den vergleichbaren Standortbedingungen in der Cordillera Talamanca mit zunehmendem Bestandesalter und zunehmender Epiphytenbiomasse auch ein Ansteigen des epiphytischen Streufalls zu beobachten. So wurden im jungen und älteren Sekundärwald mit 5 und $12 \mathrm{~g} \mathrm{~m}^{-2} \mathrm{a}^{-1}$ deutlich geringere Werte als im Altbestand verzeichnet. Bisher liegen keine vergleichbaren Untersuchungen zum Streufall von Epiphyten in Sekundärwäldern tropischer Bergregionen vor.

In der vorliegenden Untersuchung wurde bei verschiedenen, in der Kronenregion des Altbestandes häufigen Moosarten eine Bestimmung der Nährstoffgehalte durchgeführt. Diese Werte dienten auch zur Berechnung der Stoffflüsse mit der Epiphytenstreu. Die Elementkonzentrationen liegen im Bereich der von NADKARNI (1984) und HofSTEDE et al. (1993) für epiphytische Bryophyten ermittelten Werte, wobei die von NADKARNI (1984) gemessenen Stickstoffkonzentrationen deutlich über den im Altbestand gemessenen Werten lagen. Im Gegensatz zur vorliegenden Untersuchung wurde in den beiden anderen Studien die Stoffflüsse anhand der Nährstoffgehalte der Streu berechnet. Trotz dieser methodischen Unterschiede bewegen sich die in diesen Untersuchungen gefundenen Werte in ähnlichen Größenordnungen wie im Altbestand (Tab. 5-4). Die Sekundärwälder weisen aufgrund der geringeren Streumengen deutlich niedrigere Nährstoffflüsse auf. 
Tab. 5-4: Nährstoffflüsse mit der Streu epiphytischer Moose und Flechten. In der vorliegenden Arbeit beruht die Berechnung auf den Elementkonzentrationen frisch geernteter Moosarten und den jeweiligen Jahresstreumengen epiphytischer Moose und Flechten. Die Ergebnisse der anderen Autoren basieren auf den in der Epiphytenstreu ermittelten Elementkonzentrationen. Die Angaben von NADKARNI \& MATELSON (1992a) beziehen sich dabei nur auf epiphytische Bryophyten. In Klammern sind die Nährstoffflüsse der Epiphyten in Prozent der Flüsse mit der Blattstreu angegeben.

\begin{tabular}{lccccccccccc}
\hline Ort & $\begin{array}{c}\text { Höhe } \\
{[\mathrm{m} \text { ü.M.] }]}\end{array}$ & $\begin{array}{c}\text { Streu } \\
{\left[\mathrm{g} \mathrm{m}^{-2} \mathrm{a}^{-1}\right]}\end{array}$ & $\mathrm{N}$ & \multicolumn{3}{c}{$\begin{array}{c}\mathrm{Ca} \\
{\left[\mathrm{mmol} \mathrm{m}^{-2} \mathrm{a}^{-1}\right]}\end{array}$} & $\mathrm{Mg}$ & Ref. \\
\hline Costa Rica & 1500 & 37.5 & 42.3 & $(8.5)$ & 0.3 & $(2.1)$ & 7.9 & $(3.5)$ & 2.6 & $(4.4)$ & 1 \\
Kolumbien & 2550 & 11.0 & 12.9 & $(3.5)$ & 2.0 & $(2.0)$ & - & & - & 2 \\
Kolumbien & 3370 & 18.4 & 12.1 & $(7.7)$ & 1.5 & $(6.1)$ & - & & - & & 2 \\
Costa Rica & & & & & & & & & & & \\
jung. Sekw. & 2900 & 3.3 & 2.2 & $(0.4)$ & 0.3 & $(0.5)$ & 0.3 & $(0.1)$ & 0.2 & $(0.3)$ & 3 \\
ält. Sekw. & 2900 & 8.1 & 5.5 & $(0.7)$ & 0.8 & $(1.0)$ & 0.7 & $(0.2)$ & 0.4 & $(0.5)$ & 3 \\
Altbestand & 2900 & 34.5 & 23.5 & $(4.3)$ & 3.6 & $(5.2)$ & 3.0 & $(1.9)$ & 1.7 & $(3.0)$ & 3 \\
\hline
\end{tabular}

1) NADKARNI \& MATELSON 1992a, 2) VENEKLAAS 1991, 3) vorliegende Arbeit

Die Nährstoffflüsse mit dem Streufall der epiphytischen Moose und Flechten betragen im Altbestand 4\% $(\mathrm{N}), 5 \%(\mathrm{~K}), 2 \%(\mathrm{Ca})$ und $3 \%(\mathrm{Mg})$ der über die Blattstreu transportierten Nährstofffracht. In den Sekundärwäldern wird bei keinem Element die 1\%-Marke überschritten. Ähnliche Verhältnisse wie im Altbestand sind auch in den anderen Untersuchungen zu beobachten (Tab 5-4). Insgesamt sind daher die durch den Streufall der epiphytischen Moose und Flechten bedingten Nährstoffflüsse im Vergleich zur Blattstreu als gering einzuschätzen. Für die epiphytischen Gefäßpflanzen wurden keine Nährstoffkonzentrationen ermittelt. Aufgrund der niedrigen Streufallwerte ist ihre Bedeutung für die Nährstoffflüsse in den Sekundärwäldern vermutlich jedoch nur gering. Größere Auswirkungen sind hingegen im Altbestand zu erwarten, da hier die Streumengen der epiphytischen Gefäßpflanzen die der epiphytischen Moose und Flechten übertrafen.

Dennoch sind angesichts der zum Teil großen epiphytischen Biomasse in einigen primären Bergregenwäldern der Tropen die epiphytischen Streumengen und die damit verbundenen Nährstoffflüsse als verhältnismäßig gering einzuschätzen. VENEKLAAS (1991) führt niedrige epiphytische Streumengen darauf zurück, daß sich besonders Bryophyten in der Krone akkumulieren und nur zufällig durch Störungseinflüsse herabfallen. Die Nettoprimärproduktion der Epiphyten übertrifft den mit den Streufängern erfaßten Anteil daher vermutlich um ein Vielfaches. 


\section{b) Leaching aus Epiphyten}

Da leaching bei vielen Elementen vermutlich die Hauptursache für deren Anreicherung im Niederschlag während der Kronenpassage ist (PARKER 1983), ließe eine große Epiphytenbiomasse auch eine starke Elementanreicherung im Nettoniederschlag erwarten. Da Bryophyten über weniger effektive Abschlußgewebe als Gefäßpflanzen verfügen, wäre besonders hier eine starke Auswaschung $\mathrm{zu}$ erwarten. Da sich jedoch bei allen drei untersuchten Beständen ähnliche Anreicherungsfaktoren zeigen, kann der Nettoeffekt der Epiphyten nicht sehr groß sein. Hierzu trägt sicherlich auch die geklumpte, heterogene Verteilung der Epiphyten in der Krone bei.

Die in der epiphytischen Biomasse akkumulierten Nährstoffe können diesen oberirdischen Nährstoffpool auf einem weiteren Transportweg verlassen. Durch die Ausbildung eines Kronenwurzelsystems kann sich der Phorophyt selbst einen direkten Zugang zu den in der Kronenregion gespeicherten Nährstoffen verschaffen (NADKARNI 1981). Dies bestätigte sich auch in der vorliegenden Untersuchung. Im Altbestand konnten in der in den Astgabeln von Quercus copeyensis akkumulierten organischen Substanz ebenfalls Kronenwurzeln der entsprechenden Eichenart nachgewiesen werden (HERTEL, mündl. Mitteil.). 


\subsection{Hydrologische Folgen der Zerstörung primärer Bergregenwälder}

Tropische Bergregenwälder oder Wolkenwälder bedecken in Costa Rica derzeit noch 10757 $\mathrm{km}^{2}$ (KAPPELLE \& BROWN 2001), wobei ein großer Teil dieser Waldfläche in der Cordillera Talamanca zu finden ist. Für dieses Gebiet prognostizierte BLASER (1987) eine zunehmende Erschließung der montanen Eichenwälder, die aufgrund fehlender nachhaltiger Nutzungsmethoden eine massive Waldzerstörung zur Folge haben sollte. Dennoch zeigen die Entwaldungsraten im oberen Talbereich des Rio Savegre in den letzten Jahrzehnten stark rückläufige Tendenzen (VAN OMME 1998), so daß in naher Zukunft zumindest in diesem Gebiet nicht mit einer großflächigen Waldzerstörung zu rechnen ist. Insgesamt sind tropische Bergregenwälder jedoch stark im Rückgang begriffen und die Entwaldungsraten sind vermutlich höher als in allen anderen neotropischen Ökosystemen (LABASTILLE \& POOL 1978, DOUMENGE et al. 1995).

Die tiefgreifenden hydrologischen Veränderungen, die eine Waldzerstörung nach sich zieht, werden von BRUIJNZEEL (2002) analysiert. So kann nach Waldrodung Interzeption von Regen oder Nebel nicht mehr durch Bäume, sondern nur noch durch Gräser und Kräuter stattfinden, was in der Regel zu einer Erhöhung der Nettoniederschläge führt. Ferner resultiert die Waldzerstörung auch in einer Verminderung des Wasserverbrauchs durch die fehlende Transpiration der Bäume. So hat die Rodung von Bergwald in nebelarmen Gebieten eine Zunahme des Gewässerabflusses (streamflow) von etwa 100 bis $400 \mathrm{~mm}$ im Jahr zur Folge (BRUIJNZEEL 1990). Da es infolge der Waldzerstörung häufig zu einer Bodenverdichtung und einer verminderten Infiltrationskapazität der Böden kommt, gehen die potentiell zusätzlich verfügbaren Wassermengen in der Regenzeit durch oberirdischen Geländeabfluß verloren und stellen eine Überschwemmungsgefahr für tiefergelegene Regionen dar. Weil Boden- und Grundwasservorräte nicht mehr aufgefüllt werden können, kann dies einen verminderten Gewässerabfluß in der darauffolgenden Trockenzeit zur Folge haben (BRUIJNZEEL 1989).

In Wolkenwaldgebieten besteht nach dem Verschwinden des Waldes eine besonders große Gefahr durch verminderte Wasserabflüsse in der Trockenzeit (ZADROGA 1981, BRUIJNZEEL 2002). In diesen Wäldern kann das Auskämmen horizontaler Niederschläge durch die Bäume zu einem zusätzlichen Wassereintrag führen, der jedoch nach der Waldrodung verloren geht. Dies ist besonders in Trockenzeitmonaten von großer Bedeutung, wenn im Freiland keine oder nur geringe Niederschlagsmengen fallen. Durch den Rückgang des Gewässerabflusses kann die Waldzerstörung auch katastrophale Folgen für die Wasserversorgung flußabwärts gelegener Täler haben (BUDOwSKI 1976, 1980 in STADTMÜLLER 1987). Nach LABASTILLE \& PoOL (1978) können Wolkenwälder als gewaltige natürliche Bewässerungssysteme angesehen werden, die Wasser wie ein Schwamm speichern und gleichmäßig wieder abgeben. 
In der vorliegenden Arbeit konnte gezeigt werden, daß auch nach 40jähriger Waldsukzession die Epiphytenbiomasse deutliche Unterschiede zum untersuchten Altbestand aufweist. Zwar erwies sich der Einfluß der Epiphyten auf die oberirischen hydrologischen Flüsse in den untersuchten Waldbeständen als eher gering; dennoch ist zu vermuten, daß auch im oberen Savegre-Tal die Rodung von Primärwäldern zu einer Zunahme des streamflows in der Regenzeit und zu einer Abnahme des Gewässerabflusses in der Trockenzeit führen würde. Mit fortschreitender Waldsukzession wird von vielen Autoren eine Wiederherstellung der hydrologischen Prozesse erwartet. Die eigenen Ergebnisse lassen jedoch erkennen, daß sich das ältere Sekundärwaldstadium in hydrologischer Hinsicht sogar stärker vom untersuchten Altbestand unterscheidet als der junge Sekundärwald. Da im Untersuchungsgebiet kein noch älteres Sekundärwaldstadium (80 oder 100 Jahre) für weitere Untersuchungen zur Verfügung stand, bleibt ungeklärt, ob und wann sich die untersuchten Prozesse wirklich den Primärwaldbedingungen annähern. Die vergleichsweise geringe Interzeption der untersuchten Sekundärwaldbestände läßt einen erhöhten Gewässerabfluß im Vergleich zum Altbestand während der Regenzeit erwarten, wobei jedoch keine Informationen über den transpirativen Wasserverbrauch der drei Waldbestände vorliegen. Ferner ist auch wenig über die Regenerationsfähigkeit der Infiltrations- und Wasserspeicherkapazität der Böden nach Waldrodung bekannt, die besonders für den streamflow während der Trockenzeit von großer Bedeutung sein könnte. Die von HERTEL et al. (2002) auf den Untersuchungsflächen durchgeführten Bodenuntersuchungen lassen jedoch erkennen, daß sich die drei Bestände stark in der Mächtigkeit ihrer organischen Auflage unterscheiden. So beträgt die Humusauflage im jungen Sekundärwald $12.6 \mathrm{t} \mathrm{ha}^{-1}$, im älteren Sekundärwald $64.9 \mathrm{t} \mathrm{ha}^{-1}$ und im Altbestand $118.7 \mathrm{t} \mathrm{ha}^{-1}$ (HERTEL, mündl. Mitteil.). Wird der in einem ecuadorianischen Bergregenwald in $3100 \mathrm{~m}$ ü.M. von RöDERSTEIN (mündl. Mitteil.) gemessene mittlere Streuwassergehalt mehrerer Monate (400\% TG) zugrunde gelegt, ergibt sich im jungen Sekundärwald eine Wasserspeicherkapazität der Streuschicht von $5 \mathrm{~mm}$, während die Werte im älteren Sekundärwald mit $26 \mathrm{~mm}$ und im Altbestand mit $47 \mathrm{~mm}$ deutlich höher liegen. Der für den Altbestand ermittelte Wert ist etwa um den Faktor 60 höher als die geschätzte Wasserspeicherkapazität der epiphytischen Moose und Flechten in der oberen Baumschicht dieses Bestandes. Demnach hat die organische Auflage neben einer wichtigen Funktion im Nährstoffkreislauf auch eine große hydrologische Bedeutung. Allerdings ist zu berücksichtigen, daß ähnlich wie bei den Epiphyten auch hier die Wasserspeicherkapazität nicht für jedes Niederschlagsereignis zur Verfügung steht. Da es bei der Waldzerstörung meist $\mathrm{zu}$ einem vollständigen Verlust der organischen Auflage kommt, muß dies auch langfristige Auswirkungen auf den ökosystemaren Wasserhaushalt haben. Werden die im jungen und älteren Sekundärwald gemessenen Auflagemächtigkeiten von 4.2 und $9.9 \mathrm{~cm}$ zugrunde gelegt, würde die Regeneration der im Altbestand gefundenen Auflage $(18.8 \mathrm{~cm})$ rund 76 Jahre in Anspruch nehmen. Diese Zeitspanne entspricht in etwa den Angaben von KAPPELLE et al. (1996), der die nötige Zeitdauer von der Entwaldung bis zum Erreichen der ursprünglichen Waldstruktur auf mindestens 84 Jahre schätzt. In Elfenwäldern Puerto Ricos wird die nach Entwaldung nötige Sukzessionsdauer zum Erreichen der ursprünglichen pflanzlichen Biomasse sogar auf 200 Jahre geschätzt (WEAVER 1990). 
Über den genauen Verlauf der sekundären Sukzession in tropischen Bergregenwäldern ist jedoch erst sehr wenig bekannt. Zum augenblicklichen Wissensstand muß davon ausgegangen werden, daß die Zerstörung von Wolkenwäldern in vielerlei Hinsicht irreversible Folgen hat (HAMILTON 1995). Es kann gefolgert werden, daß die Zerstörung der tropischen Bergregenwälder in Costa Rica und in anderen Regionen nicht nur zu empfindlichen Biodiversitätsverlusten führen, sondern auch spürbare Auswirkungen für den regionalen und überregionalen Wasserhaushalt haben wird. 


\section{Zusammenfassung}

In einer vergleichenden Studie wurde eine Chronosequenz verschiedener Sukzessionsstadien eines Bergregenwaldes der oberen montanen Stufe der Cordillera Talamanca, Costa Rica, untersucht. Diese umfaßte einen 10-15jährigen Sekundärwald, einen 40jährigen Sekundärwald und einen Altbestand (Primärwald). Ziel der Untersuchung war die Klärung der Fragen, (a) wie sich die Bestandesstruktur und die epiphytische Biomasse der Bestände im Sukzessionsverlauf verändern und (b) welche ökosystemare Bedeutung die Epiphyten für den Kronenwasserumsatz und die Nährstoffflüsse in den drei Waldstadien haben.

Die bestandesstrukturellen Untersuchungen ergaben, daß sich die drei Waldstadien deutlich in Bestandeshöhe, Stammdichte, Anzahl der Baumschichten sowie dem Anteil von ober- und unterständigen Bäumen unterschieden. Der mit dem Blattflächenmeßgerät LAI 2000 ermittelte Blattflächenindex zeigte im jungen Sekundärwald und im Altbestand keine signifikanten Unterschiede, während im älteren Sekundärwald ein um 24\% höherer Wert gemessen wurde. Die Bestimmung des LAI anhand des Blattstreufalls ergab bei einer Blattlebensdauer von 1.5 Jahren $8.8 \mathrm{~m}^{2} \mathrm{~m}^{-2}$ im jungen Sekundärwald, $13.8 \mathrm{~m}^{2} \mathrm{~m}^{-2}$ im älteren Sekundärwald und $7.7 \mathrm{~m}^{2}$ $\mathrm{m}^{-2}$ im Altbestand.

Die Streuproduktion ließ deutliche Unterschiede zwischen den drei Waldstadien erkennen, wobei die im älteren Sekundärwald und im Altbestand ermittelten jährlichen Gesamtmengen der Feinstreu mit $1720 \mathrm{~g} \mathrm{~m}^{-2} \mathrm{a}^{-1}$ bzw. $1287 \mathrm{~g} \mathrm{~m}^{-2} \mathrm{a}^{-1} \mathrm{zu}$ den höchsten bisher in tropischen Bergregenwäldern gemessenen Werten zählen. Der Streufall der Baumblätter stellte mengenmäßig die bedeutendste Streufraktion dar, die in allen drei Beständen eine saisonale Dynamik mit deutlich erhöhten Streumengen in der Trockenzeit zeigte. Die epiphytischen Streumengen nahmen mit dem Bestandesalter vom jungen Sekundärwald $\left(4.8 \mathrm{~g} \mathrm{~m}^{-2} \mathrm{a}^{-1}\right)$ über den älteren Sekundärwald $\left(12 \mathrm{~g} \mathrm{~m}^{-2} \mathrm{a}^{-1}\right)$ zum Altbestand $\left(78.5 \mathrm{~g} \mathrm{~m}^{-2} \mathrm{a}^{-1}\right) \mathrm{zu}$, waren aber im Vergleich zu den übrigen Streufraktionen gering.

Ein Vergleich der Epiphytenbiomasse der drei Bestände zeigte mit steigendem Bestandesalter einen zunehmenden Epiphytenbewuchs in der Kronenregion. Die Schätzung der gesamten epiphytischen Biomasse auf Bestandesebene (inklusive Kronenhumus) ergab $160 \mathrm{~kg} \mathrm{ha}^{-1} \mathrm{im}$ jungen Sekundärwald, $520 \mathrm{~kg} \mathrm{ha}^{-1} \mathrm{im}$ älteren Sekundärwald und etwa $3400 \mathrm{~kg} \mathrm{ha}^{-1} \mathrm{im}$ Altbestand.

Mikrometeorologische Untersuchungen deuteten auf einen geringen Nebeleinfluß und ließen eine ausgeprägte Trockenzeit erkennen. Im Bestandesinneren wiesen alle drei Waldstadien vergleichbare Vertikalprofile von Lufttemperatur und Luftfeuchte auf. Die größere Epiphytenbiomasse des Altbestandes führte zu keiner meßbaren Erhöhung der Luftfeuchte im Bestandesinneren.

Der Bestandesniederschlag zeigte mit Werten zwischen $69 \%$ und $75 \%$ des Freilandniederschlags im Jahresmittel nur geringe Unterschiede zwischen den Beständen. Wesentlich größer waren die Bestandesunterschiede hingegen beim Stammablauf, der im jungen und älteren Sekundärwald im Jahresmittel 16\% bzw. 17\% erreichte, während im Altbestand nur 2\% gemessen wurden. Die Interzeption betrug im Altbestand 25\% und lag deutlich über den im jungen Sekundärwald (15\%) und im älteren Sekundärwald (9\%) 
ermittelten Werten. Diese Befunde werden auf Unterschiede in der Struktur und Exposition der Bestände zurückgeführt.

Beregnungsexperimente im Labor zeigten, daß bestimmte epiphytische Moosarten (Leptodontium exasperatum) mehr als das Siebenfache ihres Trockengewichts an Wasser speichern können. Die in der Kronenregion des Altbestandes bei dieser Art gemessenen Wassergehalte waren jedoch selbst in der Regenzeit deutlich niedriger (406\%). Aufgrund geringer Verdunstungsraten ist die Bedeutung epiphytischer Moose im Interzeptionsprozeß vermutlich eher als gering einzuschätzen, da die Speicherentleerung langsam verläuft. Zur recht geringen Bedeutung trägt auch die heterogene Verteilung der Epiphyten und, in den Sekundärwäldern, deren verhältnismäßig geringe Biomasse bei. Eine für den Altbestand durchgeführte hydrologische Modellrechnung, nach der die epiphytischen Moose mit nur 6\% an der Gesamtinterzeption des Bestandes beteiligt sind, bestätigt diese Ergebnisse.

Nährstoffe (mit Ausnahme von Nitrat) wurden im Jahresmittel vom Freilandniederschlag zum Nettoniederschlag während der Kronenpassage angereichert. Die bestandesinternen Nährstoffflüsse ließen in der Gesamtmenge der mit dem Niederschlag transportierten Nährstoffe nur geringe Unterschiede zwischen den drei Waldsstadien erkennen. Beim Stammabfluß zeigten sich jedoch deutliche Unterschiede, wobei hohe Nährstoffflußraten in den Sekundärwäldern auffallen. Dies wird in erster Linie auf die hohe Stammdichte und die Kronenstruktur in den Sekundärwäldern zurückgeführt, während der Einfluß der Epiphyten auf die Nährstoffflüsse als eher gering einzuschätzen ist. Die Nährstofftransfers mit der Streu epiphytischer Moose und Flechten sind im Vergleich zu den über die Blattstreu transportierten Stoffmengen ebenfalls niedrig.

Die Ergebnisse zeigen, daß die Folgen einer Konversion von Primärwald für den Wasser- und Nährstoffhaushalt auch nach 40jähriger sekundärer Waldsukzession noch deutlich erkennbar sind. Hierbei ist die Rolle der Epiphyten jedoch eher als gering einzuschätzen. Die gefundenen Unterschiede im Kronenwasserumsatz und Nährstoffkreislauf lassen sich im Wesentlichen auf strukturelle Charakteristika im Baumbestand der untersuchten Waldstadien zurückführen. 


\section{Summary}

In a comparative study, conducted in the Costa Rican Cordillera Talamanca, a chronosequence of three different successional stages of an upper montane rain forest was investigated. This comprised a 10-15 years old early secondary forest, a 40 years old later secondary forest, and an old-growth (primary) forest. The objectives of this study were (a) to elucidate how the structure of the stands and the biomass of their epiphytes changes with succession, and (b) to quantify the contribution of epiphytes to the fluxes of water and nutrients in different successional stages at the ecosystem level.

Investigation of the structure revealed marked differences between the three stands with regard to their height, stem density, number of tree layers, and the proportion of trees reaching into the lower or upper canopy layer. Leaf area indices (LAI) measured with a LAI 2000 plant canopy analyzer showed no significant differences between the early secondary forest and the old-growth forest, whereas the later secondary forest exhibited a $24 \%$ higher value. Estimates of this parameter from leaf litter collections and an assumed average life span of the leaves of 1.5 years support these data, adding up to values of $8.8 \mathrm{~m}^{2} \mathrm{~m}^{-2}$ for the early secondary forest, $13.8 \mathrm{~m}^{2} \mathrm{~m}^{-2}$ for the later secondary forest, and $7.7 \mathrm{~m}^{2} \mathrm{~m}^{-2}$ for the old-growth forest.

Amounts of litter production exhibited significant differences between the stands, with annual values found in the later secondary forest and the old-growth forest $\left(1720 \mathrm{~g} \mathrm{~m}^{-2} \mathrm{a}^{-1}\right.$ and $1287 \mathrm{~g}$ $\mathrm{m}^{-2} \mathrm{a}^{-1}$, respectively) being among the highest measured in tropical montane rain forests. Leaves of trees constituted the largest fraction of litter, which markedly increased during the dry season. Litterfall from epiphytes increased with succession from $4.8 \mathrm{~g} \mathrm{~m}^{-2} \mathrm{a}^{-1}$ in the early secondary and $12.0 \mathrm{~g} \mathrm{~m}^{-2} \mathrm{a}^{-1}$ in the later secondary forest to $78.5 \mathrm{~g} \mathrm{~m}^{-2} \mathrm{a}^{-1}$ in the old-growth forest, but was always small in comparison to other litter fractions.

A comparison of the epiphytic biomasses showed increasing values with increasing age of the investigated stand. An estimate of the total epiphytic biomass at the stand level (including crown humus) resulted in $160 \mathrm{~kg} \mathrm{ha}^{-1}$ in the early secondary forest, $520 \mathrm{~kg} \mathrm{ha}^{-1}$ in the later secondary forest, and $3400 \mathrm{~kg} \mathrm{ha}^{-1}$ in old-growth forest.

Micrometeorological measurements revealed a comparatively low influence of fog and a pronounced dry season. Inside the forests, all three stages of succession displayed similar vertical profiles of air temperature and air humidity. The greater epiphytic biomass of the oldgrowth forest did not produce a measurable increment of air humidity within the stand.

Little differences between the stands were detected with regard to throughfall, with annual values averaging to between 69 and $75 \%$ of incident precipitation. However, differences were larger with regard to the stem flow, which ranged from annual values of only about $2 \%$ in the old-growth stand and $16 \%$ and $17 \%$ in the early and later secondary forest, respectively. Interception reached $25 \%$ in the old-growth forest, whereas significantly lower values were measured in the early $(15 \%)$ and the later secondary forest $(9 \%)$. These results are due to differences in stands structure and exposition. 
Artificial rainfall experiments carried out in the laboratory showed that appointed epiphytic Bryophyte species (Leptodontium exasperatum) are capable of storing more than seven times their dry weight of water. However, water contents obtained in the canopy of the old-growth forest yielded much lower values of water storage (406\%) for these species even in the rainy season. On account of their small evaporation rates and the slow recovery of water storage capacity, the influence of epiphytic Bryophytes on the interception of rainfall is assumed to be low. It is further reduced by their heterogenous distribution and their small biomasses in the secondary forests. This assumption is confirmed by a hydrological model calculation carried out for the old-growth forest, which shows a contribution by the mossy epiphyte vegetation of only $6 \%$ to the total rate of interception.

On annual average, nutrients (with the exception of nitrate) were enriched during the crown passage from incident rainfall to net precipitation. The total amounts of nutrients transported with precipitation within the stands revealed only small differences between the different stages of succession. However, nutrient fluxes within the stem flow showed marked differences, with high values measured in the secondary forests. This is caused mainly by high stem densities and the crown structure in these forests, whereas the influence of epiphytic vegetation is suggested to be low. In comparison to the amounts of nutrients transported via the litter of leaves, nutrient transfer with the litter of epiphytic mosses and lichens is also found to be insignificant.

These results show that the effects of a conversion from primary to secondary forest on water and nutrient budgets are considerable even after 40 years of secondary succession. However, the influence of epiphytic vegetation on these budgets is probably small. The differences between stages of succession with regard to water and nutrient fluxes can be put down to structural differences between the stands. 


\section{Resumen}

En un estudio comparativo se investigó una cronosecuencia de diferentes estadios sucesionales de un bosque de altura del piso montano alto en la Cordillera Talamanca, Costa Rica. Esta comprende un bosque secundario con una edad entre 10 y 15 años, un bosque secundario de 40 años y un bosque maduro (bosque primario). La presente investigación tiene como objetivo contestar las siguientes preguntas (a) cómo cambia la estructura de los rodales y la biomasa de las epífitas durante el proceso de sucesión y (b) qué papel juegan las epífitas en el flujo de agua y nutrientes dentro del ecosistema.

La investigación sobre la estructura del bosque indicó que los tres rodales difieren claramente en la altura del rodal, la densidad de los fustes, el número de los estratos y en la proporción de los árboles del dosel inferior y del dosel superior. El índice de área foliar (LAI) determinado con el LAI 2000 no mostró una diferencia significativa entre el bosque secundario joven y el bosque maduro. En el bosque secundario más viejo se obtuvo un valor $24 \%$ más alto. La determinación del LAI por medio de la caída de hojarasca asumiendo una longevidad de las hojas de 1.5 años resultó en $8.8 \mathrm{~m}^{2} \mathrm{~m}^{-2}$ en el bosque secundario joven, $13.8 \mathrm{~m}^{2} \mathrm{~m}^{-2}$ en el bosque secundario más viejo y $7.7 \mathrm{~m}^{2} \mathrm{~m}^{-2}$ en el bosque maduro.

Se encontraron diferencias marcadas en la caída de hojarasca entre los tres rodales. Los valores anuales de la hojarasca fina total en el bosque secundario más viejo $\left(1720 \mathrm{~g} \mathrm{~m}^{-2} \mathrm{a}^{-1}\right) \mathrm{y}$ en el bosque maduro (1287 $\mathrm{g} \mathrm{m}^{-2} \mathrm{a}^{-1}$ ) pertenecen a los valores más altos para bosques tropicales de altura. De las distintas fracciones de hojarasca, cuantitativamente la hojarasca foliar es lo más importante y presentó en todos los rodales una dinámica estacional con valores elevados en la época seca. Las cantidades de la hojarasca de las epífitas aumentaron con la edad de los rodales alcanzando $4.8 \mathrm{~g} \mathrm{~m}^{-2} \mathrm{a}^{-1}$ en el bosque secundario joven, $12 \mathrm{~g} \mathrm{~m}^{-2} \mathrm{a}^{-1}$ en el bosque secundario más viejo hasta $78.5 \mathrm{~g} \mathrm{~m}^{-2} \mathrm{a}^{-1}$ en el bosque maduro, pero en comparación con las otras fracciones de hojarasca fueron bajas.

Las cantidades de la biomasa de las epífitas en las copas aumentaron con la edad de los rodales. La estimación de la biomasa de las epífitas a nivel de rodal (incluyendo el humus en las copas) resultó en $160 \mathrm{~kg} \mathrm{ha}^{-1}$ en el bosque secundario joven, $520 \mathrm{~kg} \mathrm{ha}^{-1}$ en bosque secundario más viejo y $3400 \mathrm{~kg} \mathrm{ha}^{-1}$ en el bosque maduro.

Las investigaciones micrometeorológicas mostraron una influencia baja de la niebla, así como una época seca marcada. Dentro de los tres rodales se presentaron perfiles verticales de la temperatura y la humedad del aire relativamente similares. Una mayor cantidad de la biomasa de las epífitas en el bosque maduro no resultó en un aumento cuantificable de la humedad atmosférica dentro del rodal.

El escurrimiento foliar anual osciló poco entre los tres rodales, con valores entre $69 \%$ y $75 \%$ de la precipitación total. El escurrimiento anual en fustes mostró mayores diferencias, con porcentajes de $16 \%$ en el bosque secundario joven, $17 \%$ en el bosque secundario más viejo y tan sólo $2 \%$ en el bosque maduro. La intercepción fue más grande en el bosque maduro (25\%) que en el bosque secundario joven (15\%) y el bosque secundario más viejo (9\%). Estos resultados se atribuyen a las diferencias de la estructura y la exposición de los rodales. 
Experimentos controlados (simulación de lluvia) llevados a cabo en el laboratorio mostraron que distintas especies de briofitas epífitas (Leptodontium exasperatum) presentan una alta capacidad para captar agua, con más de siete veces su propio peso seco. Mediciones en muestras de la misma especie tomadas en el dosel de las copas del bosque maduro presentaron aún en la época lluviosa contenidos de agua más bajos (406\%). Por causa de una tasa de evaporación baja, se considera que el aporte de las briofitas epífitas en el proceso de intercepción es pequeño, porque la capacidad de vaciado del depósito es lenta. La distribución heterógenea de las epífitas y su baja biomasa en los bosques secundarios restan importancia dentro del proceso de intercepción. Estos resultados están confirmados en el cálculo del modelo hidrológico llevado a cabo para el bosque maduro, indicando que las briofitas epífitas contribuyen con solamente $6 \%$ de la intercepción total.

Los nutrientes (con excepción de nitrato) mostraron en promedio anual un enriquecimiento en la precipitación neta con respecto a la precipitación total durante el paso del agua por las copas. La comparación de los flujos de nutrientes dentro de los rodales asociados con las precipitaciones mostraron sólo pequeñas diferencias en la cantidad total de los nutrientes entre los tres rodales. Mayores diferencias se encontraron en el escurrimiento en los fustes, donde los flujos de nutrientes en los bosques secundarios fueron más altos. Esto se atribuye a la alta densidad de fustes y la estructura de las copas en los bosques secundarios, mientras que la influencia de las epífitas en los flujos de nutrientes se considera baja. De igual modo los flujos de nutrientes asociados con la caída de hojarasca de las briofitas y líquenes epífitos son bajos en relación con la cantidad de nutrientes transportados con la caída de hojarasca foliar.

Los resultados indican que los efectos de la conversión del bosque primario para el balance de agua y nutrientes se pueden observar marcadamente todavía 40 años después de una sucesión secundaria del bosque. En este proceso el papel de las epífitas se estima bajo. Las diferencias en el flujo de agua y nutrientes están atribuídas a las características de la estructura del estrato arbóreo en los rodales investigados. 


\section{Literaturverzeichnis}

Acebey, A., Gradstein, S.R. \& KRÖMER, T. (2002): Species richness and habitat diversification of bryophytes in submontane rain forest and fallows of Bolivia. J. Trop. Ecol. (in press).

Asbury, C.E., McDowell, W.H., Trinidad-Pizarro, R. \& Berrios, S. (1994): Solute deposition from cloud water to the canopy of a Puerto Rican montane forest. Atmos. Environ. 28, 1773-1780.

AtAROFF, M. (1998): Importance of cloud water in Venezuelan Andean cloud forest water dynamics. In: Schemenauer, R.S., Bridgman, H.A. (eds.): First international conference on fog and fog collection, ICRC Ottawa, 25-28.

AtAROFF, M. \& RADA, F. (2000): Deforestation impact on water dynamics in a Venezuelan Andean cloud forest. Ambio 29(7), 440-444.

BAynton, H.W. (1968): The ecology of an elfin forest in Puerto Rico, 2. The microclimate of the Pico del Oeste. Journal of the Arnold Arboretum, 419-430.

BENTLEy, B.L. \& CARPENTER, E.J. (1984): Direct transfer of newly-fixed nitrogen from freeliving epiphyllous microorganisms to their host plant. Oecologia 63, 52-56.

BENZING, D.H. (1981): Mineral nutrition of epiphytes: an appraisal of adaptive features. Selbyana 5, 219-223.

BENZING, D.H. (1989): The mineral nutrition of epiphytes. In: Lüttge, U. (ed.): Vascular plants as epiphytes, Springer, Berlin, 167-199.

BENZING, D.H. (1998): Vulnerabilities of tropical forests to climate change: the significance of resident epiphytes. Climatic Change 39, 519-540.

BENZING, H. \& SEEMANN, J. (1978): Nutritional piracy and host decline: a new perspective on the epiphyte-host relationship. Selbyana 2, 133-148.

Blaser, J. (1987): Standörtliche und waldkundliche Analyse eines Eichen-Wolkenwaldes (Quercus spp.) der Montanstufe in Costa Rica, Diss. Univ. Göttingen, 235 S.

Blaser, J. \& CAMACHO, M. (1991): Estructura, composición y aspectos silviculturales de un bosque de roble (Quercus spp.) del piso montano en Costa Rica. Centro Agronómico Tropical de Investigación y Enseñanza. Informe técnico 185, Turrialba, $67 \mathrm{~S}$.

Brenes, Á. \& SABORIO, V.F. (1995): Elementos de climatología. Su aplicación didáctica a Costa Rica, Serie Geografía 1, EUNED, San José. 92 S.

Brown, S. \& Lugo, A.E. (1990): Tropical secondary forests. J. Trop. Ecol. 6, 1-32.

BRUIJNZEEL, L.A. (1989): (De)forestation and dry season flow in the tropics: a closer look. J. Trop. For. Sci. 1(3), 229-243.

BRUIJNZEEL, L.A. (1990): Hydrology of moist tropical forests and effects of conversion: a state of knowledge review. IHP-UNESCO Humid Tropical Programme, Paris, 224 S. 
BRUIJNZEEL, L.A. (2002): Hydrology of tropical montane cloud forests: a reassessment. In: Gladwell, J.S. (ed.): Proceedings Second International Colloquium on Hydrology and Water Management in the Humid Tropics. IHP-UNESCO, Paris and Cathalac, Panamá City, 352-383.

Bruijnzeel, L.A. \& Proctor, J. (1995): Hydrology and biochemistry of tropical montane cloud forests: what do we really know? In: Hamilton, L.S., Juvik, J.O., Scatena, F.N. (eds.): Tropical montane cloud forests, Ecological Studies 110, Springer, New York, 3878.

BRUiJnZEel, L.A. \& HAMiLton, L.S. (2000): Decision time for cloud forests. IHP Humid Tropics Programme Series 13, IHP-UNESCO, Paris, IUCN-NL, Amsterdam und WWF International, Gland, $44 \mathrm{~S}$.

CACERES, G. (1981): Importancia hidrologica de la intercepción horizontal en un bosque muy humedo premontano en Balalaica, Turrialba, Costa Rica. MSc thesis, Univ. of Costa Rica, Turrialba.

Callaway, R.M., Reinhart, K.O., Moore, G.M., Moore, D.J. \& Pennings, S.C. (2002): Epiphyte host preference and host traits: mechanisms for species-specific interactions. Oecologia 132, 221-230.

CAvelier, J. \& Goldstein, G. (1989): Mist and fog interception in elfin cloud forests in Colombia and Venezuela. J. Trop. Ecol. 5, 309-322.

Cavelier, J., Jaramillo, M., Solis, D. \& DE León, D. (1997): Water balance and nutrient input in bulk precipitation in tropical montane cloud forest in Panama. Journal of Hydrology 193(1-4), 83-96.

Cavelier, J., Solis, D. \& Jaramillo, M. (1996): Fog interception in montane forests across the Central Cordillera of Panama. J. Trop. Ecol. 12(3), 357-369.

Clark, K.L., Nadkarni, N.M., Schaefer, D. \& Gholz, H.L. (1998b): Atmospheric deposition and net retention of ions by the canopy in a tropical montane forest, Monteverde, Costa Rica. J. Trop. Ecol. 14, 27-45.

Clark, K.L., NadKarni, N.M., Schaefer, D. \& Gholz, H.L. (1998c): Cloud water and precipitation chemistry in a tropical montane forest, Monteverde, Costa Rica. Atmos. Environ. 32 (9), 1595-1603.

Coen, E.J. (1983): Climate. In: Janzen, D.H., Costa Rican Natural History. University of Chicago Press, Chicago, 35-46.

CoXson, D.S. (1991): Nutrient release from epiphytic bryophytes in tropical montane rain forest (Guadeloupe). Can. J. Bot. 69, 2122-2129.

COXON, D.S. \& NADKARNI, N.M. (1995): Ecological roles of epiphytes in nutrient cycles of forest ecosystems. In: Lowman, M.D., Nadkarni, N.M. (eds.): Forest Canopies, 495-543.

Defant, A.F. (1958): Physikalische Dynamik der Atmosphäre. Akad. Verl. Gesell. Frankfurt am Main, $527 \mathrm{~S}$.

Doumenge, C., Gilmour, D., Ruiz Perez, M. \& Blockhus, J. (1995): Tropical montane cloud forests: conservation status and management issues. In: Hamilton, L.S., Juvik, J.O., Scatena, F.N (eds.): Tropical montane cloud forests. Ecological Studies 110, Springer, New York, 24-37. 
EDWARDS, P.J. (1977): Studies of mineral cycling in a montane rain forest in New Guinea. II. The production and disappearance of litter. J. Ecol. 65, 971-992.

EDWARDS, P.J. (1982): Studies of mineral cycling in a montane rain forest in New Guinea: V. Rates of cycling in throughfall and litterfall. J. Ecol. 70(3), 807-827.

EDWARDS, P.J. \& GRUBB, P.J. (1977): Studies of mineral cycling in a montane rain forest in New Guinea: I. The distribution of organic matter in the vegetation and soil. J. Ecol. 65(3), 943-969.

EWEL, J.J. (1980): Tropical succession: Manifold routes to maturity. Biotropica 12 (Special Issue), 2-7.

FALLAS, J. (1996): Cuantificación de la intercepción en un bosque nuboso, Mte. de los Olivos, Cuenca del Rio Chiquito, Guanacaste, Costa Rica. CREED Technical Note 6, Tropical Science Center, San Jose, 37 S.

FAO (1988): Soil map of the world. World soil resources report 60, FAO, Rom.

Fournier, L.A. \& COMACHO DE CASTRO, L. (1973): Producción y descomposición del mantillo en un bosque secundario húmedo de premontano. Rev. Biol. Trop. 21, 59-67.

FRAHM, J.P. (1987): Which factors control the growth of epiphytic bryophytes in tropical rainforest? Symposia Biologica Hungarica 35, 639-648.

FRAHM, J.P. (1990a): Bryophyte phytomass in tropical ecosystems. Botanical Journal of the Linnean Society 104, 23-33.

FrAHM, J.P. (1990b): The ecology of epiphytic bryophytes on Mt. Kinabalu, Sabah (Malaysia). Nova Hedwigia 51(1-2), 121-132.

FRAHM, J.P. (1994): Scientific results of the BRYOTROP Expedition to Zaire and Rwanda. 1. The ecology of epiphytic bryophytes on Mt. Kahuzi (Zaire). Tropical Bryology 9, 137152.

FRAHM, J.P. (2002): Ecology of bryophytes along altitudinal and latitudinal gradients in Chile. Tropical Bryology 21, 67-79.

FREIBERG, E. (1998): Microclimatic parameters influencing nitrogen fixation in the phyllosphere in a Costa Rican premontane rain forest. Oecologia 17, 9-18.

FREIBERG, M. (2001): The influence of epiphyte cover on branch temperature in a tropical tree. Plant Ecol. 153, 241-250.

FreiberG, M. \& FreiberG, E. (2000): Epiphyte diversity and biomass in the canopy of lowland and montane forests in Ecuador. J. Trop. Ecol. 16, 673-688.

GersPer, P.L. \& HolOWAYCHUK, N. (1971): Some effects of stemflow from forest canopy trees on chemical properties of soil. Ecology 52(4), 691-702.

Golley, F., McGinnis, J. \& Clements, R. (1971): La biomasa y la estructura de algunos bosques de Darien, Panama. Turrialba 21, 189-196.

GóMEZ, L.D. (1986): Vegetación y clima de Costa Rica. EUNED 1, San José, 327 S.

Gordon, C.A., Herrera, R. \& Hutchinson, T.C. (1994a): Studies of fog events at two cloud forests near Caracas, Venezuela. I. Frequency and duration of fog. Atmos. Environ. 28(2), 317-322. 
Gordon, C.A., Herrera, R. \& Hutchinson, T.C. (1994b): Studies of fog events at two cloud forests near Caracas, Venezuela. II. Chemistry of fog. Atmos. Environ. 28(2), 323337.

GRUBB, P.J. (1974): Factors controlling the distribution of forest types on tropical mountains: new facts and a new perspective. Altitudinal zonation in Malesia. In: Flenley, J. Transactions of third Aberdeen-Hull symposium on Malesian ecology. Univ. Hull, Hull, $13-45$.

GRUBB, P.J. (1977): Control of forest growth and distribution on wet tropical mountains: with special reference to mineral nutrition. Ann. Rev. Ecol. Syst. 8, 83-107.

HAFKENSCHEID, R.L.L.J. (2000): Hydrology and biochemistry of montane rain forests of contrasting stature in the Blue Mountains of Jamaica. Diss. Vrije Univ. Amsterdam, $302 \mathrm{~S}$.

HALl, C. (1984): Costa Rica - una interpretación geográfica con perspectiva historica. Editorial Costa Rica, San José, 476 S.

HAMILTON, L.S. (1995): Montane cloud forest conservation and research: a synopsis. Mountain Research and Development 15(3), 259-266.

Hamilton, L.S., JuviK, J.O. \& Scatena, F.N. (1995): The Puerto Rico tropical cloud forest symposium: introduction and workshop synthesis. In: Hamilton, L.S., Juvik, J.O., Scatena, F.N. (eds.): Tropical montane cloud forests, Ecological Studies 110, Springer, New York, 1-23.

Heaney, A. \& Proctor, J. (1989): Chemical elements in litter in forests on Volcán Barva, Costa Rica. In: Proctor J. (ed.): Mineral nutrients in tropical forest and savanna ecosystems, Blackwell Scientific Press, Oxford, 255-271.

HERBERT, D.A. \& FownES, J.H. (1997): Effects of leaf aggregation in a broad-leaf canopy on estimates of leaf area index by the gap-fraction method. For. Ecol. Manage. 97, 277-282.

Herrera, W. (1986): Clima de Costa Rica. In: Gómez, L.D. (ed.): Vegetación y clima de Costa Rica. EUNED, San José, 118 S.

Hertel, D., Leuschner, Ch. \& Hölscher, D. (2002): Size and structure of fine root systems in old-growth and secondary tropical montane forest (Costa Rica). Biotropica (in press).

HERWITZ, S.R. (1985): Interception storage capacities of tropical rainforest canopy trees. Journal of Hydrology 77, 237-252.

Hetsch, W. \& Hoheisel, H. (1976): Standorts- und Vegetationsgliederung in einem tropischen Nebelwald. Allg. Forst- u. J.-Ztg. 147(10,11), 200-209.

Hofstede, R.G.M., Wolf, J.H.D. \& Benzing, D.H. (1993): Epiphytic biomass and nutrient status of a Colombian upper montane rain forest. Selbyana 14, 37-45.

Holdridge, L.R., Grenke, W.C., Hatheway, W.H., LiAng, T. \& Tosi, J.A. (1971): Forest environments in tropical life zones: A pilot study. Pergamon Press, Oxford, $747 \mathrm{~S}$.

Holmgren M., Scheffer M., Ezcurra E., Gutiérrez J.R. \& Mohren G.M.J. (2001): El Niño effects on the dynamics of terrestrial ecosystems. Trends Ecol. Evol. 16, 89-94. 
HöLSCHER, D. (1995): Wasser- und Stoffhaushalt eines Agrarökosystems mit Waldbrache im östlichen Amazonasgebiet. Göttinger Beiträge zur Land- und Forstwirtschaft in den Tropen und Subtropen 106. Diss. Univ. Göttingen, Goltze, Göttingen, 134 S.

Hölscher, D., SÁ, T.D., Möller, R.F., Denich, M. \& Fölster, H. (1998): Rainfall partitioning and related hydrochemical fluxes in a diverse and in a mono specific (Phenakospermum guyannense) secondary vegetation stand in eastern Amazonia. Oecologia 114, 251-257.

Hölscher, D., KöHler, L., Leuschner, Ch. \& Kappelle, M. (2002): Nutrient fluxes in stemflow and throughfall in three successional stages of an upper montane rain forest in Costa Rica. J. Trop. Ecol. (in press).

Hölscher, D., KÖHLER, L., VAN DiJK, A. \& BRUiJnZeEl, L.A. (2003): The importance of epiphytes in rainfall interception by a tropical montane rainforest in Costa Rica. (in prep.).

Holz, I. (2003): Diversity of bryophytes and macrolichenes in primary and secondary montane Quercus forests, Cordillera de Talamanca, Costa Rica. Diss. Univ. Göttingen (in prep.).

Holz, I., Gradstein, S.R., Heinrichs, J. \& Kappelle, M. (2002): Bryophyte diversity, microhabitat differentiation and distribution of life forms in Costa Rican upper montane Quercus forest. The Bryologist 105(3), (in press).

Huber, A. \& IROumÉ, A. (2001): Variability of annual partitioning for different sites and forest covers in Chile. Journal of Hydrology 248, 78-92.

ICE (Instituto Costarricense de Electricidad) (2000): Departamento de Hidrologia: Precipitacion pluvial mensual. (unveröff.).

IMN (Instituto Meteorológico Nacional) (1988): Catastro de las series de precipitaciones medidas en Costa Rica. MIRENEM (Ministerio de Recursos Naturales, Energia y Minas) San José, $361 \mathrm{~S}$.

IMN (Instituto Meteorológico Nacional) (2000): Boletin Meteorlógico Mensual (19992000). San José.

INGRAM, S.W. \& NADKARNI, N.M. (1993): Composition and distribution of epiphytic organic matter in a neotropical cloud forest, Costa Rica. Biotropica 25(4), 370-383.

JACOBSEN, N.H.G. (1978): An investigation into the ecology and productivity of epiphytic mosses. S. Afr. J. Bot. 44(3), 297-312.

JoHANNSON, D.R. (1974): Ecology of vascular epiphytes in West African rain forest. Acta Phytogeogr. Suec. 59, 1-136.

JORDAN, C.F. (1978): Stemflow and nutrient transfer in a tropical rain forest. Oikos 31, 257263.

Jordan, C., Golley, F., Hall, J. \& Hall, J. (1980): Nutrient scavening of rainfall by the canopy of Amazonian rain forest. Biotropica 12(1), 61-66.

KAPPELle, M. (1991): Distribución altitudinal de la vegetación del Parque Nacional Chirripó, Costa Rica. Brenesia 36, 1-14. 
KAPPELlE, M. (1993): Recovery following clearing of an upper montane Quercus forest in Costa Rica. Rev. Biol. Trop. 41(1), 47-56.

KAPPELLE, M. (1995): Ecology of mature and recovering Talamancan montane Quercus forest, Costa Rica. Diss. Univ. Amsterdam, 273 S.

Kappelle, M. (1996): Los bosques de roble (Quercus) de la Cordillera de Talamanca, Costa Rica: Biodiversidad, ecología, conservación y desarrollo. Univ. Amsterdam, Instituto Nacional de Biodiversidad, 319 S.

KAPPELle, M. \& GómEZ, P.L.D. (1992): Distribution and diversity of montane Pteridophytes of the Chirripo National Park, Costa Rica. Brenesia 37, 67-77.

Kappelle, M. \& Sipman, H.J.M. (1992): Foliose and fruticose lichenes of Talamanca montane Quercus forest, Costa Rica. Brenesia 37, 51-58.

KAPPELlE, M. \& JuÁREZ, M.E. (1995): Agroecological zonation along an altitudinal gradient in the montane belt of the Los Santos Forest Reserve in Costa Rica. Mountain Research and Development 15(1), 19-37.

KAPPELlE, M. \& ZAMORA, N. (1995): Changes in woody species richness along an altitudinal gradient in Talamancan montane Quercus forest, Costa Rica. In: Churchill, S.P., Balslev, E.F., Luteyn, J.L. (eds.): Biodiversity and conservation of neotropical montane forest. The New York Botanical Gardens, New York, 135-148.

KAPPELLE, M. \& LEAL, M.E. (1996): Changes in leaf morphology and foliar nutrient status along a successional gradient in a Costa Rican upper montane Quercus forest. Biotropica $28(3), 331-344$.

KAPPElle, M. \& BROWN, A. (2001): Introducción a los bosques nublados del neotropico: Una síntesis regional. In: Kappelle, M. \& Brown, A. (eds.): Bosques nublados del neotrópico. Instituto Nacional de Biodiversidad (INBio), Santo Domingo de Heredia, $704 \mathrm{~S}$.

Kappelle, M., Kennis, P.A.F. \& De VRies, R.A.J. (1995): Changes in diversity along a successional gradient in Costa Rican upper montane Quercus forest. Biodiversity and Conserv. 4, 10-34.

KAPPelle, M., Zamora, N. \& FloRes, T. (1991): Flora leñosa de la zona alta (2000-3819 m) de la Cordillera de Talamanca, Costa Rica. Brenesia 34, 121-144.

Kappelle, M., Geuze, T., Leal, M.E. \& Cleef, M. (1996): Successional age and forest structure in a Costa Rican upper montane Quercus forest. J. Trop. Ecol. 12(5), 681-698.

KERFOOT, O. (1968): Mist precipitation on vegetation. Forestry Abstracts 29, 8-20.

KLINGE, R. (1998): Wasser- und Nährstoffdynamik im Boden und Bestand beim Aufbau einer Holzplantage im östlichen Amazonasgebiet. Göttinger Beiträge zur Land- und Forstwirtschaft in den Tropen und Subtropen 122, Goltze, Göttingen, 260 S.

KunZ, M. (2000): Diversität epiphytischer Kryptogamen in der Strauchschicht montaner Eichenwälder Costa Ricas. Unveröff. Dipl. Arb. Univ. Göttingen, 66 S.

LaBastille, A. \& Pool, D.J. (1978): On the need for a system of cloud-forest parks in Middle America and the Caribbean. Environmental Conservation 5(3), 183-190.

LAMBERT, J.D.H., ARNASON, J.T. \& GALE, J.L. (1980): Leaflitter and changing nutrient levels in a seasonally dry tropical hardwood old forest, Belize. Plant and Soil 55, 429-443. 
LEUSCHNER, CH. (1986): Niederschlags-Interzeption aus ökologischer Sicht: Mikrometeorologische und physiologische Untersuchungen in krautigen Pflanzenbeständen. Diss. Univ. Göttingen, 220 S.

LEYTON, L., REYNOLDS, E.R.C. \& ThOMPSON, F.B. (1967): Rainfall interception in forest and moorland. In: Sopper, E.W., Lull, H.W. (eds.): Forest hydrology. Pergamon Press, Oxford, 163-178.

Lloyd, C.R. \& MARques, A. DE O. (1988): Spatial variability of throughfall and stemflow measurements in Amazonian rainforest. Agricultural and Forest Meteorology 42, 63-73.

LOWMAN, M. \& NADKARNI, N.M. (1995): Forest canopies: a review of research on this biological frontier. London, $624 \mathrm{~S}$.

LUNDGREN, L. \& LUNDGREN, B. (1979): Rainfall, interception and evaporation in the Mazumbai forest reserve, west Usambara Mts., Tanzania and their importance in the assessment of land potential. Geografiska Annaler 61A(3-4), 157-178.

McCune, B. (1993): Gradients in epiphyte biomass in three Pseudotsuga-Tsuga forests of different ages in western Oregon and Washington. Bryologist 96, 405-411.

McDonald, M.A. \& Healy, J.R. (2000): Nutrient cycling in secondary forest in the Blue Mountains of Jamaica. For. Ecol. Manage. 139, 257-278.

MCNaughton, K.G. \& JARVis, P.G. (1983): Predicting effects of vegetation changes on transpiration and evaporation. In: Kozlowski, T.T. (eds.): Water deficits and plant growth 7, Academic Press, London, 1-47.

MÜLleR, U. \& FRAHM, J.P. (1998): Diversität epiphytischer Moose eines westandinen Bergregenwaldes in Ecuador. Tropical Bryology 15, 29-43.

NADKARNI, N.M. (1981): Canopy roots: convergent evolution in rainforest nutrient cycles. Science 214(27), 1023-1024.

NADKARNI, N.M. (1984): Epiphyte biomass and nutrient capital of a neotropical elfin forest. Biotropica 16(4), 249-256.

NADKARNI, N.M. (2000): Colonization of stripped branch surfaces by epiphytes in a lower montane cloud forest, Monteverde, Costa Rica. Biotropica 32(2), 358-363.

NADKARni, N.M. \& MAtelson, T.J. (1991): Fine litter dynamics within the tree canopy of a tropical cloud forest. Ecology 72(6), 2071-2082.

NADKARNi, N.M. \& MATElson, T.J. (1992a): Biomass and nutrient dynamics of epiphytic litterfall in a neotropical montane forest, Costa Rica. Biotropica 24(1), 24-30.

NADKARNi, N.M. \& MAtelson, T.J. (1992b): Biomass and nutrient dynamics of fine litter of terrestrially rooted material in a neotropical montane forest, Costa Rica. Biotropica 24(2a), 113-120.

NiEUwOLT, S. (1977): Tropical climatology: An introduction to the climates of the low latitudes. Wiley, London, $207 \mathrm{~S}$.

PARKER, G.G. (1983): Throughfall and stemflow in the forest nutrient cycle. Advances in Ecological research 13, 57-133. 
PERRY, D. (1978): A method of access into the crowns of emergent and canopy trees. Biotropica 10(2), 155-157.

Pócs, T. (1980): The epiphytic biomass and its effect on the water balance of two rain forest types in the Uluguru Mountains (Tanzania, east Africa). Acta Botanica Academiae Scientiarum Hungaricae 26(1-2), 143-167.

Proctor, J. (1983): Tropical forest litterfall. I. Problems of data comparison. Special publication of the British Ecological Society, 267-273.

Proctor, J. (1984): Tropical forest litterfall. II. The dataset. In: Sutton, S.L., Chadwick A.C. (eds.): Tropical rain-forest: the Leeds symposium. The Leeds Philosophical and Natural History Society, Leeds, 83-113.

Proctor, J., Anderson, J.M. \& Vallack, H.W. (1983): Comparative studies on forests, soils and litterfall at four altitudes on Guning Mulu, Sarawak. Malaysian Forester 46(1), 60-76.

Proctor, J., Phillipps, C., Duff, G.K., Heaney, A. \& Robertson, F.M. (1989): Ecological studies on Gunung Silam, a small ultrabasic mountain in Sabah, Malaysia. II. Some forest processes. J. Ecol. 77, 317-331.

PrSKAwETZ M. \& LEXER M.J. (2000): Evaluierung des LI-COR LAI-2000 zur Ermittlung des Blattflächenindex in Buchenjungbeständen. Allg. Forst- und J.-Ztg. 171(9-10), 185-191.

QuiRÓS, G.E. (1990): El Niño - Oscilación del Sur. ENOS. Universidad Nacional Heredia, Costa Rica, $54 \mathrm{~S}$.

RHOADES, F. M. (1995): Nonvascular epiphytes in forest canopies: worldwide distribution, abundance, and ecological roles. In: Lowman, M.D., Nadkarni N.M. (eds.): Forest Canopies, 353-408.

Richards, P.W. (1952): The tropical rain forest. Cambridge University Press. Cambridge, England, $450 \mathrm{~S}$.

Richards, P.W. (1984): The ecology of tropical forest bryophytes. In: Schuster, R.M. (ed.): New Manual of Bryology 2, 1233-1270.

RichARDSON, B. A. (1999): The bromeliad microcosm and the assessment of faunal diversity in a neotropical forest. Biotropica 31(2), 321-336.

Roberts, J.M., Cabral, O.M.R., DA Costa, J.P., McWilliam, A.-L.C. \& DE A SÁ, T.D. (1996): An overview of the leaf area index and physiological measurements during ABRACOS. In: Gash, J.H.C., Nobre, C.A., Roberts, J.M, Victoria, R. (eds.): Amazonian deforestation and climate. Wiley \& Sons Chichester, New York, 287-305.

RuDlOFF, W. (1981): World climates, with tables of climatic data and practical suggestions. WVG, Stuttgart, 632 S.

SCHAEFER, D.A. \& REINERS, W.A. (1990): Throughfall chemistry and canopy processing mechanisms. In: Lindberg, S.E., Page, A.L., Norton, S.A (eds.): Acidic Precipitation 3, Sources, Depositions and Canopy Interactions. Advances in Environmental Science, Springer, New York, 241-284.

Schemenauer, R.T. \& CereCDA, P. (1994): A proposed standard fog collector for use in high-elevation regions. J. Appl. Meteorol. 33(11), 1313-1322. 
SCHIMANNEK, R. (1999): Untersuchungen zu Vegetationsstrukturen und Landnutzung in der unteren montanen Stufe der Cordillera de Talamanca, Costa Rica. Unveröff. Dipl. Arb. Univ. Münster, $108 \mathrm{~S}$.

SCHLESINGER, W.H. \& MARKS P.L. (1977): Mineral cycling and the niche of Spanish moss, Tillandsia usneoides L.. Journal of American Botany 64, 1254-1262.

Schroth, G., Elias, M.E.A., Uguen, K., Seixas, R. \& Zech, W. (2001): Nutrient fluxes in rainfall, throughfall and stemflow in tree-based land use systems and spontaneous tree vegetation of central Amazonia. Agriculture, Ecosystems and Environment 87, 37-49.

Soll Survey Staff (1975): Soil taxonomy. Soil Conservation Service U.S. Dept. Agric. Handbk. 436, USDA, Washington, D.C., 754 S.

STADTMÜller, T. (1987): Cloud forests in the humid tropics. United Nations University, Tokyo and Centro Agronomico Tropical de Investigacion y Enseñanza Turrialba, Costa Rica, $85 \mathrm{~S}$.

StAdTMÜller, T. \& AgUdelo, N. (1990): Amount and variability of cloud moisture input in a tropical cloud forest. International Association of Hydrological Science Publication 193, 25-32.

STEINHARDT, U. (1979): Untersuchungen über den Wasser- und Nährstoffhaushalt eines andinen Wolkenwaldes in Venezuela. Diss. Univ. Göttingen, $181 \mathrm{~S}$.

Stiles, F.G., Skutch, A.F. \& Gardner, D. (1998): Guía de Aves de Costa Rica. Instituto Nacional de Biodiversidad, Heredia, Costa Rica, $580 \mathrm{~S}$.

Sugden, A.M. \& RoBins, R.J. (1979): Aspects of the ecology of vascular epiphytes in Colombian cloud forest. I. The distribution of the epiphytic flora. Biotropica 11(3), 173188.

TANNER, E.V.J. (1977): Four montane rain forests of Jamaica: a quantitative characterization of the floristics, the soils and the foliar mineral levels, and a discussion of the interrelations. J. Ecol. 65, 883-918.

TANNER, E.V.J. (1980a): Studies on the biomass and productivity in a series of montane rain forest in Jamaica. J. Trop. Ecol. 68, 573-588.

TANNER, E.V.J. (1980b): Litterfall in montane rain forests of Jamaica and its relation to climate. J. Ecol. 68, 833-848.

TANNER, E.V.J. (1985): Jamaican montane forests: nutrient capital and cost of growth. J. Ecol. 73(2), 553-568.

Tanner, E.V.J., VitouseK, P.M. \& Cuevas, E. (1998): Experimental investigation of nutrient limitation of forest growth on wet tropical mountains. Ecology 79, 10-22.

Ter Steege, H. \& CoRnelissen, J.H.C. (1989): Distribution and ecology of vascular epiphytes in lowland rain forest of Guyana. Biotropica 21(4), 331-339.

Thomas, P. (1988): Die Niederschlagsverhältnisse in Costa Rica. Unveröff. Dipl. Arb. Univ. Augsburg, $130 \mathrm{~S}$.

TUKEY, JR. H.B. (1970): The leaching of substances from plants. Annu. Rev. Plant Physiol. $31,305-324$. 
VAHRSON, W.G. (1997): Charakteristika, Verteilung und geoökologische Bedeutung tropischer Starkregen. Deutsche Hochschulschriften 1138, Dr. Hänsel-Hohenhausen, $180 \mathrm{~S}$.

VANCE, E.D. \& NADKARNI, N.M. (1990): Microbial biomass and activity in canopy organic matter and the forest floor of a tropical cloud forest. Soil Biology and Biochemistry 22, 677-684.

VAN DER Hammen, T. (1984): Datos eco-climatologicos del transecto Buritaca y alrededores (Sierra Nevada de Santa Marta). In: Van der Hammen, T., Ruiz, P.W. (eds.): La Sierra Nevada de Santa Marta (Colombia). Stud. Trop. Andean Ecosyst. 2, Cramer, Berlin, Stuttgart, 45-66.

VAN DiJK, A. \& BRUIJNZEEL, L.A. (2001): Modelling rainfall interception by vegetation of variable density using an adapted analytical model. Part 1. Modell description. Journal of Hydrology 247, 230-238.

VAN EK, R. (1995): Rainfall interception and the significance of epiphytes in a cloud forest in the Central Cordillera, Colombia. In: Van der Hammen, T., Dos Santos, A.G. (eds.): Stud. Trop. Andean Ecosyst. 13, Cramer, Berlin, 451-461.

VAN OMME, L. (1998): Present vegetation patterns and deforestation trends over the past 55 years in a high altitude cloud forest watershed area, Costa Rica. Internal Report 311, Hugo de Vries Laboratory, Univ. Amsterdam, $32 \mathrm{~S}$.

VAn ReEnen, G.B.A. \& Gradstein, S.R. (1983): A transect analysis of the bryophyte vegetation along an altitudinal gradient on the Sierra Nevada de Santa Marta, Colombia. Acta Botanica Neerlandica 32, 163-175.

VAN REENEN, G.B.A. \& GRADSTEIN, S.R. (1984): An investigation of bryophyte distribution and ecology along an alitudinal gradient in the Andes of Colombia. Journal of Hattori Botanical Laboratory 56, 79-84.

VeneKLAas, E.J. (1990): Nutrient fluxes in bulk precipitation and throughfall in two montane tropical rain forests, Colombia. J. Ecol. 78, 974-992.

VeNEKLAAS, E.J. (1991): Litterfall and nutrient fluxes in two montane tropical rain forests, Colombia. J. Trop. Ecol. 7, 319-336.

VeneKLAas, E. \& VAN EK, R. (1990): Rainfall interception in two tropical montane rain forests, Colombia. Hydrological Processes 4, 311-326.

Veneklaas, E.J., Zagt, R.J., Van Leerdam, A., Van Ek, R., Broekhoven, A.J. \& VAN GENDEREN, M. (1990): Hydrological properties of the epiphyte mass of a montane tropical rain forest, Colombia. Vegetatio 89, 183-192.

VITOUSEK, P.M. (1984): Litterfall, nutrient cycling, and nutrient limitation in tropical forests. Ecology 65(1), 285-298.

VogelmanN, H.W. (1973): Fog precipitation in the cloud forests of eastern Mexico. Bioscience 23(2), 96-100.

WeAVER, P.L. (1990): Succession in elfin woodland of the Luquillo Mountains of Puerto Rico. Biotropica 22, 83-89.

WeAVER, P.L. (1972): Cloud moisture interception in the Luquillo Mountains of Puerto Rico. Caribbean Journal of Science 12, 129-144. 
Weaver, P.L., Medina, E., Pool, D., Dugger, K., Gonzales-Liboy, J. \& Cuevas, E. (1986): Ecological observations in the dwarf cloud forest of the Luquillo Mountains in Puerto Rico. Biotropica 18(1), 79-85.

West, G.B., Brown, J.H. \& EnQuist, B.J. (1999): A general model for the structure and allometry of plant vascular systems. Nature 400, 664-667.

WeYL, R. (1980): Geology of Central America. Bornträger, Stuttgart, 371 S.

WhitMORE, T.C. (1962): Studies in systematic bark morphology. II. General features of bark construction in Dipterocarpaceae. New Phytol. 61, 208-220.

WhitMORE, T. C. (1963): Studies in systematic bark morphology. IV. The bark of beech, oak and sweet chestnut. New Phytol. 62, 161-168.

Williams-Linera, G. \& TOlOME, J. (1996): Litterfall, temperate and tropical dominant trees, and climate in a Mexican lower montane forest. Biotropica 28(4b), 649-656.

WoLF, J.H.D. (1993a): Diversity patterns and biomass of epiphytic bryophytes and lichens along an altitudional gradient in the northern Andes. Ann. Missouri Bot. Gard. 80, 928960 .

WOLF, J.H.D. (1993b): Epiphyte communities of tropical montane rainforest in the northern Andes. II. Upper montane communities. Phytocoenologia 22, 53-103.

YASIN, S. (2001): Water and nutrient dynamics in microcatchments under montane forest in the south Ecuadorian Andes. Bayreuther Bodenkundliche Berichte 73, $192 \mathrm{~S}$.

ZADROGA, F. (1981): The hydrological importance of a montane cloud forest area of Costa Rica. In: Lal, R., Russell, E.W. (eds.): Tropical Agricultural Hydrology. Wiley, New York, 59-73.

ZotZ, G. (1999): Altitudinal changes in diversity and abundance of non-vascular epiphytes in the tropics-an ecophysiological explanation. Selbyana, 20(2), 256-260.

Zotz, G. \& Winter, K. (1994): Photosynthesis and carbon gain of the lichens, Leptogium azureum, in a lowland tropical forest. Flora 189, 179-186. 


\section{Verzeichnis der Tabellen und Abbildung im Text}

\section{Verzeichnis der Tabellen im Text}

Tab. 2-1: Bodenchemische Parameter der drei Untersuchungsflächen

Tab. 2-2: Vegetationsbedeckung des oberen Tales des Rio Savegre, Costa Rica

Tab. 2-3: Artenliste der Baum- und Straucharten im jungen Sekundärwald

Tab. 3-1: Anzahl der Proben zur Ermittlung der epiphytischen Biomasse

Tab. 4-1: Bestandesstruktur der drei untersuchten Bestände

Tab. 4-2: Spezifische Blattfläche verschiedener Baumarten des jungen Sekundärwaldes

Tab. 4-3: Jahressumme der Feinstreu verschiedener Streufraktionen

Tab. 4-4: Blattflächenindex der drei untersuchten Bestände

Tab. 4-5: Biomasse epiphytischer Moose und Flechten und epiphytischer Gefäßpflanzen in den drei untersuchten Beständen

Tab. 4-6: Freilandniederschlag, Bestandesniederschlag, Stammablauf und Interzeption von Juni 1999 bis Mai 2000

Tab. 4-7: Kenngrößen des Wasserhaushalts verschiedener Epiphyten der Kronenregion des Altbestandes sowie der Borke von Quercus copeyensis

Tab. 4-8: Jahresmittelwerte der Elementkonzentrationen im Freilandniederschlag, Bestandesniederschlag und Stammablauf

Tab. 4-9: Nährstoffflüsse mit dem Freilandniederschlag, Bestandesniederschlag und Stammablauf

Tab. 4-10: Elementgehalte von Eichenblättern, Moosen, Kronenhumus und Borke

Tab. 4-11: Elementgehalte der Blattstreu der drei untersuchten Bestände

Tab. 4-12: Nährstoffflüsse mit der Streu der Baumblätter, Phoradendron sowie epiphytischer Moose und Flechten

Tab. 5-1: Übersicht der Literaturangaben zur epiphytischen Gesamtbiomasse

Tab. 5-2: Anreicherungsfaktoren der Nährstoffflüsse während der Kronenpassage vom Freilandniederschlag zum Nettoniederschlag

Tab. 5-3: Literaturübersicht von Blattstreumengen und Nährstoffflüssen mit der Blattstreu

Tab. 5-4: Nährstoffflüsse mit der Streu epiphytischer Moose und Flechten 


\section{Verzeichnis der Abbildungen im Text}

Abb. 2-1: Lage des Forstreservates Los Santos und der untersuchten Waldbestände 3

Abb. 2-2: Vorherrschende Windsysteme in Costa Rica 7

Abb. 2-3: Jahresgang der monatlichen Niederschläge (Ojo de Agua, Villa Mills) 9

Abb. 2-4: Verbreitungszone der montanen Eichenwälder in der Cordillera Talamanca 11

Abb. 3-1: Standort der Bestandesmeßstation während des Untersuchungszeitraumes 19

Abb. 3-2: Versuchsaufbau im Altbestand 20

Abb. 4-1: Verteilung der Stammzahlen nach Größenklassen des Brusthöhen$\begin{array}{ll}\text { durchmessers } & 33\end{array}$

Abb. 4-2: Monatlicher Streufall der Baumblätter sowie der Zweige und Pflanzenreste 35

Abb. 4-3: Monatlicher Streufall der epiphytischen Gefäßpflanzen sowie der epiphytischen Moose und Flechten

Abb. 4-4: Relativer Anteil der lebenden Eichenblätter an der Gesamtzahl einer markierten Blattpopulation

Abb. 4-5: Biomasse epiphytischer Moose und Flechten in den drei Beständen

Abb. 4-6: Monatliche Niederschlagssummen (A), mittlere monatliche Lufttemperatur (A, B) und mittleres monatliches Wasserdampfsättigungsdefizit (B)

Abb. 4-7: Mittlere monatliche Nettostrahlung (A) und mittlere monatliche (A, B) Windgeschwindigkeit (B)

Abb. 4-8: Anzahl der monatlichen Nebeltage im Altbestand

Abb. 4-9: Messungen der Regensammler (vertikaler Freilandniederschlag) und mit den Nebelsammlern gemessener horizontaler Niederschlag

Abb. 4-10: Höhengradient der Lufttemperatur und des Sättigungsdefizites in verschiedenen Baumhöhen des Altbestandes

Abb. 4-11: Höhengradient des Sättigungsdefizites in verschiedenen Baumhöhen im jungen und älteren Sekundärwald

Abb. 4-12: Mittlerer Tagesverlauf der Sättigungsdefizite in unterschiedlichen Baumhöhen der drei Bestände sowie im Freiland während der Trockenzeit

Abb. 4-13: Mittlerer Tagesverlauf der Sättigungsdefizite in unterschiedlichen Baumhöhen der drei Bestände sowie im Freiland während der Regenzeit

Abb. 4-14: Differenzen zwischen den mittleren Sättigungsdefiziten im Freiland und im Bestand

Abb. 4-15: Mittlere Piche-Evaporation in vier unterschiedlichen Baumhöhen des Altbestandes sowie im Freiland 
Abb. 4-16: Monatlicher Bestandesniederschlag in Prozent des Freilandniederschlags 60

Abb. 4-17: Monatlicher Stammablauf in Prozent des Freilandniederschlags 61

Abb. 4-18: Zusammenhang zwischen Freilandniederschlag und Nettoniederschlag im Altbestand

Abb. 4-19: Häufigkeitsverteilung des Bestandesniederschlags nach Größenklassen des Freilandniederschlags

Abb. 4-20: Relativer Stammablauf im jungen Sekundärwald vor und nach Entlaubung der Bäume

Abb. 4-21: Wasserspeicherung der Moosarten Pilotrichella flexilis und Leptodontium exasperatum bei experimenteller Beregnung

Abb. 4-22: Wasserspeicherung der Blätter von Oreopanax spec. und der Triebe von Quercus copeyensis bei experimenteller Beregnung

Abb. 4-23: Aktueller monatlicher Wassergehalt des epiphytischen Polstermooses Leptodontium exasperatum und des epiphytischen Farnes Elaphoglossum spec. in der Kronenregion des Altbestandes

Abb. 4-24: Aktueller Wassergehalt von Leptodontium-Moospolstern getrennt nach A, B Humus- und Rhizoid-Anteil bzw. photosynthetisch aktivem, grünen Teil (A). Blattwassergehalt von Bromelienblättern (Vriesea orosiensis) getrennt nach unteren und oberen Blattbereichen (B)

Abb. 4-25: Experimentell ermittelte Wasserspeicherkapazität der Phytotelmen von Vriesea orosiensis (Bromeliaceae)

Abb. 4-26: Niederschlag in Regensammlern mit experimentell angebrachten Moosen (Pilotrichella flexilis) im relativen Verhältnis zum Niederschlag in Regensammlern ohne Moose (tägliche Auflösung)

Abb. 4-27: Niederschlag in Regensammlern mit experimentell angebrachten Moosen (Pilotrichella flexilis) im relativen Verhältnis zum Niederschlag in Regensammlern ohne Moose (wöchentliche Auflösung)

Abb. 4-28: Austrocknungskurven verschiedener Epiphyten des Altbestandes

Abb. 4-29: Austrocknungskurven von Eichenborke

Abb. 5-1: Stammablauf in den drei untersuchten Waldstadien. Mittlere Jahressummen A, B der Kronenbäume (A) sowie mittlerer auf Bestandesebene bezogener Stammablauf der Kronenbäume (B)

Abb. 5-2: Interzeption im jungen und älteren Sekundärwald in wöchentlicher Auflösung

Abb. 5-3: Kaliumfluß mit dem Stammablauf im Monat Mai 2000 


\section{Anhang}

\section{Verzeichnis der Tabellen im Anhang}

Tab. A-1: Stammzahlen nach Größenklassen des Brusthöhendurchmessers.

Tab. A-2: Monatliche Streumengen von Baumblättern, epiphytischen Moosen und Flechten, epiphytischen Gefäßpflanzen, der Restfraktion sowie der Gesamtstreu.

Tab. A-3: Lebensdauer von Eichenblättern (Quercus copeyensis) in den drei untersuchten Beständen.

Tab. A-4: Auf der Freifläche in Sekundärwaldnähe gemessener Freilandniederschlag und die mit der mikrometeorologischen Freilandmeßstation erhobenen Daten (Lufttemperatur, Wassersättigungsdefizit (VPD), Strahlung und Windgeschwindigkeit) sowie die Anzahl der Nebeltage im Altbestand.

Tab. A-5: Messungen der Regensammler (vertikaler Freilandniederschlag) und mit den Nebelsammlern gemessener horizontaler Niederschlag an einzelnen Tagen der Regen- und Trockenzeit.

Tab. A-6: Höhengradient der Lufttemperatur und des Sättigungsdefizites (VPD) in verschiedenen Baumhöhen des Altbestandes sowie VPD in verschiedenen Baumhöhen des jungen und älteren Sekundärwaldes.

Tab. A-7: Mittlere Piche-Evaporation in vier unterschiedlichen Baumhöhen des Altbestandes sowie im Freiland.

Tab. A-8: Relativer monatlicher Bestandesniederschlag und Stammablauf in den drei untersuchten Beständen.

Tab. A-9: Freilandniederschlag und Nettoniederschlag in den drei untersuchten Beständen während 19 Tagen in der Regen- und Zwischentrockenzeit.

Tab. A-10: Häufigkeitsverteilung des Bestandesniederschlags nach Größenklassen des Freilandniederschlags.

Tab. A-11: Relativer Stammablauf im jungen Sekundärwald während zwei Wochen vor und zwei Wochen nach Entlaubung der Bäume.

Tab. A-12: Wasserspeicherung der Moosarten Pilotrichella flexilis und Leptodontium exasperatum bei experimenteller Beregnung mit unterschiedlichen Regenmengen.

Tab. A-13: Wasserspeicherung der Blätter von Oreopanax spec. und der Triebe von Quercus copeyensis bei experimenteller Beregnung mit unterschiedlichen Regenmengen. 
Tab. A-14: Aktueller monatlicher Wassergehalt des epiphytischen Polstermooses Leptodontium exasperatum und des epiphytischen Farnes Elaphoglossum spec. in der Kronenregion des Altbestandes.

Tab. A-15: Aktueller Wassergehalt von Leptodontium-Moospolstern und Bromelienblättern (Vriesea orosiensis).

Tab. A-16: Experimentell ermittelte Wasserspeicherkapazität der Phytotelmen von Vriesea orosiensis.

Tab. A-17: Niederschlag in Regensammlern mit experimentell angebrachten Moosen im relativen Verhältnis zum Freilandniederschlag.

Tab. A-18: Niederschlag in Regensammlern mit experimentell angebrachten Moosen im relativen Verhältnis zum Freilandniederschlag in wöchentlicher Auflösung.

Tab. A-19: Austrocknungskurven von Pilotrichella flexilis und Sticta ferax.

Tab. A-20: Austrocknungskurven von Leptodontium exasperatum und Eichenborke. 
Tab. A-1: Stammzahlen nach Größenklassen des Brusthöhendurchmessers (BHD) bei Stämmen $\geq 3$ $\mathrm{cm}$ in den drei untersuchten Beständen.

\begin{tabular}{rccc}
\hline BHD [cm] & $\begin{array}{c}\text { junger } \\
\text { Sekundärwald }\end{array}$ & $\begin{array}{c}\text { älterer } \\
\text { Sekundärwald }\end{array}$ & Altbestand \\
\hline $3-5$ & 3200 & 1830 & 1610 \\
$5-10$ & 2080 & 1590 & 1030 \\
$10-20$ & 400 & 1020 & 390 \\
$20-40$ & 50 & 330 & 230 \\
$40-80$ & 0 & 30 & 110 \\
$>80$ & 0 & 0 & 90 \\
\hline
\end{tabular}

Tab. A-2: Monatliche Streumengen von Baumblättern (BB), epiphytischen Moosen und Flechten $(\mathrm{M}+\mathrm{F})$, epiphytischen Gefäßpflanzen (Gef.), der Restfraktion sowie der Gesamtstreu in den drei untersuchten Beständen. Bezogen auf eine ebene Fläche, n=10.

\begin{tabular}{|c|c|c|c|c|c|c|c|c|c|c|c|}
\hline & \multicolumn{11}{|c|}{ Streufall $\left[\mathrm{g} \mathrm{m}^{-2}\right]$} \\
\hline & & BB & Stabw & $\mathrm{M}+\mathrm{F}$ & Stabw & Gef. & Stabw & Rest & Stabw & Ges. & Stabw \\
\hline \multirow{13}{*}{ 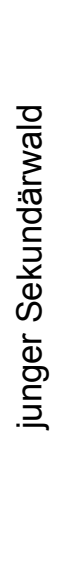 } & $M$ & 41.9 & 15.6 & 0.1 & 0.2 & 0.0 & 0.0 & 16.9 & 16.4 & 59.0 & 18.9 \\
\hline & $J$ & 52.1 & 37.1 & 0.2 & 0.4 & 0.0 & 0.0 & 15.7 & 13.2 & 68.0 & 47.5 \\
\hline & $J$ & 36.7 & 14.7 & 0.1 & 0.2 & 0.0 & 0.0 & 9.7 & 8.5 & 46.4 & 21.4 \\
\hline & $A$ & 37.7 & 13.8 & 0.3 & 0.4 & 0.0 & 0.1 & 10.4 & 8.8 & 48.5 & 19.9 \\
\hline & $S$ & 28.7 & 9.5 & 0.2 & 0.2 & 0.0 & 0.0 & 10.6 & 6.6 & 39.5 & 10.4 \\
\hline & O & 35.5 & 17.9 & 0.1 & 0.1 & 0.1 & 0.2 & 7.0 & 5.5 & 42.6 & 19.7 \\
\hline & $\mathrm{N}$ & 47.0 & 14.1 & 0.2 & 0.4 & 0.0 & 0.0 & 6.0 & 6.0 & 53.2 & 16.1 \\
\hline & $\mathrm{D}$ & 57.4 & 42.0 & 0.4 & 0.7 & 0.2 & 0.3 & 18.6 & 24.6 & 76.6 & 52.1 \\
\hline & $\mathrm{J}$ & 80.1 & 26.8 & 0.4 & 0.5 & 0.4 & 0.8 & 9.5 & 7.6 & 90.4 & 29.2 \\
\hline & $\mathrm{F}$ & 124.4 & 68.2 & 0.4 & 0.3 & 0.0 & 0.1 & 11.4 & 7.4 & 136.2 & 72.9 \\
\hline & $\mathrm{M}$ & 111.1 & 68.6 & 0.4 & 0.2 & 0.3 & 0.6 & 13.8 & 9.9 & 125.5 & 72.6 \\
\hline & A & 65.4 & 28.4 & 0.3 & 0.3 & 0.5 & 1.4 & 5.4 & 2.6 & 71.6 & 30.0 \\
\hline & $M$ & 68.5 & 23.5 & 0.3 & 0.3 & 0.0 & 0.1 & 7.2 & 4.6 & 76.0 & 22.6 \\
\hline \multirow{13}{*}{ 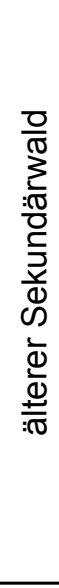 } & $\mathrm{N}$ & 1.3 & 25.8 & 0.3 & 0. & 0.0 & 0.0 & 18.7 & 10. & 70.3 & 28.4 \\
\hline & $\mathrm{J}$ & 46.5 & 20.3 & 0.3 & 0.5 & 0.0 & 0.0 & 18.3 & 15.2 & 65.2 & 31.4 \\
\hline & $\mathrm{J}$ & 39.8 & 17.4 & 0.3 & 0.3 & 0.1 & 0.3 & 16.6 & 12.3 & 56.7 & 23.9 \\
\hline & A & 42.8 & 19.8 & 0.7 & 1.2 & 0.9 & 2.8 & 26.6 & 19.0 & 71.0 & 33.6 \\
\hline & $S$ & 43.3 & 21.1 & 0.4 & 0.3 & 0.0 & 0.0 & 11.6 & 9.8 & 55.3 & 28.4 \\
\hline & O & 77.7 & 30.5 & 0.4 & 0.3 & 0.0 & 0.0 & 17.7 & 17.9 & 95.7 & 47.6 \\
\hline & $\mathrm{N}$ & 82.0 & 25.4 & 0.6 & 0.9 & 1.2 & 2.5 & 57.6 & 58.2 & 141.5 & 58.7 \\
\hline & D & 72.7 & 14.7 & 2.9 & 3.9 & 0.6 & $1 . \varepsilon$ & 146.0 & 88.0 & 222.1 & 93.5 \\
\hline & $\mathrm{J}$ & 125.3 & 30.3 & 0.4 & 0.3 & 0.0 & 0.0 & 19.8 & 13.7 & 145.4 & 32.6 \\
\hline & $\mathrm{F}$ & 272.5 & 79.9 & 0.7 & 0.7 & 1.0 & 3.3 & 44.2 & 27.9 & 318.4 & 96.0 \\
\hline & $\mathrm{M}$ & 241.0 & 79.3 & 0.6 & 0.8 & 0.0 & 0.1 & 38.2 & 17.7 & 279.9 & 94.4 \\
\hline & A & 101.7 & 34.8 & 0.2 & 0.2 & 0.0 & 0.0 & 13.8 & 7.2 & 115.3 & 39.6 \\
\hline & $\mathrm{M}$ & 62.5 & 24.6 & 0.4 & 0.5 & 0.0 & 0.1 & 20.0 & 12.7 & 82.9 & 22.9 \\
\hline \multirow{13}{*}{ 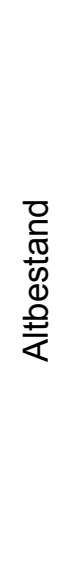 } & $\mathrm{M}$ & 15.9 & 5.8 & 1.8 & 1.1 & 3.5 & 3.6 & 16.2 & 5.7 & 37.5 & 5.2 \\
\hline & $\mathrm{J}$ & 26.1 & 6.7 & 1.4 & 1.3 & 5.7 & 12.6 & 10.5 & 3.8 & 43.6 & 16.4 \\
\hline & $\mathrm{J}$ & 24.2 & 10.0 & 0.5 & 0.6 & 1.3 & 3.1 & 11.8 & 4.9 & 37.7 & 13.6 \\
\hline & A & 20.4 & 6.2 & 1.6 & 1.9 & 1.4 & 2.6 & 18.3 & 9.0 & 41.8 & 12.8 \\
\hline & S & 12.7 & 3.2 & 0.8 & 0.8 & 1.2 & 2.1 & 11.4 & 6.2 & 26.1 & 9.0 \\
\hline & O & 21.3 & 4.9 & 1.3 & 1.2 & 1.8 & 3.0 & 14.6 & 6.7 & 39.1 & 7.8 \\
\hline & $\mathrm{N}$ & 20.6 & 6.1 & 1.1 & 1.1 & 2.9 & 3.6 & 33.7 & 22.2 & 58.2 & 27.0 \\
\hline & D & 81.8 & 21.9 & 14.4 & 5.3 & 16.2 & 25.5 & 211.3 & 68.7 & 323.6 & 73.7 \\
\hline & $\mathrm{J}$ & 130.1 & 44.2 & 2.7 & 2.7 & 0.6 & 0.9 & 22.8 & 12.6 & 156.3 & 47.1 \\
\hline & $\mathrm{F}$ & 154.1 & 52.5 & 5.8 & 3.4 & 4.9 & 11.0 & 46.9 & 19.1 & 211.7 & 59.6 \\
\hline & $\mathrm{M}$ & 124.9 & 25.8 & 1.3 & 1.0 & 0.5 & 0.9 & 38.0 & 24.0 & 164.7 & 36.0 \\
\hline & A & 51.9 & 11.0 & 0.3 & 0.3 & 0.1 & 0.3 & 18.4 & 5.1 & 70.7 & 10.3 \\
\hline & $\mathrm{M}$ & 35.4 & 19.9 & 1.4 & 2.4 & 3.9 & 10.9 & 35.1 & 12.5 & 75.8 & 21.0 \\
\hline
\end{tabular}


Tab. A-3: Lebensdauer von Eichenblättern (Quercus copeyensis) in den drei untersuchten Beständen.

\begin{tabular}{rcccc}
\hline \multicolumn{5}{c}{ relativer Anteil lebender Eichenblätter [\%] } \\
Altbestand & $\begin{array}{c}\text { älterer Sekundärwald } \\
\text { (Krone) }\end{array}$ & $\begin{array}{c}\text { junger } \\
\text { Sekundärwald }\end{array}$ \\
\hline 0 & 100 & 100 & 100 & \\
2 & 99.4 & 96.5 & & \\
6 & 99.4 & & 92 & \\
7 & & & & \\
9 & 98.2 & 86.0 & & \\
10 & & & & \\
11 & & 86.0 & & \\
12 & 96.4 & & & \\
13 & 94.0 & 86.0 & & \\
14 & 93.4 & 84.2 & & \\
15 & 93.4 & 84.2 & & \\
17 & 91.6 & & & \\
\hline
\end{tabular}

Tab. A-4: Auf der Freifläche in Sekundärwaldnähe gemessener Freilandniederschlag und die mit der mikrometeorologischen Freilandmeßstation erhobenen Daten (Lufttemperatur, Wassersättigungsdefizit (VPD), Strahlung, Windgeschwindigkeit). Außerdem ist die Anzahl der Nebeltage im Altbestand dargestellt.

\begin{tabular}{|c|c|c|c|c|c|c|c|}
\hline Monat & $\begin{array}{l}\mathrm{FN} \\
{[\mathrm{mm}]}\end{array}$ & Stabw & $\begin{array}{l}\text { Temp. } \\
{\left[{ }^{\circ} \mathrm{C}\right]}\end{array}$ & $\begin{array}{l}\text { VPD } \\
{[\mathrm{hPa}]}\end{array}$ & $\begin{array}{l}\text { Strahlung } \\
{\left[\mathrm{W} \mathrm{m}^{-2}\right]}\end{array}$ & $\begin{array}{l}\text { Wind } \\
{\left[\mathrm{m} \mathrm{s}^{-2}\right]}\end{array}$ & $\begin{array}{l}\text { Nebel } \\
\text { [Tage] }\end{array}$ \\
\hline Apr. & 86 & 1 & 11.6 & 4.6 & 109.1 & 0.8 & \\
\hline Mai & 431 & 5 & 11.4 & 2.9 & 94.9 & 0.5 & \\
\hline Jun. & 462 & 6 & 11.0 & 2.5 & 96.3 & 0.4 & \\
\hline Jul. & 191 & 1 & 10.9 & 3.0 & 90.5 & 0.9 & \\
\hline Aug. & 318 & 3 & 10.9 & 2.7 & 107.6 & 0.5 & \\
\hline Sep. & 405 & 2 & 10.8 & 2.3 & 81.8 & 0.3 & \\
\hline Okt. & 399 & 6 & 10.9 & 2.3 & 87.7 & 0.3 & \\
\hline Nov. & 163 & 3 & 10.7 & 2.0 & 86.2 & 0.7 & \\
\hline Dez. & 368 & 10 & 10.1 & 2.2 & 95.4 & 1.3 & \\
\hline Jan. & 152 & 17 & 9.6 & 3.2 & 109.5 & 1.6 & \\
\hline Feb. & 78 & 4 & 9.8 & 3.5 & 125.2 & 1.2 & 5 \\
\hline Mär. & 20 & 2 & 11.3 & 5.3 & 130.0 & 0.6 & 8 \\
\hline Apr. & 62 & 2 & 11.4 & 4.1 & 116.6 & 0.8 & 11 \\
\hline Mai & 282 & 2 & 11.5 & 2.8 & 95.4 & 0.4 & 22 \\
\hline Jun. & 450 & 8 & 11.3 & 2.7 & 93.3 & 0.6 & 18 \\
\hline Jul. & 96 & 1 & 10.9 & 3.1 & 111.0 & 0.9 & 11 \\
\hline Aug. & 242 & 3 & 11.2 & 3.2 & 102.0 & 0.9 & 17 \\
\hline Sep. & & & & & & & 18 \\
\hline
\end{tabular}


Tab. A-5: Messungen der Regensammler (vertikaler Freilandniederschlag) und mit den Nebelsammlern gemessener horizontaler Niederschlag an einzelnen Tagen der Regenzeit im Mai 2000 und in der Trockenzeit im Januar 2000 während einer Derrame-Wetterlage.

\begin{tabular}{ccccccc}
\hline \multicolumn{3}{c}{$\begin{array}{c}\text { horizontaler } \\
\text { Niederschlag } \\
{[\mathrm{ml}]}\end{array}$} & Stabw & $\mathrm{n}$ & $\begin{array}{c}\text { vertikaler } \\
\text { Niederschlag } \\
{[\mathrm{mm}]}\end{array}$ & Stabw \\
\hline 24.05 .00 & 86.7 & 9.5 & 3 & 35.7 & 0.3 & 5 \\
26.05 .00 & 38.7 & 7.8 & 3 & 22.1 & 0.7 & 5 \\
27.05 .00 & 98.7 & 26.0 & 3 & 25.7 & 0.3 & 5 \\
29.05 .00 & 80.7 & 20.1 & 3 & 25.7 & 0.4 & 5 \\
30.05 .00 & 110.0 & 18.0 & 3 & 37.3 & 0.3 & 5 \\
31.05 .00 & 121.7 & 33.7 & 3 & 38.1 & 0.7 & 5 \\
13.01 .00 & 680 & & 1 & 10.5 & 0.7 & 5 \\
14.01 .00 & 1662 & & 1 & 26.8 & 1.2 & 5 \\
15.01 .00 & 2190 & & 1 & 38.2 & 2.7 & 5 \\
16.01 .00 & 1308 & & 1 & 12.7 & 1.7 & 4 \\
17.01 .00 & 1400 & & 1 & 14.3 & 0.8 & 5 \\
\hline
\end{tabular}

Tab. A-6: Höhengradient der Lufttemperatur und des Sättigungsdefizites (VPD) in verschiedenen Baumhöhen des Altbestandes sowie VPD in verschiedenen Baumhöhen des jungen und älteren Sekundärwaldes (Mittelwerte aus vier Regenzeitwochen (Rz) und vier Trockenzeitwochen $(\mathrm{Tz}))$.

\begin{tabular}{|c|c|c|c|c|c|c|c|c|c|c|}
\hline \multicolumn{5}{|c|}{ Altbestand } & \multicolumn{3}{|c|}{ junger Sekundärwald } & \multicolumn{3}{|c|}{ älterer Sekundärwald } \\
\hline \multirow{2}{*}{$\begin{array}{l}\text { Höhe } \\
{[\mathrm{m}]}\end{array}$} & \multicolumn{2}{|c|}{ Temp. $\left[{ }^{\circ} \mathrm{C}\right]$} & \multicolumn{2}{|c|}{ VPD [hPa] } & \multirow{2}{*}{$\begin{array}{l}\text { Höhe } \\
\text { [m] }\end{array}$} & \multicolumn{2}{|c|}{ VPD $[\mathrm{hPa}]$} & \multirow{2}{*}{$\begin{array}{l}\text { Höhe } \\
{[\mathrm{m}]}\end{array}$} & \multicolumn{2}{|c|}{ VPD [hPa] } \\
\hline & $\mathrm{Rz}$ & $\mathrm{Tz}$ & $\mathrm{Rz}$ & Tz & & $\mathrm{Rz}$ & $\mathrm{Tz}$ & & $\mathrm{Rz}$ & $\mathrm{Tz}$ \\
\hline 0.5 & 9.1 & 8.6 & 0.2 & 2.8 & 0.2 & 0.4 & 2.5 & 0.2 & 0.4 & 2.4 \\
\hline 17 & 9.6 & 9.1 & 0.9 & 3.6 & 4.0 & 0.7 & 2.8 & 4 & 0.8 & 3.0 \\
\hline 25 & 9.7 & 9.2 & 1.1 & 3.7 & 6.0 & 1.1 & 3.1 & 7 & 0.9 & 3.1 \\
\hline 26 & 9.9 & 9.3 & 1.0 & 3.6 & & & & 8 & 0.7 & 3.0 \\
\hline 30 & 10.2 & 9.6 & 1.1 & 3.7 & & & & 11 & 1.1 & 3.5 \\
\hline
\end{tabular}

Tab. A-7: Mittlere Piche-Evaporation in vier unterschiedlichen Baumhöhen des Altbestandes sowie im Freiland. Dargestellt sind die Mittelwerte der Messungen während drei einzelner Tage in der Trockenzeit.

\begin{tabular}{lcccc}
\hline & $\begin{array}{c}\text { Höhe } \\
{[\mathrm{m}]}\end{array}$ & $\begin{array}{c}\text { Evaporation } \\
{\left[\mathrm{cm}^{3} \mathrm{~h}^{-1}\right]}\end{array}$ & $\mathrm{n}$ & Stabw \\
\hline Altbestand & 30 & 0.60 & 3 & 0.12 \\
& 25 & 0.58 & 3 & 0.06 \\
& 18 & 0.59 & 3 & 0.07 \\
& 1 & 0.34 & 2 & 0.04 \\
Freiland & 1.5 & 1.21 & 2 & 0.08 \\
\hline
\end{tabular}


Tab. A-8: Monatlicher Bestandesniederschlag und Stammablauf in den drei untersuchten Beständen [\% Freilandniederschlag].

\begin{tabular}{|c|c|c|c|c|c|c|c|c|c|c|c|c|c|c|c|c|}
\hline \multirow[b]{3}{*}{ Monat } & \multicolumn{6}{|c|}{ Bestandesniederschlag } & \multicolumn{10}{|c|}{ Stammablauf } \\
\hline & \multirow{2}{*}{\multicolumn{2}{|c|}{$\begin{array}{l}\text { jung. Sekw. } \\
\text { Mw Stabw }\end{array}$}} & & \multicolumn{2}{|c|}{ Altbestand } & \multirow{2}{*}{\multicolumn{2}{|c|}{$\begin{array}{c}\text { jung. Sekw. } \\
\text { Krone }\end{array}$}} & \multicolumn{4}{|c|}{ ält. Sekw. } & \multicolumn{4}{|c|}{ Altbestand } \\
\hline & & & $\mathrm{Mw}$ & Stabw & Mw & Stabw & & & & $\begin{array}{l}\text { one } \\
\text { Stabw }\end{array}$ & $\begin{array}{c}\text { unters } \\
\mathrm{Mw}\end{array}$ & $\begin{array}{l}\text { tändig } \\
\text { Stabw }\end{array}$ & $\begin{array}{r}\mathrm{Kr} \\
\mathrm{Mw} \\
\end{array}$ & $\begin{array}{l}\text { one } \\
\text { Stabw }\end{array}$ & $\begin{array}{c}\text { unterst } \\
\mathrm{Mw}\end{array}$ & $\begin{array}{l}\text { tändig } \\
\text { Stabw }\end{array}$ \\
\hline Apr & & & 67.0 & 21.5 & 69.6 & 16.7 & & & & & & & & & & \\
\hline Mai & 62.0 & 24.8 & 71.4 & 27.6 & 77.8 & 17.2 & 23.0 & 12.5 & 13.6 & 7.2 & & & & & & \\
\hline Jun & 76.3 & 31.1 & 76.8 & 27.1 & 72.0 & 23.4 & 19.7 & 13.7 & 12.9 & 7.3 & & & 0.6 & 0.3 & & \\
\hline Jul & 75.8 & 37.3 & 76.2 & 31.5 & 77.6 & 29.9 & 17.4 & 11.7 & 10.7 & 6.5 & & & 0.6 & 0.3 & & \\
\hline Aug & 79.3 & 57.5 & 72.6 & 26.3 & 67.0 & 16.2 & 13.5 & 8.0 & 9.8 & 5.9 & & & 0.5 & 0.2 & & \\
\hline Sep & 68.6 & 47.5 & 73.4 & 27.5 & 74.8 & 18.5 & 14.0 & 10.8 & 13.3 & 7.7 & & & 0.8 & 0.3 & & \\
\hline Okt & 68.4 & 33.3 & 75.4 & 27.7 & 80.0 & 19.9 & 17.5 & 14.2 & 14.8 & 9.0 & & & 0.9 & 0.3 & & \\
\hline Nov & 63.1 & 29.3 & 71.2 & 25.1 & 72.7 & 30.3 & 16.3 & 13.1 & 8.0 & 5.3 & & & 0.5 & 0.2 & & \\
\hline Dez & 63.8 & 25.7 & 80.2 & 27.1 & 84.8 & 24.6 & 18.1 & 13.0 & 20.3 & 12.0 & & & 0.6 & 0.2 & 1.0 & 0.2 \\
\hline Jan & 59.7 & 41.5 & 80.9 & 43.4 & 62.5 & 26.9 & 13.8 & 13.3 & 15.9 & 10.3 & & & 0.3 & 0.2 & 1.1 & 1.2 \\
\hline Feb & 56.3 & 38.9 & 73.0 & 27.9 & 44.2 & 16.3 & 10.2 & 12.3 & 9.7 & 7.8 & & & 0.1 & 0.0 & 0.8 & 0.7 \\
\hline Mrz & 37.4 & 21.8 & 42.8 & 12.9 & 39.0 & 18.1 & 4.3 & 4.2 & 0.4 & 0.5 & 0.2 & 0.4 & 0.2 & 0.1 & 0.3 & 0.3 \\
\hline Apr & 55.1 & 32.1 & 62.3 & 18.2 & 44.0 & 16.5 & 10.3 & 6.7 & 5.0 & 3.8 & 1.3 & 1.2 & 0.1 & 0.0 & 0.7 & 0.6 \\
\hline Mai & 68.2 & 39.1 & 71.9 & 22.0 & 69.8 & 19.2 & 15.4 & 9.3 & 9.0 & 5.7 & 2.9 & 3.0 & 0.5 & 0.2 & 1.5 & 1.3 \\
\hline Jun & 65.6 & 41.8 & 69.8 & 19.9 & 73.1 & 12.5 & 16.3 & 9.3 & 13.9 & 8.5 & 3.7 & 3.5 & 0.7 & 0.2 & 2.0 & 1.6 \\
\hline Jul & 61.2 & 40.6 & 60.9 & 15.6 & 39.0 & 13.6 & 11.9 & 6.3 & 5.0 & 3.4 & 2.6 & 2.6 & 0.1 & 0.0 & 0.6 & 0.9 \\
\hline Aug & 66.3 & 42.1 & 64.0 & 16.2 & 61.7 & 12.7 & 11.2 & 6.0 & 6.4 & 4.4 & 2.4 & 2.7 & 0.6 & 0.2 & 2.1 & 2.0 \\
\hline
\end{tabular}

Tab. A-9: Freilandniederschlag und Nettoniederschlag in den drei untersuchten Beständen während 19 Tagen in der Regen- und Zwischentrockenzeit.

\begin{tabular}{|c|c|c|c|c|c|}
\hline \multirow[b]{3}{*}{ Datum } & \multicolumn{4}{|c|}{ Nettoniederschlag [mm] } & \multirow[b]{3}{*}{ Freilano } \\
\hline & junger & älterer & & & \\
\hline & \multicolumn{2}{|c|}{ Sekundärwald } & Freiland & Altbestand & \\
\hline 23.05 .00 & 0.6 & 0.6 & 1.3 & 0.9 & 3.2 \\
\hline 24.05 .00 & 34.4 & 31.5 & 35.7 & 44.7 & 49.6 \\
\hline 25.05 .00 & 0.3 & 0.3 & 0.9 & 0.2 & 1.1 \\
\hline 26.05 .00 & 17.4 & 17.2 & 22.1 & 13.2 & 22.8 \\
\hline 27.05 .00 & 24.7 & 19.9 & 25.7 & 10.5 & 14.2 \\
\hline 28.05 .00 & 1.3 & 1.3 & 2.3 & 0.6 & 2.2 \\
\hline 29.05 .00 & 21.1 & 22.2 & 25.7 & 9.9 & 17.4 \\
\hline 30.05 .00 & 22.7 & 25.2 & 37.3 & 28.2 & 34.6 \\
\hline 31.05 .00 & 31.7 & 34.4 & 38.1 & 36.4 & 40.2 \\
\hline 1.06 .00 & 1.0 & 0.9 & 2.6 & 0.8 & 3.0 \\
\hline 2.06 .00 & 0.3 & 0.4 & 0.9 & 0.1 & 0.7 \\
\hline 3.06 .00 & 2.9 & 2.3 & 5.2 & 1.6 & 5.6 \\
\hline 4.06 .00 & 9.1 & 7.5 & 10.9 & 8.0 & 12.7 \\
\hline 5.06 .00 & 23.1 & 20.0 & 25.9 & 32.4 & 40.4 \\
\hline 18.07 .00 & 0.0 & 0.0 & 0.3 & 0.0 & 0.4 \\
\hline 24.07 .00 & 6.3 & 3.1 & 10.2 & 0.7 & 5.9 \\
\hline 25.07 .00 & 5.4 & 7.7 & 6.7 & 1.2 & 3.9 \\
\hline 26.07 .00 & 0.5 & 0.2 & 1.1 & 0.1 & 0.7 \\
\hline 27.07 .00 & 18.4 & 17.5 & 21.7 & 10.4 & 18.1 \\
\hline
\end{tabular}


Tab. A-10: Häufigkeitsverteilung des Bestandesniederschlags nach Größenklassen [in \% des Freilandniederschlags] Mittelwerte von 14 täglich durchgeführten Niederschlagsmessungen. $\mathrm{n}=30$ Sammler je Bestand.

\begin{tabular}{cccc}
\hline & \multicolumn{3}{c}{ Häufigkeit [\%] } \\
Klasse [\% FN] & junger Sekundärwald & älterer Sekundärwald & Altbestand \\
\hline $20-40$ & 16.7 & 6.7 & \\
$40-60$ & 40.0 & 23.3 & 6.7 \\
$60-80$ & 20.0 & 43.3 & 60.0 \\
$80-100$ & 20.0 & 20.0 & 23.3 \\
$100-120$ & & 3.3 & 6.7 \\
$120-140$ & & 3.3 & 3.3 \\
$140-160$ & & & \\
$160-180$ & & & \\
$180-200$ & & & \\
$200-220$ & 3.3 & & \\
\hline
\end{tabular}

Tab. A-11: Relativer Stammablauf im jungen Sekundärwald während zwei Wochen vor und zwei Wochen nach Entlaubung der Bäume. $n=4$.

\begin{tabular}{cccccccc}
\hline \multicolumn{8}{c}{ Relativer Stammablauf [\% des Freilandniederschlags] } \\
\multicolumn{4}{c}{ Entlaubungsvariante } \\
vorher & nachher & & & \\
$\mathrm{Mw}$ & Stabw & $\mathrm{Mw}$ & Stabw & $\mathrm{Mw}$ & Stabw & $\mathrm{Mw}$ & Stabw \\
\hline 10.93 & 6.84 & 1.36 & 1.14 & 9.50 & 6.79 & 7.58 & 5.53 \\
\hline
\end{tabular}

Tab. A-12: Wasserspeicherung der Moosarten Pilotrichella flexilis und Leptodontium exasperatum bei experimenteller Beregnung mit unterschiedlichen Regenmengen. $\mathrm{n}=8$.

\begin{tabular}{ccccc}
\hline & \multicolumn{2}{c}{ Pilotrichella } & \multicolumn{2}{c}{ Leptodontium } \\
$\begin{array}{c}\text { Beregnungsmenge } \\
{[\mathrm{ml}]}\end{array}$ & $\begin{array}{c}\text { Speicher } \\
{\left[\mathrm{ml} \mathrm{g} \mathrm{TG}^{-1}\right]}\end{array}$ & Stabw & $\begin{array}{c}\text { Speicher } \\
{\left[\mathrm{ml} \mathrm{g} \mathrm{TG}^{-1}\right]}\end{array}$ & Stabw \\
\hline 0.6 & 0.1 & 0.0 & 0.1 & 0.0 \\
2.8 & 0.3 & 0.1 & 0.3 & 0.1 \\
5.5 & 0.9 & 0.2 & 0.7 & 0.1 \\
11.0 & 1.8 & 0.3 & 1.3 & 0.2 \\
27.7 & 4.0 & 0.7 & 2.9 & 0.5 \\
55.4 & 6.2 & 1.2 & 5.4 & 1.0 \\
110.8 & 8.0 & 1.4 & 5.3 & 1.0 \\
\hline
\end{tabular}


Tab. A-13: Wasserspeicherung der Blätter von Oreopanax spec. $(\mathrm{n}=8)$ und der Triebe von Quercus copeyensis $(\mathrm{n}=5)$ bei experimenteller Beregnung mit unterschiedlichen Regenmengen.

\begin{tabular}{|c|c|c|c|c|c|}
\hline \multirow[b]{2}{*}{$\begin{array}{l}\text { Beregnungs- } \\
\text { menge [ml] }\end{array}$} & \multicolumn{2}{|l|}{ Oreopanax } & \multicolumn{3}{|c|}{ Quercus } \\
\hline & $\begin{array}{l}\text { Speicher } \\
{\left[\mathrm{ml} \mathrm{g} \mathrm{TG}^{-1}\right]}\end{array}$ & Stabw & $\begin{array}{l}\text { Beregnungs- } \\
\text { menge [ml] }\end{array}$ & $\begin{array}{l}\text { Speicher } \\
{\left[\mathrm{ml} \mathrm{g} \mathrm{TG}^{-1}\right]}\end{array}$ & Stabw \\
\hline 0.72 & 0.26 & 0.04 & 0.50 & 0.20 & 0.05 \\
\hline 1.44 & 0.45 & 0.12 & 2.50 & 0.63 & 0.19 \\
\hline 2.88 & 0.59 & 0.24 & 7.50 & 0.73 & 0.18 \\
\hline 4.32 & 0.55 & 0.14 & 12.50 & 0.99 & 0.15 \\
\hline 7.20 & 0.42 & 0.13 & 20.00 & 0.95 & 0.19 \\
\hline 11.52 & 0.51 & 0.11 & 25.00 & 0.93 & 0.13 \\
\hline 14.40 & 0.53 & 0.13 & & & \\
\hline
\end{tabular}

Tab. A-14: Aktueller monatlicher Wassergehalt des epiphytischen Polstermooses Leptodontium exasperatum und des epiphytischen Farnes Elaphoglossum spec. in der Kronenregion des Altbestandes von November 1999 bis August 2000.

Wassergehalt [\% Trockengewicht]

Leptodontium

Elaphoglossum

\begin{tabular}{ccccccc} 
Monat & Mw & Stabw & $\mathrm{n}$ & Mw & Stabw & $\mathrm{n}$ \\
\hline Nov & 290.9 & 16.5 & 10 & 228.5 & 39.3 & 10 \\
Dez & 405.7 & 30.8 & 10 & 267.2 & 39.9 & 10 \\
Jan & 137.9 & 44.8 & 10 & 151.1 & 23.6 & 10 \\
Feb & 31.5 & 10.4 & 7 & 114.5 & 30.4 & 10 \\
Mär & 24.1 & 1.4 & 8 & 42.2 & 26.9 & 6 \\
Apr & 101.2 & 31.5 & 7 & 76.2 & 46.6 & 6 \\
Jun & 264.1 & 15.8 & 8 & 185.0 & 33.4 & 10 \\
Jul & 37.6 & 14.8 & 8 & 82.6 & 16.7 & 8 \\
Aug & 229.2 & 18.4 & 8 & 169.0 & 23.2 & 8 \\
\hline
\end{tabular}

Wassergehalt [\% Trockengewicht]

\begin{tabular}{lcc} 
& Mw & Stabw \\
\hline Leptodontium & & \\
Humus/Rhizoide & 82.3 & 12.4 \\
grüne Pflanze & 17.9 & 2.0 \\
$\quad$ Vriesea & & \\
Blatt unten & 743.3 & 76.2 \\
Blatt oben & 400.8 & 14.7 \\
\hline
\end{tabular}

Tab. A-15: Aktueller Wassergehalt von Leptodontium-Moospolstern und Bromelienblättern (Vriesea orosiensis) im Februar 2000 (Trockenzeit) im Altbestand $(n=5)$. 
Tab. A-16: Experimentell ermittelte Wasserspeicherkapazität der Phytotelmen von Vriesea orosiensis.

\begin{tabular}{ccc}
\hline & \multicolumn{2}{c}{ Bromelien- } \\
Nr. & $\begin{array}{c}\text { Durchmesser } \\
{[\mathrm{cm}]}\end{array}$ & $\begin{array}{c}\text { Speicher } \\
{[\mathrm{ml}]}\end{array}$ \\
\hline 1 & 40 & 500 \\
2 & 40 & 300 \\
3 & 40 & 270 \\
4 & 46 & 560 \\
5 & 45 & 750 \\
6 & 42 & 600 \\
7 & 35 & 140 \\
8 & 23 & 125 \\
9 & 27 & 50 \\
10 & 30 & 100 \\
11 & 25 & 56 \\
12 & 24 & 55 \\
13 & 19.5 & 30 \\
\hline
\end{tabular}

Tab. A-17: Niederschlag in Regensammlern mit experimentell angebrachten Moosen im relativen Verhältnis zum Freilandniederschlag. $\mathrm{n}=7$ (Mai), $\mathrm{n}=5$ (Januar).

\begin{tabular}{lcc}
\multicolumn{3}{c}{ \% Freilandniederschlag } \\
Monat & Mw & Stabw \\
\hline Jan 2000 & & \\
12 & 84.7 & 6.7 \\
13 & 137.3 & 12.6 \\
14 & 185.4 & 19.2 \\
15 & 124.6 & 16.8 \\
16 & 35.6 & 15.9 \\
17 & 133.1 & 16.7 \\
18 & 95.0 & 30.1 \\
Mai 2000 & & \\
23 & 61.6 & 10.7 \\
24 & 93.1 & 2.5 \\
25 & 60.5 & 8.4 \\
26 & 84.5 & 4.2 \\
27 & 84.2 & 4.8 \\
28 & 61.7 & 7.7 \\
29 & 84.7 & 5.3 \\
& &
\end{tabular}

Tab. A-18: Niederschlag in Regensammlern mit experimentell angebrachten Moosen im relativen Verhältnis zum Freilandniederschlag in wöchentlicher Auflösung. Dez. bis Mrz. $: \mathrm{n}=5$, Mai bis Aug.: $\mathrm{n}=7$.

\begin{tabular}{cccccc}
\hline \multirow{2}{*}{ Monat } & Mw & \% des Freilandniederschlags & & \\
Stabw & Monat & Mw & Stabw \\
\hline \multirow{5}{*}{ Jez } & 79.3 & 4.1 & Mrz & 67.0 & 3.3 \\
& 87.3 & 4.3 & & 32.2 & 7.8 \\
& 91.7 & 6.7 & Mai & 86.9 & 3.5 \\
& 58.3 & 6.7 & Jun & 88.8 & 3.1 \\
& 38.3 & 10.3 & & 79.3 & 5.0 \\
& 147.9 & 11.9 & & 92.4 & 2.2 \\
& 51.5 & 6.0 & & 86.2 & 4.1 \\
& 28.4 & 14.9 & Jul & 74.5 & 5.5 \\
& 71.2 & 8.6 & & 69.5 & 8.6 \\
& 17.5 & 6.4 & & 53.7 & 10.2 \\
& 106.2 & 12.0 & & 74.1 & 4.7 \\
& 36.8 & 7.4 & Aug & 82.6 & 4.0 \\
& & & 73.8 & 4.4 \\
\hline
\end{tabular}


Abb. A-19: Austrocknungskurven von Pilotrichella flexilis und Sticta ferax aufgenommen in situ am Standort. Dargestellt ist der zeitliche Verlauf der Austrocknung nach Wasseraufsättigung an einem Tag in der Regen- und in der Trockenzeit im Altbestand. Pilotrichella $\mathrm{n}=7$, Sticta $\mathrm{n}=$ 8.

\begin{tabular}{|c|c|c|c|c|c|c|c|c|}
\hline \multirow{4}{*}{ Uhrzeit } & \multicolumn{8}{|c|}{ Wassergehalt [\% der max. Aufnahmekapazität] } \\
\hline & \multicolumn{4}{|c|}{ Pilotrichella } & \multicolumn{4}{|c|}{ Sticta } \\
\hline & \multicolumn{2}{|c|}{ Trockenzeit } & \multicolumn{2}{|c|}{ Regenzeit } & \multicolumn{2}{|c|}{ Trockenzeit } & \multicolumn{2}{|c|}{ Regenzeit } \\
\hline & Mw & Stabw & Mw & Stabw & Mw & Stabw & $\mathrm{Mw}$ & Stabw \\
\hline 6.30 & 100.0 & & 100.0 & & 100.0 & & 100.0 & \\
\hline 6.45 & & & & & 75.0 & 4.8 & & \\
\hline 7.00 & 71.0 & 4.3 & 90.1 & 1.7 & 56.7 & 2.7 & 93.2 & 3.8 \\
\hline 7.15 & & & & & 46.9 & 5.6 & & \\
\hline 7.30 & 52.7 & 7.0 & 82.9 & 2.5 & 37.0 & 4.7 & 88.0 & 4.8 \\
\hline \multicolumn{9}{|l|}{7.45} \\
\hline 8.00 & 29.9 & 8.0 & & & 24.2 & 3.3 & 83.6 & 4.7 \\
\hline \multicolumn{9}{|l|}{8.15} \\
\hline 8.30 & 18.6 & 8.0 & 75.1 & 3.6 & 18.5 & 2.8 & 79.6 & 4.7 \\
\hline \multicolumn{9}{|l|}{8.45} \\
\hline 9.00 & 12.5 & 6.7 & & & 16.6 & 2.3 & 75.0 & 5.2 \\
\hline \multicolumn{9}{|l|}{9.15} \\
\hline 9.30 & 10.2 & 4.9 & 61.0 & 5.8 & & & & \\
\hline \multicolumn{9}{|l|}{9.45} \\
\hline 10.00 & 7.8 & 3.9 & & & 10.7 & 2.2 & 69.4 & 5.3 \\
\hline \multicolumn{9}{|l|}{10.15} \\
\hline 10.30 & & & 45.6 & 7.4 & & & & \\
\hline \multicolumn{9}{|l|}{10.45} \\
\hline 11.00 & 6.1 & 2.5 & & & 10.6 & 2.3 & 55.9 & 5.9 \\
\hline \multicolumn{9}{|l|}{11.15} \\
\hline 11.30 & & & 33.9 & 7.8 & & & & \\
\hline \multicolumn{9}{|l|}{11.45} \\
\hline 12.00 & 5.6 & 1.9 & & & 10.6 & 2.3 & 46.0 & 7.2 \\
\hline \multicolumn{9}{|l|}{12.15} \\
\hline 12.30 & & & 28.3 & 7.6 & & & & \\
\hline \multicolumn{9}{|l|}{12.45} \\
\hline 13.00 & 5.6 & 1.7 & & & & & 41.8 & 6.4 \\
\hline \multicolumn{9}{|l|}{13.15} \\
\hline 13.30 & & & 26.1 & 7.3 & & & & \\
\hline \multicolumn{9}{|l|}{13.45} \\
\hline 14.00 & 6.0 & 1.3 & & & & & 36.1 & 6.8 \\
\hline 14.15 & & & & & & & & \\
\hline 14.30 & & & & & & & & \\
\hline 14.45 & & & & & & & & \\
\hline 15.00 & 5.9 & 1.1 & & & & & 35.6 & 6.6 \\
\hline 15.15 & & & & & & & & \\
\hline 15.30 & & & & & & & & \\
\hline 15.45 & & & & & & & & \\
\hline 16.00 & 5.8 & 1.2 & & & & & 35.6 & 6.3 \\
\hline 16.15 & & & & & & & & \\
\hline 16.30 & & & & & & & & \\
\hline 16.45 & & & & & & & & \\
\hline 17.00 & 5.7 & 1.3 & & & & & & \\
\hline
\end{tabular}


Abb. A-20: Austrocknungskurven von Leptodontium exasperatum und Eichenborke aufgenommen in situ am Standort. Dargestellt ist der zeitliche Verlauf der Austrocknung nach Wasseraufsättigung an einem Tag in der Regen- und in der Trockenzeit im Altbestand. Leptodontium $\mathrm{n}=7$, Eichenborke $\mathrm{n}=8$.

\begin{tabular}{|c|c|c|c|c|c|c|c|c|}
\hline \multirow{4}{*}{ Uhrzeit } & \multicolumn{8}{|c|}{ Wassergehalt [\% der max. Aufnahmekapazität] } \\
\hline & \multicolumn{4}{|c|}{ Leptodontium } & \multicolumn{4}{|c|}{ Eichenborke } \\
\hline & \multicolumn{2}{|c|}{ Trockenzeit } & \multicolumn{2}{|c|}{ Regenzeit } & \multicolumn{2}{|c|}{ Trockenzeit } & \multicolumn{2}{|c|}{ Regenzeit } \\
\hline & Mw & Stabw & Mw & Stabw & Mw & Stabw & $\mathrm{Mw}$ & Stabw \\
\hline 6.30 & 100.0 & & & & 100.0 & & 100.0 & \\
\hline \multicolumn{9}{|l|}{6.45} \\
\hline 7.00 & 98.9 & 0.5 & 100.0 & & 84.7 & 4.0 & 87.2 & 6.0 \\
\hline \multicolumn{9}{|l|}{7.15} \\
\hline 7.30 & 98.0 & 1.0 & 97.7 & 1.2 & 66.5 & 12.1 & 79.3 & 10.1 \\
\hline \multicolumn{9}{|l|}{7.45} \\
\hline 8.00 & 97.2 & 1.3 & & & 50.5 & 12.4 & 69.2 & 12.8 \\
\hline \multicolumn{9}{|l|}{8.15} \\
\hline 8.30 & 95.8 & 1.4 & & & 43.7 & 11.3 & 65.1 & 14.2 \\
\hline \multicolumn{9}{|l|}{8.45} \\
\hline 9.00 & 94.9 & 1.6 & 94.2 & 2.2 & 35.2 & 11.9 & & \\
\hline \multicolumn{9}{|l|}{9.15} \\
\hline 9.30 & 94.0 & 1.8 & & & 23.3 & 11.7 & 56.4 & 15.9 \\
\hline \multicolumn{9}{|l|}{9.45} \\
\hline 10.00 & 92.7 & 2.1 & 92.2 & 2.5 & & & & \\
\hline \multicolumn{9}{|l|}{10.15} \\
\hline 10.30 & & & & & 11.3 & 8.0 & 42.0 & 15.8 \\
\hline \multicolumn{9}{|l|}{10.45} \\
\hline 11.00 & 90.2 & 2.3 & 90.6 & 2.7 & & & & \\
\hline \multicolumn{9}{|l|}{11.15} \\
\hline 11.30 & & & & & 7.5 & 6.0 & 37.5 & 13.7 \\
\hline \multicolumn{9}{|l|}{11.45} \\
\hline 12.00 & 88.7 & 2.8 & 89.3 & 3.0 & & & & \\
\hline \multicolumn{9}{|l|}{12.15} \\
\hline 12.30 & & & & & 6.7 & 5.2 & 32.8 & 12.2 \\
\hline \multicolumn{9}{|l|}{12.45} \\
\hline 13.00 & 87.5 & 2.9 & 88.1 & 3.8 & & & & \\
\hline 13.15 & & & & & & & & \\
\hline 13.30 & & & & & 5.9 & 5.2 & 29.9 & 10.7 \\
\hline 13.45 & & & & & & & & \\
\hline 14.00 & 86.7 & 3.1 & & & & & & \\
\hline 14.15 & & & & & & & & \\
\hline 14.30 & & & & & 6.1 & 5.7 & 29.4 & 10.3 \\
\hline 14.45 & & & & & & & & \\
\hline 15.00 & 86.2 & 3.2 & 87.9 & 3.7 & & & & \\
\hline 15.15 & & & & & & & & \\
\hline 15.30 & & & & & 6.3 & 5.2 & 29.2 & 10.3 \\
\hline 15.45 & & & & & & & & \\
\hline 16.00 & 85.5 & 3.3 & & & & & & \\
\hline 16.15 & & & & & & & & \\
\hline 16.30 & & & & & & & & \\
\hline 16.45 & & & & & & & & \\
\hline 17.00 & 84.5 & 3.3 & & & & & & \\
\hline
\end{tabular}




\section{Abkürzungsverzeichnis}

a

BHD

BN

$\mathrm{e}_{\mathrm{a}}$

$\mathrm{e}_{\mathrm{s}}$

FG

FN

$\mathrm{h}$

ha

$\mathrm{hPa}$

I

K

$\mathrm{KB}$

LAI

$\mathrm{Mw}$

$\mathrm{n}$

$\mathrm{p}$

$\mathrm{r}$

rh

$\mathrm{S}$

Stabw

TG

ü.M.

UB

VPD

WG
Jahr

Brusthöhendurchmesser

Bestandesniederschlag

aktueller Dampfdruck

Sättigungsdampfdruck

Frischgewicht

Freilandniederschlag

Stunde

Hektar $=10000 \mathrm{~m}^{2}$

Hektopascal

Interzeption

Kelvin

Kronenbäume

Blattflächenindex (Leaf Area Index)

Mittelwert

Stichprobenumfang

Irrtumswahrscheinlichkeit

Korrelationskoeffizient

relative Luftfeuchte (relative humidity)

Stammablauf

Standardabweichung

Trockengewicht

über Meereshöhe

unterständige Bäume

Wasserdampfsättigungsdefizit (Vapor Pressure Deficit)

Wassergehalt 


\section{Danksagung}

An erster Stelle möchte ich Prof. Dr. Christoph Leuschner und Dr. Dirk Hölscher danken, mit deren Unterstützung ich sowohl in Costa Rica als auch in Deutschland jederzeit rechnen konnte und die entscheidend zum Gelingen dieser Arbeit beigetragen haben.

Auch Prof. Dr. S. Rob. Gradstein und Dr. Maarten Kappelle möchte ich Dank sagen für die tatkräftige Hilfe in Costa Rica. Dr. Kappelle war auch bei der Bestimmung der Gefäßpflanzen behilflich.

Mein besonderer Dank gilt Dr. Dietrich Hertel der mir durch seine ständige Diskussionsbereitschaft und seine Anregungen eine große Hilfe bei der Anfertigung dieser Arbeit war.

Daran, daß die Arbeit und das Leben in San Gerardo de Dota in Costa Rica so gut verlaufen sind, hat Ingo Holz einen großen Anteil. Von ihm wurde auch die Bestimmung der Moosarten durchgeführt.

Die Bewohner San Gerardo de Dotas haben durch ihre Gastfreundschaft und Hilfsbereitschaft wesentlich dazu beigetragen, daß das Leben fast immer ,pura vida“ war.

Bedanken möchte ich mich bei Arturo Serrano, der mich nicht allein im Regen stehen ließ und mir half, 32440 Liter Freilandniederschlag, Bestandesniederschlag und Stammablauf zu sammeln.

Der Familie Kappelle habe ich es zu verdanken, daß ich auch außerhalb des „Untersuchungsgebietes“ immer eine Bleibe hatte, muchas gracias.

Korrekturen und Verbesserungsvorschläge für die Arbeit erhielt ich von: Christoph, Dirk, Dietrich, Stella, Tom, Dagoberto, Florian und meiner Mutter. Vielen Dank möchte ich aber auch allen übrigen Freunden und Kollegen für die außergewöhnlich nette Stimmung in der Arbeitsgruppe aussprechen.

Heike Thienenkamp danke ich für die schöne Bromelien-Zeichnung.

Die Durchführung der Arbeit wäre ohne das Instituto Nacional de Biodiversidad (INBio) nicht möglich gewesen.

Die Universidad de Costa Rica stellte mir freundlicherweise Waage und Trockenschrank zur Verfügung.

Finanziert wurde dieses Projekt von der DFG (HO 2119/ 1-3).

Mein ganz besonderer Dank gilt meinen Eltern, die Interesse für meine Unternehmungen gezeigt haben und auf deren Unterstützung ich immer zählen konnte. 